ORNL/TM-2000/2

\title{
High Temperature Materials Laboratory
}

\section{Eleventh Annual Report: October 1997 Through September 1998}

\author{
A. E. Pasto \\ B. J. Russell
}




\title{
High Temperature Materials Laboratory
}

\section{ELEVENTH ANNUAL REPORT: OCTOBER 1997 THROUGH SEPTEMBER 1998}

\author{
A. E. Pasto \\ B. J. Russell
}

Date Published-March 2000

\author{
Research sponsored by the \\ U.S. Department of Energy \\ Assistant Secretary for Energy Efficiency \\ and \\ Renewable Energy \\ Office of Transportation Technologies \\ as part of the \\ High Temperature Materials Laboratory \\ User and Fellowship Programs \\ Oak Ridge National Laboratory \\ managed by \\ LOCKHEED MARTIN ENERGY RESEARCH CORP. \\ for the \\ U.S. DEPARTMENT OF ENERGY \\ under contract DE-AC05-96OR22464
}




\section{CONTENTS}

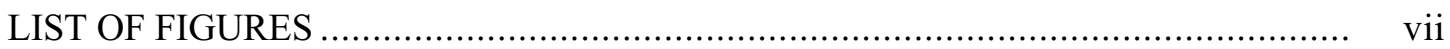

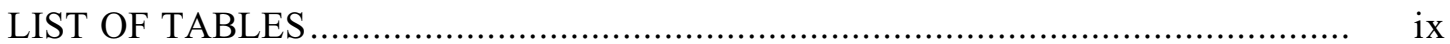

ACRONYMS AND ABBREVIATIONS ……................................................

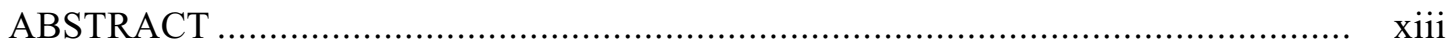

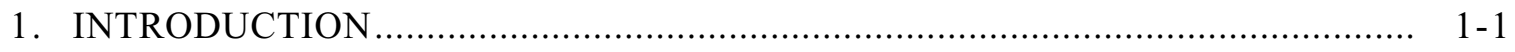

2. MAJOR ACCOMPLISHMENTS IN FY 1995 AND FY 1996_............................. 2-1

2.1 HTML PROGRAM ITEMS ................................................................. 2-1

2.1.1 Web Proposal Development Database Undergoing Continuing

Development ....................................................................... 2-1

2.1.2 HTML's Web Site Improved ........................................................... 2-1

2.2 SPECIAL VISITORS, HONORS, AND AWARDS ……................................ 2-2

2.2.1 HTML Shows Off Its Prowess for Vice President Gore ....................... 2-2

2.2.2 United States Advanced Ceramics Association Meeting in Oak Ridge...... 2-2

2.2.3 Deputy Assistant Secretary for Energy Efficiency and Renewable Energy Participates in HTML Remote Operations Demonstration......... 2-2

2.2.4 Conference and Exhibition Participation............................................ 2-3

2.2.5 Honors, Awards, and Appointments.................................................. 2-4

2.3 MATERIALS ANALYSIS USER CENTER (MAUC) HIGHLIGHTS ................. 2 2-4

2.3.1 DOE2000 Program..................................................................... 2-4

2.3.2 Remote Microscopy Activities ........................................................ 2-4

2.3.3 A Focused Ion Beam Micromill for HTML ........................................ 2-5

2.4 DIFFRACTION USER CENTER (DUC) HIGHLIGHTS.............................. 2 2-5

2.4.1 Remote Collaboration Possible at HTML's Synchrotron Beam Line....... 2-5

2.4.2 New X-Ray Diffractometer Installed at DUC ....................................... 2-5

2.4.3 Proposal for Characterization of New Permanent Magnet Materials Presented to U.S. Council for Automotive Research (USCAR) ............... 2-5

2.4.4 Texture Characterized for Tantalum Processed by Equal-Channel Angular Extrusion

2.4.5 Phase Transformations in Doped Lanthanum Gallate Solid Oxide Fuel-Cell Electrolytes Studied by Calorimetry and High-Temperature Diffraction

2.4.6 High-Temperature Diffraction Used to Investigate Phase Transformations in Zeolites

2.5 RESIDUAL STRESS USER CENTER (RSUC)....

2.5.1 Web-Based Control and Scientific Collaboration at the Neutron Residual Stress Facility (NRSF), High Flux Isotope Reactor (HFIR)

Demonstrated at Congressional Expo

2.5.2 Neutron Goniometers Approved for Shipping to ORNL...................... 2-7

2.5.3 HTML Assists Norton/Saint-Gobain Evaluate the Next-Generation Grinding Wheel................................................................................. 2-7

2.5.4 Effects of Tool-Edge Geometry and Workpiece Hardness on Surface Residual Stresses.

2.5.5 RSUC Assists Cummins Engine Company To Characterize Iron Nitride Layers.

2.5.6 Evaluation of Residual Stress in a Turbine Disk for Aircraft

Engine Application.

2.5.7 Cummins Engine Company Examines Residual Stress Variations

in Case Hardened Forged Steels 
2.6 THERMOPHYSICAL PROPERTIES USER CENTER (TPUC)...................... 2-9

2.6.1 New Thermophysical Properties Capability: Hot Disk

Thermal Constants Analyzer........................................................ 2-9

2.6.2 TPUC's New High-Speed Noncontact Technique for Measuring

Temperature Was Successfully Demonstrated at Ford's Scientific

Research Laboratory........................................................................... 2-10

2.6.3 Nondestructive-Evaluation Applications of Infrared Thermography....... 2-10

2.6.4 Thermal Diffusivity of Alternative Automotive Brake Materials........... 2-11

2.6.5 Thermal Conductivity and Thermal Stability of New Ternary Carbides... 2-11

2.6.6 High-Temperature Thermal Properties of Advanced Thermoelectric

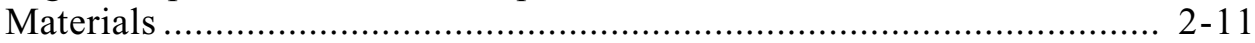

2.7 MECHANICAL CHARACTERIZATION

AND ANALYSIS USER CENTER (MCAUC) HIGHLIGHTS ........................ 2-12

2.7.1 IR Camera Used To Detect Cracks in Thermal Barrier Coatings (TBCs) as They Develop .................................................................... 2-12

2.7.2 Stress Relaxation in Superalloy Has Been Measured.................................. 2-12

2.7.3 Fracture-Toughness Measurement Using a Vickers Indenter on the Nanoindenter Has Been Successful .............................................. 2-13

2.7.4 Remote Control and Datalogging Demonstrated Using Labview.............. 2-13

2.8 MACHINING AND INSPECTION RESEARCH

USER CENTER (MIRUC) HIGHLIGHTS ............................................... 2-13

2.8.1 Work Continues on Cummins Fuel Systems Division User Project.......... 2-13

2.8.2 Allison Engine Develops Improved Methods for Producing Drilled Holes in Silicon Nitride Combustor Housings....................................... 2-14

2.8.3 Grinding Studies Performed in Conjunction with the Institute of Advanced Manufacturing Sciences Under

Work-For-Others Program........................................................ 2-14

2.8.4 Machining Research, Inc., Performs Machinability Studies on Hardened Steels Using Instrumented Weldon Cylindrical Grinder........ 2-14

2.9 HTML FELLOWSHIP PROGRAM HIGHLIGHTS .................................... 2-15

3. HTML USER STATISTICS .................................................................... $3-1$

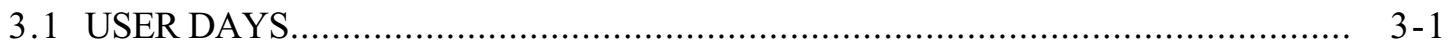

3.2 USER AGREEMENTS AND PROPOSALS .............................................. $3-3$

4. HTML USER CENTER …......................................................................... $4-1$

4.1 MATERIALS ANALYSIS USER CENTER ............................................... $4-1$

4.1.1 Staff and Current Capabilities.............................................................. 4-1

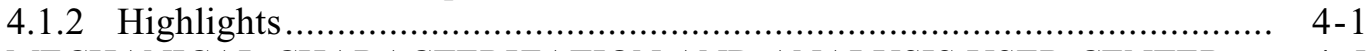

4.2 MECHANICAL CHARACTERIZATION AND ANALYSIS USER CENTER .... 4-5

4.2.1 Staff and Current Capabilities...................................................... 4-5

4.2.2 Major Research Areas........................................................... 4-6

4.2.3 Major Activities in FY 1998 ....................................................... 4-9

4.3 THERMOPHYSICAL PROPERTIES USER CENTER .............................. 4-12

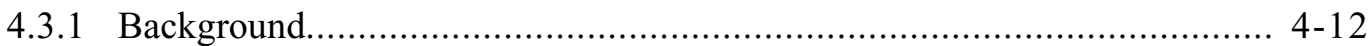

4.3.2 Staff and Major Instruments ...................................................... 4-12

4.3.3 Developments and New Capabilities............................................... 4-14

4.4 RESIDUAL STRESS USER CENTER (RSUC) ........................................... 4-17

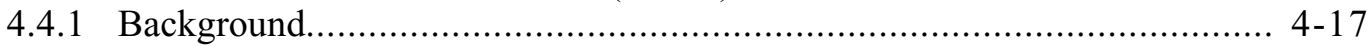

4.4.2 Staff and Major Instruments ..................................................... 4-17

4.4.3 New Capabilities …........................................................................... 4-18

4.4.4 Major Activities ................................................................... 4-19

4.5 DIFFRACTION USER CENTER (DUC) ............................................ 4-24

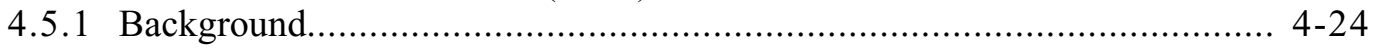


4.5.2 Staff and Major Instruments .................................................... 4-24

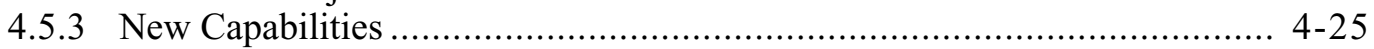

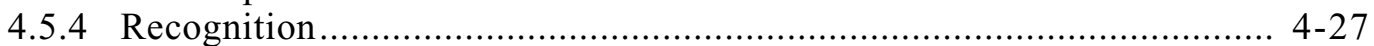

4.6 MACHINING AND INSPECTION RESEARCH USER CENTER ..................... 4-27

4.6.1 Staff and Major Instruments ...................................................... 4-27

4.6.2 New Capabilities .......................................................................... 4-30

4.6.3 Major Activities in FY 1998........................................................... 4-30

5. HTML FELLOWSHIP PROGRAM ………………....................................... $5-1$

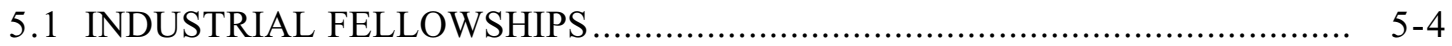

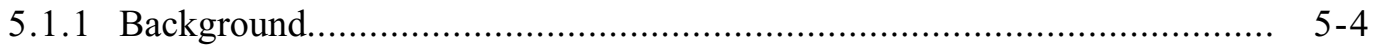

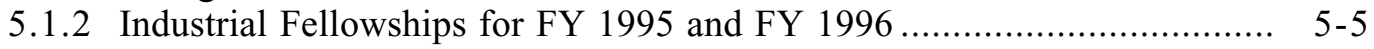

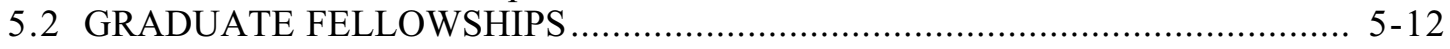

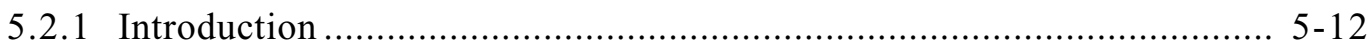

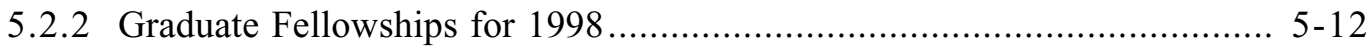

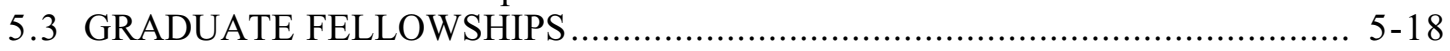

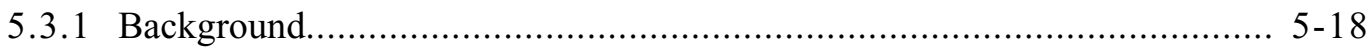

5.3.2 Graduate Fellows for FY 1995 and FY 1996..................................... 5-18

APPENDIX A. STANDARD NONPROPRIETARY USER AGREEMENTS ................ A-1

$\begin{array}{ll}\text { APPENDIX B. } & \text { FY } 1998 \text { NONPROPRIETARY RESEARCH } \\ & \text { PROPOSALS HISTORY ........................................................... B-1 }\end{array}$

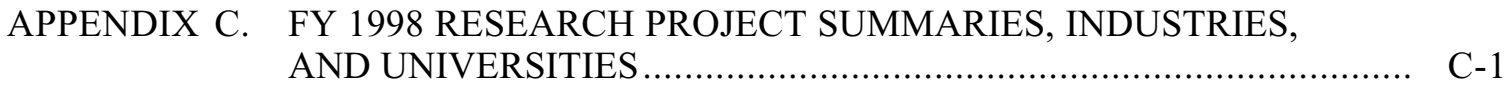

APPENDIX D. PUBLICATIONS AND PRESENTATIONS................................ D-1 


\section{LIST OF FIGURES}

$\begin{array}{lll}\text { Figure } & \text { Page }\end{array}$

3.1 A history of user days of research expended in the HTML since its inception........ 3-3

3.2 Numbers of materials-related user agreements received by the ORNL Office of Science and Technology Partnerships.

3.3 Cumulative number of user agreements received by the ORNL Office of Science and Technology Partnerships.

3.4 History of technical proposals received by the HTML........................................ 3-5

3.5 Cumulative history of technical proposals received by HTML ............................. 3-6

3.6 Cumulative technical proposals and user agreements received ............................ 3-7

5.1 Various frictional contact conditions observed in automotive disk brakes.............. 5-7

5.2 Scanning Auger Microprobe composition profile of DLC on steel substrate ........... 5-10

5.3 Cross-section TEM image and diffraction pattern of [a] the amorphous DLC, $100,000 \mathrm{X}$ and $[\mathrm{b}]$ the Me-DLC multiple sub-layers, 50,000X

5.4 Cross-section TEM images of carbon layer, metal interlayer, and steel substrate..... 5-11

5.5 Preliminary Aging curve for $2009-\mathrm{Al} / 15 \mathrm{p} / \mathrm{SiC}$ composite

5.6 A fully dense silicon nitride-chromium multilayer composite with seven silicon nitride layers (dark color) and six chromium layers (light color)

5.7 Strain rate compared with strain sensitivity for superplastic Al-5083.................... 5-18

5.8 Microtexture data for superplastic AL-5083 ............................................. 5-18 


\section{LIST OF TABLES}

Table

Page

3.1 History of HTML user days by fiscal year............................................... $3-1$

3.2 HTML user days for FY 1998, by User Center............................................. 3-2

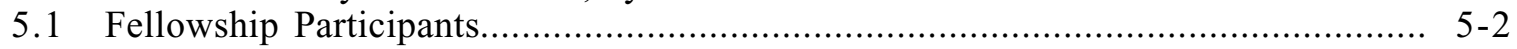

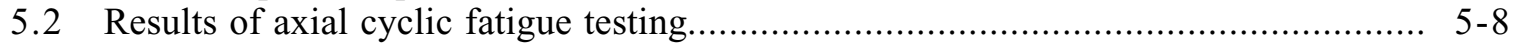

5.3 NT154 specimen test matrix for compressive creep ..................................... $5-9$

5.4 Minimum creep rates in compression measured at the end of approximately

150 hours, or after approximately 100 hours of steady-state creep..................... 5-9

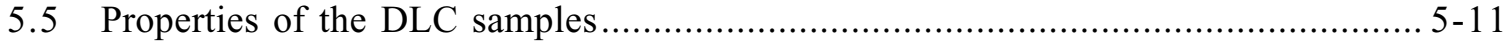

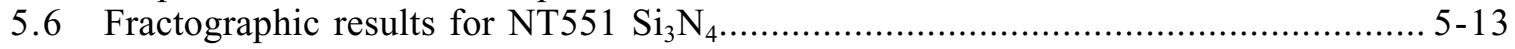

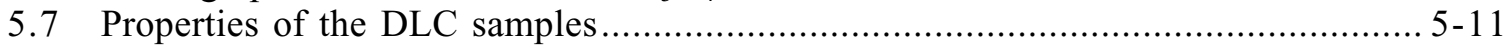

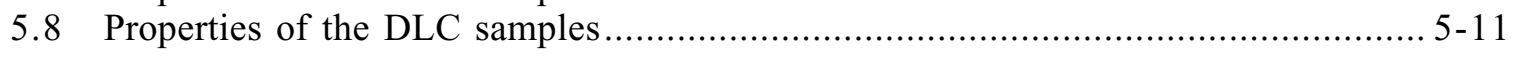




\section{ACRONYMS AND ABBREVIATIONS}

\begin{tabular}{|c|c|}
\hline ABET & Accrediting Board for Technology \\
\hline AEM & analytical electron microscope \\
\hline AES & auger electron spectroscopy \\
\hline AISI & American Iron and Steel Institute \\
\hline AML & Arizona Materials Laboratory \\
\hline ANOVA & analysis of variance \\
\hline APS & air plasma sprayed/spraying \\
\hline AZS & alumina zirconia silica \\
\hline BES & U.S. Department of Energy, Office of Basic Energy Sciences \\
\hline BMAS & barium-magnesium-alumino-silicate \\
\hline CASTLE & Center for the Application of Science and Technology to Law Enforcement \\
\hline $\mathrm{CFCC}$ & continuous fiber ceramic composites \\
\hline CGTS & ceramic grindability test system \\
\hline $\mathrm{CMC}$ & Ceramic Manufacturability Center \\
\hline CMM & coordinate measuring machine \\
\hline $\mathrm{CNC}$ & computer numerically controlled \\
\hline CRADA & cooperative research and development agreement \\
\hline CVD & chemical vapor deposition \\
\hline DCB & double cantilever beam \\
\hline DOE & U.S. Department of Energy \\
\hline DOE-ORO & U.S. Department of Energy, Oak Ridge Operations \\
\hline DP & U.S. Department of Energy, Defense Programs \\
\hline DSC & differential scanning calorimetry \\
\hline DSE & directionally solidified eutectic \\
\hline DTA & differential thermal analysis \\
\hline DUC & Diffraction User Center \\
\hline EB-PVD & electron beam-physical vapor deposition \\
\hline EDAX & energy dispersive analysis of $\mathrm{X}$ rays \\
\hline EDS & energy dispersive spectroscopy \\
\hline EE & U.S. Department of Energy, Office of Energy Efficiency and Renewable Energy \\
\hline EELS & electron energy loss spectroscopy \\
\hline EGA & evolved gas analysis \\
\hline ER & U.S. Department of Energy, Office of Energy Research \\
\hline EXAFS & extended X-ray absorption fine structure \\
\hline FE & Fossil Energy \\
\hline FEA & finite element analysis \\
\hline FEG-TEM & field emission gun-transmission electron microscope/microscopy \\
\hline FEG-SEM & field emission gun-scanning electron microscope/microscopy \\
\hline FEM & finite element modeling \\
\hline FY & fiscal year \\
\hline GIF & Gatan imaging filter \\
\hline GIXD & grazing incidence $\mathrm{X}$-ray diffraction \\
\hline HFIR & High Flux Isotope Reactor \\
\hline HIP & hot isostatically pressed \\
\hline HREM & high-resolution electron microscope/microscopy \\
\hline HTML & High Temperature Materials Laboratory \\
\hline HVOF & high-volume oxy-fuel \\
\hline $\mathrm{IC}$ & integrated circuit \\
\hline ID & inside diameter \\
\hline IR & infrared \\
\hline LDRD & Laboratory Director's Research and D \\
\hline
\end{tabular}




\begin{tabular}{|c|c|}
\hline LMER & Lockheed Martin Energy Research Corp. \\
\hline LMES & Lockheed Martin Energy Systems, Inc. \\
\hline LSU & Louisiana State University \\
\hline MAUC & Materials Analysis User Center \\
\hline MCAUC & Mechanical Characterization and Analysis User Center \\
\hline MICS & Mathematics, Information, and Computation Division \\
\hline MIRUC & Machining and Inspection Research User Center \\
\hline MOR & modulus of rupture \\
\hline MPLUS & Metals Processing Laboratory User Centers \\
\hline NASA & National Aeronautics and Space Administration \\
\hline NRSF & Neutron Residual Stress Facility \\
\hline NRSUC & Neutron Residual Stress User Center \\
\hline NSLS & National Synchrotron Light Source \\
\hline NSRF & Neutron Scattering Research Facilities \\
\hline OD & outside diameter \\
\hline OIT & Office of Industrial Technologies \\
\hline ORNL & Oak Ridge National Laboratory \\
\hline OSTP & ORNL Office of Science and Technology Partnerships \\
\hline OT T & Office of Transportation Technologies \\
\hline PEELS & parallel electron energy-loss spectrometer \\
\hline PNGV & Partnership for a New Generation of Vehicles \\
\hline PPG & Pittsburgh Plate Glass \\
\hline PRT & participating research team \\
\hline PSD & position-sensitive detector \\
\hline PSZ & partially stabilized zirconia \\
\hline PTS & polycrystalline texture stress \\
\hline PVD & physical vapor deposition \\
\hline $\mathrm{R} \& \mathrm{D}$ & research and development \\
\hline RSUC & Residual Stress User Center \\
\hline RT\&HTXRD & room-temperature and high-temperature X-ray diffraction \\
\hline $\mathrm{RT}$ & room temperature \\
\hline RTXRD & room-temperature X-ray diffraction \\
\hline RUS & resonant ultrasound facility \\
\hline SAM & scanning auger microscope \\
\hline SEM & scanning electron microscope \\
\hline SMAC & Surface Modification and Characterization Facility \\
\hline STA & simultaneous thermal analysis \\
\hline STCM & scanning thermal conductivity microscope \\
\hline STEM & scanning transmission electron microscopy \\
\hline $\mathrm{TBC}$ & thermal barrier coating \\
\hline TEI & thermal elastic instability \\
\hline TEM & transmission electron microscope \\
\hline TG & thermogravimetry \\
\hline TG/IR & thermal gravimetrical infrared \\
\hline TPUC & Thermophysical Properties User Center \\
\hline TQM & total quality management \\
\hline USCAR & U.S. Council for Automotive Research \\
\hline VPS & vacuum plasma sprayed/spraying \\
\hline WC & tungsten carbide \\
\hline WDS & wavelength dispersive spectroscopy \\
\hline XRD & $\mathrm{X}$-ray diffraction \\
\hline YAG & yttrium-aluminum-garnet \\
\hline
\end{tabular}




\begin{abstract}
The High Temperature Materials Laboratory (HTML) has completed its eleventh year of operation as a designated U.S. Department of Energy User Facility at the Oak Ridge National Laboratory. This document profiles the historical growth of the HTML User and Fellowship Programs since their inception in 1987. Growth of the HTML programs has been demonstrated by the number of institutions executing user agreements and by the number of days of instrument use (user days) since the HTML began operation. A total of 522 agreements (351 industry, 156 university, and 15 other federal agency) are now in effect (452 nonproprietary and 70 proprietary). This represents an increase of 75 user agreements since the last reporting period (for FY 1997). A state-by-state summary of the nonproprietary user agreements is given in Appendix A. Forty-six states are represented.

During FY 1998, the HTML User Program evaluated 80 nonproprietary proposals (32 from industry, 45 from universities, and 3 from other government facilities) and several proprietary proposals. Appendix B provides a detailed breakdown of the nonproprietary proposals received during FY 1998. The HTML User Advisory Committee approved about 95\% of those proposals, sometimes after the prospective user revised the proposal based on comments from the committee.

This annual report discusses activities in the individual user centers as well as plans for the future. It also gives statistics about users, proposals, and publications as well as summaries of the nonproprietary research projects active during 1998.
\end{abstract}




\section{INTRODUCTION}

The High Temperature Materials Laboratory (HTML) is a modern research facility at Oak Ridge National Laboratory (ORNL) that houses a unique collection of instruments for characterizing materials. The instruments in the six user centers provide a comprehensive set of tools for performing state-of-the-art determination of the structure and properties of solids and some liquids at high temperature. A dedicated staff trains and guides the user in conducting the research.

Highly computerized instrumentation is used to improve the efficiency of the data collection and interpretation process. Research projects start as submitted proposals that, when approved, provide the user access to any of the HTML instruments needed to perform the work. User projects typically include research to relate materials properties to structure or to manufacturing processes, or to train users and provide them access to the equipment necessary to perform their own materials research. Both an external oversight advisory committee and an on-site proposal review committee assist in the successful operation of the HTML User Program. The external committee, known as the HTML Programs Senior Advisory Committee, provides guidance on strategic issues facing the HTML. The following list contains the current members of the committee.

\section{FY 1998 HTML PROGRAMS SENIOR ADVISORY COMMITTEE}

\author{
Dr. Ronald H. Chand (1992) \\ Chand Kare Technical Ceramics \\ Worcester, Mass. \\ Dr. William J. McLean (1998) \\ St. Gobain/Norton Industrial \\ Ceramics Corp. \\ East Granby, Conn.
}

\author{
Dr. Maxine L. Savitz (1990) \\ AlliedSignal Ceramic Components \\ Torrance, Calif.
Dr. Andrew Sherman (1997)
Ford Motor Company
Scientific Research Laboratory
Dearborn, Mich.

\author{
Dr. James W. Patten (1991) \\ Cummins Engine Co. \\ Columbus, Ind.
}

\author{
Dr. Wendell S. Williams (1996) \\ Dept. of Materials Science \& Engineering \\ Case Western Reserve University \\ Cleveland, Ohio
}

Early in the User Program, user agreements were developed that established the intellectual property and liability rights of the user institution and Martin Marietta Energy Systems, Inc. (prior to the establishment of Lockheed Martin Energy Research Corp.). The first user agreement was signed on July 15, 1987; since that time, 452 nonproprietary agreements have been executed. 
A state-by-state listing of the approved user agreements that involve materials research and provide access to the HTML is provided in Appendix A.

Two types of standard agreements are used: a "nonproprietary agreement" and a "proprietary agreement." The nonproprietary user agreement requires that users, along with HTML technical staff, jointly publish the results of their research within 6 months of completing the user project. Proprietary agreements do not require users to publish with HTML staff but do require payment on a full-cost-recovery basis.

These 452 nonproprietary user agreements have yielded 819 project proposals since the inception of the HTML. In the current reporting period (FY 1998), 80 nonproprietary research proposals were received, and these are listed in Appendix B.

Work was performed in the HTML on numerous projects during this period, including several that were initiated in previous years. Summary descriptions of these projects are given in Appendix C. From these projects arose several presentations and publications, which are listed in Appendix D.

Since shortly after the beginning of the User Program, there has been a user logbook for each instrument in the user centers. The entries from these logbooks are annually tallied up by each user center for each instrument; then the user-center data are rolled into one set of data for the HTML. Each 8-hour period of time, or fraction of an 8-hour period, that an instrument is being used is tallied as a "user day." Since 1987, the user-day data have been collected for industry, university, and internal ORNL staff. In FY 1998, there were 13,391 user days of effort. A full discussion of these statistics is presented in Sect. 3. 


\section{MAJOR ACCOMPLISHMENTS IN FY 1998}

During the FY 1998 reporting period, the HTML experienced continued growth, both in the number of users performing research and in the number of proposals received. The user centers undertook activities in new areas and expanded their existing expertise and capabilities. The following sections contain summaries of many accomplishments at the HTML during this time.

\subsection{HTML PROGRAM ITEMS}

\subsubsection{Web Proposal Development Database Undergoing Continuing Development}

There is now a new way to complete and submit an HTML User Proposal. The latest version of Filemaker Pro supports database access from the Web. Using this capability, HTML personnel have developed the HTML Proposal Development Database or PDD, which parses the official HTML User Proposal form into eight pages that can be filled out via Web browsers over the Internet. The PDD has medium-security protection and is designed for nonproprietary proposals; proprietary information should not be entered into this database.

To use the PDD, potential users contact the HTML Programs Assistant, Billie Russell, to receive a password and a unique proposal ID. Billie then creates a new record in the database and assigns it to that user. The user or users can then sign on through the Web and enter proposal information. They save their input at the end of a session and can have as many sessions as they desire to complete their proposal. The data reside on a dedicated PC server in the HTML, where backups are performed routinely. Users and HTML staff can sign on through the internet from various locations and can work on and edit a proposal in essentially real time; each data-save from one location causes an update that all can see.

When a proposal is complete, the user clicks a "submit" button and an e-mail message is sent automatically to Billie to alert her that the proposal is ready. The next step is another major time saver. In the past, proposal information such as names, titles, and summaries had to be entered manually into the main HTML Proposal Database. Now, with the click of a software button, all pertinent information on a proposal is automatically imported from the PDD to the secure HTML Proposal Database. The proposal is then ready for review by the Proposal Review Committee. This is an example of how considerable improvements in efficiency can be realized using state-of-the-art application software and a small amount of computer programming.

\subsubsection{HTML's Web Site Improved}

The appearance of the HTML World Wide Web site has been changed to make it more consistent with current styles and conventions commonly seen on the Internet. The size and resolution of graphic images and background images have been reduced slightly to improve web performance and ensure that pages can be downloaded quickly, even with a slow modem connection. Several formatting problems were corrected, and the appearance of the site has been 
tested on several different platforms. The content has been updated for each user center. Redundant information has been removed. More options are presented for filling out user proposal forms, including an on-line form that will eliminate a tremendous amount of re-keying of information. Downloadable forms work on both Macintosh and IBM platforms, where they didn't in the past. (There may still be some isolated problems if the user's browser is not set up properly.)

More changes can be expected in the near future. For example, Laura Riester is working on a complete rework of the Mechanical Characterization and Analysis Group (MCAG) site, but it is not yet complete. Some of the biographical information for staff will be included.

\subsection{SPECIAL VISITORS, HONORS, AND AWARDS}

\subsubsection{HTML Shows Off Its Prowess for Vice President Gore}

During Vice President Albert Gore's visit to ORNL to announce the start of the new Spallation Neutron Source, HTML staff members demonstrated DOE2000 Materials MicroCharacterization Collaboratory (MMC) tools for Mr. Gore. The demonstration included Cam Hubbard talking about measurement of residual stresses with neutrons in Cummins pistons. Then Mr. Gore sat with Larry Allard at a Macintosh computer and ran the Hitachi HF-2000 transmission electron microscope (TEM) in the HTML, taking pictures of model catalyst Pt particles at a magnification that revealed the atomic planes. Mr. Gore was clearly impressed and later made very positive statements about our collaboratory efforts during his formal announcement to the Laboratory directors and the press.

\subsubsection{United States Advanced Ceramics Association Meeting in Oak Ridge}

On March 17 and 18, 1998, the United States Advanced Ceramics Association (USACA) held its spring meeting in Oak Ridge, partially in recognition of the major role that ORNL plays in development of advanced ceramics. As a part of their meeting, USACA representatives were given a tour of the HTML.

\subsubsection{Deputy Assistant Secretary for Energy Efficiency and Renewable Energy Participates in HTML Remote Operations Demonstration}

Arvid Pasto, Ted Nolan, and Larry Allard demonstrated MMC tools to Energy Efficiency and Renewable Energy (EERE) Assistant Secretary Dan Reicher, from U.S. Department of Energy (DOE) Headquarters. A presentation was made to Mr. Reicher outlining the HTML's need for a new TEM and our suggestions for the capabilities to be included on the new instrument. 


\subsubsection{Conference and Exhibition Participation}

The Director and/or staff of the HTML attended numerous conferences and exhibitions, including the American Society of Materials - the Minerals, Metals, Materials Society (ASMTMS) Materials Exposition (September 16-19, a conference in Indianapolis where HTML had an exhibition booth) and "Discover Ceramics '97" (September 23-26, a conference in Columbus, Ohio, where HTML also had an exhibition booth. Staff also attended, and some presented papers at the Conference on Transportation Technologies, U.S. Department of Transportation (DOT) Volpe Center, Cambridge, Massachusetts (9/16-18/97); the USACA Meeting in Washington (9/23-24/97); the National Conference on the Advancement of Research, in Oak Ridge, to which Arvid was invited (9/21-24/97); the International Symposium on Ceramic Materials for Engines in Japan (10/97); and the Annual Contractors' Coordination Meeting (CCM) in Dearborn, Michigan (10/27-30/97).

The Director and/or staff of the HTML attended the Defense Manufacturing Conference, December 1-4, 1997, at Palm Springs, California, where HTML had an exhibition booth. Arvid, along with Edgar Voelkl and Larry Allard of the Materials Analysis User Center (MAUC), visited several sites of Hitachi Corporation and JEOL in Japan in November to assess the state of the art in electron microscopy. Arvid made a presentation to the graduate students and faculty of the University of Tennessee on November 18. Arvid also participated in the DOE Office of Heavy Vehicle Technologies (OHVT) Workshop in Washington on December 10-11 to help put together the OHVT response to Government Performance and Results Act (GPRA).

The HTML Programs Senior Advisory Committee met on November 21, 1997. In attendance were Dr. Wendell Williams, Case Western University (emeritus professor); Dr. James Patten, Cummins Engine Co.; Dr. Andrew Sherman, Ford Motor Company; Mr. Bryan McEntire, Norton Co.; Mr. Ron Chand, Chand Kare Technical Ceramics; and Dr. Sidney Diamond, our sponsor from the DOE Office of Transportation Technologies (OTT).

Arvid attended the Cummins Worldwide Materials Functional Excellence Conference at Cummins Engine Company in January and gave an invited dinner meeting presentation on the HTML and its capabilities, making some very useful contacts in the Cummins companies.

Arvid also attended the OHVT Peer Review at Sandia National Laboratory-Livermore.

Arvid presented an invited paper focusing on the capabilities of the HTML and made several important contacts at the "Advanced Ceramics for the New Millennium," conference (March 10-12, Atlanta, Georgia).

In May, Arvid hosted an exhibition booth at the American Ceramic Society's 100th Annual Meeting, in Cincinnati, Ohio.

Arvid described the capabilities of the HTML at a meeting of the Oak Ridge Breakfast Rotary Club on September 30.

In July, Arvid attended the Fifth International Conference on Composites Engineering (ICCE/5) in Las Vegas, Nevada, and presented an invited paper in the plenary session describing the HTML and its capabilities related to composites.

During the week of July 20th, Dr. Sidney Diamond and Mr. Richard Wares of DOE-OTTHQ spent a week at ORNL and were shown the latest accomplishments of the HTML. 
During August, Arvid hosted an exhibition booth at the Southern Automotive Manufacturing Conference in Nashville, Tennessee. The event was sponsored by the Society of Automotive Engineers (SAE).

During the week of September 21, Arvid attended the SAE Brake Colloquium, in San Francisco.

\subsubsection{Honors, Awards, and Appointments}

Several HTML staff received special honors or awards, and/or were appointed or elected to office in scientific organizations during this fiscal year.

\subsection{MATERIALS ANALYSIS USER CENTER (MAUC) HIGHLIGHTS}

\subsubsection{DOE2000 Program}

A new initiative, DOE2000, sponsored by the Mathematics, Information, and Computation Division (MICS) of DOE is under way; this initiative seeks to develop and demonstrate "collaboratory" concepts such as remote instrument operation, electronic whiteboards and notebooks, and telepresence tools. We participated with Argonne and Lawrence Berkeley national laboratories in the submission of a proposal to MICS to perform a pilot project called the Materials Microcharacterization Collaboratory (MMC).

The proposal was successful, and the HTML has received funding to support 1.5 FTEs. We are now in a position to implement collaboratory concepts in the HTML User Program, thus improving and increasing user productivity, while saving both time and money for our users.

\subsubsection{Remote Microscopy Activities}

There have been many remote microscopy developments during this year; these include the following. Ford Research Laboratory personnel have installed computers and communication lines so that they can participate as remote partners in MMC-sponsored research on NOx reduction catalysts. A meeting was held at Ford during the week of CCM, and the firewall/security issues were resolved. We began beneficial research using remote microscopy in December 1998. The first international demonstration of our remote microscopy capabilities occurred in September. Edgar Voelkl operated the HF 2000 TEM as a part of the biannual European "Three Country Conference" on microscopy capabilities held in Regensburg, Germany. The second international demonstration of remote microscopy capabilities occurred in Japan on November 6 at the Japanese Electron Optics Laboratory (JEOL), one of the three largest manufacturers of TEM and SEM instruments in the world. JEOL is an industrial participant in the MMC. New hardware and software for the JEOL 733 electron probe became operational, which allows the probe to be operated remotely. The probe is quite important for quantitative elemental analysis on catalysts and other materials systems. 


\subsubsection{A Focused Ion Beam Micromill for the HTML}

The Materials Analysis User Center has been chosen by SNA-Hitachi Scientific Instrument company for a no-cost consignment of the latest generation Focused Ion Beam instrument (FIB), valued at $\sim \$ 700 \mathrm{~K}$. The period of the consignment will be a minimum of 6 months, and will probably extend to at least a year. Delivery was scheduled for early 1999. This is the newest tool for preparation of specimens for electron microscopy, and is especially useful for preparation of cross-sections of layered materials and coated/treated surfaces.

\subsection{DIFFRACTION USER CENTER (DUC) HIGHLIGHTS}

\subsubsection{Remote Collaboration Possible at HTML's Synchrotron Beam Line}

It is now possible to view live video of the X14A beam line at National Synchrotron Light Source (NSLS) used for Residual Stress User Center (RSUC) and DUC projects over the internet. The only software required at the viewing end is a web browser such as Netscape. Four video feeds are available: the sample position inside the hutch, two views of the operator area, and the NSLS status information TV channel. The four video signals are fed through a video processor/switch that allows a quad screen display of all four images at once; any one feed can also be selected. This switch is controlled from the same Web page as the one showing the video images. In addition to the live images at $160 \times 120$ resolution, it is possible to view still images at up to $640 \times 480$ resolution. Multiway video conferencing is available for remote, live collaboration.

\subsubsection{New X-Ray Diffractometer Installed in DUC}

Installation of a used Scintag X-ray diffractometer in the DUC was completed, and the instrument was put into productive use. The purpose is to better accommodate the growing demand for high-precision data collection on both powders and solids. Minor repairs were completed in-house, and the new instrument was approved for productive use by ORNL radiation protection personnel. The new goniometer, as well as the other DUC instruments, runs under common Windows NT-based software control. The new instrument has been configured for precision powder-diffraction measurements, primarily on solid polycrystalline samples. The older instrument will soon be equipped with an attachment to allow loading of multiple powder samples, with a spinner to improve the accuracy of data collection for powder specimens.

\subsubsection{Proposal for Characterization of New Permanent Magnet Materials Presented to U.S. Council for Automotive Research (USCAR)}

A proposal for development of improved, low-cost processing methods for Nd-Fe-B permanent magnets was submitted to USCAR by HTML's E. A. Payzant and Argonne National Laboratory's J. Hull. This team was then invited to present the research proposal to the 
Partnership for a New Generation of Vehicles (PNGV) Electronic Materials Tech Team in April 1998 at USCAR. The joint proposal would couple the strengths of the two laboratories in an effort to improve high-strength permanent magnets for use in automotive applications.

\subsubsection{Texture Characterized for Tantalum Processed by Equal-Channel Angular Extrusion}

The textures produced in iron deformed by conventional processes such as rolling and drawing are well known. Equal-channel angular extrusion (ECAE) is a recently developed process in which the deformation takes place by simple shear. Multiple-pass ECAE allows for large amounts of deformation and corresponding microstructure development without any change in the cross sectional area of a billet. A user from Texas A\&M University successfully utilized the X-ray diffraction texture mapping facilities of the HTML to characterize the effect of different ECAE processing routes on development of orientation textures in tantalum. The results will be published.

\subsubsection{Phase Transformations in Doped Lanthanum Gallate Solid Oxide Fuel-Cell Electrolytes Studied by Calorimetry and High-Temperature Diffraction}

Strontium- and magnesium-doped lanthanum gallate has been identified as a promising candidate material for use as an electrolyte material in solid oxide fuel cells (SOFC) that could run at significantly lower temperatures than present materials permit. The crystal structure is based on perovskite, but crystal symmetry changes, as a function of doping and temperature, directly affect the ionic conductivity. A user from the University of Washington has utilized the differential scanning calorimetry (DSC), high-temperature X-ray diffraction (HTXRD), and neutron diffraction facilities of the HTML to investigate these phase transformations on powder samples prepared by the combustion synthesis method.

\subsubsection{High-Temperature Diffraction Used to Investigate Phase Transformations in Zeolites}

A user from Mobil Corporation has initiated a project utilizing HTXRD facilities of the HTML to investigate the effect of thermal processing on the structure of ZSM-5 zeolites. Environmental effects (oxidative vs reducing gases, dry vs humid) were also studied at temperature. Mobil has offered to assist HTML in developing an improved high-temperature $\mathrm{X}$-ray furnace for diffraction studies of materials under high-temperature steam environments. 


\subsection{Residual Stress User Center (RSUC)}

\subsubsection{Web-Based Control and Scientific Collaboration at the Neutron Residual Stress Facility (NRSF), High Flux Isotope Reactor (HFIR) Demonstrated at Congressional Expo}

The first phase of development of remote control and installation of tools for scientific collaboration at the NRSF at the HFIR has been completed. The first-phase developments included Timbuktu and Web-based control of the LabView-based data collection system as well as integration of streaming video viewable and controllable over the World Wide Web. Input is from four video cameras providing views of the instrument and operators. Shared use of a Webaccessible electronic notebook is a key component of collaborating via the World Wide Web. The first demonstration was conducted from the House Science Conference Room as part of the Materials Microcharacterization Collaboratory Congressional Expo June 17 and 18, 1998.

\subsubsection{Neutron Goniometers Approved for Shipping to ORNL}

Two new goniometers for neutron residual stress mapping were tested and approved for shipment to ORNL. The goniometers were built by Newport Corp. specifically for use in neutron-diffraction strain mapping. One is designed for macro stress mapping in large industrial components with higher accuracy and more than double the specimen weight and translation ranges of our current instrument. The second system is designed to permit rapid mapping of strain tensors and texture throughout the volume of smaller polycrystalline specimens as well as highly textured and single-crystal specimens. Both systems were received at ORNL in late September. On-site assembly and performance testing will be performed in the early fall.

\subsubsection{HTML Assists Norton/Saint-Gobain Evaluate the Next-Generation Grinding Wheel}

The Norton Company's Innovative Grinding Wheel Program aims to develop a nextgeneration wheel for cost-effective cylindrical grinding of advanced ceramics. An experimental metal-bonded wheel that demonstrated superior wheel life and a fivefold increase in material removal rate when compared with resin- and vitrified-bonded wheels was developed by Norton. In addition, there was no need for truing and dressing during the extended grinding tests. These results suggest that the experimental wheel can create significant cost-effective improvements in the cylindrical grinding of advanced ceramics.

Residual stress (in conjunction with surface finish), retained strength, and machining damage were used to determine how the surface integrity of a part is affected when using different wheels, speeds and feeds. As no significant difference was observed in the surface finish, retained strength, or failure-causing flaws, the expectation was that there would be no significant difference in residual stress between these samples.

RSUC worked with Norton/Saint-Gobain in determining and comparing near-surface residual stresses in $6 \mathrm{~mm}$-diameter machined cylinders. To tackle this experimentally challenging problem, 
the high-intensity, parallel beam of the X14A beam line within the National Synchrotron Light Source was required. The residual stresses in the axial direction of these cylinders were measured. Large changes in peak position were observed for all samples relative to the strain-free peak position, indicating large compressive residual stresses. The profiles showed that the residual stress decays rapidly within the first $10 \mu \mathrm{m}$. The metal-bonded and resin-bonded wheels have effectively the same peak positions for transverse grinding, indicating little difference in residual stress state. However, the two wheels have different stress profiles for plunge grinding, indicating potentially significant different residual-stress states between the two wheel types.

\subsubsection{Effects of Tool-Edge Geometry and Workpiece Hardness on Surface Residual Stresses}

Determination of the effects of tool-edge geometry and workpiece hardness on the surface residual stresses for finish hard turning of AISI 52100 steel was performed by users from Georgia Institute of Technology at the RSUC at HTML. Results of this study show that edge geometry and hardness are statistically significant with respect to residual stresses. Specifically, a 0.0009-in. edge hone produces tensile residual stresses in the axial and circumferential directions for each feed rate and hardness value. The 0.0048-in. edge hone tool generally produces compressive residual stresses in these directions. The larger goals of this research are to study the effects of these parameters on surface roughness and surface integrity and, concurrently, to develop a comprehensive explanation of the surface-generation process. Increased understanding of the surface-generation process will provide a scientific contribution to the area of machining process modeling.

\subsubsection{RSUC Assists Cummins Engine Company To Characterize Iron Nitride Layers}

Cummins Engine Company is seeking a better understanding of the crystallographic nature and mechanical properties in the surface white layer formed in a carbo-nitriding process. While this is a widely used surface-hardening treatment, little basic information about the surface constituents is available because the layer is traditionally removed. A scientist from Cummins Engine Company visited the RSUC to determine the phases and residual stresses in representative white layers on two different substrate materials, H13 and 501 steels. Diffraction data show that the white layer is composed predominantly of $\mathrm{Fe}_{3} \mathrm{~N}$. Both the conventional $\sin ^{2} \psi$ technique and grazing incidence X-ray diffraction were used on the nitrided H13 sample to collect residual stress data. The residual stresses were found to be tensile in the white layer. A suspected nitrogen gradient in the white layer needs to be quantified via TEM and electron microprobe before further residual stress analysis can continue.

\subsubsection{Evaluation of Residual Stress in a Turbine Disk for Aircraft Engine Application}

Strain measurements were recently initiated at HTML's NRSF on a fast-quenched engine disk to aid a National Aeronautics and Space Administration (NASA) consortium involving AlliedSignal Engines, Allison Engine Company, GE Aircraft Engines, Pratt \& Whitney, Ladish 
Co., and Wyman Gordon in predicting residual stress in superalloy engine disks. The overall goal of this consortium is to reduce development costs by being able to accurately predict a throughthickness residual stresses after quenching. Simulation tools being developed are to be used as standards by U.S. industries for predicting turbine-engine-disk residual stresses. These stresses critically affect further disk processing such as machining. To assist in this endeavor, throughthickness strain was measured at HFIR on an engine disk at different locations and depths. These measurements indicated that strains become increasingly compressive with depth and will complement near-surface strains obtained by other techniques such as X-ray and hole drilling. This information will assist in the development of simulation tools and will be vital in the validation of these predictions.

\subsubsection{Cummins Engine Company Examines Residual Stress Variations in Case Hardened Forged Steels}

In the past, forgings have been normalized, quenched, and tempered after the forging process. Industry is working toward the elimination of these heat-treatment operations and going directly to the use of as-forged parts. However, the increased demands made on these forged components have raised interest in using forgings with a fine-tempered martensite case obtained with induction heating. High tensile residual stresses are anticipated in the transition zone between the martensite case and the ferrite/pearlite core; the probability of reducing the endurance limit of the part is high.

Neutron residual strain mapping was used to characterize the strain distributions in a critical region of a diesel engine part with the objective of defining the residual stresses operating in the region of the microstructural transition between the case martensite and the core ferrite/pearlite. The presence of martensite is clearly revealed by the observation of double diffraction peaks arising from the ferrite and martensite phases. The behavior of the residual stresses to depths of $1 / 2$ in., as indicated by one of the strain components, shows a variation between compressive character at the surface to a tensile character toward the interior. Comparison of strains near the surface by neutron diffraction and X-ray residual stress measurements at the surface show reasonable consistency. Based on the initial successful through-thickness strain mapping, more detailed work is to follow. It is clear that the neutron strain-mapping measurements will yield a clearer picture of the mechanical state of the case-hardened forging. Improvements in processing to achieve increased endurance limits for high-performance forgings will be achieved with a better understanding of subsurface residual stress.

\subsection{Thermophysical Properties User Center (TPUC)}

\subsubsection{New Thermophysical Properties Capability: Hot Disk Thermal Constants Analyzer}

TPUC expanded its capability with the addition of a new Hot Disk Thermal Constants Analyzer. Procurement was aided by funds from the Office of Industrial Technologies (OIT) 
Advanced Industrial Materials Program. The Hot Disk system can be used to measure thermal properties of a variety of materials, especially low-conductivity ceramics, plastics, powders, and granular materials such as sands. Many of these materials are difficult to measure with the flash diffusivity technique because of transparency in the infrared spectrum and high porosity. Some typical materials that have been measured are high- $\mathrm{T}_{\mathrm{c}}$ superconductors, glasses, refractories, casting sand, metal alloys, composites, polystyrene, bricks, liquids, and biomaterials. User proposals to use this instrument for measurement of the thermal conductivity of casting sands have already been approved.

The system is based on the Transient Plane Source method, which is a precise and convenient technique for studying bulk thermal transport properties. This technique is capable of measuring thermal conductivity, thermal diffusivity, and volume-specific heat simultaneously. The Hot Disk sensor is usually sandwiched between two pieces of sample during measurement. The sensor consists of an electrically conducting pattern in the shape of a double spiral laminated between two thin sheets of insulating material (e.g., Kapton, Mica). The sensor is used both as a heat source and as a dynamic temperature sensor.

\subsubsection{TPUC's New High-Speed Noncontact Technique for Measuring Temperature Was Successfully Demonstrated at Ford's Scientific Research Laboratory}

TPUC has been working for the past two years with Ford and other automotive-brakesystem original equipment manufacturers (OEMs) on mapping the temperature around rotors during braking. This information is useful in understanding and eliminating brake roughness. Previously, TPUC developed a technique that used a high-speed infrared camera to obtain data, and this work was recently highlighted on the cover of the July issue of Photonics Spectra. However, converting the 2-D imagery into temperature maps and then comparing the data with dynamometer data (such as torque variation or thickness variation) proved to be time-consuming and cumbersome. To eliminate this difficulty, TPUC developed an ultra-high-speed infraredbased system to measure the temperature of the rotor and feed this information directly into the brake dynamometer. This upgrade allows engineers to immediately compare temperatures with other important parameters without learning any new software or lengthy postprocessing steps. This system is fast enough to take hundreds of temperature measurements per rotor rotation. Each side of the rotor can be measured at six different locations for less than the cost of an infrared camera. This system will also be used in other applications that can benefit from highspeed noncontact temperature measurement, such as die casting.

\subsubsection{Nondestructive-Evaluation Applications of Infrared Thermography}

TPUC has demonstrated the capability to use the high-speed, high resolution infrared (IR) camera for nondestructive evaluation (NDE) of structural components for subsurface flaws and delamination. Besides testing small specimens and components in the laboratory, the portable system can be used for field tests on real structural components and objects of interest. The IR camera is used to monitor the surface temperature of an object either after a short heat pulse or during continuous-point or line heating. Flaws such as delaminations, cracks, and hidden 
corrosion will disturb the uniform heat flow and appear as hot spots or areas that can be detected by the IR camera.

\subsubsection{Thermal Diffusivity of Alternative Automotive Brake Materials}

Ford Research Lab continued prior-year research on alternative brake rotor materials. Thermal diffusivity and specific heat capacity of two new aluminum metal matrix composites manufactured in Europe were tested up to 500 and $425^{\circ} \mathrm{C}$, respectively. Aging treatments of the metal matrix composites at $250^{\circ} \mathrm{C}$ for 65 hours were also carried out. Thermal diffusivity of 12 specimens before and after the heat treatment was measured at room temperature. The increasing trend in thermal diffusivity as a function of heat-treatment history agreed very well with previously tested aluminum metal matrix composites obtained from different manufacturers. These data are valuable in brake design and for performance comparisons of existing brake systems.

\subsubsection{Thermal Conductivity and Thermal Stability of New Ternary Carbides}

Drexel University users have characterized $\mathrm{Ti}_{3} \mathrm{SiC}_{2}$ (312) and related H-Phase compounds (e.g., $\mathrm{Ti}_{2} \mathrm{AlC}, \mathrm{Ti}_{2} \mathrm{AlN}, \mathrm{Nb}_{2} \mathrm{SnC}$, and $\mathrm{Hf}_{2} \mathrm{SnC}$ ) that are layered ternary carbides of great interest because of their unique high-temperature properties. These compounds have shown a combination of high yield strength, thermal shock resistance, high room temperature thermal conductivity, and oxidation resistance, making them potentially very important materials for a variety of applications, including high-temperature structural components. Thermal properties of these compounds, especially the high-temperature thermal conductivity, are unknown and are not available in the literature.

Simultaneous thermal analysis (STA) runs were conducted up to $1500^{\circ} \mathrm{C}$ in argon on $\mathrm{Ti}_{3} \mathrm{SiC}_{2}$, $\mathrm{Ti}_{2} \mathrm{AlC}, \mathrm{Nb}_{2} \mathrm{SnC}$, and $\mathrm{Hf}_{2} \mathrm{SnC}$. All of the compounds appeared to be thermally stable over this temperature range. Specific heat values were determined for $\mathrm{Ti}_{3} \mathrm{SiC}_{2}, \mathrm{Ti}_{2} \mathrm{AlC}$, and $\mathrm{Nb}_{2} \mathrm{SnC}$ from 100 to $1000^{\circ} \mathrm{C}$. The thermal diffusivity of two compounds, $\mathrm{Ti}_{3} \mathrm{SiC}_{2}$ and $\mathrm{Ti}_{2} \mathrm{AlN}$, was measured using the Laser Flash Thermal Diffusivity system from room temperature to $1200^{\circ} \mathrm{C}$. The thermal diffusivity of the two compounds is $0.160 \mathrm{~cm}^{2} / \mathrm{s}$ at $100^{\circ} \mathrm{C}$ to $0.095 \mathrm{~cm}^{2} / \mathrm{s}$ at $1200^{\circ} \mathrm{C}$. Diffusivity, specific heat, and density values will be used to calculate their thermal conductivity as a function of temperature. These results, combined with prior HTML DUC studies of lattice parameters and thermal expansion coefficients, will help the researchers to understand thermal properties of these new ternary carbides.

\subsubsection{High-Temperature Thermal Properties of Advanced Thermoelectric Materials}

Researchers from the GM Research and Development Center have completed their study of a new class of thermoelectric materials called filled skutterudites. These materials are strong candidates for thermoelectric generators in automotive applications. They can be used for conversion of waste exhaust gas and radiator latent heat to supplemental electrical power and for 
solid-state heating and cooling systems. Rare earth elements such as $\mathrm{Ce}$ and $\mathrm{Nd}$ were used to "fill" the cages in binary skutterudite compounds such as $\mathrm{CoSb}_{3}$. Samples with different filling fractions were studied. Thermal diffusivity of these samples was measured from 100 to $450^{\circ} \mathrm{C}$. Room-temperature thermal diffusivity was measured by the xenon flash system. Specific heat of the specimens was measured by the differential scanning calorimetry (DSC) system.

\subsection{MECHANICAL CHARACTERIZATION AND ANALYSIS USER CENTER (MCAUC) HIGHLIGHTS}

\subsubsection{IR Camera Used To Detect Cracks in Thermal Barrier Coatings (TBCs) as They Develop}

Dr. Maria Arana of the Westinghouse Power Division (Orlando, Florida) has performed lowcycle fatigue testing of TBC-coated, Ni-based superalloy cylindrical specimens. Both air-plasmasprayed (APS) and electron-beam physical-vapor-deposited (EB-PVD) coatings have been characterized. Strain-controlled testing was used; this is the most difficult among the other possible control modes (load or displacement). Dr. Arana used the IR imaging system to monitor the surface coating in situ for possible crack growth within it and temperature changes (which may be an indication of damage accumulation). A fatigue curve (i.e., "S-N curve") is being generated; temperature and strain are being used as the independent variables, and cycles to failure or cycles to identifiable crack growth are being used as the dependent parameter. This project has been successful in several ways. A very unusual test setup was successfully developed, both in terms of the strain control of a coated specimen and in the innovative use of the IR camera to detect temperature changes during cycling and at the onset of spallation.

\subsubsection{Stress Relaxation in Superalloy Has Been Measured}

Dr Michael Fahrmann of INCO Alloys (Huntington, West Virginia) performed a user project designed to examine the stress-relaxation behavior of a developmental Ni-based superalloy grade, IN783. In this alloy, there is a phase that precipitates out in a time-dependent fashion when this alloy is subjected to elevated temperatures. Because of this, specimens made from this material that are mechanically constrained will actually experience a time-dependent stress increase. This phenomenon is also called "negative creep." To address this, INCO compiled a stress-relaxation test matrix that examines the stress relaxation behavior of this alloy between 482 and $649^{\circ} \mathrm{C}$ at strains of 0.1 and $0.2 \%$. These temperatures and strains bracket typical service conditions for components made by some of INCO's customers. The stress increase was minimal and sluggish at $482^{\circ} \mathrm{C}$, greater and faster at $537^{\circ} \mathrm{C}$, and the greatest and quickest at $593^{\circ} \mathrm{C}$. At $649^{\circ} \mathrm{C}$, the "negative creep" mechanism threshold temperature was exceeded and the material exhibited classical stress relaxation (i.e., stress decrease with time). 


\subsubsection{Fracture-Toughness Measurement Using a Vickers Indenter on the Nanoindenter Has Been Successful}

A Vickers indenter was carefully characterized and calibrated. Its suitability for fracture toughness measurement was assessed. To date, tests have been completed on barium titanate. Indentations were made with a Wilson/Tukon Vickers hardness tester as well as a Vickers indenter on the Nanoindenter. Crack lengths were measured, and fracture toughness was calculated for both methods. The fracture toughness was in good agreement for both indenters. We now can get hardness/modulus and indentation fracture-toughness data with one indenter. The method has also been used to characterize thin (1 micron or less) zirconia/alumina coatings, with varying the amount of zirconia and varying processing conditions. The hardness, Young's Modulus, and fracture toughness of these thin films have been assessed and successfully used as indicators for the quality of the deposited films. This work was part of a Ph.D. thesis by David Stollberg at Georgia Institute of Technology.

\subsubsection{Remote Control and Datalogging Demonstrated Using Labview}

Remote control and datalogging were demonstrated to the HTML Programs Senior Advisory Committee in November. Using Labview and the internet, Dr. Matt Ferber of MCAG was able to control instruments by means of a simple client/server system. The system is very flexible and can be set up at several levels of access according to the needs of the customer (i.e., experiments can be controlled or simply observed).

\subsection{MACHINING AND INSPECTION RESEARCH USER CENTER (MIRUC) HIGHLIGHTS}

\subsubsection{Work Continues on Cummins Fuel Systems Division User Project}

Mike Bowling of Cummins Engine Fuel Systems Division used a cubic boron nitride wheel on the Weldon instrumented cylindrical grinder to perform high-speed grinding experiments on $\mathrm{Si}_{3} \mathrm{~N}_{4}$ specimens. The experiment was an extension of earlier work conducted by Dr. Albert Shih at the HTML and was designed to study the relationships between grinding wheel speeds and wheel wear, grinding ratio, part surface finish, and part roundness. Such experiments are crucial to the success of our efforts to develop cost-effective ceramic machining processes.

This current work identified mechanical limitations in our Weldon cylindrical grinder that needed to be corrected if the machine is to be useful for future experimental work by Cummins. These limitations involved the inability of the grinder to produce repeatable surface finishes and roundness values under controlled grinding conditions. The problem was caused by a combination of mechanical looseness, errors in mechanical alignment, mechanical imbalance in rotating components, and structural resonances in the machine itself. A dynamic vibration analysis was performed in an attempt to understand the sources of the machining problems. Collaborative efforts between the machine manufacturer and HTML staff resulted in greatly improved machine 
performance, and experiments designed to determine grinding ratios under a variety of grinding/wheel dressing conditions were run again as a part of a user proposal from Cummins. A cubic-boron-nitride wheel was dressed under varying, controlled conditions and was used to grind zirconia specimens at four different wheel speeds. The test results show that, in general, higher wheel speeds result in higher grinding ratios with little or no degradation in surface finish of the part.

\subsubsection{Allison Engine Develops Improved Methods for Producing Drilled Holes in Silicon Nitride Combustor Housings}

Numerous through-holes must be machined in the combustor housing component, which is made from silicon nitride. Allison has been experiencing a serious problem with material chipping on the inside surface of combustors where the drill exits the surface of the combustor wall. The holes are typically fabricated by outside vendors. A series of grinding experiments was conducted under the HTML User Program to evaluate various backing materials, abrasive drilling tools, and drilling/fixturing techniques in an attempt to minimize the chipping problem. A low-melttemperature metal was applied to the inner surface of test coupons and special diamond-core drills and fixturing techniques were used to produce holes in simulated combustor housings. The chipping problem appears to have been completely eliminated. Flexure tests are being performed on the specimens to verify that the machining process does not degrade the mechanical properties of the material. The technique will be demonstrated on a real combustor housing in the near future, and Allison plans to encourage its vendors to work with the HTML to implement the improved process as soon as the experimental work is completed.

\subsubsection{Grinding Studies Performed in Conjunction with the Institute of Advanced Manufacturing Sciences under Work-For-Others Program}

The Institute of Advanced Manufacturing Sciences (IAMS) has signed a memorandum of understanding with the Oak Ridge Centers for Manufacturing Technology in which Oak Ridge technical resources can be made available to IAMS customers. The HTML has agreed to participate in the MOU as appropriate. Recently, IAMS and MIRUC staff jointly conducted grinding studies designed to evaluate the effects of using a water-soluble-oil-based coolant that had been deliberately contaminated with tramp oil. Conventional aluminum oxide grinding wheels were used to grind hardened steel specimens under controlled conditions on the instrumented Weldon grinder under various concentrations of coolant/contaminant.

\subsubsection{Machining Research, Inc., Performs Machinability Studies on Hardened Steels Using Instrumented Weldon Cylindrical Grinder}

Under the HTML User Program, Guy Hughes performed grinding studies on AerMet 100 and HYTUF high-strength steels in the hardened condition. A limited test matrix of varied wheel and part speeds, feeds, and plunge depths was used to investigate wheel wear rates. Grinding forces and spindle power were measured during the tests. The objective was to determine the 
relative influence of the grinding parameters on wheel wear rates and grinding forces. The results of the work will be presented as grinding ratio curves that will be widely published. Grinding force and power data will also be useful for those interested in determining the size of machine necessary to produce parts from these materials.

\subsection{HTML FELLOWSHIP PROGRAM HIGHLIGHTS}

Most of our fellowship program projects, like the user projects, involve users coming to the HTML to do their work; however, some of our equipment is portable. In the case of the fellowship program project with James W. Fash of Ford Motor Company, Dr. Ralph Dinwiddie (of TPUC) took the high-speed IR camera to the Ford Scientific Research Laboratories and participated in the project aimed at improving brakes and braking systems for automobiles. The process of sending HTML staff to fellowship program participant sites has been dubbed the "reverse fellowship" process. This process was essentially repeated this year with the participation of Dr. Kwang-Jin Lee of Delphi Chassis Systems, who utilized the expertise and equipment of HTML on a brake system project.

During this period, several HTML graduate fellowship program students completed their studies and graduated. Elizabeth Dickey of Northwestern University completed her dissertation defense and is now employed as an assistant professor at the University of Kentucky. Ron Ott of the University of Alabama-Birmingham (UAB) successfully defended his thesis on March 14, 1997, concluding his fellowship. He has taken a position as a post-doctoral researcher at UAB. Allen Haynes of UAB successfully completed his thesis defense, which ends his fellowship. Dr. Haynes is now employed by Oak Ridge Institute for Science and Education and works in a postdoctoral position in the Ceramic Surface Systems Group at ORNL. Matt Stough of Penn State University successfully defended his dissertation on June 23, 1997. The ex-graduate fellow is now employed at Osram Sylvania, Exeter, New Hampshire. His work has led to an important new understanding of the zirconia-alumina phase diagram, with better definition of solubilities of the $\mathrm{Zr}$ and $\mathrm{Al}$ species in each other's oxide lattices. 


\section{HTML USER STATISTICS}

This section provides tables and graphs that summarize selected HTML user, fellowship, and other statistics, including user demographics, user agreements, and user proposal history.

\subsection{USER DAYS}

Individuals from industrial companies, universities, other DOE laboratories, and other agencies, along with internal users from the HTML, the Metals and Ceramics Division, and other ORNL divisions, utilize the equipment within the HTML. Since shortly after the beginning of the User Program, there has been a user logbook for each instrument in the user centers. The entries from these logbooks are tallied annually by each user center for each instrument, then the totals are rolled into one set of data for the HTML. Each 8-hour period, or fraction of an 8-hour period, that an instrument is being used is tallied as a "user day." Since 1987 (with the exceptions of 1987 and 1995), the user day data have been collected for industry and university users as well as for internal ORNL staff.

Recently, with the advent of a FileMaker Pro database, we have been collecting more complete user-day data on each instrument. We now collect data on industry, university, and internal ORNL users, but also include numerous other users. We have also separated the HTML Fellowship Program data; previously, it had been included in the user activity. Table 3.1 contains all of the data since the second full year of operation (data for the first full year do not exist). Empty cells in the table indicate that no data were recorded, not that a given type of user work was not performed.

Table 3.1. History of HTML user days, by fiscal year

\begin{tabular}{lrrrrrrrrr|r} 
& $\mathbf{1 9 8 9}$ & $\mathbf{1 9 9 0}$ & $\mathbf{1 9 9 1}$ & $\mathbf{1 9 9 2}$ & $\mathbf{1 9 9 3}$ & $\mathbf{1 9 9 4}$ & $\mathbf{1 9 9 6}$ & $\mathbf{1 9 9 7}$ & $\mathbf{1 9 9 8}$ & Total \\
\hline User & & & & & & & & & & \\
Industry & 581 & 956 & 3201 & 3692 & 2695 & 4719 & 5326 & 1672 & 1672 & 24514 \\
University & 248 & 607 & 674 & 880 & 1353 & 2163 & 2181 & 1801 & 1130 & 11037 \\
Proprietary & 31 & & & & & & 256 & 166 & 93 & 546 \\
Other agency & 9 & & & & & & 20 & 3 & 38 & 70 \\
Fellowship & & & & & & & & & & 0 \\
Industry & & & & & & & 622 & 1844 & 1576 & 4042 \\
Graduate & & & & & & & 1417 & 932 & 199 & 2548 \\
Faculty & & & & & & & 148 & 4 & 1 & 153 \\
Subtotal & 869 & 1563 & 3875 & 4572 & 4048 & 6882 & 9970 & 6422 & 4709 & 42910 \\
WFO & & & & & & & 158 & 70 & 463 & 691 \\
ORNL & 1427 & 1758 & 5309 & 4661 & 9666 & 7301 & 8958 & 13683 & 7903 & 60666 \\
CRADA & & & & & & & 2706 & 1877 & 316 & 4899 \\
\hline
\end{tabular}


Data for FY 1998 are included from the HTML Fellowship Program in all three of its operational categories: "industrial," "graduate," and "faculty." User-day data are compiled according to user center in Table 3.2.

The data for total, industrial, university, and internal ORNL user days are plotted in Fig. 3.1. As the figure shows, although there is some irregularity in the growth pattern, in general, the HTML experienced a steady increase in the annual number of user days performed for each category through FY 1996, leveling off in FY 1997 and decreasing in FY 1998.

The increase in use of HTML facilities has been partially attributable to continuing efforts toward providing lower-cost service (making the program more cost effective) and to the continuing commitment to customers exhibited by the HTML staff. By pleasing the customer, we get repeat business (see Sect. 3.2), and we get new business because customers spread the word about us. Also, the continued growth can be attributed to our ongoing marketing, in which we inform potential customers of our services through in-house visits, tours, and presentations at universities, conferences and expositions, and our World Wide Web site. Major growth has occurred this year in the ORNL internal use category, in which we support several other DOE programs, including the Heavy Vehicle Propulsion Materials Program, the Continuous Fiber Ceramic Composites Program, the Advanced Turbine Systems Program, and others. However, this growth has been offset by a decreasing number of external industrial user days and, to a lesser extent, by a decreasing number of external university user days, after years of steady growth in these areas. There is no ready answer to why this has occurred, as university and industry interest level remains high (see the increased numbers of proposals submitted, described below).

Table 3.2 HTML user days for FY 1998, by User Center

\begin{tabular}{|c|c|c|c|c|c|c|c|}
\hline & DUC & MAUC & MCAUC & MIRUC & RSUC & TPUC & TOTAL \\
\hline \multicolumn{8}{|l|}{ User } \\
\hline Industry & 65 & 49 & 1033 & 98 & 304 & 123 & 1672 \\
\hline University & 242 & 130 & 60 & 23 & 417 & 258 & 1130 \\
\hline Proprietary & 6 & 59 & 6 & 0 & 14 & 8 & 93 \\
\hline Other agency & 9 & 1 & 0 & 0 & 28 & 0 & 38 \\
\hline \multicolumn{8}{|l|}{ Fellowship } \\
\hline Industry & 0 & 24 & 1460 & 0 & 34 & 58 & 1576 \\
\hline Graduate & 0 & 88 & 78 & 0 & 27 & 6 & 199 \\
\hline Faculty & 0 & 1 & 0 & 0 & 0 & 0 & 1 \\
\hline Subtotal & 322 & 352 & 2637 & 121 & 824 & 453 & 4709 \\
\hline $\begin{array}{c}\text { Work for } \\
\text { Others }\end{array}$ & 1 & 0 & 454 & 0 & 3 & 5 & 463 \\
\hline ORNL & 522 & 960 & 4047 & 1628 & 342 & 404 & 7903 \\
\hline CRADA & 0 & 6 & 276 & 12 & 1 & 21 & 316 \\
\hline Total & 845 & 1318 & 7414 & 1761 & 1170 & 883 & 13391 \\
\hline Service & 7 & 13 & 0 & 0 & 259 & 2 & 281 \\
\hline Grand total & 852 & 1331 & 7414 & 1761 & 1429 & 885 & 13672 \\
\hline
\end{tabular}




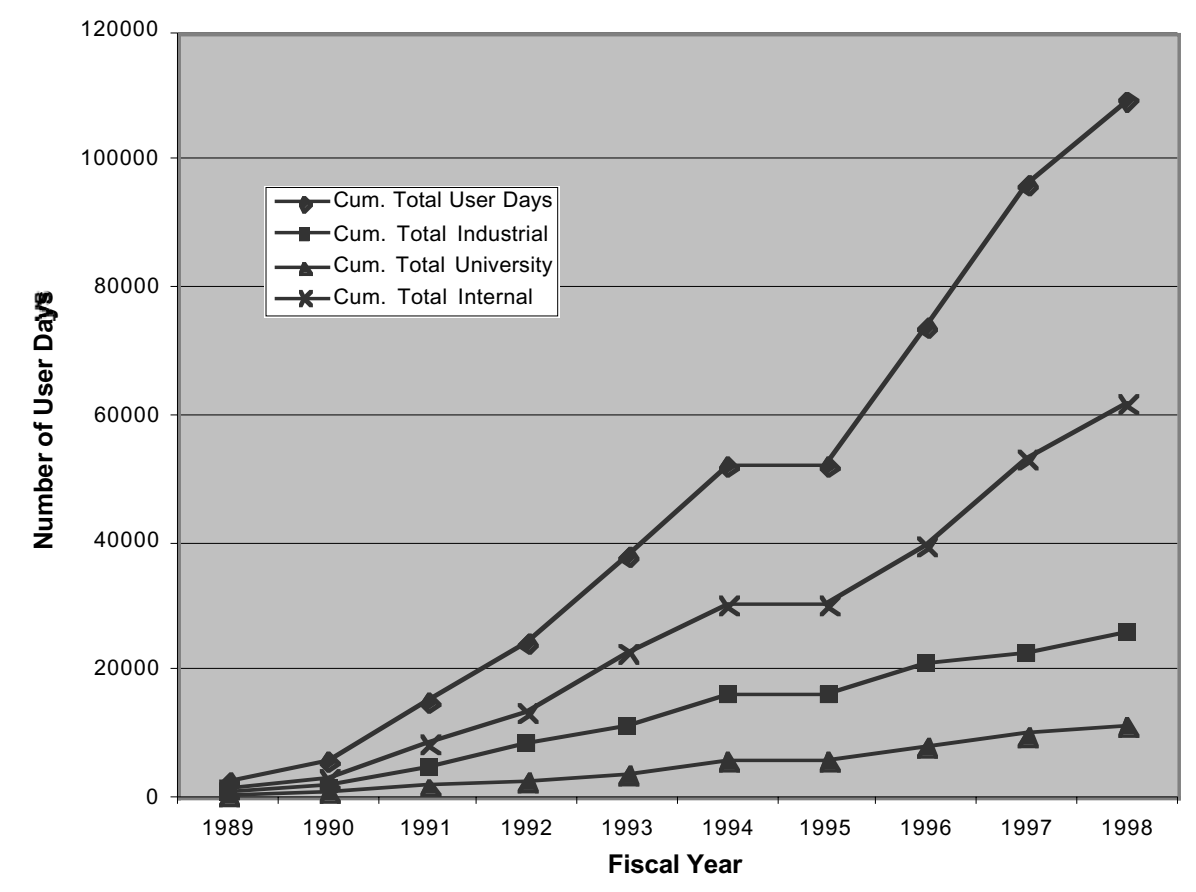

Fig. 3.1. A history of user days of research expended in the HTML since its inception.

To meet the continuing demand for some instruments, we have purchased duplicates (e.g., a second nanoindenter and several tensile test machines). However, we occasionally have to delay a user's visit to HTML because of difficulties in scheduling our limited staff and equipment. We are now very close to or have reached a "saturation" in user-day capability at the current budget level.

\subsection{USER AGREEMENTS AND PROPOSALS}

A user agreement between LMER and the user institution is the legal vehicle that allows a user to perform work in the HTML. It specifies personal liability and the handling of intellectual property. The agreements are handled and tracked by the ORNL Office of Science and Technology Partnerships (OSTP), which provides a listing of all of the user agreements within LMER.

A user agreement allows a company or university access to any of the 15 user facilities at ORNL. The user completes another document, called a technical proposal, after both parties have signed the user agreement. Technical proposals are handled and tracked by the HTML Program Office. Figures 3.2 through 3.5 illustrate user agreements received by OSTP and technical proposals received by the HTML.

Figure 3.2 illustrates the annual history of user agreements received at OSTP. Many are written expressly for interaction with the HTML user centers, although some were written for multiple-user facility access or for access to other ORNL facilities, such as the Metals 


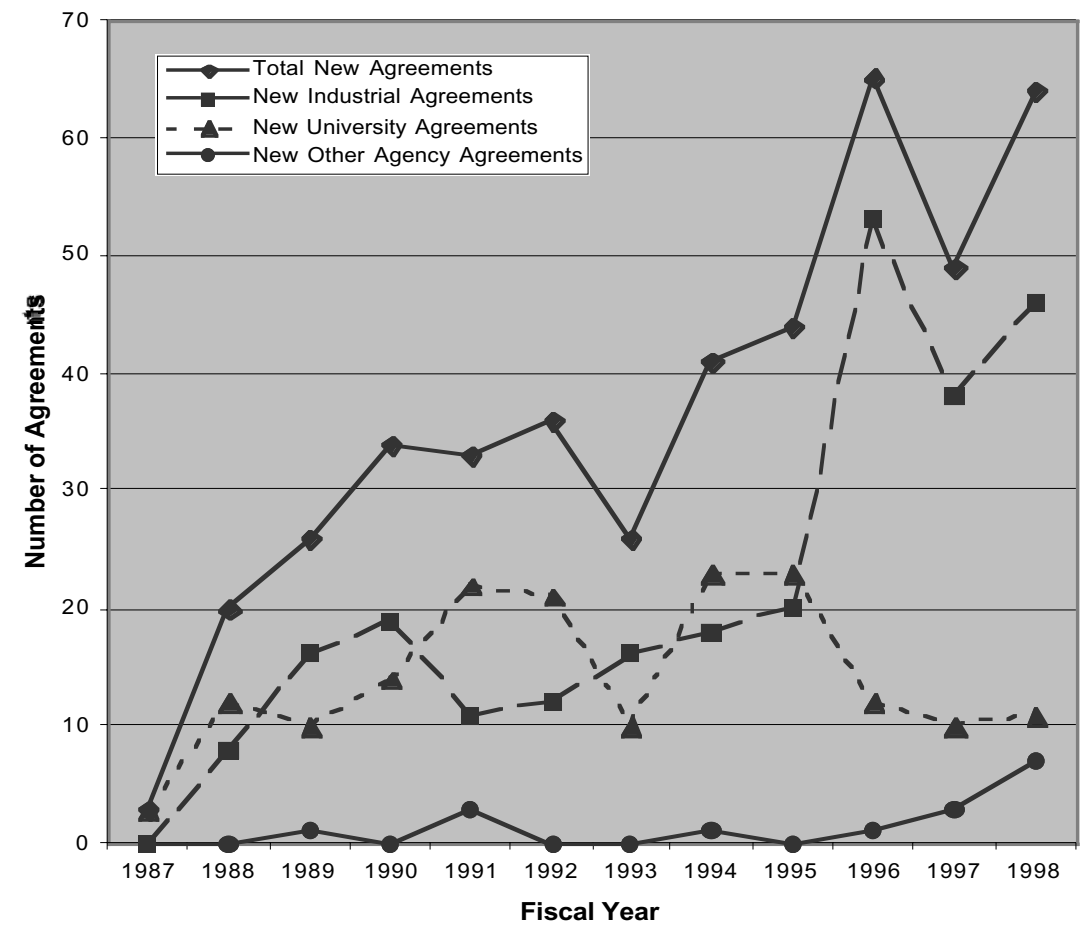

Fig. 3.2. Numbers of materials-related user agreements received by the ORNL Office of Science and Technology Partnerships.

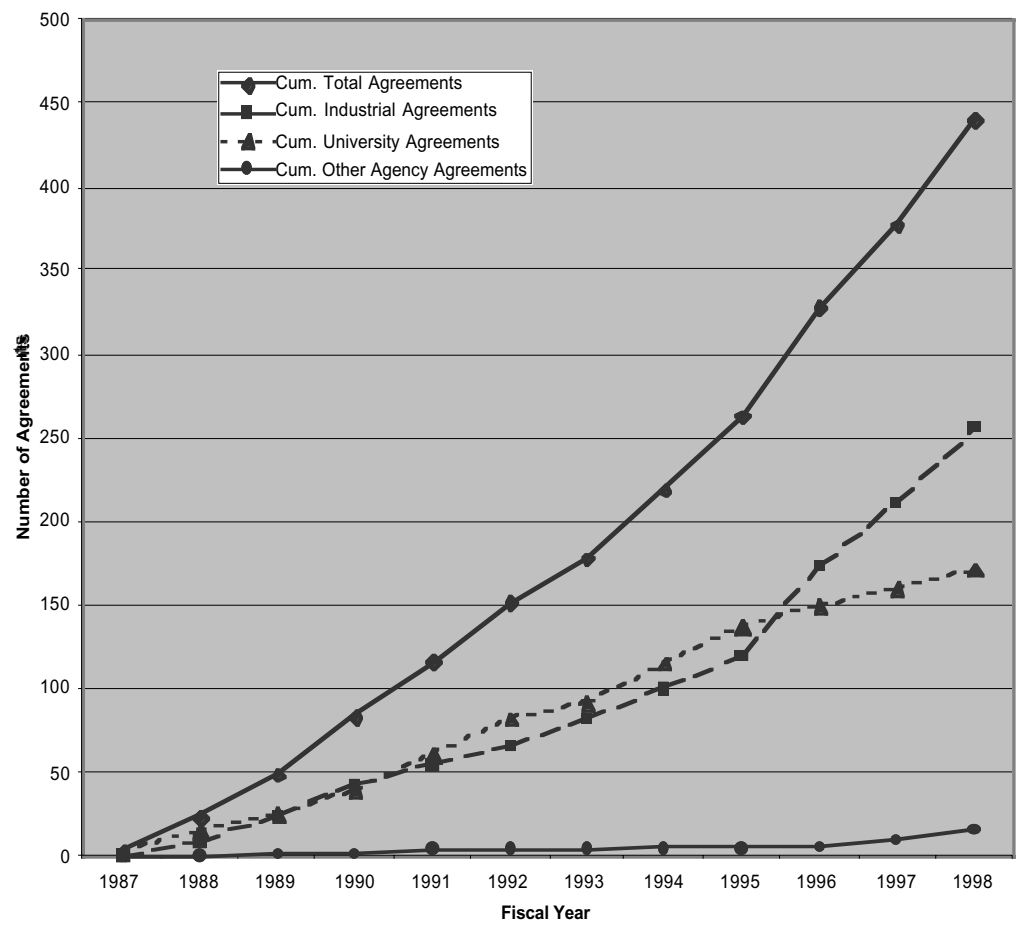

Fig. 3.3. Cumulative number of user agreements received by the ORNL Office of Science and Technology Partnerships. 
Processing Laboratory User Center (MPLUS) or the Surface Modification and Characterization Facility (SMAC). After a quick rise in the numbers of user agreements during HTML startup, the annual number stabilized at about 30, with approximately equal numbers of industrial and university agreements. The industrial numbers increased in the years 1994 through 1996 because HTML program and research staff aggressively marketed the facility, because new customer interest in HTML was stimulated by word-of-mouth, and because new user centers at ORNL, such as MPLUS and SMAC, brought in new users. The increased number of user agreements bodes well for the future of the HTML Program. During FY 1997, however, the number of new agreements decreased slightly.

The history of technical proposals submitted to HTML is illustrated in Fig. 3.4. Like the user agreements, the number of proposals increased until about 1990 as the HTML programs were starting up. Since then, however, the rates for proposals have varied quite widely. The rate of receipt of user proposals (especially industrial proposals, which showed a steady 4-year decline) decreased noticeably from about 1993 through 1996. There were many possible reasons for this.

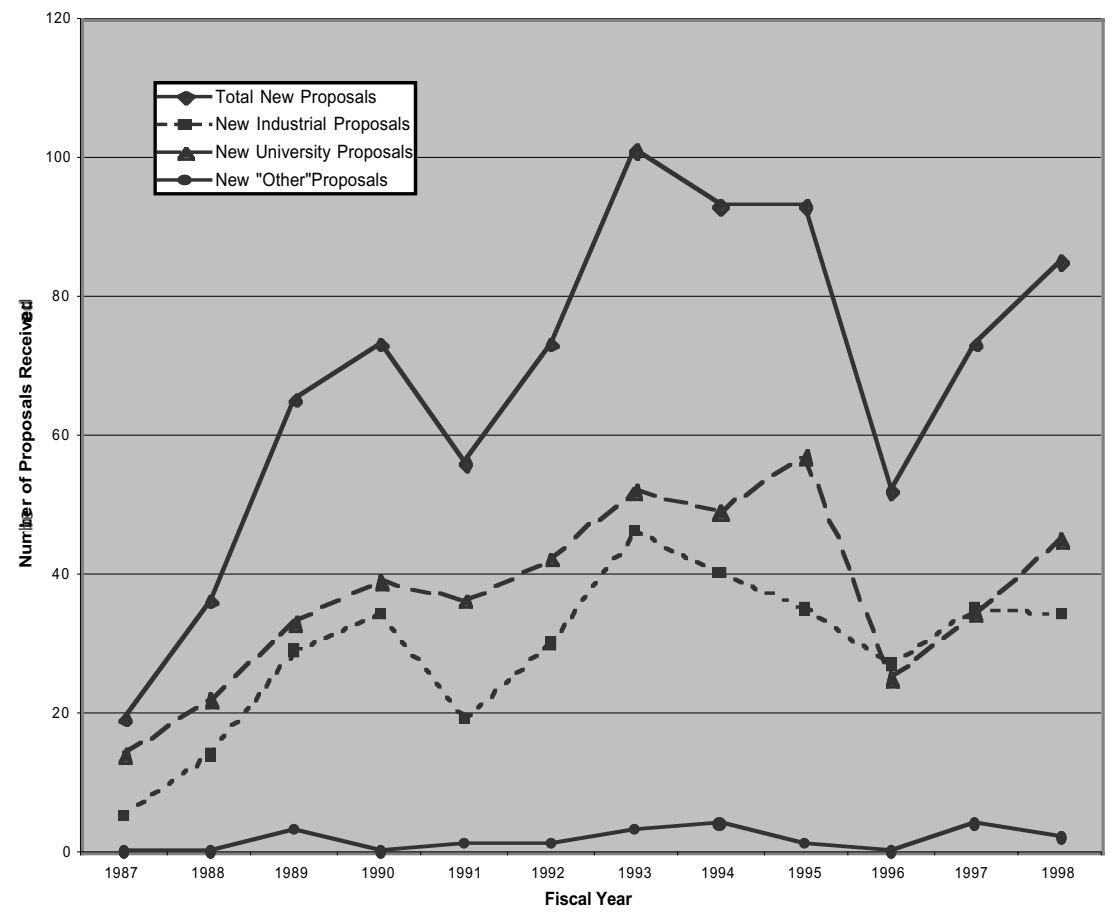

Fig. 3.4. History of technical proposals received by the HTML.

One factor was that many companies were continuing to work under previously existing proposals, maintaining their presence at HTML. New proposals were not being written, and no specific means to close out old proposals existed. This caused a problem because the HTML user program is charged a quarterly fee for each "active" user clearance into ORNL. Money was sometimes being spent needlessly on clearances for projects that had been closed.

A new mechanism was instituted in FY 1996 to close out old proposals, cause new ones to be written, and eliminate the clearance costs for users who were no longer active. At the end of each year, a letter is sent to each user institution thought to be active, inquiring about its status 
and asking for a written summary if the work is completed (for our annual report) and to provide the publications that resulted from the work. In this way, we get a clear understanding of their project status, a summary, and a paper if the work has been completed. This action may be partly responsible for the increase in the number of proposals submitted in FY 1997.

A second possible reason is that, in 1993, companies took advantage of the new openness of the Democratic administration and its encouragement of cooperative research and development agreements (CRADAS) and other industry-laboratory interactions. Several companies "tested the waters" in 1993 and 1994, and, as a result, we saw an increase in the number of proposals. We are now returning to a steadier rate.

A third possible reason is that HTML staff members are concentrating their efforts on a few relatively important projects as the HTML program approaches saturation.

Whatever the reasons, the turnaround in FY 1997 was quite dramatic.

Figure 3.5 presents a picture of the cumulative history of technical proposals, showing that the total number of proposals received has now exceeded 800 . Universities continue to lead industries in the submission rate.

Figure 3.6 depicts the cumulative history of user agreements and technical proposals received, illustrating that the ratio of proposals to agreements is $819 / 444$, or about 2 . This figure indicates that, on the average, users tend to come to the ORNL user facilities about twice to perform research and development $(\mathrm{R} \& \mathrm{D})$ projects. This repeat business is evidence of the satisfaction we provide to our customers.

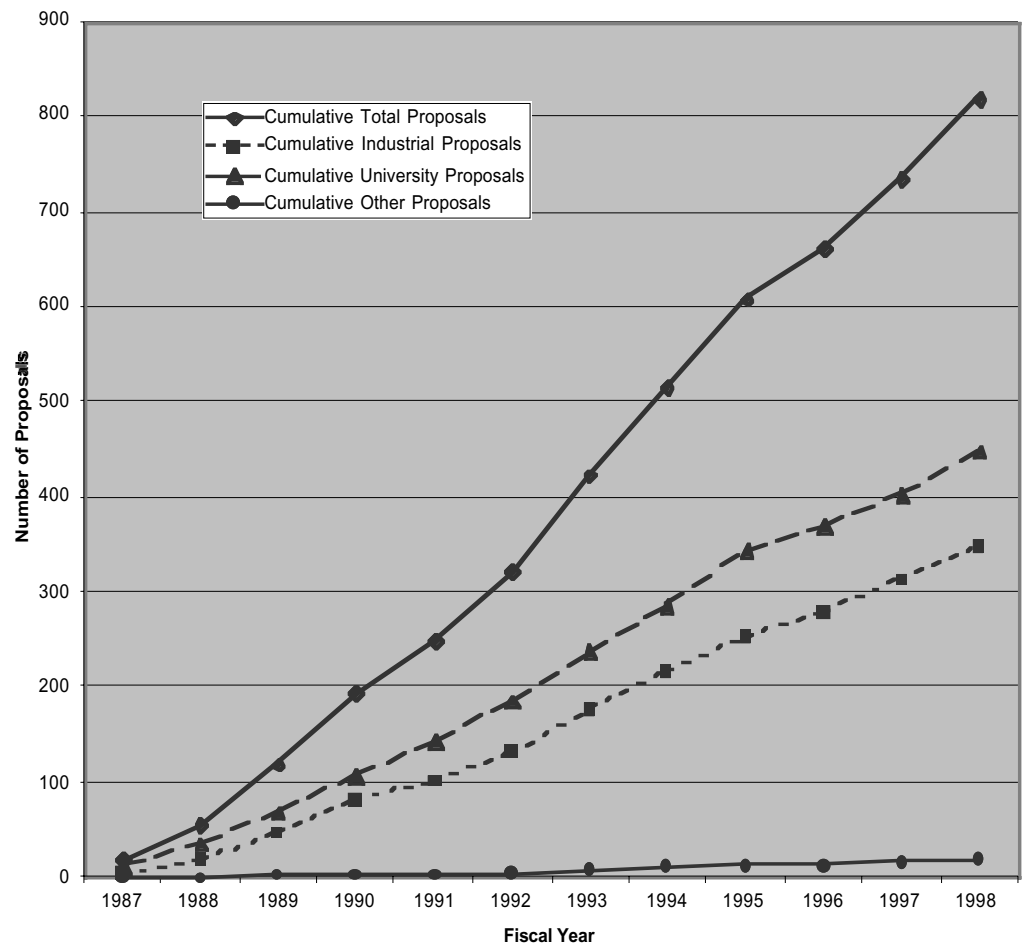

Fig. 3.5. Cumulative history of technical proposals received by HTML. 


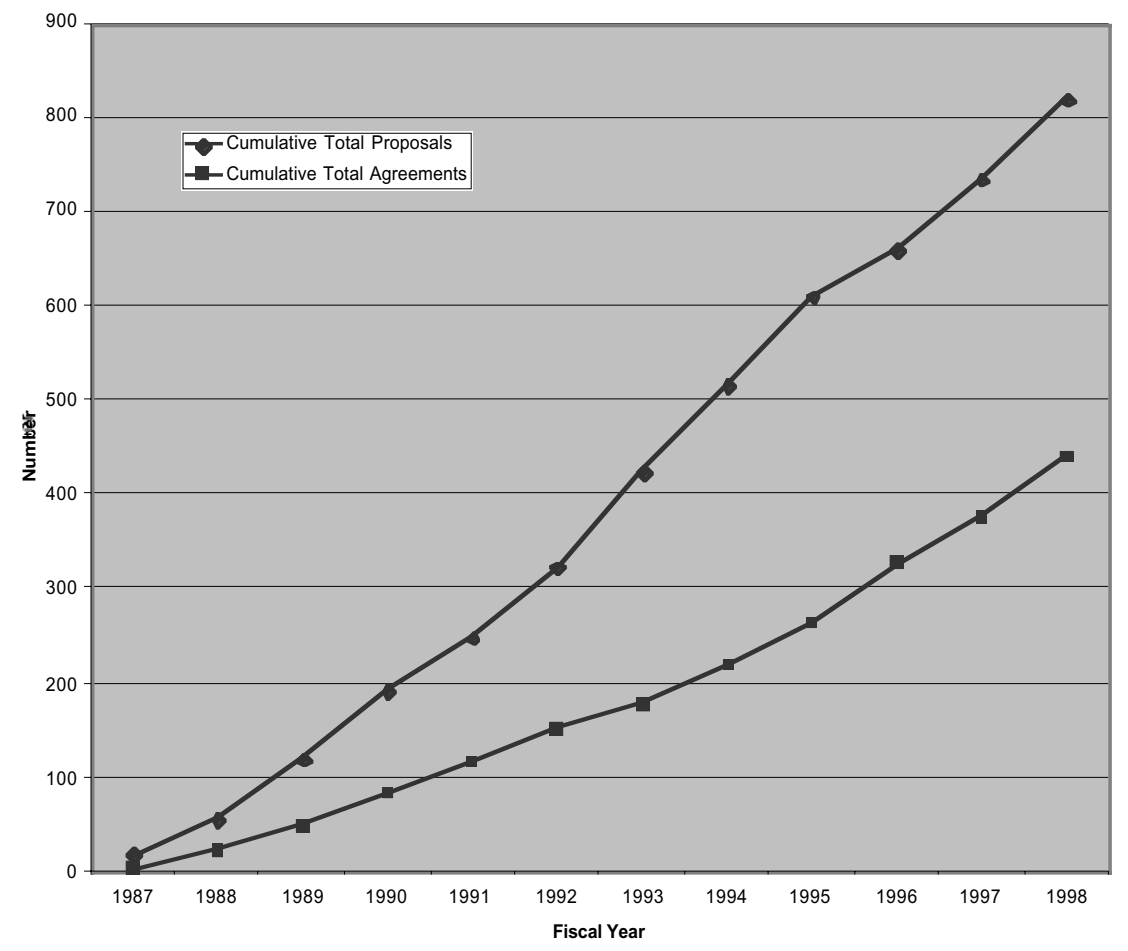

Fig. 3.6. Cumulative technical proposals and user agreements received. 


\section{HTML USER CENTERS}

\subsection{MATERIALS ANALYSIS USER CENTER}

\subsubsection{Staff and Current Capabilities}

MAUC uses electron microscopy and surface chemical analysis techniques to characterize the structure and chemistry of advanced structural materials. The information obtained from these characterizations is used to elucidate the mechanisms that control material performance.

T. A. (Ted) Nolan is the group leader of MAUC. Additional MAUC staff members are listed below, along with the instruments for which they have primary operating responsibility:

- Dr. L. F. (Larry) Allard—Hitachi HF-2000 field emission gun transmission electron microscope (FEG-TEM);

- D. W. (Dorothy) Coffey-Hitachi S-800 FEG scanning electron microscope (SEM) and S4500 FEG-SEM;

- L. R. (Larry) Walker-JEOL 733 electron microprobe;

- Dr. K. L. (Karren) More-JEOL 4000EX high-resolution transmission electron microscope (HREM);

- Dr. E. (Edgar) Völkl — electron holography, digital and remote microscopy;

- Dr. B. (Bernhard) Frost (University of Tennessee research staff)—Topometrix scanning probe microscope;

- Professor D. C. (David) Joy (Joint ORNL and University of Tennessee Distinguished Scientist) - SEM and electron solid interaction theory;

- Ms. Cheryl Lee-Administrative Support.

\subsubsection{Highlights}

\subsubsection{New and Upgraded Instrumentation}

\section{Electron Microprobe Upgrade}

The JEOL Electron Microprobe had been in use for approximately 13 years without significant upgrade. The old computer system (PDP-1173) and software were lagging well behind the technological advances that had been realized with other instrumentation within the group and industry. All data and some images required hard copy or manual input into the plant data system. Additionally, new correction algorithms and other software advances were not available for this system. For these reasons, a new automation system from Geller Microanalytical was purchased. This system utilizes a PC running Windows 95 and includes software that incorporates many of the advances in technology that were developed over the last several years.

Several of the more recently developed correction algorithms as well as the classic algorithms are available for converting intensity ratios to compositional values. Large area imaging, 
combining stage and digital beam scanning in one collection routine, can be used to show macro effects such as corrosion attack or an entire weld. Most importantly, the data are compatible with other PC- and Mac-based software so that a multitude of programs can now be used for processing, transmitting to the customer, and storing to central servers.

To a lesser extent than some of the other instruments, the microprobe can now be operated remotely. Functions controlled through the computer that are now accessible remotely include stage, wavelength spectrometers, energy-dispersive spectrometer, image collection (including Xray maps), and qualitative and quantitative analyses. The complexity of the probe is such that it may never be operated routinely from remote locations by users. However, Larry Walker, our probe operator, is now making excellent use of the remote capabilities. Maps showing the locations of elements in metal alloy samples, for example, may take many hours to acquire. Larry waits to start these maps in the evening. He takes a few minutes once or twice in the evening to sign on from home on his PC (password-protected access), initiates new scans, and evaluates results. Thus the probe has considerably more productive time at essentially no additional cost to our programs.

\section{Hitachi S-4700 SEM Acquisition}

The Hitachi S-4500 field emission SEM with its excellent resolution at low accelerating voltage has been extremely valuable in the study of ceramics. Low-voltage imaging minimizes electrical charging on insulating materials such as ceramics and ceramic composites. A new SEM, the S-4700, has been introduced by Hitachi. This instrument has significant improvements over the S-4500 and any other SEMs presently on the commercial market. The S-4700 has the very best low voltage resolution available. It employs a virtual aperture and alignment system that allows changing the accelerating voltage without having to realign the microscope. This is a major advantage for the user program because expert operator intervention is minimized during user sessions. Finally, the S-4700 is completely controlled by and operated from two PCs. Thus, it is fully remotely operable. We have negotiated with Hitachi to trade our S-4500 and our JEOL 2000FX TEM for the S-4700 (worth about \$500k) for a differential cost of \$125k. The installation date was December 1998.

\section{Focused Ion Beam (FIB) Consignment}

MAUC has been chosen by NSA-Hitachi Scientific Instruments company for a no-cost consignment of the latest-generation focused ion beam (FIB) instrument, valued at $\sim \$ 700 \mathrm{~K}$. The period of the consignment will be a minimum of 6 months and will probably extend to at least a year. The delivery date is April 1999.

The FIB is an instrument that uses a beam of gallium ions to precisely mill a bulk plate ( $\sim 50$ micron-thick) from a direction normal to an edge of the plate. A very thin "shelf" of material up to 20 microns wide by 20 microns deep by about $30 \mathrm{~nm}$ thick is left, supported by the remainder of the plate. The shelf is essentially parallel-sided, nearly uniform in thickness over the whole area, and ideal for electron transmission. This is the newest method of preparation of specimens for electron microscopy and is especially useful for preparation of cross sections of layered 
materials and coated/treated surfaces. It is a rapid process and allows virtually $100 \%$ success rates for sample preparation to be achieved from just about any type of solid material in 2 to 3 hours. The instrument will greatly facilitate our HTML user programs and other programs studying cutting tools, hardened or coated metal parts, composites, and electronic devices. It can be used to produce specimens for SEM and auger analysis and to manufacture micromechanical devices. The FIB will also be available for Basic Energy Sciences (BES) and other research programs.

The placement of the FIB in the MAUC is the result of Hitachi's recognition of the international reputation of the HTML in electron microscopy. They know that the FIB will receive a great deal of exposure from the many users and visitors who come to the HTML.

\subsubsection{Remote and Digital Microscopy}

Some time ago, we recognized the value of a capability for our users to interact directly with the scientists and instrumentation in our laboratory by internet connections during microscopy sessions. Therefore, the concept of "remote microscopy" in a "virtual laboratory" was a natural step to expand capabilities and make our facilities available to a much-expanded user base. To this end, we have successfully developed control and image-processing algorithms for the digital imaging and control system of the Hitachi HF-2000 FEG-TEM, our "flagship" instrument. The Hitachi S-4500 SEM and the JEOL 733 super electron probe are now remotely operable. Typical functions that can be controlled remotely include focus, specimen position, magnification, and acquisition of a high-definition image. Algorithms are being worked on to test and monitor the performance of the SEM automatically, while the TEM continues to be automated further to facilitate its remote use.

The initiative of DOE called DOE2000, sponsored by MICS is in its second year; this initiative seeks to develop and demonstrate collaboratory concepts such as remote instrument operation, electronic whiteboards and notebooks, and telepresence tools. We collaborate with Argonne and Lawrence Berkeley national laboratories, as well as the University of Illinois, on the pilot project called Materials Microcharacterization Collaboratory (MMC). This proposal was one of two selected for funding and is supporting the continued development of remote microscopy. The MMC has as its principal mission the use of the abovementioned tools to solve materials problems that are important to DOE and the nation. The problem being addressed by HTML researchers is that of using the microstructural characterization tools available through the $\mathrm{MMC}$ to assist in producing a better $\mathrm{NO}_{\mathrm{x}}$ reduction catalyst. This effort is strongly supported by the Office of Heavy Vehicle Technologies (OHVT), and this office has authorized the reallocation of a portion of the user funds to match the MICS funds for testing and using collaboratory tools on this important problem. We have teamed with researchers at Ford Research Laboratory who are making new experimental catalyst formulations for $\mathrm{NO}_{\mathrm{x}}$ reduction. This work is described in some detail in the next section.

The first international demonstration of our remote microscopy capabilities occurred the week of September 8. Edgar Voelkl operated the HF-2000 TEM as a part of the biannual European "Three Country Conference" on microscopy held in Regensburg, Germany.

Surprisingly, there was excellent bandwidth through the internet. The second international 
demonstration of remote microscopy capabilities occurred in Japan on November 6 at the Japanese Electron Optics Laboratory (JEOL), one of the three largest manufacturers of TEM and SEM instruments in the world. JEOL is an industrial participant in the MMC.

The remote microscopy concept has moved from demonstration phase to beneficial use. Universities are continuing to use remote operation of top-level microscopes not available at their places in microscopy and materials science courses. Ford Research Laboratory and Dow Corning continue to work with us on-line, and several other industrial institutions are in the process of setting up their computers and refining their networks and firewall conditions to perform remote microscopy with us.

\subsubsection{Ex Situ Reactor for Catalyst Studies}

The ex situ reactor system is currently being used extensively for studies of catalyst reactions by users such as Dow Chemical and Ford Research Laboratory. The Ford work comprises studies of several catalysts being tested as candidates for reduction of $\mathrm{NO}_{\mathrm{x}}$ emissions from diesel truck engines. Dow scientists are using the capability of the specimen holder to be transferred between the reactor and the microscope without atmospheric exposure to study carbon-based catalysts designed for chemical industry applications.

The Ford work continues to be conducted largely via remote microscopy as a component of the MMC and the HTML user program. Through these sessions, we have gained a large amount of experience in the conduct of research using this new paradigm and find that it is hugely successful. Our work with Ford colleagues on $\mathrm{NO}_{\mathrm{x}}$ reduction catalysts has been refined by the addition of the capability to accurately simulate real diesel exhaust gas compositions for exposure of TEM specimens in the ex situ reactor. For this capability, we designed a sophisticated precision gas control system that would allow control of the mixing of the numerous components of a simulated diesel exhaust prior to injection into the reactor. Since water vapor concentration is critical in the exhaust gas mixture, we included the capability to control the concentration of water vapor in the final mixture. A large number of calibration runs were conducted and showed that measured and calculated values of the amount of water in the gas mixture matched nicely, giving us confidence that we could indeed provide the desired environment for reaction of experimental catalysts. Work has been conducted with this system on $\mathrm{Pt} / \mathrm{TiO} \mathrm{O}_{2}, \mathrm{Pt} / \mathrm{Al}_{2} \mathrm{O}_{3}$ and $\mathrm{Pt} /$ mixed oxide systems, as well as on Pt supported by silica-modified alumina. Samples are supported on special holey lanthanum chromate films prepared in our laboratory, which resist deterioration in the oxidizing environment required for the $\mathrm{NO}_{\mathrm{x}}$ reduction reactions.

\subsubsection{New Project}

Edgar Voelkl is a co-principal investigator in a new laboratory-directed R\&D project titled "Real-Time Direct-To-Digital Hologram Acquisition and Replay." This project aims to perform true real-time 3D holographic replay in order to view 3D live images without additional gadgets like special glasses. Off-axis type holograms are recorded and processed using the algorithms developed within the holography project of the HTML. The reconstructed complex image wave is then imprinted live-time on a phase-change crystal from which the 3D view is generated. 


\subsection{MECHANICAL CHARACTERIZATION AND ANALYSIS USER CENTER}

\subsubsection{Staff and Current Capabilities}

MCAG specializes in the mechanical characterization of structural materials, including hightemperature materials. MCAG performs mechanical testing and analysis, develops test methods and supplemental analytical techniques, and conducts finite-element and life-prediction analyses of monolithic ceramics, ceramic composites, and ceramic coatings. Numerous mechanical test frames are available to visiting researchers from industry and academia, and capabilities are supported to conduct tension, compression, flexure, shear, and micromechanical tests in controlled environments and at elevated temperatures on standard and customized specimens. MCAG staff have expertise with a wide range of materials, mechanical test designs, finiteelement and analytical modeling, life-prediction analysis, statistical design, and failure analysis.

Staff and their areas of expertise are as follows:

- Dr. Kristin Breder, Group leader Mechanical/environmental testing, fractography and failure analysis, statistical analysis. E-mail: brederk@ornl.gov, Phone (865) 574-5089

- Dr. Mattison K. Ferber, Senior Research Staff Member

Characterization of creep, stress-rupture, and fatigue behavior of structural ceramics in tension, flexure, and special test configurations; data acquisition software and hardware. E-mail: ferbermk@ornl.gov, Phone (865) 576-0818

- Mr. Timothy P. Kirkland, Principal Technologist Measurement of mechanical properties of structural materials. E-mail: kirklandtp@ornl.gov, Phone (865) 574-0034

- Dr. Edgar Lara-Curzio, Development Staff Member Characterization of mechanical behavior of composites and their constituents (fibers, fiber coatings, interfaces), environmental effects, reliability and durability, modeling of mechanical behavior and constitutive relations, standard test methods and special test configurations. E-mail: laracurzioe@ornl.gov, Phone (865) 574-1749

- Ms. Laura Riester, Development Associate Micro-mechanical testing, atomic force microscopy, microscopy, imaging, web-page development and maintenance. E-mail: riesterl@ornl.gov, Phone (865) 574-2588 
- Dr. Andrew A. Wereszczak, Development Staff Member

Creep, fatigue and corrosion behavior, life-prediction, and reliability analysis; finite-element analysis, fracture mechanics, and testing methodologies.

E-mail: wereszczakaa@ornl.gov, Phone (865) 574-7601

- Ms. Jessie B. Whittenbarger, Group administrative support

E-mail: whittenbarjb@ornl.gov, Phone (865) 576-1818

- Mr. Mark J. Andrews, HTML Graduate Fellow

Mechanical testing and reliability analysis.

E-mail: andrewsmj1@ornl.gov, Phone (865) 241-4571

- Ms. Donna L. Haynes, HTML Graduate Fellow

Metal matrix composites.

E-mail: 21h@ornl.gov, Phone (865) 574-4824

- Mr. James G. Hemrick, Graduate student, University of Missouri-Rolla

Mechanical characterization of advanced refractories.

E-mail: hemrickjg@ornl.gov, Phone (865) 241-4537

\subsubsection{Major Research Areas}

\subsubsection{High-Temperature Tensile Test Facility}

- Eleven 35-kN-capacity electromechanical test machines equipped with self-aligning grips for accommodating a wide array of specimen geometries, including button-head tensile and flat specimens.

- Two servohydraulic test machines capable of monotonic, static, dynamic, and cyclic testing of a wide variety of specimen geometries.

- All test machines equipped with integral, electronic controllers and function generators, and compact two-zone resistance-heated furnaces (maximum temperature, $1700^{\circ} \mathrm{C}$; sustained testing in ambient air, $1500^{\circ} \mathrm{C}$ ).

- All machines equipped with low-contact force, capacitance extensometers (accuracy, $\sim 0.1 \mu \mathrm{m}$ at room temperature and $\sim 0.5 \mu \mathrm{m}$ at $1500^{\circ} \mathrm{C}$ ).

- Servohydraulic axial-torsion test machine capable of loads to $100 \mathrm{kN}$. 


\subsubsection{Tensile Creep/Stress Rupture and Stress Relaxation Facility}

- Creep and Stress Rupture

- Nine electromechanical tensile machines designated for long-duration creep-stress rupture, and low-frequency tension-tension fatigue testing.

- Computerized control and data acquisition using an in-house-developed software application.

- Compact two-zone furnaces (maximum temperature, $1700^{\circ} \mathrm{C}$ ).

- Low-contact force capacitance extensometers.

- Stress Relaxation

- Two stress-relaxation test frames devoted to metals and superalloy testing equipped with averaging extensometers and furnaces capable of $1100^{\circ} \mathrm{C}$.

- Two stress-relaxation test frames devoted to ceramics testing equipped with averaging extensometers and furnaces capable of $1500^{\circ} \mathrm{C}$.

\subsubsection{Ceramic Flexure Test Facility}

- Six test frames with pneumatic actuators, each with loading capacity $2.2 \mathrm{kN}$ to test simultaneously three flexure samples, C-rings, or compression specimens.

- Standard mechanical property tests (room temperature to $1500^{\circ} \mathrm{C}$ ):

- static fatigue (time to failure measured as a function of static stress),

- dynamic fatigue (fracture stress measured as a function of loading rate), and

- low-cycle flexural fatigue.

\subsubsection{Electromechanical Test Facility}

- $200-\mathrm{kN}$ universal (electromechanical) test machine with high-temperature $\left(1800^{\circ} \mathrm{C}\right)$ furnace.

- Small universal test machine dedicated to room-temperature testing of flexure specimens and C-rings, as well as fracture toughness testing.

- Standard mechanical property tests (using standard as well as specially designed test fixtures):

- static fatigue (time-to-failure measured as a function of static stress),

- dynamic fatigue (fracture stress measured as a function of loading rate),

- cyclic fatigue (cycles-to-failure measured as a function of cyclic stress),

- fast-fracture tensile and compressive strength,

- shear strength,

- fracture toughness, and

- capability for compression creep tests with straight cylindrical specimens and contact extensometer (accuracy, $\sim 0.5 \mu \mathrm{m}$ ) and compressive creep rates (room temperature to $1800^{\circ} \mathrm{C}$; stresses, as low as $0.05 \mathrm{MPa}$ ).

- Rotary bend fatigue machine equipped with small furnace for testing small $(\sim 75 \mathrm{~mm}$ long and

$\sim 10 \mathrm{~mm}$ diam) cylindrical specimens in fully reversed cyclic loading. 


\subsubsection{Electromechanical Test Facilities with Environmental Testing}

- High-temperature clamshell furnace and ceramic retort for both compression and flexure tests in air, inert gas, or vacuum at temperatures up to $1500^{\circ} \mathrm{C}$.

- Environmental tensile test facility: environmental chamber mounted on test machine (screwdriven), mechanical pump, diffusion pump, regenerative gettering furnace, and temperature controller. High-temperature static, tension-tension cyclic, or dynamic loading in vacuum or inert environments (room temperature to $1600^{\circ} \mathrm{C}$ using button-head tensile specimen geometry).

\subsubsection{High-Temperature Compression Test Facility}

- Designated high-temperature compressive creep test facility with clamshell furnace and contacting extensometers ( $\mathrm{SiC}$ and sapphire extensometer rods).

\subsubsection{Test Facility for Composites and their Constituents}

- Six in-house-developed electromechanical, universal test machines.

- 10-kN load capacity, 150-mm stroke, and 8-nm displacement resolution.

- Computerized data acquisition and control.

- Environmental chambers to conduct tests in controlled atmospheres (e.g., inert gases with less than $10 \mathrm{ppm} \mathrm{O}_{2}$, oxidizing and reducing environments, and water vapor).

- Non-contact laser extensometry.

- Various specimen geometries, gripping arrangements, and fixtures (e.g., shoulder-loaded tensile specimens, minincomposites, single small-diameter fibers and filaments, doublenotched shear specimens, Iosipescu shear specimen).

- Micromechanical universal testing machine

- 1000-N load capacity, 25-mm stroke and 100-nm displacement resolution.

- Equipped with miniature load cells, encoders, and capacitance gauges.

- Specially suited for composite interfacial testing by means of single-fiber push-in and push-out tests.

- Array of indenter geometries (e.g., Vickers, Knoop, Cube Corner, Diamond, and WC flat punch) to conduct indentation tests.

\subsubsection{Mechanical Properties and Scanning Force Microprobes}

- Special microhardness tester capable of operating at four load ranges $(0-4,0-20,0-100$, $0-650 \mathrm{mN}$ ).

- Sensitive capacitance gage for constant monitoring of position of indenter relative to surface of specimen.

- Constant monitoring of load as a function of displacement. 
- Plastic and elastic components of displacement are separated either by continuous sensing of sample stiffness while force is being applied or by calculating the hardness based on the recorded measurements of load vs displacement.

- The scanning force microprobe gives information on the response of materials to indentation by compiling a three-dimensional image from an array of single line profile scans.

\subsubsection{Life-Prediction Analysis (FEA + ERICA/CERAMIC + CARES)}

- Work station with two life-prediction algorithms and integrated finite-element programs for performing finite-element analysis (FEA) and reliability modeling work to predict probability of component survivability in a known service environment and at a known stress level:

- mechanical test data from standard specimens,

- FEA data for stress in actual components, and

- FEA support provided for other mechanical testing of monolithic ceramics and composites.

\subsubsection{Resonant Ultrasound Spectroscopy (RUS) Facility}

- Characterization and inspection of mechanical integrity of ceramic specimens and components.

- Resonance spectrum generated by sweeping frequency of ultrasound signal applied to component and by detecting resonance frequencies of component.

- Applicable to determining with high accuracy the full elastic constants of isotropic and anisotropic materials (e.g., single crystals, textured polycrystals, and composites).

\subsubsection{Additional Capabilities}

- Infrared imaging used in situ with mechanical testing

- Acoustic emission capabilities

- Strain gaging facilities

- Testing of ceramic-ceramic joints

- Testing of intermetallics

- Thermal shock testing

- failure analysis

- tube testing and test of tubular filters

\subsubsection{Major Activities in FY 1998}

Ten new proposals were submitted to MCAUC in FY 1998 and eight continued from the previous year. Some new capabilities were developed, and improvement to equipment is a continuous effort.

Work on thermal barrier coatings (TBCs) continued in FY 1998 with a combination of user activity and fellowship activity. In collaboration with researchers from Siemens Westinghouse, 
cyclic fatigue testing of cylindrical metal specimens with TBCs were initiated. A test setup was devised where contacting extensometers were used to control the test such that a strain-controlled cyclic fatigue test could be performed. MCAG's IR camera was used to monitor the test. As the specimen was cycled, the surface temperature could be observed to change some, but as subsurface cracks or initial delamination of the coating occurred, it was seen as a distinct discontinuity at the surface. The image was recorded on a video cassette recorder (VCR), and, simultaneously, an image of the cyclic count was recorded. In that way, the exact cycle where the spallation or cracking occurred could be recorded. The furnace used with the servohydraulic test machine was equipped with a special window to allow for the IR camera to also measure at elevated temperatures. The function of the system was documented, and measurements on various $\mathrm{TBC}$ systems are ongoing.

Research on refractories has increased over the past few years. Compressive creep of five different $\mathrm{MgO}$ refractories containing $\mathrm{CaO} / \mathrm{SiO}_{2}$ was measured over a temperature range of 1400 to $1550^{\circ} \mathrm{C}$ at stresses of 0.1 to $0.3 \mathrm{MPa}$. The application of these refractories was for soda-lime glass furnace regenerators, and comparative data suitable for design were lacking for these high temperatures and low stresses. Cylindrical test specimens were core-drilled from as-received bricks and were ground parallel. Creep tests were performed in air using an electromechanical test frame in load control. The load train consisted of $\mathrm{SiC}$ rods, and high-purity alumina disks were used between the push rod and the specimens to prevent reactions. Contacting extensometers with sapphire rods were used for the same reason. Creep tests up to $250 \mathrm{~h}$ duration were performed. The creep resistance was different among the five grades tested. The relative amounts of porosity, impurities, types of phases present, and the grain size distribution were found to affect the creep resistance. The more creep-resistant grades tended to have a combination of a larger average grain size and a wider size distribution, a low iron content, and an absence of CaO$\mathrm{MgO}-\mathrm{SiO}_{2}$ ternary compounds. The values for the creep exponent suggested that the compressive creep was either dominated by a diffusion mechanism or by a grain boundary sliding through viscous deformation of the calcium silicate grain boundary phase. Some of the tested refractories exhibited a time-hardening behavior, making the interpretation of these creep data rather difficult. New user projects have been initiated in the refractories area, and additional results will help understand the behavior of these rather complex materials.

The stress-relaxation behavior of a recently developed superalloy that has a low coefficient of thermal expansion was studied over a range of temperatures between 480 and $650^{\circ} \mathrm{C}$ at strain levels up to $0.2 \%$. (Inco Alloys International Inc.) The test conditions were chosen because they were representative of bolting applications in steam turbines. Negative creep (i.e., specimen contraction in a tensile creep test or a stress rise during a stress relaxation test) has been observed in a number of superalloys. This is generally due to a volumetric change during a phase transformation and is most pronounced at low strains. In many practical applications, these transformation strains may be of minor importance; however, under mechanical restraints such as in bolting operations, they can translate to a stress increase and may need to be taken into consideration by the designer. Depending on the temperature and strain, a wide range of stress relaxation behavior was observed. At the lowest temperature, a continual stress increase due to ongoing microstructural transformations was seen; while at the highest temperature, an instantaneous decrease in stress due to creep was observed. The magnitude of any stress rise was 
found to be small compared with the yield strength of the material at the given temperature. This project successfully demonstrated the capabilities to perform creep testing of superalloys at these intermediate temperatures, and additional work on superalloys are ongoing.

Mechanical properties of fully dense nanophase Fe from ball-milled powders were studied at room temperature. The material was produced at the Louisiana State University by a two-step sinter forging process. Fully dense specimens with grain sizes in the range of 60 to $100 \mathrm{~nm}$ were obtained by this process. The compressive strength was measured using small cube specimens with appropriate lubricant on the anvils. High compressive yield strengths $(>2.4 \mathrm{GPa})$ were obtained, and, in some cases, a plastic strain of several percent with little or no work hardening was observed. The results indicate that the materials had a low impurity and flaw concentration and that flow in nanophase materials is not restricted to materials with a two-phase or an amorphous microstructure.

The nanoindentation technique was used on several different material systems, notably coatings and thin films. A method to measure fracture toughness in coatings by indenting both from the top and through a cross section using Vickers or cube-cornered indenters have been refined. The method is being used to monitor the changes in a flame-spray-coating technique being developed at Georgia Tech. The change in fracture toughness and hardness as a function of spraying conditions is measured in order to help determine optimum manufacturing conditions.

Long-term testing of ceramic composites is ongoing. Users have worked on interfacial and mechanical characterization of Hi-Nicalon SiC fibers with BN interfaces in SiC composites as well as long-term properties of oxide-oxide composites. Under the user program and in conjunction with other programs, the test methods for these materials are being developed and refined.

In addition to the work in the user center, researchers in MCAUC are performing extensive research in other DOE programs, and, within these, we have extensive collaborations with other groups at ORNL as well as with industry. Examples of these are

\section{- Heavy Vehicle Materials Program (DOE/OTT)}

- International Energy Agency (IEA) collaboration

- Reliability of NT551 silicon nitride and NT551 silicon nitride valves

- Advanced Automotive Materials Program (DOE/OTT)

- Reliability of electronic ceramic substrates, dielectrics, multilayer capacitors (MLCs), and silicon

- Thermal shock strength testing

\section{- Advanced Turbine Systems Program (DOE/OIT)}

- Long-term testing of ceramics for gas turbines

- Materials support for industrial (Solar Turbines) field testing of advanced turbine systems (ATS) machine

- Specimen size effect on creep of silicon nitride

- $\quad$ TBC/environmental barrier coatings (EBC) evaluation 
- Continuous Fiber Ceramic Composites (CFCC) Program (DOE/OIT)

- Materials testing development

- Environmental/mechanical testing of CFCCs

- Prediction of service life for CFCCs (with Virginia Tech)

- Advanced Industrial Materials Program (DOE/OIT)

- Creep of refractories for the glass-manufacturing industry

- Probabilistic Failure of refractories

- Fossil Materials Program (DOE/FE)

- Testing of filters for fossil-fueled power plants

- CRADAs and Work for Others (WFO) projects

- Participation in development of standards and design codes through the American Society for Testing Materials (ASTM), American Society of Mechanical Engineers (ASME), Mil-Handbook, and international collaboration [the Versailles Agreement on Material Testing and Standards (VAMAS), the International Organization for Standardization (ISO), and the International Energy Agency (IEA)]

\subsection{THERMOPHYSICAL PROPERTIES USER CENTER}

\subsubsection{Background}

The Thermophysical Properties User Center (TPUC) is dedicated to measuring thermophysical properties as a function of temperature and correlating these properties with the processing, microstructure, and performance of materials. Specifically, the TPUC staff work with users to determine thermophysical properties such as thermal diffusivity, thermal conductivity, specific heat, and thermal expansion and to characterize the thermal stability, high-temperature reactions and compatibility, and high-temperature oxidation and corrosion properties of materials. The materials studied include structural ceramics, engineering alloys, ceramic and metal matrix composites, superconducting materials, ceramic precursors, carbon materials, and carbonfiber composites.

\subsubsection{Staff and Major Instruments}

\subsubsection{Staff}

TPUC is one component of the Diffraction and Thermophysical Properties Group. Members of the group with prime responsibilities for thermophysical property activities include the following:

- Dr. Ralph B. Dinwiddie - thermal transport and thermal imaging;

- Mr. Wallace (Wally) D. Porter-thermal analysis;

- Dr. Hsin Wang - thermal transport and thermal imaging;

- Ms. Joy L. Kilro - group administrative support; and 
- Dr. Camden (Cam) R. Hubbard—group leader.

Dr. Hsin Wang, previously an ORISE postdoctoral appointee, became a staff member in early FY 1998. He received his Ph.D. from Alfred University's College of Ceramics. His thesis research emphasized measurement of properties of $\mathrm{ZnO}$ ceramics.

\subsubsection{Major Instruments}

The major facilities of TPUC are divided into three areas: thermal analysis, thermal transport, and the new focus of thermal imaging.

\section{Thermal Analysis}

- Stanton Redcroft STA1500 simultaneous thermal analyzer (STA)

- differential thermal analysis (DTA)

- thermogravimetry (TG)

- evolved gas analysis (EGA) by mass spectrometry

- Stanton Redcroft DSC1500 differential scanning calorimeter

- Theta dual push rod dilatometer

- Cahn TG

The simultaneous thermal analyzer ( $\mathrm{STA}=\mathrm{DTA}+\mathrm{TG}+\mathrm{EGA}$ ) and the differential scanning calorimeter both are capable of operation to $1500^{\circ} \mathrm{C}$ in 1-atm inert or oxidizing atmospheres. The thermal analysis laboratory also contains a dual push rod dilatometer for bulk thermal-expansion measurements to $1500^{\circ} \mathrm{C}$. The Cahn large-mass, high-temperature, high-sensitivity TG, with concurrent DTA attachment, provides measurement capability to $1700^{\circ} \mathrm{C}$ for samples having masses up to $100 \mathrm{~g}$. This instrument supports measurements in vacuum, inert, oxidizing, reducing, and corrosive atmospheres, and thus considerably extends TPUC's capabilities in thermal analysis.

\section{Thermal Transport}

- Anter laser flash thermal diffusivity system

- Xenon flash thermal diffusivity system

- Topometrix scanning thermal conductivity microscope (STCM)

- 3-omega system thin-film thermal conductivity of non-electrically conductive materials

- Hot disk thermal constants analyzer

The laser flash and xenon flash systems measure thermal diffusivity of materials under a variety of conditions. With the laser flash system (discussed in more detail in Sect. 4.3.3), researchers can make measurements as a function of temperature to $2500^{\circ} \mathrm{C}$, measurement of thermal diffusivity of molten metals, and analyses of two- and three-layer samples. The xenon flash system is optimized for room-temperature thermal diffusivity measurements. 
The Topometrix STCM maps thermal-conductivity variations in materials such as composites on a submicrometer scale, providing microstructural information not available by other means.

The 3-omega system was recently assembled to provide a direct means to measure thermal conductivity as a function of temperature. The greatest strength of this technique is the ability to measure the thermal conductivity of electrically insulating thin films and bulk specimens.

The hot disk system is based on the Transient Plane Source (TPS) method, which is one of the most precise and convenient techniques for studying thermal-transport properties. This technique is capable of measuring thermal conductivity, thermal diffusivity, and volume-specific heat simultaneously. The hot disk system can be used to measure thermal properties of a variety of materials, especially low-conductivity ceramics, plastics, powders, and granular materials such as sands. Many of these materials are difficult to measure using the flash diffusivity technique due to transparency in the infrared spectrum and high porosity. Some typical materials that have been measured are high- $\mathrm{T}_{\mathrm{c}}$ superconductors, glasses, refractories, casting sand, metal alloys, composites, polystyrene, bricks, liquids and biomaterials.

\section{Thermal Imaging}

- Amber IR camera

- Selected Ge lenses for both microscopic and broad field imaging

- Image-processing software

- Portable system including a computer and triggering circuitry

A high-speed IR focal-plane-array camera for 2-D thermal diffusivity and nondestructive thermography is the newest instrument in TPUC. The camera was purchased by the DOE-OIT Advanced Turbine Systems program to study thermal-transport characteristics of TBCs on turbine blades and to assess its applicability to detection of defects (see Sect. 4.3.3).

\section{Supporting Facilities}

- Five-cell helium pycnometer for density

- Sample preparation facilities, including the following:

- diamond core drill

- low-speed diamond cutoff saw

- diamond band saw

- vacuum deposition chamber

- polisher

\subsubsection{Developments and New Capabilities}

\subsubsection{Thermal Conductivity of Coatings}

Coatings are being widely used to increase the performance life of gas turbine engine hotsection components with a future goal of increasing operating temperatures and, hence, fuel efficiency. Thin films are also widely used as protective oxide coatings, wear-resistant coatings, 
and corrosion-resistant coatings, and as active elements in electronic components. The 3-omega technique is used to determine thermal conductivity of electrically nonconductive coatings. A photolithographic method is used to deposit a small heater on the surface of the specimen. Using a variable-frequency ac power supply, a lock-in amplifier, and a furnace enables measurement of thermal conductivity as a function of both depth and temperature (to $500^{\circ} \mathrm{C}$ ). The new 3-omega capability enhances HTML's ability to study the effects of processing conditions, thermal history, and microstructure on the thermal conductivity of high-performance coatings.

\subsubsection{Laser Flash Thermal Diffusivity System}

TPUC purchased a state-of-the-art laser flash thermal diffusivity system in FY 1996 that significantly expanded TPUC's thermal-transport measurement capabilities. This highly flexible system can operate from room temperature up to $2500^{\circ} \mathrm{C}$ in vacuum or inert gas. Two furnaces are used to achieve this: one for the range from room temperature to $500^{\circ} \mathrm{C}$ and a carbon furnace for the 500 to $2500^{\circ} \mathrm{C}$ ranges. In addition, measurements of thermal diffusivity may be made in oxidizing or reducing atmospheres from 25 to $1700^{\circ} \mathrm{C}$ using a third alumina tube furnace. Sixsample carousels on the two vacuum/inert-atmosphere furnaces greatly increase the number of tests that can be made in a single day. In addition to standard disc-shaped samples, the new system will also measure square plates, powders, molten metals, and coatings. Completion of installation of accessory attachments and debugging of the measurement software was followed by significant growth in productive user activity.

\subsubsection{Thermophysical Properties of Molten and Semisolid Metals}

In FY 1996, TPUC carefully assessed industry's current and future needs for knowledge of thermophysical properties. Based on that study, TPUC expanded its focus to include measuring the properties of molten and semisolid metals. These data have recently become very valuable in the national efforts to model materials processes such as welding, casting, quenching, and hot forging or rolling. TPUC has contributed to several user and DOE projects needing properties of molten metals. The new laser flash thermal diffusivity system has demonstrated the capability to determine the thermal diffusivity of difficult-to-measure molten alloys. TPUC also developed and applied techniques for determining the density of molten metal utilizing our existing dilatometer. These data are often coupled with studies on casting modeling.

\subsubsection{Infrared Camera for Two-Dimensional Thermal Diffusivity Mapping and Thermography}

TPUC has developed a system capable of producing quantitative thermal diffusivity maps of test coupons, plates, and tubes, as well as thermal effusivity maps of components with complex shapes, such as turbine blades and vanes. This system is ideal for the study of composites and coatings. At the heart of the system is a high-speed, high-sensitivity IR camera with a $256 \times 256-$ pixel focal plane array operating in snapshot mode. Each one of the 65,536 detectors that make up the focal plane array is exposed at the same time and for the same length of time. This allows 
for a straightforward pixel-to-pixel comparison in each image. With Ge lenses, the spatial resolution can be adjusted down to $7.5 \mu \mathrm{m}$, and the temperature resolution can be as sensitive as $0.015^{\circ} \mathrm{C}$. The camera can operate at speeds up to 130 full frames per second or up to 1480 images per second at a resolution of $64 \times 64$ pixels. The exposure time for each image can be adjusted down to $2 \mu \mathrm{s}$, allowing the study of very hot and/or fast-moving targets, such as cutting tools, boilers, and brake rotors, during operation. The camera can be calibrated for absolute temperature measurement.

For 2-D thermal diffusivity mapping, 1000-W quartz lamps, a 1000-W xenon illuminator, or $4800-\mathrm{W}$ xenon flash lamp heat the sample or part. The camera is used to record the temperature response of the heated surface with time. In some cases, the thermal response of the back side of the sample is recorded. Custom software is then used to calculate the thermal diffusivity or thermal effusivity for each point in the image. The result is a thermal diffusivity or effusivity map of the object under test. This data can be viewed in a variety of ways, including a spreadsheet format, a 2-D false-color image, or a 3-D surface plot.

In addition to the measurement of temperature and thermal properties, the camera can be used for thermography applications for nondestructive evaluation of components. The use of IR transmitting fibers coupled to the camera was demonstrated and has great potential for temperature measurement within systems such as dies during liquid metal insertion.

TPUC developed a portable camera-control capability to allow off-site fieldwork. The first demonstration of this portability was in a reverse HTML Fellowship with the Ford Scientific Research Laboratory. The purpose of this investigation was to simultaneously image hot spots on the inboard and outboard sides of a brake rotor during braking on a dynamometer. These hot spots result in localized thermal expansion of the rotor that cause the torque variation known as "brake roughness" or "brake judder." During the three visits to Ford, the TPUC staff were able to record thousands of images of this hot-spotting phenomenon as a function of initial rotor temperature and speed, brake pad manufacturer and design, and braking behavior (i.e., dragging or stopping). In addition to the qualitative images that show the spatial and time evolution of the hot spots, a calibration was performed that allowed the quantitative measurement of temperature as a function of time and location.

These results have both short- and long-term benefits. In the short term, brake system components that are less likely to cause hot spotting can be selected for cars about to be introduced into the market. In the long term, the thermoelastic models that describe hot spotting may be refined and used to evaluate future designs before they go into production. Visits to GM Delphi Chassis Systems and the University of Southern Illinois are currently being planned for additional work on brake systems and materials. 


\subsection{RESIDUAL STRESS USER CENTER (RSUC)}

\subsubsection{Background}

User projects and DOE programs are increasingly concerned with life prediction and failure analysis of engineering structures. In many of these cases, knowledge of residual stresses gradients (sign and magnitude) as a function of location at both the surface and throughout the volume of a component is critical information for failure-analysis and life-prediction models. RSUC was established to meet this need and to provide a facility for research into controlling residual stresses, either through modifying the forming and finishing processes, by changes in the design, or through stress-relief procedures. RSUC activities now include both the X-ray residual stress facility, the neutron residual stress facility (discussed in detail in Sect. 4.4.3), and the developing use of synchrotron radiation and the Raman microprobe. The diffraction facilities can be utilized to measure macro (long-range) and micro (short-range) residual stresses in polycrystalline materials. The Raman microprobe is currently focused on alumina.

RSUC also characterizes the nonrandom grain distribution or texture in materials and relates this to directionally dependent materials properties. Texture is very common in materials subject to deformation and also in thin films, both areas of increasing importance.

\subsubsection{Staff and Major Instruments}

\subsubsection{Staff}

The NRSF is operated in a team mode with members of the Metals and Ceramics Division, Solid State Division, and Instrumentation and Controls Division participating. Unless otherwise noted, the following staff members are from the Diffraction and Thermophysical Properties Group, Metals and Ceramics Division.

- Dr. E. Andrew Payzant—residual stress mapping, instrument specification;

- Dr. Roberta (Robbie) Peascoe - texture (UT) (Dr. Peascoe is a subcontractor from University of Tennessee, Knoxville, and received her degree from Texas A\&M University in Inorganic Chemistry and Crystallography);

- Dr. Steve Spooner - residual stress mapping by neutron diffraction (Solid State Division);

- Dr. Christina Hoffmann - residual stress mapping by neutron diffraction and refractory corrosion (Dr. Hoffmann is an ORISE postdoc who received her Ph.D. in Mineralogy and Crystallography from the University of Bern, Switzerland);

- Dr. D. Q. (David) Wang-residual stress mapping and neutron transport modeling (Dr. Wang is a postdoc who received his Ph.D. in Materials Science and Technology from The Open University, United Kingdom);

- Dr. Xun-Li Wang - micro and macro residual stress by neutron diffraction;

- Dr. Thomas R. Watkins - X-ray residual stress and grazing incidence diffraction;

- Dr. Michael Wright - instrumentation design for neutron strain mapping (Instrument and Controls Division); 
- Ms. Joy L. Kilroy—group administrative support; and

- Dr. Camden R. Hubbard - group leader and NRSF project leader.

\subsubsection{Major Instruments}

- Scintag PTS four-axis goniometer with $18-\mathrm{kW}$ rotating-anode generator,

- Scintag PTS four-axis goniometer with 2-kW sealed-tube generator,

- neutron spectrometer with XYZ mapping system for macroresidual stress mapping,

- neutron powder diffraction spectrometer and furnace for microresidual stress analysis, and

- X14A beam line at the National Synchrotron Light Source (NSLS) (RSUC is a participating research team member on this ORNL beam line).

Both of the neutron spectrometers are owned and managed by the Neutron Scattering Section of the Solid State Division, ORNL. RSUC is provided a portion of the time on these instruments to establish and operate the neutron residual stress effort based on an agreement between DOE's BES and Energy Efficiency (OTT) programs and ORNL's Solid State and Metals and Ceramics Divisions. The long-term goal is to establish a dedicated stress-mapping instrument at the HFIR.

\subsubsection{Accessory Instrumentation}

- Position-sensitive and Peltier $\mathrm{Si}(\mathrm{Li}) \mathrm{X}$-ray detectors;

- laser position sensor for X-ray polycrystalline-texture-stress (PTS) units;

- grazing incidence optics;

- strain gage capabilities;

- tensile load frame for use on the neutron diffraction, residual stress mapping facility; and

- Huber full-circle Eulerian cradle for use on the neutron diffraction, residual stress mapping facility; and

- high-temperature furnace.

\subsubsection{New Capabilities}

\subsubsection{Grazing Incidence X-Ray Diffraction (GIXRD)}

Following an earlier demonstration of the application of methods for depth-profiling residual stresses over a very shallow, near-surface region of specimens, the user interest in this technique has exceeded the capacity at which we can make measurements on our laboratory systems. Numerous proposals and inquiries related to grinding-induced subsurface stresses and to stresses in thin coatings have been received. GIXRD employs low angles of X-ray incidence to control the depth of X-ray penetration. By approaching the angle of total external reflection, the depth of sampling can range from tens of angstroms to a few micrometers. With this technique, diffraction information about phase content, texture, and residual stress can be obtained as a function of sampling depth. 
Of particular importance is the nondestructive measurement of strains induced by grinding and the range-of-depth profiling. RSUC continues to pursue projects to provide a scientific basis for aspects of this technique and to support further development of this technique and instrumentation. The particular limiting aspect is slow data collection, which limits the extent of user proposals we can address and further limits the number of specimens that can be studied. To address this shortfall, we have assessed several options to increase the flux and instrument time or to develop alternate instrument access. These include multilayer X-ray mirrors, focusing capillary optics, and synchrotron radiation. We demonstrated that a 30 -fold enhancement could be achieved with use of a multilayer X-ray mirror. A capillary optics device did not look promising for this application. Tests using the ORNL X14A beam line at NSLS have been encouraging, and additional testing and optimization of the facilities there are under way. An order was placed for an X-ray mirror in FY 1999.

\subsubsection{Neutron Residual Stress Facility}

A cooperative joint effort - signed in April 1994 between EE, OTT, and ER/BES, Division of Material Sciences - established NRSF. As part of the HTML's RSUC, NRSF is a collaborative effort to meet expressed industrial and academic needs for through-thickness strain mapping. This joint program is a direct result of a multiple-year Laboratory-Directed Research and Development (LDRD) project proposed and led by HTML staff at HFIR. NRSF is operated by a team consisting of staff from the HTML in the Metals and Ceramics Division, the Neutron Scattering Group of the Solid State Division, and the Instrumentation and Controls Division.

The goal of the joint program is to establish and operate user facilities for macro- and microresidual stress analysis in conjunction with the existing RSUC X-ray facilities in HTML and the neutron scattering facilities program at HFIR. We currently are meeting this goal by using a portion of the beam time on two Solid State Division spectrometers (HB-2 and HB-4). Another goal is to develop a dedicated instrument at HFIR optimized for macroresidual stress analysis, and thus to greatly expand both the capabilities and speed of measurement.

HFIR operation in FY 1998 was comparable to that during FY 1995 and FY 1996 and well above that in FY 1997, when operational problems reduced the days of reactor operation.

\subsubsection{Major Activities}

\subsubsection{Complementary Projects}

In the reporting period, the residual stress facilities have also been used on a number of DOE and Work for Others projects. The former includes measurement of stresses in clad boiler tubes, weld overlays, and dies used for aluminum castings by automotive companies. The DOE projects have led to additional nonproprietary user projects as well as proprietary projects from industrial users. The NRSF was used in several proprietary projects during the period, and the staff are currently working with candidate users in conducting research and developing additional proposals. 


\subsection{Advanced Computer Simulations for the Design of Neutron Scattering Instrumentation}

Significant progress has been made on LDRD project on Monte Carlo simulation of neutron beam optics. The LDRD effort aims to develop sophisticated computational models for various neutron optical components commonly used in the construction of neutron scattering instruments. By linking these modules together, it will be possible to design and optimize instruments in a much more powerful way than is currently achievable. Computational models are also a necessary first step in the development of data analysis and visualization tools, and are fundamental to a coherent approach to data analysis that includes experimental considerations, such as instrumental resolution and multiple scattering, which cannot be readily addressed in any other way. A key to the success of this project is setting a standard for the interface of the modules that simulate individual optical elements. With this standard, modules written by different programmers can be exchanged and reused. The ORNL team was instrumental in drafting the interface standard that is currently under review by a committee formed by representatives from major neutron scattering laboratories around the world. As a test of ORNL's approach and to facilitate future collaboration with scientists at Los Alamos National Laboratory, a computer model was setup to evaluate the design features of the residual stress diffractometer to be installed at the upgraded Los Alamos Neutron Science Center (LANSCE) facility. The simulation results point out some of the areas in the optical system design that could be further optimized. Current efforts are being directed toward writing modules commonly used on reactor neutron sources. These modules will be used in a computer model for designing the new HTML residual stress diffractometer at the upgraded HFIR.

\subsection{Development of Materials for Kraft Black Liquor Recovery Boilers}

The project on failure of composite boiler tubes in Kraft recovery boilers is coming to a successful end. Composite tubing of stainless steel on carbon steel is an essential part of a recovery boiler used in Kraft pulp mills. While the use of composite tubes has solved most of the corrosion problems experienced by carbon steel tubes, significant cracking has been reported in the stainless steel layer of composite tubes subjected to periods of service. After years of multidisciplinary research, it has been determined that the principal cracking mechanism is stresscorrosion cracking. A remaining question is at what temperature the cracking starts to occur. To answer this question, experimental techniques were developed for in situ measurements of residual stress at elevated temperatures. The goal is to quantify residual stresses at normal operating temperatures and to determine how they change following a temperature excursion. Commercial heating tape was used as a heating element in an experimental setup that allowed controlled heating of a composite tube specimen up to $410^{\circ} \mathrm{C}$. Temperatures within the tube were monitored with eight thermocouples, four on the inside and four on the outside surfaces. With the setup, a rather uniform temperature field was established within the tube specimen, as indicated by data from the eight thermocouples. In tests up to $410^{\circ} \mathrm{C}$, the maximum temperature gradient between outer and inner surfaces was found to be less than $2^{\circ} \mathrm{C}$. Neutron diffraction was used to determine the hoop residual stress as a function of temperature. The test results show that at 
normal operating temperature, which is about $300^{\circ} \mathrm{C}$, the residual stresses in the clad layer are compressive and remain compressive even after an excursion to $410^{\circ} \mathrm{C}$. In order to produce a tensile stress at operating temperature, a temperature excursion to at least $500^{\circ} \mathrm{C}$ is required. Because the temperature excursion in the boiler is usually less than $100^{\circ} \mathrm{C}$ (maximum temperature $<400^{\circ} \mathrm{C}$ ), the experimental data show that the cracking most likely occurs during cooling from operating temperature. These experimental data are used in finite element models to redefine the boundaries of the property diagram in the design of replacement materials.

\subsubsection{Macroresidual Stress Mapping Instrumentation}

The demand for macroresidual stress mapping by neutron diffraction continues to exceed the time available. We can schedule approximately 40 experiment days every 3 months (two of every three fuel cycles at HFIR). However, we encountered a demand that is typically $100 \%$ in excess of the available days. To meet this demand as soon as possible, we have given high priority to the development of an enhanced, dedicated stress-mapping facility. This effort has been stretched out by several factors:

- the decision by DOE to spread the new instrument's capital funding over 3 years,

- design analysis that recommended a horizontal beam arrangement,

- Solid State Division's need to continue to use HB-2 and, in the future, to split that beam to support four major research instruments (including the stress mapping),

- a proposal to build a thermal guide hall using HB-2 beam as the source, and

- a DOE decision to upgrade HB-2 but not to build the thermal guide hall at this time.

In the guide hall plans, the neutron-based residual stress program would have had two stations on a thermal guide. The thermal guide hall proposal had been rated as the number one proposal for upgrade of DOE's neutron facilities by an independent committee, but the proposal faced tough budgetary concerns and ultimately was not funded.

HTML and Solid State Division staff have been working within this picture of uncertainty to improve the existing instrumentation and, simultaneously, to plan for the possibilities of the thermal guide hall or the fallback of a multi-instrumented HB-2. During this period, it has become clear that HB-2 will be upgraded and will support four dedicated instruments, with residual stress being one. We have divided the new instrument development task into several components. The first component involves expanding the number of neutron detectors from one to seven to increase detection efficiency and to produce data on the strain tensor without specimen rotation. The second involves developing new monochromators that deliver a significantly higher flux at the specimen. The third component was to specify and order two new goniometers for use at HFIR and potentially the thermal guide hall. The fourth component involved assessing the requirements for a multi-instrumented HB-2 based on new shielding and monochromators. Progress on each of these is described in the following subsections. 


\subsection{Seven-Detector Array for Neutron Residual Stress Mapping}

One action we have taken to increase our measurement capacity is to expand the number of position-sensitive detectors (PSDs) from one to seven. A prototype vertically stacked array of seven PSDs was designed; the seven detectors, shielding, and electronics were installed; and software was developed. Testing demonstrates that the seven-detector array has increased our measurement capability by at least three; however, limitations of the HB-2 goniometer prevent full utilization of this detector array. An improved design for shielding and stable detector mounting will be developed when we have acquired the new goniometer system.

Each detector in the array has an active area of $4 \times 10 \mathrm{~cm}$ and a linear resolution of $1 \mathrm{~mm}$. They are spaced at $7^{\circ}$ intervals on an arc having an $80-\mathrm{cm}$ radius. Each detector can be rotated about the normal to the detector face to compensate for the apparent curvature of the Debye Scherrer cone at $2 \theta$ angles away from $90^{\circ}$. A numerical model to correct the data for geometric errors and irregularities in the alignment of the detector array has been developed. Calibration data are collected on diffraction lines of a nickel powder standard. A least-squares fitting method is used to minimize the error between observed and calculated peak positions simultaneously in all seven detectors. The variables include sample-to-detector distance, spacing of the detectors along the array arc, tilt of the array from vertical, variation of the height of the array with $2 \theta, 2 \theta$ zero offset, and neutron wavelength. With profile fitting of the diffraction peak plus background, reproducibility of the peak position measurement of better than $0.003^{\circ}$ of $2 \theta$ has been demonstrated. For typical data, the calibration procedure provides measured $2 \theta \mathrm{s}$ with an absolute accuracy of $0.02^{\circ}$ for all detectors. The seven-detector system was further improved during early FY 1997 and then was placed into productive use. Results to date all show increased accuracy in measurement along with a reduction in data collection time.

\subsection{Neutron Monochromator Design for Stress Mapping}

Increases in neutron flux on the gage volume in a residual stress sample combined with reduced diffraction peak width can be achieved simultaneously with the use of a vertically focusing, horizontally curved perfect silicon monochromator, according to the calculations made for us by the University of Missouri (Columbia). Flux improvements as large as a factor of 7 have been predicted with the instrumental diffraction peak width reduced by 2 . To fully achieve this increase will require an enlargement of the beam dimension at HB-2. Without the taller beam, a gain of a factor of 2 to 3 was expected. A doubly bent silicon monochromator that is elastically bent in the scattering plane and mechanically focused out of the scattering plane was ordered in FY 1996 and was installed with its own monochromator plug at the HB-2 beam port in FY 1997. The monochromator was designed and built by the University of Missouri. The new monochromator achieved a gain in peak intensity of $60 \%$ and a measurable reduction in peak breadth. During the latest period, we have systematically evaluated a number of additional monochromator options for the upgraded HB-2. 


\subsection{New Goniometer Specifications}

Specifications for new goniometers for use at HFIR for neutron residual stress were completed in FY 1996. The goal is to provide for larger specimens $(\sim 2 \times$ larger than currently possible to study), achieve higher accuracy in the rotational axes via use of absolute encoders, permit ready exchange of detector systems, enable for the first time routine single crystal strain and polycrystalline texture measurements, and support various accessories such as tensile frames and furnaces. One of the two systems will have a sample orienter (Kappa geometry) for studies of strain in single-crystal or highly oriented polycrystalline materials. This sample orienter will also permit texture-mapping experiments and the ability to characterize the variation of texture as a function of processing parameters throughout the volume of a specimen. The two instruments were ordered in FY 1997 and delivered late FY 1998.

\subsection{Dedicated NRSF Installation}

Because the thermal neutron guide hall construction proposal was not funded, the alternate plan is to increase the beam size, design a new shutter, and install thermal neutron guides at HB-2 to support various scattering instruments of the Solid State Division and NRSF. The modified beam delivery concept will provide a dedicated location at HFIR for the NRSF, utilizing a taller beam than is currently available and hence increase the flux for stress mapping.

Monte Carlo analysis indicates a potential of significant intensity gains via redesign of the Be reflector tube and shutter. Considerable debate and changes in the plans for which instruments will be accommodated at the upgraded HB-2 have occurred and continue to occur. However, all designs to date provide for the large-specimen residual-stress-mapping instrument.

The upgrade process will impact the neutron stress measurements for approximately 12 months, beginning early in year 2000. The down time will be used to procure new monochromators, redesign the prototype seven-detector array, revise automation and datacollection algorithms, and to prepare for the new instrument installation. Current models indicate an overall gain of an order of magnitude in instrument effectiveness after the upgrade.

\subsubsection{DOE2000, Materials Microcharacterization Collaboratory}

Late in FY 1997, the DOE office of Mathematics, Information, and Computer Science joined OTT-HTML in initiating a pilot project to develop, install, and test tools for conducting "Science at a Distance" with a focus on materials microcharacterization. The goal is to improve user access to and collaboration with major DOE user facilities via use of the internet and new computational facilities. Besides several DOE electron microscopy facilities, two beam lines at major national facilities were included. These are the Neutron Residual Stress Mapping facility at HFIR and ORNL's X14A beam line at Brookhaven National Laboratory (BNL), both operated by the RSUC. Initial efforts were to establish the foundation for enhanced remote instrument operation for video images of the experimental area as well as video conferencing between scientists. Equipment and networking were ordered, installed, and tested in FY 1998. 


\subsection{DIFFRACTION USER CENTER (DUC)}

\subsubsection{Background}

The DUC uses room-temperature and high-temperature X-ray and neutron diffraction methods to characterize crystalline phase(s) and stability of advanced structural ceramics, alloys, catalysts, and other industrially relevant materials. The data, obtained individually as a function of temperature and environment, and frequently in conjunction with data from thermal analysis or electron microscopy, are used to relate materials processing and performance with phase transformations, reactions (solid-solid, liquid-solid, and gas-solid), lattice expansion, atomic structure, crystallization from the melt, and phase stability.

In addition to supporting users' diffraction needs, the HTXRD facilities are extensively used by qualified staff in the Metals and Ceramics Division who are conducting a wide variety of ceramic and alloy R\&D efforts. DUC also provides technical expertise in diffraction and materials science in support of a number of DOE-funded projects.

\subsubsection{Staff and Major Instruments}

\subsubsection{Staff}

DUC is a central part of the Diffraction and Thermophysical Properties Group. Members who had prime responsibilities for activities in this user center during the reporting period include the following:

- Dr. E. A. (Andrew) Payzant - development staff member, room-temperature (RT) and HTXRD, neutron and synchrotron diffraction methods

- Dr. C. J. (Claudia) Rawn - research staff member, X-ray, and neutron diffraction, crystal chemistry

- Mr. O. B. (Burl) Cavin- (subcontractor) RT and HTXRD

- Dr. R (Robbie) Peascoe-(UT subcontractor), RTXRD and crystal chemistry

- Dr. KiSup Chung (ORISE postdoc) synchrotron diffraction

- J. L. (Joy) Kilroy-group administrative support

- Dr. C. R. (Cam) Hubbard-group leader, X-ray and neutron diffraction

Mr. Cavin, who had been with DUC since the beginning of the HTML, retired September 1993. Fortunately, he has continued to participate in the operation of the X-ray facilities by supporting users and by assisting ORNL staff members. Dr. Payzant, formerly an ORISE postdoc in RSUC, became the lead staff member with prime responsibility for the DUC. Dr. Rawn joined the group as a postdoc and became an ORNL staff member in October 1998. Her expertise is in use of HTXRD for phase equilibria and solid state chemistry. Dr. Ki-Sup Chung joined the Group as a postdoc and works at the X14A synchrotron beam line.

Dr. Hubbard, whose primary research focus is X-ray and neutron diffraction method, fills out the Diffraction program's team. 


\subsubsection{Major Instruments}

- Scintag PAD V goniometer with Peltier cooled $\mathrm{Si}(\mathrm{Li})$ detector;

- Scintag XDS 2000 goniometer with graphite monochromator and scintillation detector;

- Scintag PAD X goniometer with Buehler high-temperature furnace system and choice of either a position-sensitive detector or a Peltier cooled $\mathrm{Si}(\mathrm{Li})$ detector

- High-resolution neutron powder diffractometer (HB-4) at HFIR with furnace and cryostats;

- X14A beam line at the NSLS with Buehler high-temperature furnace system.

The neutron powder diffractometer facilities are part of the Neutron Scattering Research Facilities (NSRF) at HFIR sponsored by ER. HTML user projects that also require neutron powder diffraction are accommodated under a collaborative arrangement.

DUC is a member of the Participating Research Team (PRT) for the X14A beam line at NSLS. This beam line was constructed with funding from the DOE-ER, via ORNL, and industrial and academic members of the PRT. As a member of the PRT, HTML is conducting hightemperature diffraction and stress analysis as well as adding reflectometry and extended X-ray absorption fine structure (EXAFS) capabilities for research use by HTML users. The extremely high flux, 3 to 6 orders of magnitude greater than our laboratory-based systems, will enable users to study smaller specimens, to study rapid reactions and kinetics, and to resolve subtle phase transformations that cannot be determined with the laboratory-based systems. The X-ray optics of X14A will be upgraded in early FY 1999, providing a two- to fourfold increase in flux and replacing some troublesome components.

\subsubsection{New Capabilities}

\subsubsection{Rietveld Full-Pattern-Fitting Refinement Method}

The Rietveld full-pattern-fitting structural refinement method has become a frequently requested data analysis method for diffraction studies. The Rietveld method has developed as a powerful new method for extracting detailed atomic structure and microstructure information from powder diffraction data that could only previously be extracted from single crystal data. This enables polycrystalline powders with known compositions to be analyzed and the structural changes and defects to be correlated to physical (e.g., electrical, thermal) properties. The Rietveld method refines lattice parameters, profile shapes, atomic coordinates, thermal motion parameters, site occupancies, and instrumental aberrations. For a multiphase sample, the user can obtain accurate information on the volume fraction of each phase in a mixture. The user center now has several codes operational for Rietveld refinement (GSAS, Rietan, RIQAS, FullProf). Each code has different advantages and limitations, thus requiring mastery of several of them by DUC staff. The General Structure Analysis System (GSAS) software package can accommodate multiple data sets combining laboratory X-ray, synchrotron X-ray, and neutron diffraction data, all available through the DUC. Synchrotron X-ray powder diffraction data can be collected where the wavelength has been tuned near and away from the absorption edges of different elements having a similar number of electrons, allowing 
identification of elements that are hard to distinguish by conventional laboratory $\mathrm{X}$ rays. Using GSAS to combine data sets collected at different wavelengths provides valuable information for understanding the defect chemistry from the site occupancies of similar cations or anions. GSAS also allows the combined analysis of X-ray and neutron diffraction data. Neutron data (highly penetrating with the ability to "see" lighter atoms like $\mathrm{H}, \mathrm{Li}, \mathrm{C}$, and $\mathrm{O}$, and the ability to disclose both the magnitude and direction of magnetic moments) complements laboratory and/or synchrotron X-ray powder diffraction data. Using HTXRD and full-pattern-fitting, users are able to accurately determine lattice parameters without use of an internal standard, thus avoiding possible chemical interactions between the standard and the sample. Users can subsequently calculate bond distances and angles as a function of temperature from the atomic coordinates.

\subsubsection{Neutron Powder Diffraction}

High-resolution neutron powder diffraction capabilities, managed by the Neutron Scattering Group, Solid State Division, are now available to HTML users. This became possible by developing a cooperative understanding and referral process. When an HTML project would benefit by including neutron powder diffraction, users can include this request in the HTML proposal; members of the DUC team will then obtain the necessary additional review by the Solid State Division's neutron powder diffraction staff. When the HTML staff receives a request for extensive neutron powder diffraction research, they forward this request to the Neutron Scattering Group for consideration under the Basic Energy Science's Neutron Scattering Facilities Program. HTML and the Neutron Scattering Group have jointly acquired a high-temperature vacuum furnace $\left(1600^{\circ} \mathrm{C}\right)$ for neutron powder diffraction measurements and made it operational. We have jointly tested and demonstrated this furnace facility and successfully made it available to HTML and Neutron Scattering Group users at HFIR. This furnace has design constraints that make it impractical for use with oxidative sample environments, so a new tube furnace was purchased to allow for studies in air at temperatures up to $1200^{\circ} \mathrm{C}$. This furnace has been successfully used to obtain high-temperature neutron powder diffraction patterns.

\subsubsection{High-Temperature XRD Furnace for X14A}

A Buehler high-temperature furnace and power supply essentially identical to the system used at HTML has been tested during one experimental cycle at NSLS. The X14A postdocs are working to write SPEC subroutines that will permit temperature control as part of experimental data collection at X14A. 


\subsubsection{Capillary Mount for X14A Data Collection}

A rotating capillary mount has been attached to the Huber goniometer at X14A. Data collection is optimized by containing samples in a rotating capillary, by reducing absorption and eliminating the preferred orientation, and by increasing the number of grains contributing to the diffraction pattern. Successful data has been collected on $\mathrm{La}_{0.9} \mathrm{Sr}_{0.1} \mathrm{Ga}_{0.8} \mathrm{Mg}_{0.2} \mathrm{O}_{3}$, where the high resolution was necessary for space group determination, and on $\mathrm{Ba}_{16} \mathrm{Ce}_{32} \mathrm{Ti}_{64} \mathrm{O}_{192}$, where a large unit cell and low symmetry causes a high degree of peak superpositioning, making characterization by conventional laboratory X-ray diffraction techniques difficult.

\subsubsection{Advanced Data Collection and Analyses}

The XRD instruments in DUC and RSUC have been converted from a VAX cluster to networked Pentium PCs running WindowsNT, with Scintag DMSNT software for data acquisition and analysis. DUC also employs a variety of state-of-the-art powder diffraction software packages for pattern and structure analysis including Jade+ and GSAS (PC and Mac).

\subsubsection{Recognition}

The staff of the Diffraction Program team have been very successful in launching new programs involving extensive use of diffraction methods. Claudia Rawn, in collaboration with staff in the Ceramic Processing Group, is developing and characterizing new dielectrics for microwave communications. Andrew Payzant, in collaboration with $\mathrm{M} \& \mathrm{C}$ and Pacific Northwest National laboratory (PNNL) staff, is reducing the temperature and increasing the oxygen ion conductivity of ceramic electrolytes, which potentially will be used for gas separation and fuel cells. These programs add considerably to the strength and expertise within the team.

\subsection{MACHINING AND INSPECTION RESEARCH USER CENTER}

The Machining and Inspection Research User Center (MIRUC) provides basic facilities for investigation of grinding processes for high-performance ceramic materials, design and fabrication of mechanical property test specimens, dimensional characterization of test specimens and other components, and tribology.

\subsubsection{Staff and Major Instruments}

\subsubsection{Staff}

S. B. (Sam) McSpadden, leader of the Machining and Inspection Research Group, has overall responsibility for MIRUC. Other group members and the equipment and technologies for which they have primary responsibility are as follows: 
- Peter Blau - a nationally recognized expert in the field of tribology (friction, wear, and lubrication). Dr. Blau is responsible for all tribological research performed in MIRUC. Numerous custom-designed friction and wear testing instruments, scratch testers, and repetitive-impact testers are now available for use by guest researchers.

- Tyler Jenkins - responsible for operation of the Harig surface grinders; coolant management; and health, safety, and environmental issues.

- Tom Morris - a technical specialist in grinding and ceramics machining, principal investigator on cooperative research and development agreements (CRADAs) involving cost-effective machining of ceramics.

- Lawrence O'Rourke - responsible for operation of the Weldon cylindrical grinder, Nicco creep-feed cylindrical grinder, grinding wheel management, and procurement.

- Randy Parten - responsible for dimensional metrology, with emphasis on programming and operation of the coordinate measuring machine (CMM), Mahr form tester, Taylor-Hobson Talysurf surface profile measuring instrument, and the Rodenstock noncontact laser surface topography measuring instrument.

- Earl Shelton-responsible for operation and CNC programming of the Cincinnati Milacron centerless grinder and the Sabre vertical grinding center.

- Jessie Whittenbarger-group administrative support.

\subsubsection{Major Instruments}

Five types of numerically controlled grinders are available to guest researchers for their projects at MIRUC. The grinders were selected for their similarity to those used in manufacturing facilities throughout the United States. Grinders are instrumented to permit realtime measurement of key grinding-process parameters, including grinding forces, spindle power, spindle vibration, acoustic emission, and coolant temperature. Data may be collected, displayed, stored, and analyzed using specialized Labview programs and other analysis software. Major machining equipment includes

- Weldon Cylindrical Grinder

- Bridgeport/Harig Surface Slicer/Grinder

- Nicco Creep-Feed Surface Grinder

- Cincinnati Milacron Twingrip ${ }^{\mathrm{TM}}$ Centerless Grinder with high-speed spindle

- Cincinnati Milacron Sabre ${ }^{\mathrm{TM}}$ Multiaxis Grinder with high-speed spindle

- Ded-Tru ${ }^{\mathrm{TM}}$ centerless grinding attachment for use with surface grinders to grind small components 
- Compact Grindability Test System

- SmartCAM ${ }^{\mathrm{TM}}$ Production Turning Package

- SmartCAMTM Production Milling Package

- AutoDesk ${ }^{\mathrm{TM}}$ Mechanical Desktop with AutoCAD ${ }^{\mathrm{TM}} \mathrm{R} 13$

- DADiSPTM (data analysis and display software)

- Statistica ${ }^{\mathrm{TM}}$ (statistical analysis software)

The center maintains state-of-the-art dimensional and surface texture measuring equipment for use by guest researchers. Our technical staff is available to assist researchers in the operation of the more complex equipment, such as the centerless grinder, multi-axis grinder and the coordinate measuring machine. Our equipment is computer-controlled, and inspection data can be easily exported to advanced analysis software and CAD/CAM software using a laboratory-wide network. Major inspection equipment includes

- Electronic Measuring Devices (EMD) Legend ${ }^{\mathrm{TM}}$ Integrated Metrology Center, a precision coordinate measuring machine (CMM) with both contact and noncontact scanning capability

- Mahr/Perthen Formtester ${ }^{\mathrm{TM}}$

- Talysurf Model 120 Stylus Surface Texture Measurement System

- EOIS Mini-moiré Sensor

- Nikon Optical Comparator

- Rodenstock RM600 Laser Surface Texture Measurement System

Physical testing and material analysis constitute a major portion of the work in the tribology laboratory. Experiments are designed to screen materials, effect simulations of components, or study the basic relationships between the microstructures and compositions of surfaces and their friction and wear behavior. Available machines fall into three categories: (1) commercially developed testing machines, (2) machines designed under subcontract, and (3) machines designed and built by ORNL for special purposes. Most of the testing machines are aimed at sliding wear, but abrasive wear, impact wear, and rolling-contact wear tests are also available. Tribology testing at high temperatures and controlled atmospheres is also within the capabilities of the user center. Major tribology equipment includes

- Reciprocating Friction and Wear Tester

- Repetitive Impact Testing System

- Friction Microprobe

- Cameron-Plint TE-77 Reciprocating Sliding Wear Tester

- Instrumented Scratch Tester

- High-Temperature Pin-on-Disk System

- Multimode Friction and Wear Tester

- Micro-Abrasive Wear Tester

- Sather Lubricant Load-Carrying-Capacity Screening Rig

- Teledyne-Taber Portable Scratch Tester

- Wilson Microindentation Hardness Tester 
- Talysurf 10 Surface Roughness Measuring System

\subsubsection{New Capabilities}

\subsubsection{Dedicated Workstation Acquired for Users' Office Area}

An office area has been set aside for the use of visiting researchers who are participating in ceramic machining and inspection research under the HTML User Program. The office has been equipped with a PC-based workstation suitable for CAD/CAM applications and analysis of data collected during the grinding process. The SurfCAM ${ }^{\mathrm{TM}} \mathrm{CAD} / \mathrm{CAM}$ software package was acquired to provide a quick and simple means of generating complex numerically controlled tool paths for the grinding equipment.

\subsubsection{Further Improvements Made to Compact Grindability Test System}

The compact grindability test system, developed by Chand Kare Technical Ceramics, uses a diamond abrasive belt to measure the relative grindability of ceramic specimens. New instrumentation has been added to permit accurate calibration of grinding force, belt speed, and coolant temperature. A dedicated computer was added to the system and a customized database application was written for collecting grindability data.

\subsubsection{Major Activities in FY 1998}

\subsubsection{High-Speed, High-Material-Removal-Rate Cylindrical Grinding Experiments Continued}

As a follow-on to work begun in 1997, high-speed (up to $127 \mathrm{~m} / \mathrm{s}$ ) and high-material-removalrate grinding experiments were conducted using a vitreous bond cubic boron nitride (CBN) wheel to investigate the effects of material removal rate, wheel speed, dwell time, and dressing speed ratio on cylindrical grinding of silicon nitride and zirconia. Experimental results show that operating the grinding wheel at a high surface speed can reduce the effective chip thickness, lower grinding forces, enable high material removal rates, and achieve a higher grinding ratio (G-ratio). The material removal rate was increased to 9.6 and $7.6 \mathrm{~mm} 3 / \mathrm{s} / \mathrm{mm}$ for zirconia and silicon nitride, respectively, to explore the advantage of using high wheel speeds for cost-effective, highmaterial-removal-rate grinding of ceramics. Overall, this study showed that high grinding wheel surface speed is beneficial to the grinding of ceramics. These experiments simulate productiongrinding operations required to produce ceramic fuel systems components.

\subsubsection{CRADA with Cummins Engine Company Continued}

A CRADA entitled Precision Grinding of Components for Diesel Fuel Systems Applications continued throughout FY 1998. Mr. Tom Morris is the principal investigator for the Machining and Inspection Research Group. Mr. Darryl Gust replaced Dr. Albert Shih as the principal 
investigator for Cummins when Dr. Shih accepted an assistant professorship at North Carolina State University.

\subsubsection{CRADA with Caterpillar, Inc., Signed}

A 12-month CRADA entitled Studying the Scuffing Resistance of Zirconia Fuel Injector Components for Diesel Engine Applications was signed with Caterpillar. The purpose of the CRADA is to understand the relationship between the zirconia composition (grain size, stabilizer, and residual stress) and surface preparation (grinding conditions, grinding wheel composition, and grinding direction) on the scuffing resistance of zirconia fuel injector components operating under low lubricity conditions against AISI 52100 mild steel.

\subsubsection{Users from Allison Engines Solve Manufacturing Problem Involving the Drilling of Holes into Silicon Nitride Materials}

The machining of holes and passages into silicon nitride materials and components is frequently conducted for use in attachments and/or cooling features in turbine engine components. The ability to accomplish hole generation with accurate geometric positioning and minimal damage to the ceramic is an important characteristic for the successful implementation of ceramic components in advanced engines. Three machining techniques were evaluated for producing through-holes in Kyocera SN252 $\mathrm{Si}_{3} \mathrm{~N}_{4}$, and seven different material systems were evaluated for hole backing to minimize chipping. Specimens backed with an alumina-filled epoxy exhibited minimal chipping and high strengths, especially when used in conjunction with a machining cycle known as "peck-drilling." 


\section{HTML FELLOWSHIP PROGRAM}

The HTML Fellowship Program was created in FY 1992 to

- provide a mechanism for training industrial and university researchers in state-of-the-art advanced characterization techniques,

- encourage research in areas of interest to DOE,

- improve the quality and output of DOE programs, and

- help make U.S. industry more competitive in a world market.

Four categories of fellowships currently exist: industrial, faculty, graduate, and postdoctoral. This program is administered for the HTML by the Oak Ridge Institute for Science and Education. Research must relate to the following DOE Transportation Technology Program areas of interest:

- processing of advanced materials;

- machining of hard materials;

- structure of materials;

- physical and thermophysical properties of materials;

- mechanical properties of materials;

- corrosion of materials;

- gas-phase reactions with solids;

- tribology of solid surfaces;

- characterization of materials for energy-related applications; and

- high-temperature structural materials (ceramics, composites, intermetallics, and metals).

Fellowship applications are reviewed by the HTML director along with an external committee that represents university, industrial, and private sectors. As with the User Program, a standard nonproprietary user agreement must be in place before work can be performed in the HTML. Once a fellowship appointment has been made, HTML staff work with the respective fellow to schedule instrument time. The current committee members are

- Gary Fischman (Food and Drug Administration),

- Bob Powell (General Motors),

- Andy Sherman (Ford Motor Co.),

- Bob Bitting (Alfred University),

- Joe Panzarino (JNP, formerly of Norton), and

- Gene Haertling (Clemson University). 
As of the end of FY 1998, a total of 39 fellowship appointments have been awarded (18 industrial, 14 graduate, and 7 faculty). A complete listing is provided in Table 5.1.

Table 5.1. Fellowship Participants

\begin{tabular}{|c|c|c|c|c|c|c|}
\hline Name & Organization & Type & Sponsor & $\begin{array}{l}\text { Beginning } \\
\text { date }\end{array}$ & $\begin{array}{l}\text { Ending } \\
\text { date }\end{array}$ & Research title \\
\hline Chris Berndt & $\begin{array}{l}\text { State University } \\
\text { of New York } \\
\text { (Stonybrook) }\end{array}$ & Faculty & OTT & $7 / 1 / 95$ & $6 / 30 / 97$ & $\begin{array}{l}\text { Cracking Studies in Thermal Spray } \\
\text { Systems }\end{array}$ \\
\hline $\begin{array}{l}\text { W. Roger } \\
\text { Cannon }\end{array}$ & $\begin{array}{l}\text { Rutgers } \\
\text { University }\end{array}$ & Faculty & OTT & $3 / 1 / 96$ & $2 / 28 / 97$ & $\begin{array}{l}\text { Measurement of Crack Tip Stresses in } \\
\text { Cracks Grown at High Temperatures }\end{array}$ \\
\hline $\begin{array}{l}\text { Maria } \\
\text { Gajdardiska- } \\
\text { Josifovska }\end{array}$ & $\begin{array}{l}\text { University of } \\
\text { Wisconsin- } \\
\text { Milwaukee }\end{array}$ & Faculty & OTT & $7 / 1 / 95$ & $8 / 31 / 96$ & $\begin{array}{l}\text { High-Resolution Electron } \\
\text { Holography of Oxide Supported } \\
\text { Metal Catalysts. The Novel System of } \\
\mathrm{Pt} / \mathrm{MgO}(111)\end{array}$ \\
\hline $\begin{array}{l}\text { Brian } \\
\text { Sheldon }\end{array}$ & $\begin{array}{l}\text { Brown } \\
\text { University }\end{array}$ & Faculty & OTT & $6 / 1 / 95$ & $12 / 31 / 96$ & $\begin{array}{l}\text { Interfacial Chemistry of Model } \\
\text { Interfaces for Ceramic Matrix } \\
\text { Composites }\end{array}$ \\
\hline Kris Chawla & $\begin{array}{l}\text { New Mexico } \\
\text { Tech. }\end{array}$ & Faculty & OTT & $6 / 1 / 94$ & $6 / 30 / 95$ & $\begin{array}{l}\text { Mechanical Behavior of Oxide } \\
\text { Fiber/Oxide Matrix Ceramic } \\
\text { Composites }\end{array}$ \\
\hline Abaya Datye & $\begin{array}{l}\text { University of } \\
\text { New Mexico }\end{array}$ & Faculty & OTT & $6 / 1 / 93$ & $8 / 10 / 93$ & $\begin{array}{l}\text { Metal-Oxide Reactions in Automotive } \\
\text { Exhaust Catalysts }\end{array}$ \\
\hline $\begin{array}{l}\text { Elizabeth } \\
\text { Dickey }\end{array}$ & $\begin{array}{l}\text { University of } \\
\text { Kentucky }\end{array}$ & Faculty & OIT & $7 / 1 / 98$ & $1 / 1 / 99$ & Oxidation of PtAl Bond Coats \\
\hline Shawn Ailey & $\begin{array}{l}\text { North Carolina } \\
\text { State University }\end{array}$ & Graduate & OTT & $7 / 1 / 95$ & $7 / 4 / 98$ & $\begin{array}{l}\text { Microstructural Analysis of the } \\
\text { Stability of BN Interfacial Coatings in } \\
\text { Continuous Fiber Ceramic } \\
\text { Composites at Elevated Temperatures } \\
\text { under Oxidizing Conditions and } \\
\text { Exposure to Moisture }\end{array}$ \\
\hline $\begin{array}{l}\text { Mark } \\
\text { Andrews }\end{array}$ & $\begin{array}{l}\text { New Mexico } \\
\text { State University }\end{array}$ & Graduate & OAAT & $1 / 2 / 98$ & $10 / 29 / 99$ & $\begin{array}{l}\text { Life Prediction and Mechanical } \\
\text { Reliability Assessment of Structural } \\
\text { Ceramics }\end{array}$ \\
\hline Alex Cozzi & $\begin{array}{l}\text { University of } \\
\text { Florida }\end{array}$ & Graduate & OTT & $2 / 1 / 93$ & $6 / 30 / 96$ & $\begin{array}{l}\text { Theory and Application of Microwave } \\
\text { Joining }\end{array}$ \\
\hline $\begin{array}{l}\text { Elizabeth } \\
\text { Dickey }\end{array}$ & $\begin{array}{l}\text { Northwestern } \\
\text { University }\end{array}$ & Graduate & $9 / 18 / 95$ & $1 / 31 / 97$ & & $\begin{array}{l}\text { Interphase Interface Structure/ } \\
\text { Property Relationships: } \\
\text { Understanding the Role of Interfaces } \\
\text { in Bimaterial Fracture }\end{array}$ \\
\hline $\begin{array}{l}\text { Donna } \\
\text { Graves- } \\
\text { Haynes }\end{array}$ & $\begin{array}{l}\text { University of } \\
\text { Alabama- } \\
\text { Birmingham }\end{array}$ & Graduate & OAAT & $9 / 2 / 97$ & $1 / 31 / 00$ & $\begin{array}{l}\text { Fatigue and Thermomechanicanal } \\
\text { Fatigue of Aluminum/Silicon Carbide } \\
\text { Composites }\end{array}$ \\
\hline Allen Haynes & $\begin{array}{l}\text { University of } \\
\text { Alabama- } \\
\text { Birmingham }\end{array}$ & Graduate & OAAT & $11 / 1 / 93$ & $7 / 31 / 97$ & $\begin{array}{l}\text { Oxidation and Degradation of Thermal } \\
\text { Barrier Coating Systems }\end{array}$ \\
\hline $\begin{array}{l}\text { Michael } \\
\text { Lance }\end{array}$ & $\begin{array}{l}\text { Rutgers } \\
\text { University }\end{array}$ & Graduate & OTT & $7 / 5 / 95$ & $6 / 30 / 98$ & Piezospectroscopy of Ceramics \\
\hline $\begin{array}{l}\text { Erin } \\
\text { McDevitt }\end{array}$ & $\begin{array}{l}\text { Northwestern } \\
\text { University }\end{array}$ & Graduate & OTT & $9 / 2 / 97$ & $10 / 14 / 98$ & $\begin{array}{l}\text { Coating Transformations in the Early } \\
\text { Stages of Hot-Dip Galvannealing of } \\
\text { Steel Sheet }\end{array}$ \\
\hline
\end{tabular}


Table 5.1. (continued)

\begin{tabular}{|c|c|c|c|c|c|c|}
\hline Name & Organization & Type & Sponsor & $\begin{array}{l}\text { Beginning } \\
\text { date }\end{array}$ & $\begin{array}{c}\text { Ending } \\
\text { date }\end{array}$ & Research title \\
\hline $\begin{array}{l}\text { David } \\
\text { Mitchell }\end{array}$ & $\begin{array}{l}\text { University of } \\
\text { Florida }\end{array}$ & Graduate & OAAT & $10 / 1 / 97$ & $6 / 30 / 00$ & $\begin{array}{l}\text { Processing and Properties of a } \\
\text { Multilayer Composite Raceway } \\
\text { Materials for Use with Silicon } \\
\text { Nitride Hybrid Bearings in Extreme } \\
\text { Operating Conditions }\end{array}$ \\
\hline Ron Ott & $\begin{array}{l}\text { University of } \\
\text { Alabama- } \\
\text { Birmingham }\end{array}$ & Graduate & OTT & $1 / 1 / 97$ & $4 / 30 / 97$ & $\begin{array}{l}\text { Evaluation of the Influence of } \\
\text { Grinding Forces }\end{array}$ \\
\hline $\begin{array}{l}\text { Sharon } \\
\text { Robinson }\end{array}$ & $\begin{array}{l}\text { Rutgers } \\
\text { University }\end{array}$ & Graduate & OTT & $7 / 5 / 95$ & 7/19/98 & $\begin{array}{l}\text { Microstructural Control of Silicon } \\
\text { Carbide Via Liquid Phase Sintering }\end{array}$ \\
\hline John Sinclair & Texas A\&M & Graduate & OAAT & $11 / 9 / 97$ & $8 / 31 / 98$ & $\begin{array}{l}\text { Influence of Second-Phase Particles } \\
\text { on the Superplastic Behavior of Al- } \\
5083 \text { Processed by Equal Channel } \\
\text { Angular Extrusion }\end{array}$ \\
\hline Matt Stough & Penn State & Graduate & OTT & $1 / 1 / 96$ & $6 / 30 / 97$ & $\begin{array}{l}\text { Study Solid State Interactions } \\
\text { (Solubility and Diffusivity) in the } \\
\text { A12O3-ZrO2 System }\end{array}$ \\
\hline Doug Taylor & $\begin{array}{l}\text { University of } \\
\text { Arizona }\end{array}$ & Graduate & OTT & $12 / 1 / 93$ & $5 / 7 / 95$ & $\begin{array}{l}\text { High Temperature Mechanical } \\
\text { Properties of Coated Fiber } \\
\text { Reinforced Ceramic Matrix } \\
\text { Composites }\end{array}$ \\
\hline $\begin{array}{l}\text { Maria Antelo } \\
\text { Arana }\end{array}$ & Westinghouse & Industrial & OIT & $8 / 1 / 97$ & $7 / 31 / 00$ & $\begin{array}{l}\text { Failure Capture of TBC Under } \\
\text { Mechanical Loads }\end{array}$ \\
\hline Y. T. Cheng & General Motors & Industrial & OTT & $5 / 1 / 96$ & $5 / 1 / 98$ & $\begin{array}{l}\text { Structural Characterization and } \\
\text { Thermal Stability Studies of } \\
\text { Nanocomposite Thin Film Materials } \\
\text { for Advanced Coating Applications }\end{array}$ \\
\hline Jay Curtis & LoTEC, Inc. & Industrial & OTT & $2 / 1 / 96$ & $1 / 31 / 97$ & $\begin{array}{l}\text { Physical, Thermophysical, and } \\
\text { Mechanical Properties of NZP } \\
\text { Powders and Ceramics }\end{array}$ \\
\hline $\begin{array}{l}\text { Roger } \\
\text { England }\end{array}$ & $\begin{array}{l}\text { Cummins Engine } \\
\text { Co. }\end{array}$ & Industrial & OTT & $1 / 1 / 98$ & $7 / 31 / 00$ & $\begin{array}{l}\text { Correlation of Neutron and X-ray } \\
\text { Diffraction Stress Measurements on } \\
\text { Diesel Engine Components }\end{array}$ \\
\hline $\begin{array}{l}\text { James W. } \\
\text { Fash }\end{array}$ & Ford Motor Co. & Industrial & OTT & $5 / 1 / 96$ & $4 / 30 / 97$ & $\begin{array}{l}\text { Fatigue and Durability of } \\
\text { Automotive Materials. Brake System } \\
\text { Research in Friction Materials, } \\
\text { Tribology, and Wear. }\end{array}$ \\
\hline $\begin{array}{l}\text { Changsheng } \\
\text { Guo }\end{array}$ & $\begin{array}{l}\text { ChandKare } \\
\text { Associates }\end{array}$ & Industrial & OTT & $6 / 1 / 96$ & $8 / 29 / 97$ & $\begin{array}{l}\text { Determination of Dominant Factors } \\
\text { Controlling Ceramic Grindability }\end{array}$ \\
\hline $\begin{array}{l}\text { Cynthia } \\
\text { Hsieh }\end{array}$ & Caterpillar & Industrial & OTT & $6 / 1 / 96$ & $5 / 31 / 97$ & $\begin{array}{l}\text { Characterization of Sub-Micron } \\
\text { Particles for Developing Innovative } \\
\text { Steels for Heavy Equipment } \\
\text { Applications }\end{array}$ \\
\hline Guy Hughes & $\begin{array}{l}\text { Machining } \\
\text { Research Inc. }\end{array}$ & Industrial & OTT & $4 / 1 / 96$ & $3 / 31 / 99$ & $\begin{array}{l}\text { Influence of Centerless Grinding } \\
\text { Truing Parameters on Surface Quality }\end{array}$ \\
\hline $\begin{array}{l}\text { Barrett } \\
\text { Jackson }\end{array}$ & LoTEC, Inc. & Industrial & OTT & $7 / 1 / 93$ & $6 / 30 / 94$ & $\begin{array}{l}\text { Thermophysical Properties of (NZP) } \\
\text { Type Ceramics }\end{array}$ \\
\hline Paul Korinko & $\begin{array}{l}\text { Allison Engine } \\
\text { Co. }\end{array}$ & Industrial & OIT & $10 / 1 / 97$ & $9 / 30 / 98$ & $\begin{array}{l}\text { Thermal Barrier Degradation from } \\
\text { Infiltration of Particulate Matter }\end{array}$ \\
\hline
\end{tabular}


Table 5.1. (continued)

\begin{tabular}{|c|c|c|c|c|c|c|}
\hline Name & Organization & Type & Sponsor & $\begin{array}{l}\text { Beginning } \\
\text { date }\end{array}$ & $\begin{array}{l}\text { Ending } \\
\text { date }\end{array}$ & Research title \\
\hline $\begin{array}{l}\text { Kwangin } \\
\text { Mike Lee }\end{array}$ & General Motors & Industrial & OAAT & $11 / 1 / 97$ & $4 / 30 / 99$ & $\begin{array}{l}\text { Thermal and Frictional Behavior of } \\
\text { Friction Pairs in Automotive } \\
\text { Disk/Drum Brake Systems }\end{array}$ \\
\hline Nanu Menon & $\begin{array}{l}\text { AlliedSignal } \\
\text { Engine Co. }\end{array}$ & Industrial & OTT & $9 / 1 / 95$ & $8 / 30 / 98$ & $\begin{array}{l}\text { Tensile Cyclic Fatigue and } \\
\text { Compression Creep Behavior of } \\
\text { NT154 Silicon Nitride }\end{array}$ \\
\hline Ben Nagaraj & $\begin{array}{l}\text { GE Aircraft } \\
\text { Engines }\end{array}$ & Industrial & OTT & $4 / 15 / 94$ & $4 / 1 / 96$ & $\begin{array}{l}\text { Development of Advanced Thermal } \\
\text { Barrier Coatings }\end{array}$ \\
\hline $\begin{array}{l}\text { Krishnan } \\
\text { Narisimhan }\end{array}$ & Valenite & Industrial & OTT & $5 / 1 / 96$ & $4 / 30 / 97$ & $\begin{array}{l}\text { Study of Physical and Metallurgical } \\
\text { Properties of CVD Hard Coatings on } \\
\text { Cutting Tools, and Modeling of } \\
\text { Response of Multi-Layer-Coated } \\
\text { Tools in Machining }\end{array}$ \\
\hline $\begin{array}{l}\text { Chaitanya } \\
\text { Narula }\end{array}$ & Ford Motor Co. & Industrial & OTT & $1 / 1 / 96$ & $12 / 31 / 96$ & $\begin{array}{l}\text { Structural Characterization of Sol- } \\
\text { Gel Processed Materials for } \\
\text { Automotive Exhaust Reduction } \\
\text { Catalyst }\end{array}$ \\
\hline $\begin{array}{l}\text { Suzanne } \\
\text { Raebel }\end{array}$ & $\begin{array}{l}\text { Cummins Engine } \\
\text { Co. }\end{array}$ & Industrial & OTT & $1 / 11 / 93$ & $4 / 16 / 93$ & $\begin{array}{l}\text { Analysis of Surface Related } \\
\text { Phenomena Occurring on Fuel } \\
\text { Systems for Diesel Engines }\end{array}$ \\
\hline David Snow & $\begin{array}{l}\text { UTRC-Pratt \& } \\
\text { Whitney }\end{array}$ & Industrial & OIT & $3 / 1 / 99$ & $2 / 28 / 00$ & $\begin{array}{l}\text { Microstructure and Microchemistry } \\
\text { of Oxide Scale Formation in the } \\
\text { Nickel Base Superalloys PWA } 1484 \\
\text { and PWA } 1487\end{array}$ \\
\hline Earl Winters & $\begin{array}{l}\text { Coors Electronic } \\
\text { Packaging Co. }\end{array}$ & Industrial & OTT & $5 / 1 / 95$ & $5 / 1 / 96$ & $\begin{array}{l}\text { Characterization of the } \\
\text { Microstructure, Diffusion Barrier, } \\
\text { and Mechanical Properties of High- } \\
\text { Speed Gold Deposits Used in } \\
\text { Ceramic Electronic Packages }\end{array}$ \\
\hline Jian Zhang & Caterpillar & Industrial & OTT & $4 / 1 / 96$ & $3 / 31 / 99$ & $\begin{array}{l}\text { Characterization of CrN Coatings on } \\
\text { Steel }\end{array}$ \\
\hline
\end{tabular}

\subsection{INDUSTRIAL FELLOWSHIPS}

\subsubsection{Background}

To apply for a fellowship, industrial researchers must submit an application to the HTML Fellowship program coordinator. While projects under the User Program are typically short-term and limited to two weeks of hands-on work at the HTML, the Fellowship Program provides an opportunity for longer-term research (which can be performed at intermittent intervals) and often covers more basic research studies. One advantage of a fellowship appointment is that travel, lodging, research expenses, and salaries (Graduate and Faculty Fellowships) are covered by the HTML Fellowship Program. Another mechanism that exists for industrial fellowships is the reverse fellowship. Using this mechanism, an HTML researcher can travel to a company or university to perform on-site research. 


\subsubsection{Industrial Fellowships for FY 1998}

\section{Roger D. England, Cummins Engine Company, "Neutron and X-Ray Diffraction Stress Measurements on Diesel Engine Components" [FEL98-56(38)18I]}

\section{RSUC}

The purpose of this HTML Fellowship is to provide Cummins Engine Co. with direct access to ORNL scientists and equipment to investigate and understand materials issues important to Cummins. The impact of this fellowship to Cummins is insight into solving issues related to materials challenges required by today's competitive market. Specifically, to date, the fellowship work has focused primarily on two projects: the residual stresses in an induction hardened crankshaft and the characterization of the iron nitride (white) layer on nitrided parts.

The induction-hardened crankshaft project was initiated as Cummins, to save energy, moved from crankshaft forgings that were quenched and tempered to forgings without any core heat treatment. The increased grain size of the core due to this change in processing was identified as a possible cause of decreased fatigue life, and this became an opportunity to better understand the interface between martensitic case and perlitic/ferritic core microstructures.

The stress state at the interface was measured using neutron diffraction at the HFIR. Neutron residual strain scanning has been used as a nondestructive method of mapping strain distributions at various depths, particularly in critical regions of a component. Here, the objective was to define the residual stresses existing in the region of this microstructural transition. During the measurements, we discovered an unexpected peak adjacent to the normal martensite and ferrite peak. This peak appears to be a complete resolution of the ferrite peak from the martensite peak. These peaks normally are superimposed, and this situation is unique. The theory is that the martensite can support a more significant residual stress than the ferrite, thus the ferrite, with its lower modulus, will plastically deform. This would account for the resolution because the ferrite interplanar spacing has been altered by the volume increase associated with the formation of the martensite. The correlating peak locations of the two phases would move apart because the plastic deformation of the ferrite allows relaxation of the local residual stress field and because the martensitic constituent is rigid enough to support the stresses from the volumetric expansion. Because there are other possibilities to explain this peak split, further examination will be done to determine whether this hypothesis is correct. The further measurement of the strains in the microstructural transition zone will be facilitated by sectioning the part with strain gages placed to measure the change in the stress state due to sectioning. HTML's new large-specimen residual stress unit will also be employed in making surface measurements on the sectioned area both before and after machining to better define any changes that have occurred from that process.

This project has gained additional funding from the State Partnership Program through ORNL's EERE Program, in conjunction with the Indiana State Energy Office. The Indiana State Energy Office, due to their involvement, is planning on hosting a materials technology workshop in Indianapolis at the State Capitol Building.

Cummins Engine Company is also seeking a better understanding of the crystallographic nature and mechanical properties in iron nitride (white) layers because little basic information about this material is available. Because several critical engine components are nitrided and other applications of nitriding are being evaluated, the physical properties of this white layer are 
necessary to the calculations of accurate life predictions of these components. Work through the fellowship has allowed us to successfully measure and present the X-ray elastic constants for $\mathrm{Fe}_{3} \mathrm{~N}$. These constants are necessary for the conversion of measured strains into stresses. In addition, nanohardness indentor data were used to measure the bulk elastic properties. $\mathrm{Fe}_{3} \mathrm{~N}$ only exists as a coating, so the data were unavailable in the literature. This bulk constant was then applied to a strain gage measurement on a sample placed in a four-point bend fixture. The change in the interplanar spacing was then measured by X-ray diffraction and plotted against applied stresses measured from the strain gages. The slope of this line is the X-ray elastic constant.

The residual stresses were then measured using both the conventional $\psi$ tilt method and as a function of depth using grazing incidence X-ray diffraction (GIXRD). Electron microprobe data were used to determine the nitrogen level as a function of depth. The data were applied to determine the unstressed lattice spacing as changes in the amount of nitrogen occupying the octahedral interstitial sites alter the unstressed lattice spacing. Stresses were calculated as a function of depth, and the change in the measured interplanar spacing associated with the residual stress was isolated from that due to the changing nitrogen content.

Future work at the HTML will entail the publication of the data received from the $\mathrm{Fe}_{3} \mathrm{~N}$ work so that this information is available to other industrial entities. Future work on the crankshaft project will entail the use of thermal expansion data to accurately calculate the volume fraction of the various phases present, and this data will be combined with neutron and X-ray residual stress data to better understand this phenomenon. This analysis should lead to a better understanding of the interface between the martensitic case and the pearlitic/ferritic core microstructures, a valuable tool in life-prediction modeling calculations.

\section{Kwangjin M. Lee, Delphi Automotive Systems, “An Experimental Observation of Frictionally Excited Thermoelastic Instability in Automotive Disk Brakes," [FEL98- 55(37)-17I]}

\section{MCAUC/MAUC}

This work was first started under Proposal No. 97-016.

In automotive disk brake systems, frictional heat is not uniformly distributed due to various reasons such as thermal expansion and imperfections in geometry (see Fig. 5.1). When sliding speed reaches a certain critical value called critical speed, thermoelastic distortion due to frictional heating affects the contact pressure distribution and can lead to thermoelastic instability or TEI, where the contact load is concentrated in one or more small regions on the brake disk surface. These regions then reach very high temperatures and the passage of these hot spots moving under the brake pads can cause low frequency vibration called brake judder. Disk thickness variation (DTV) will further promote the localized contact. Nonuniform contact can also be generated by disk lateral runout (LRO).

This study investigated the effects of various contact conditions on the heating patterns and judder characteristics of a disk brake by using a state-of-the-art infrared camera technology developed by HTML. Hot spot formations in automotive disk brakes were clearly observed under the various operating conditions, and the effects of brake system design modifications were 
studied to reduce the judder propensity. The baseline friction material used in the study was modified based on the theory of thermoelastic instability, and the infrared images captured during braking confirmed that the modified material had higher critical speed.

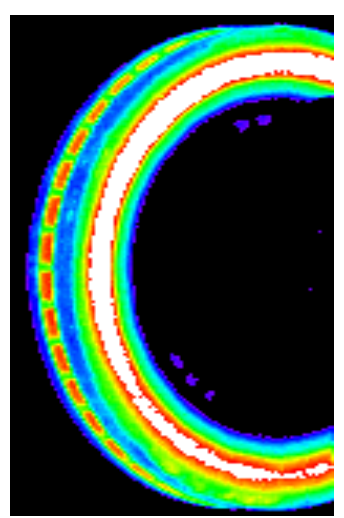

Hot Banding

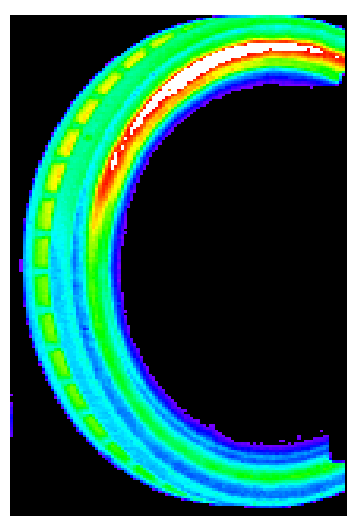

Hot Arching

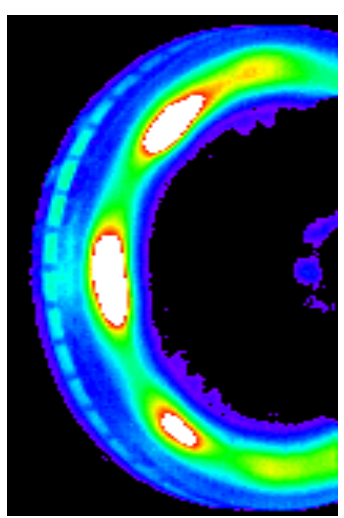

High Order

Hot Spotting

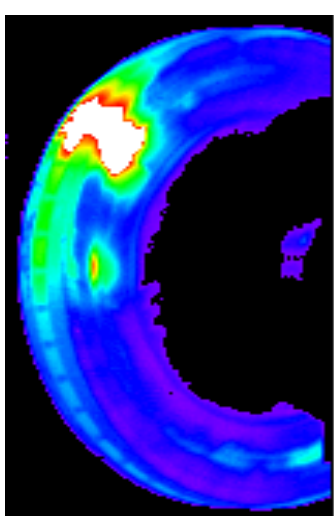

Low Order

Hot Spotting

Fig. 5.1. Various frictional contact conditions observed in automotive disk brakes.

This user program was completed, and the remaining work was carried over to the HTML Fellowship Program.

\section{Nanu Menon, AlliedSignal Engines, "Tensile Cyclic Fatigue and Compression Creep Behavior of NT154 $\mathrm{Si}_{3} \mathrm{~N}_{4}$ " [FEL95-27(19)-5I]}

\section{MCAUC}

Status:

\section{Cyclic Fatigue:}

Ceramic turbine blades are often subjected to cyclic loading in their applications. Crack growth under cyclic loading has been observed to be faster than that under static loading at intermediate temperatures. ${ }^{1}$ The objective of this part of the research is to understand the cyclic fatigue phenomenon in silicon nitrides.

Fifteen AS800 specimens have been tested at the following conditions: Temperature $=$ $1300^{\circ} \mathrm{F}$, Stress Ratio $\left(\mathrm{R}_{\mathrm{s}}\right)=0.1$, Max. Stress $=500-600 \mathrm{MPa}$, and Frequency $(v)=50 \mathrm{~Hz}$. The results are shown in Table 5.2.

The information includes results from the SEM fractography. All specimens failed from pores/white spots.

\footnotetext{
${ }^{1}$ C. J. Gilbert, R. H. Dauskardt and R. O. Ritchie, "Behavior of Cyclic Fatigue Cracks in Monolithic Silicon Nitride," J. Am. Ceram. Soc. 78[9], 2291-2300, 1995.
} 


\section{Compressive Creep:}

Compressive creep rates in $\mathrm{Si}_{3} \mathrm{~N}_{4}$ are considerably lower than tensile creep rates. ${ }^{2}$ Hence, compressive creep models are needed for accurate estimation of stress redistributions in $\mathrm{Si}_{3} \mathrm{~N}_{4}$ components subjected to elevated temperatures. In addition, if compressive creep models are available, flexure creep can be modeled using finite-element methods. Since flexure creep tests involve much lower cost than the tensile creep tests, a considerable cost saving could be realized in production lot testing if flexure specimens are employed in place of the current tensile specimens as a benchmark for ensurance of the right sintering conditions in product lot testing.

The test matrix for compressive testing is given Table 5.3. The key results are shown in Table 5.4.

A model for secondary creep has already been established. The viscoelastic part of the compressive strains is now being analyzed.

Table 5.2. Results of axial cyclic fatigue testing

\begin{tabular}{|c|c|c|c|c|}
\hline $\begin{array}{l}\text { Specimen } \\
\text { ID }\end{array}$ & $\begin{array}{l}\text { Max/Min } \\
\text { Stress }\end{array}$ & $\begin{array}{l}\text { Cycles to } \\
\text { Failure }\end{array}$ & Fractography & Remarks \\
\hline 35835 & $500 / 50$ & $10,000,000$ & Further tested & \\
\hline 35835 & $550 / 55$ & $10,000,000$ & Further tested & \\
\hline 35844 & $550 / 55$ & $10,000,000$ & Further tested & \\
\hline 35836 & $550 / 55^{*}$ & $20,084,630^{*}$ & Pore, surface & Ran out at 20E6, taken out of machine, and retested \\
\hline 35827 & $550 / 55^{*}$ & & Pore, internal & * Broke at $513 \mathrm{MPa}$ during loading of 1 st cycle \\
\hline 35819 & $550 / 55^{*}$ & 34,928 & Pore, surface & \\
\hline 35820 & $550 / 55^{*}$ & $3,279,547$ & Pore, internal & \\
\hline 35811 & $550 / 55^{*}$ & & Pore, internal & * Broke at $514 \mathrm{MPa}$ during loading of 1 st cycle \\
\hline 35812 & $550 / 55^{*}$ & & Pore, surface & * Broke at $451 \mathrm{MPa}$ during loading of 1 st cycle \\
\hline 35860 & $570 / 57$ & 689,570 & Pore, internal & \\
\hline 35828 & $570 / 57$ & 48,237 & Pore, internal & \\
\hline 35804 & $570 / 57^{*}$ & & Pore, internal & * Broke at $454 \mathrm{MPa}$ during loading of 1 st cycle \\
\hline 35852 & $570 / 57^{*}$ & 4,998 & Pore, surface & * Broke while tuning : Max stress $561 \mathrm{MPa}$ \\
\hline 35859 & $570 / 57^{*}$ & & Pore, surface & * Broke at $447 \mathrm{MPa}$ during loading of 1 st cycle \\
\hline 35851 & $570 / 57^{*}$ & 17,193 & Pore, surface & * Broke while tuning : Max stress $549 \mathrm{MPa}$ \\
\hline 35835 & $600 / 60$ & 7,208 & Pore, internal & Tested at $500 \& 550 \mathrm{MPa}$ prior \\
\hline 35867 & $600 / 60^{*}$ & & Pore, internal & * Broke at $576 \mathrm{MPa}$ during loading of 1 st cycle \\
\hline 35844 & $600 / 60^{*}$ & 2,332 & Pore, internal & $\begin{array}{l}\text { * Tested prior at } 550 \mathrm{MPa} \text {, broke while } \\
\text { tuning at } 583 \mathrm{MPa}\end{array}$ \\
\hline
\end{tabular}

${ }^{2}$ M. K. Ferber, M. G. Jenkins and V. J. Tennery, "Comparison of Tension, Compression and Flexure Creep for Alumina and Silicon Nitride Ceramics," Ceram. Eng. Sci. Proc., 11 [7-8] 1028-1045, 1990. 
Table 5.3. NT154 specimen test matrix for compressive creep

\begin{tabular}{cc}
\hline Temperature, ${ }^{\circ} \mathrm{C}$ & Stresses, MPa (One specimen at each stress) \\
\hline 1316 & $125,200,300,400,500$ \\
1343 & $300,400,500$ \\
1371 & $30,100,200,300,400,500$ \\
1399 & $25,50,100,200,300$ \\
\hline
\end{tabular}

Table 5.4. Minimum creep rates in compression measured at the end of approximately 150 hours, or after approximately 100 hours of steady-state creep

\begin{tabular}{ccc}
\hline $\begin{array}{c}\text { Temperature } \\
\left({ }^{\circ} \mathbf{C}\right) /\left({ }^{\circ} \mathbf{F}\right)\end{array}$ & $\begin{array}{c}\text { Applied } \\
\text { compressive } \\
\text { stress } \\
(\mathbf{M P a}) /(\mathbf{k s i})\end{array}$ & $\begin{array}{c}\text { Minimum } \\
\text { creep rate } \\
\left(\mathbf{x} \mathbf{1 0}^{-\mathbf{1 0}} \mathbf{- 1}\right)\end{array}$ \\
\hline $1316 / 2400$ & $300 / 43.5$ & 2.7 \\
$1316 / 2400$ & $400 / 58.0$ & 9.3 \\
$1316 / 2400$ & $500 / 72.5$ & 10 \\
$1343 / 2450$ & $300 / 43.5$ & 9.3 \\
$1343 / 2450$ & $400 / 58.0$ & 12 \\
$1343 / 2450$ & $500 / 72.5$ & 16 \\
$1371 / 2500$ & $100 / 14.5$ & 5.3 \\
$1371 / 2500$ & $200 / 29.0$ & 12 \\
$1371 / 2500$ & $300 / 43.5$ & 11 \\
$1371 / 2500$ & $400 / 58.0$ & 13 \\
$1371 / 2500$ & $500 / 72.5$ & 8.4 \\
$1399 / 2550$ & $50 / 7.3$ & 10 \\
$1399 / 2550$ & $100 / 14.5$ & 16 \\
$1399 / 2550$ & $200 / 29.0$ & 21 \\
$1399 / 2550$ & $300 / 43.5$ & 13 \\
\hline
\end{tabular}

CATERPILLAR INC.

MAUC, MCAUC, PPUC, RSUC

HTML Proposal No. Fe195-37 (21)-81, "Characterization Of Thin Film Coatings".

Caterpillar: Jian Zhang

MAUC Stuff: Larry Allard, Dave Braski ,Dorothy Coffey

MCAUC Stuff: Laura Riester

RSUC Staff: Tom Watkins

In the third year of this program, the objective was to study the properties and microstructure of diamond like carbon (DLC) and metal containing DLC (Me-DLC) coatings in order to understand the relationships among deposition process, coating properties, and tribological performance of these thin film coatings. Characterization of coating chemical and mechanical properties, as well as microstructure analysis were performed at HTML using the 
PHI 660 Scanning Auger Microscope, HF-2000 200-kV TEM, Nanoindentor II, and Scintag PTS Goniometer with a High-Flux rotation anode X-ray source. Related tribological and adhesion tests were conducted at Caterpillar.

The composition profile of a DLC sample (Fig. 5.2) identified a two-layer structure of the coating; a pure carbon layer with a thin metallic interlayer (bond layer) next to the steel substrate. Using cross-section TEM and electron diffraction (Fig. 5.3 [a]) the carbon layer was determined to be amorphous. While the Me-DLC also has two layers, the high carbon layer of the M e-DLC

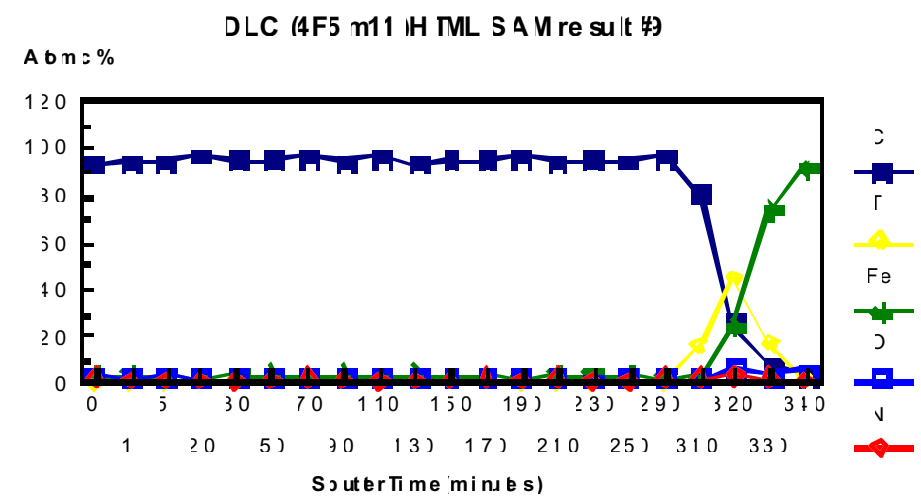

Fig. 5.2. Scanning Auger Microprobe composition profile of DLC on steel substrate.

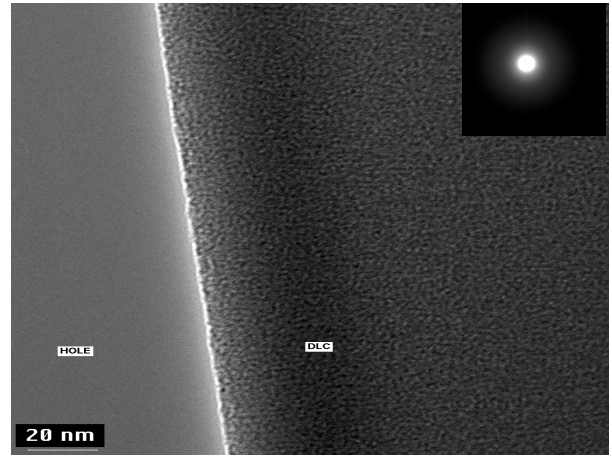

[a]

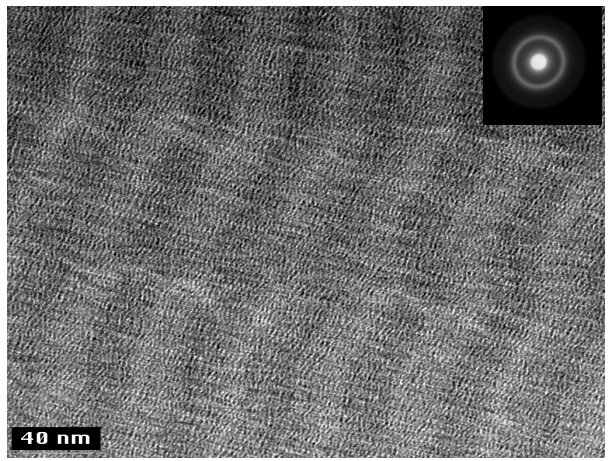

[b]

Fig. 5.3. Cross-section TEM image and diffraction pattern of [a] the amorphous DLC, $100,000 X$ and $[b]$ the Me-DLC multiple sub-layers, 50,000X. 
coating consists of a large number of sub-layers with thickness of about 20 to $30 \mathrm{~nm}$. Based on the TEM and diffraction results, these sub-layers have a quasi-crystalline structure (Fig.2 [b]). Amorphous DLC and sub-layer Me-DLC structures reduced apparent friction during Caterpillar tribological testing about $45 \%$ and $25 \%$ lower than that of the steel baseline, respectively (see Table 5.5). Table 5.5 also shows that both coatings have a higher hardness than the baseline, and lower moduli. Interestingly, the Me-DLC shows a much better adhesion than DLC, which is likely one of the benefits of the layered structure. Figure 5.4 shows the interfaces between the carbon layer, metallic interlayer, and steel substrate of both coatings. Diffusion bands can be seen between the carbon layers and the metallic interlayer for both cases; but sharp boundaries between the metallic interlayer and steel substrate were found, indicating less chemical bonding at these interfaces. Further study is needed to understand the effects of the interface structure on coating adhesion and performance.

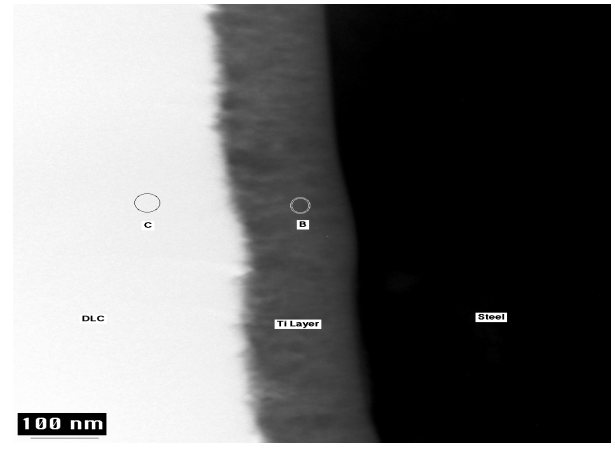

[a]

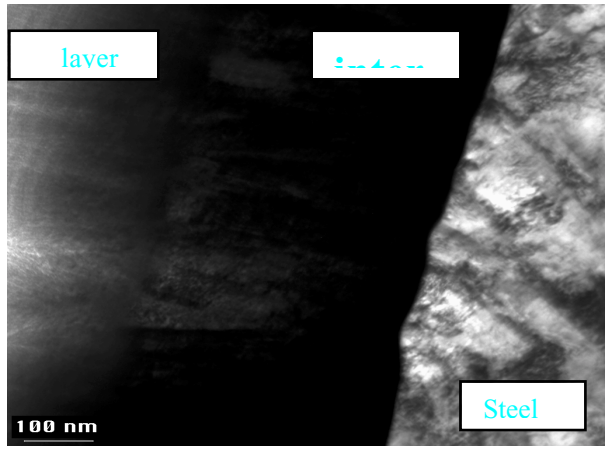

[b]

Fig. 5.4. Cross-section TEM images of carbon layer, metal interlayer, and steel substrate

Table 5.5. Properties of the DLC samples

\begin{tabular}{lcccc}
\hline & Friction Coeff. & Hardness (GPa) & Modulus (GPa) & Adhesion (DB) \\
\hline DLC & 0.027 & 24.0 & 241.3 & 5 \\
Me-DLC & 0.038 & 12.5 & 144.3 & 3 \\
52100 steel & 0.05 & 8.9 & 254 & N/A \\
\hline
\end{tabular}

The knowledge of the DLC coating microstructure and properties obtained from this program is critical for understanding the coating performance and failure mechanisms. The data collected at HTML has been analyzed with lab testing results at Caterpillar and used for coating selection and performance modeling. 


\subsection{GRADUATE FELLOWSHIPS}

\subsubsection{Introduction}

For graduate students the following criteria are applicable:

- the student must be a U.S. citizen and be studying in an engineering department having Accrediting Board for Technology (ABET) accreditation of the undergraduate program,

- the candidate must be prepared to conduct a substantial part of his or her thesis research in residence at HTML,

- the candidate must have an undergraduate grade point average of at least 3.5 in a 4.0 system, and

- a standard nonproprietary user agreement must be in place.

The student's thesis research progress is evaluated once a year by the HTML director, the HTML staff advisor, and the student's professor to determine whether significant progress has been made and to establish future research goals. This meeting also serves as a mechanism to determine whether funding is to continue. An HTML staff member serves as an on-site advisor and is a member of the student's dissertation committee at the university. Each graduate student receives a monthly stipend for the duration of the fellowship appointment.

\subsubsection{Graduate Fellowships for 1998}

\section{J. Andrews, New Mexico State University, "Life Prediction and Mechanical Reliability of NT551 $\mathrm{Si}_{3} \mathrm{~N}_{4}$," HTML No. FEL98-58(40)-25G}

\section{MCAUC}

The generation of a materials design database for NT551, a $\mathrm{Si}_{3} \mathrm{~N}_{4}$ manufactured by Saint Gobain Norton Industrial Ceramics, was completed during the past fiscal year. Three different test specimens were used in generating the database: an ASTM C 1161-B flexure bar, a cylindrical flexure bar, and a modified ORNL tension specimen. The strength data derived from the materials database will be used as input into a recently developed life prediction algorithm by AlliedSignal Engines, Inc., to estimate the inert strength and fatigue performance of a $\mathrm{Si}_{3} \mathrm{~N}_{4}$ diesel engine exhaust valve made from NT551. The NT551 materials design database has resulted in two proceedings publications, one journal publication, and one poster presentation.

The results of fractographic analyses for the three test specimens as functions of temperature and loading rate are presented in Table 5.6.

All three test specimens were machined using a 320-grit diamond grinding wheel but each using a different machining process. The cylindrical flexure specimens were made using a centerless machining process that left unique grinding patterns not found on the surface of the other two test specimens. A different extrinsic flaw type (SUR2-MD) was designated for the cylindrical flexure specimens. 
Preliminary analysis of the data presented in Table 5.6 support the following statements:

1) The dominant mode of failure at $20^{\circ} \mathrm{C}$ for all test specimens was surface damage due to machining processes.

2) The cylindrical flexure specimens exhibited a single and unique failure mechanism not seen with the other two test specimens and is believed to be a result of the centerless machining process.

3) The modified ORNL tension specimens exploited the greatest percentage of intrinsic volume flaws when compared to the other two flexure test specimens.

4) A significant change of failure mechanism occurred for the ASTM C 1161-B flexure bars as the temperature increased and the loading rate decreased, as illustrated in Table 5.6. The dominant mode of failure at $20^{\circ} \mathrm{C}$ and at the fastest loading rate was SUR1-MD while the dominant mode of failure at $850^{\circ} \mathrm{C}$ and at the slowest loading rate was VOL-SF.

Table 5.6. Fractographic results for $\mathrm{NT551} \mathrm{Si}_{3} \mathrm{~N}_{4}{ }^{a}$

\begin{tabular}{|c|c|c|c|c|}
\hline Loading rate $(\mathrm{N} / \mathrm{s})$ & VOL-SF & VOL-AGG & SUR1-MD & UNK \\
\hline \multicolumn{5}{|c|}{ Transversely machined ASTM C 1161-B specimens tested at $20^{\circ} \mathrm{C}$} \\
\hline 36 & 8 & 0 & 22 & 0 \\
\hline 0.36 & 2 & 0 & 28 & 0 \\
\hline 0.0036 & 5 & 0 & 24 & 0 \\
\hline \multicolumn{5}{|c|}{ Transversely machined ASTM C 1161-B specimens tested at $700^{\circ} \mathrm{C}$} \\
\hline 36 & 11 & 1 & 3 & 0 \\
\hline 0.36 & 10 & 2 & 2 & 0 \\
\hline 0.0036 & 13 & 0 & 2 & 0 \\
\hline \multicolumn{5}{|c|}{ Transversely machined ASTM C 1161-B specimens tested at $850^{\circ} \mathrm{C}$} \\
\hline 36 & 5 & 3 & 12 & 10 \\
\hline 0.36 & 21 & 0 & 6 & 2 \\
\hline 0.0036 & 30 & 1 & 0 & 9 \\
\hline Loading rate $(\mathrm{N} / \mathrm{s})$ & VOL-SF & VOL-AGG & SUR2-MD & UNK \\
\hline
\end{tabular}

Cylindrical four-point-flexure specimens tested at $20^{\circ} \mathrm{C}$

$\begin{array}{lllll}14.67 & 0 & 0 & 30 & 0 \\ 0.1467 & 0 & 0 & 30 & 0 \\ 0.001467 & 0 & 0 & 30 & 0\end{array}$

\begin{tabular}{ccccc}
\hline Loading rate (N/s) & VOL-SF & VOL-AGG & SUR1-MD & UNK \\
\hline & Modified ORNL tension specimens tested & at & $20^{\circ} \mathrm{C}$ & \\
288.6 & 0 & 2 & 11 & 0 \\
2.886 & 1 & 1 & 10 & 0 \\
0.02886 & 1 & 1 & 10 & 0 \\
\hline
\end{tabular}

${ }^{a}$ The number of specimens for each flaw type is shown.

$K E Y$

VOL-SF: intrinsic flaw type having the appearance of snowflakes

VOL-AGG: intrinsic flaw type due to an agglomeration

SUR1-MD: extrinsic flaw type; surface damage from machining processes

SUR2-MD: extrinsic flaw type; surface damage from machining processes

UNK: failure mechanism not identified 


\section{D.L. Haynes, University of Alabama at Birmingham, "Effects of Aging Time and Test Temperature on the Tensile Behavior and Damage Evolution of Al/SiCp Composites," HTML No. FEL97-47(32)-18G}

\section{MCAUC}

Aluminum/silicon carbide $(\mathrm{Al} / \mathrm{SiC})$ composites are being utilized at temperatures at or near their age-hardening temperatures; however, little is known about the combined effects of overaging and elevated temperature on the mechanical behavior of this composite system. The purpose of this work is to determine the effects of aging time and test temperature on the tensile behavior of commercially available SiC-particulate-reinforced aluminum alloys (DWA Composite Specialties, Inc., Chatsworth, California).

This work is being conducted as a graduate research (Masters level) project in conjunction with The University of Alabama at Birmingham. From September 1997 through January 1998, coursework was completed and research was performed at intervals between class quarters. Research continues on a full-time basis until project completion.

Preliminary aging curves were developed for two aluminum composite systems: 6092$\mathrm{Al} / 17.5_{\mathrm{p}} / \mathrm{SiC}$ and $2009-\mathrm{Al} / 15_{\mathrm{p}} / \mathrm{SiC}$ (Fig. 5.5). Peak- and over-aged times were determined from these curves. Elevated temperature tensile tests will be performed at 150,175 , and $200^{\circ} \mathrm{C}$ on samples in the peak-and over-aged conditions. These tests, along with subsequent characterization, will be used to determine the effect of aging time and testing temperature on yield stress, flow stress, tensile ductility. Further study will include the use of scanning electron microscopy, nanoindentation, X-ray diffraction and fractography to analyze the effects of residual stress, matrix strength and strengthening mechanisms, elastic modulus, damage initiation and evolution, fracture morphology and particle cracking. Preliminary tensile test results performed at room temperature are consistent with those achieved by DWA Composite Specialties, Inc. The project completion date is projected as December 1999.

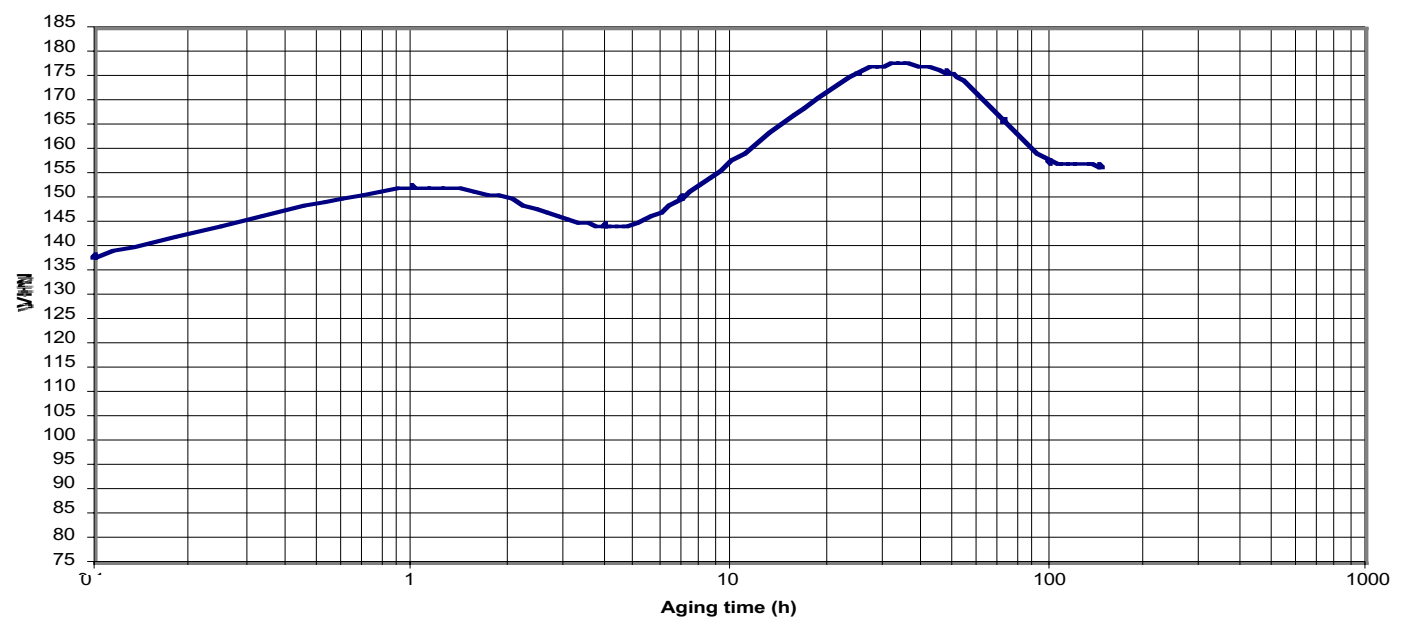

Fig. 5.5. Preliminary Aging curve for 2009-Al/15p/SiC composite. 


\section{Erin McDevitt, Northwestern University, "Coating Transformations in the Early Stages of Hot-Dip Galvannealing of Steel Sheet," [FEL97-50(33)-21G}

\section{MAUC}

Hot-dip Zn-coated steel sheet has become the material of choice for corrosion-resistant exposed body panels. However, the complex reactions that occur while the steel substrate is resident in the $\mathrm{Zn}$ bath are poorly understood. These bath reactions significantly affect the performance of the coated sheet in press forming and welding and affect the painted surface appearance. This research was the first comprehensive study of the interfacial reactions that occur during hot dipping and the subsequent annealing process.

High-resolution analytical electron microscopy and electron diffraction were used to discover the course of the coating microstructural development early in the hot-dipping process. It was found that an $\mathrm{Fe}_{2} \mathrm{Al}_{5}$ inhibition layer formed on the surface of the steel substrate in the first instants of immersion in $\mathrm{Zn}$ baths containing as low as $0.10 \mathrm{wt} . \% \mathrm{Al}$. When hot-dipping samples in a 0.14 wt. $\% \mathrm{Al}$, the as-dipped coating microstructure consisted of an $\mathrm{Fe}_{2} \mathrm{Al}_{5}$ layer on the steel surface. That layer was covered by a layer of an Fe-Zn compound, which was covered by the unalloyed $\mathrm{Zn}$. A mechanism for coating microstructure development in the $\mathrm{Zn}$ bath that is consistent with all the experimental results was proposed, and, from this model, the metallurgical variables that govern inhibition layer formation were discerned.

Similarly, the subsequent evolution of the coating microstructure during annealing was observed. The breakdown of the $\mathrm{Fe}_{2} \mathrm{Al}_{5}$ inhibition layer during galvannealing at $500^{\circ} \mathrm{C}$ occurred without the formation of outbursts. Instead, the grain boundary diffusion of Al into the steel substrate accounted for dissolution of the inhibition layer in the first second of galvannealing. Padditions to the substrate affected only the rate at which the inhibition layer dissolved and did not affect the rate of Fe-Zn compound formation. $\mathrm{P}$ in the substrate blocked grain boundary diffusion of $\mathrm{Al}$ into the substrate, thus slowing inhibition layer dissolution. The slower overall galvannealing behavior often observed on P-bearing substrates is due to a longer period of inhibition layer survival which results in a longer incubation period for the initiation of the formation of Fe- $\mathrm{Zn}$ compounds.

These discoveries will significantly decrease the process development time for introduction of new high strength steel substrates as Zn-coated exposed body panels because the way in which the alloying elements affect the coating reactions is now better understood. Solid solution strengthening alloys that segregate to Fe grain boundaries (e.g., P, S) might slow the interface reactions during galvannealing by preventing the diffusion of $\mathrm{Al}$ into the substrate, thus preventing inhibition layer dissolution. Also, this new information on bath reactions will be essential to the implementation of new exposed hot-dip $\mathrm{Zn}$ coatings to eliminate. 


\section{J. Mitchell, University of Florida, "Processing and Properties of a Silicon Nitride Multilayer Composite Toughened by Metallic Lamina," [FEL97-51(34)-22G]}

\section{MIRUC}

Ceramic materials show promise as structural materials for use in applications involving high temperatures and/or excessive wear. Ceramic materials, in general, have low density and high hardness and are stable at higher temperatures than metals. The primary limitation of structural ceramics is their inherent brittleness and catastrophic failure mechanisms. Increasing the toughness and damage tolerance of ceramic materials is critical in order to enable increased use of advanced ceramic materials in high-temperature and high-wear applications.

The focus of this research was to increase the toughness and eliminate the catastrophic failure mechanism of silicon nitride through formation of a multilayer ceramic-metallic composite. The metallic layers have the capability to provide ductility and damage tolerance to the silicon nitride. Composite properties may be designed between the inherent ceramic and metallic material properties through manipulation of the composite layer structure.

The individual layer materials were formed via tape casting, and the composite was hotpressed to facilitate densification. The laminate composite was developed to strategically balance the mechanical properties between the two monolithic materials. This composite has potential for use as a bearing raceway material and in high-temperature structural applications where high toughness is required.

The laminates consisted of alternate layers of silicon nitride and pure chromium metal. Chromium metal was chosen because it forms a protective oxide coating, forms relatively high melting temperature eutectic compositions with silicon, and has a thermal expansion coefficient slightly higher than silicon nitride. The thermal expansion mismatch between chromium $\left(6.2 \times 10^{-6} /{ }^{\circ} \mathrm{C}\right)$ and silicon nitride $\left(3.0 \times 10^{-6} /{ }^{\circ} \mathrm{C}\right)$ results in the silicon nitride layers being left in a state of residual compression and the chromium layers being left in a state of residual tension in the plane of the plate after cooling from the hot-pressing temperature. Laminates were formed using seven silicon nitride layers and six chromium layers, which results in both outer layers being silicon nitride. It is preferable that both outer layers be silicon nitride because silicon nitride has relatively high wear resistance and chemical stability. In addition, the in-plane compressive residual stress helps to prevent crack initiation at the surface and propagation through the cross section.

Although composite fabrication and testing are still under way, silicon nitride-chromium composite materials have been successfully fabricated. Preliminary results indicate that the individual layer materials have elastic moduli and hardness values similar to values reported in literature, and the layers are diffusion bonded to each other, forming an interface slightly weaker than the individual monolithic materials. Figure 5.6 shows an SEM photomicrograph of a silicon nitride-chromium multilayer composite. 


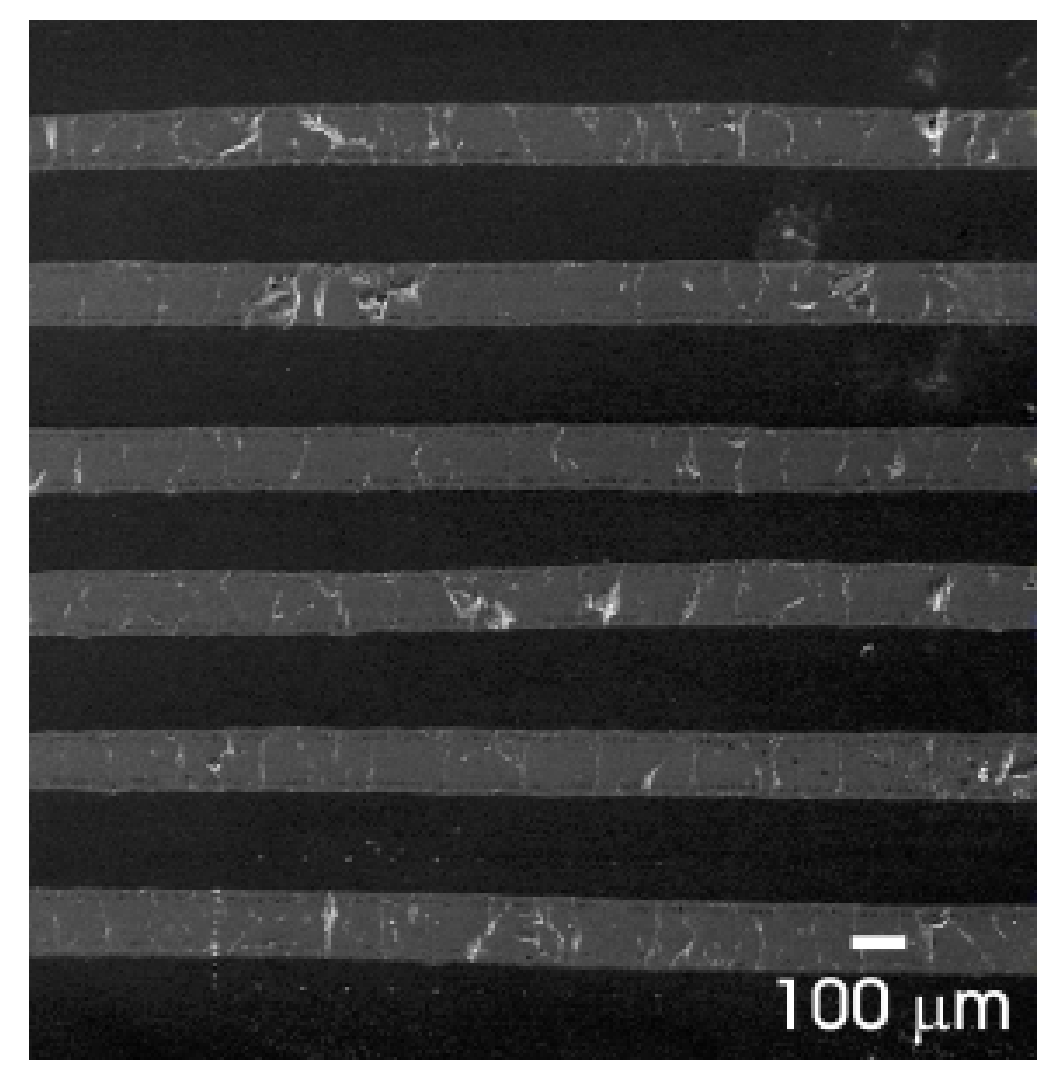

Fig. 5.6. A fully dense silicon nitride-chromium multilayer composite with seven silicon nitride layers (dark color) and six chromium layers (light color).

John W. Sinclair, Texas A\&M University, "Microstructure and Mechanical Properties of Al-5083 Processed by Equal Channel Angular Extrusion” [FEL97-53(35)-24G]

\section{MAUC}

The severe plastic deformation technique known as equal channel angular extrusion (ECAE) was utilized to produce a submicron-grain (SMG)-sized microstructure in billets of ingot Al5083. Al-5083 is a low-cost alloy that, when specifically processed, possesess superplastic properties. There were two objectives of this research. The first was to demonstrate the ability of ECAE processing to produce a high-angle-boundary microstructure in bulk product form, which is suitable for superplastic deformation. The second, because of the SMG-sized microstructure, was to investigate potential for high-strain-rate superplasticity in a relatively low-cost aluminum alloy (see Fig. 5.7). Theoretically, the commercial importance of bulk superplastic material could reside in the ability to perform superplastic extrusions and the ability to produce complex shapes in a one-step operation rather than more costly, multi-step built-up sections. 


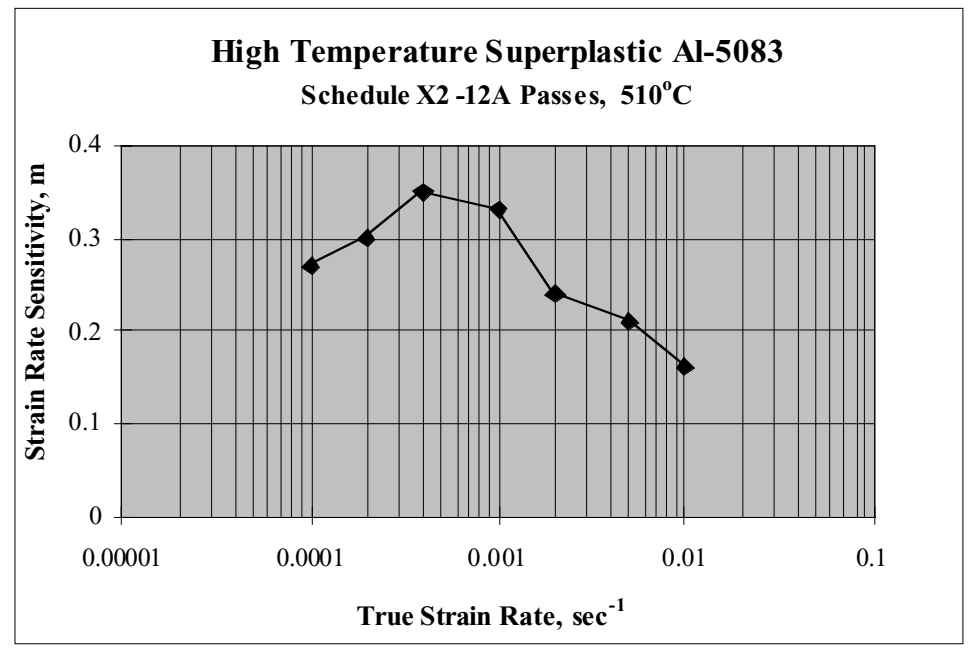

Fig. 5.7. Strain rate compared with strain sensitivity for superplastic Al-5083.

Results of microtexture data, shown in Fig. 5.8, demonstrate that ECAE is capable of producing a high-angle-boundary microstructure. While the ECAE-processed A1-5083 SMG material was unstable against grain growth at the conventional superplastic forming temperature of $510^{\circ} \mathrm{C}$, the bulk material displayed reasonable superplastic properties. Elongation-to-failure was over $400 \%$ with a strain-rate sensitivity index of $\sim 0.35$ at the conventional strain-rate of $0.0004 \mathrm{sec}^{-1}$.
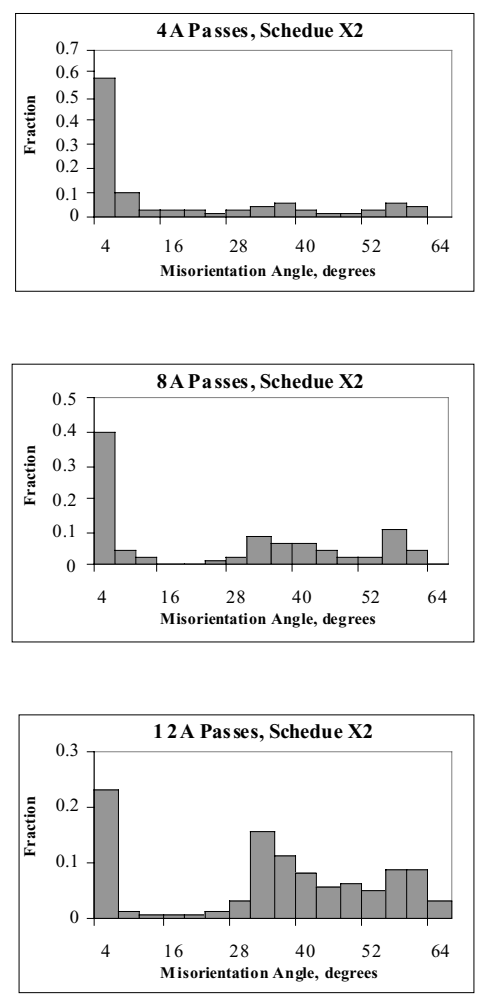

Fig. 5.8. Microtexture data for superplastic Al-5083. 
APPENDIX A

STANDARD NONPROPRIETARY USER AGREEMENTS 



\section{APPENDIX A. STANDARD NONPROPRIETARY USER AGREEMENTS}

\section{U. S. Industry - 281}

\section{Alabama}

Advanced Optical Systems (Huntsville)

Citation Corp.

Monarch Tile, Inc. (Florence)

Southern Research Institute (Birmingham)

United Defense LP (Anniston)

Arizona

Advanced Ceramics Research (Tucson) AlliedSignal (Phoenix)

Materials Focus Inc. (Tucson)

Motorola (Tempe)

RASTRA of the Americas (Litchfield Park)

\section{California}

AlliedSignal EMRC (Los Angeles)

Alzeta Corp. (Santa Clara)

Amercom Inc. (Chatsworth)

Applied Materials, Inc. (Santa Clara)

Ceradyne, Inc. (Costa Mesa)

CERCOM, Inc. (Vista)

Ensei, Inc. (Pismo Beach)

FMC Corp., (Santa Clara)

Guidance \& Control Systems/Litton Ind. (Woodland Hills)

IBM Almaden Research Center (San Jose)

Lockheed Martin Skunk Works (Palmdale)

Membrane Technology Research (Menlo Park)

Northrop Corp. (Pico Rivera)

Nuclear \& Aerospace Materials Corp. (Poway)

Rohr Inc. (Chula Vista)

Solar Turbines, Inc. (San Diego)

SRI International (Menlo Park)

Sullivan Mining Corp. (San Diego)

Sundstrand Power Systems (San Diego)

Ultramet (Pacoma)

\section{Colorado}

CDM Optics, Inc. (Boulder)

Coors Ceramics Company (Golden)

Golden Technologies Co. (Golden)

Quantum Peripherals (Louisville)

Schuller Int'l Inc. (Littleton)

TDA Research Inc. (Wheat Ridge)

Connecticut

ABB C-E Services, Inc. (Windsor)

Steven Winter Associates, Inc. (Norwalk)

Torrington Co. (Torrington)

United Technologies/Pratt \& Whitney (East Hartford)
Delaware

E. I. DuPont de Nemours (Wilmington)

E. I. DuPont de Nemours

(Fluorochemicals)

Guidance \& Control Systems-Litton

Rodel, Inc. (Newark)

District of Columbia

American Iron \& Steel Institute

SPI/SPFD

Structural Insulated Panel Assoc.

Florida

GELTECH, Inc./LMES (Orlando)

Martin Marietta Elect. Info \& MissileLMES (Winter Garden)

National High Magnetic Field Laboratory (Tallahassee)

Pratt \& Whitney (W. Palm Beach)

Siemens Westinghouse Power Corp. (Orlando)

Westinghouse Electric Corp.

(W. Palm Beach)

Georgia

Advanced Engineered Materials (Atlanta)

AMERCORD, Inc. (Lumber City)

BRH, Inc. - LMES (Lawrenceville)

Ceradyne, Inc. (Scottdale)

Ionic Atlanta, Inc. (Atlanta)

Institute of Paper Science \& Tech. (Atlanta)

ITI MOVATS-LMES (Kennesaw)

Microcoating Technologies (Chamblee)

Motorola (Lawrenceville)

RCF Seals (Vidalia)

Rolls Royce, Inc. (Atlanta)

Thermal Ceramics (Augusta)

\section{Illinois}

A. Finkl \& Sons (Chicago)

Adtech Nepth, Inc. (Oak Park)

AlliedSignal (Des Plains)

Alloy Eng. \& Casting (Champagne)

Caterpillar, Inc./Tech. Ctr. (Peoria)

Wagner Castings Co. (Decatur)

$$
\text { Indiana }
$$

AlliedSignal (South Bend)

Allison Engine Co. (Indianapolis)

Cummins Engine Co. (Columbus)

Dana Corp. (Richmond)

Firestone Building Products Co. (Camel)

GM Corporation/Delco Remy

(Andersonville)

Haynes International (Kokomo)
Kentucky

ARCO Aluminum, Inc. (Louisville)

Florida Tile Industries (Lawrenceburg)

Lexmark (Lexington)

Machining Research, Inc. (Florence)

Stoody Co. (Bowling Green)

Louisiana

Dow Chemical Co. (Plaquemine)

Lockheed Martin Michould Space

Systems (New Orleans)

Maine

Surmet Corporation (Burlington)

Maryland

Krispin Technologies (Rockville)

RCMA (Rockville)

Refractory Composites Inc. (Glen Burnie)

W. R. Grace \& Co. /Conn. (Columbia)

Massachusetts

American Superconductor Corp. (Westborough)

Busek Co. (Natick)

Ceramics Process Systems Corp. (Cambridge)

Chand Kare Tech. Ceramics (Worcester)

Foster-Miller, Inc. (Waltham)

GTE Laboratories, Inc. (Waltham)

JPS Elastomerics Co. (Holyoke)

MicroE (Natuk)

Morton Advanced Materials (Woburn)

Norton Co. (Northboro)

Norton/TRW Ceramics (Northboro)

Osram Sylvania/Univ. of Massachusetts At Lowell (Lower)

Refractory Testing Associates (Chestnut Hill)

Sarnafil, Inc. (Canton)

Single Ply Roofing Institute (SPRI) (Needham)

SSG, Inc. (Wilmington)

Textron Specialty Materials (Lowell)

Uniform Metal Tech. LLC (Watertown)

\section{Michigan}

Bosch Braking Systems (Farmington Hills)

Chrysler Corporation (Highland Park)

Detroit Diesel Corp. (Detroit)

Dow Corning Corp. (Midland)

Duro-Last Roofing, Inc. (Saginaw)

Eaton Corp. (Southfield)

Energy Conversion Devices, Inc. (Troy)

Ford Motor Company (Ann Arbor)

GM AC-Rochester (Flint)

GM Powertrain Group (Pontiac)

GM Research \& Development (Warren) 


\section{Michigan (continued)}

Hoskins Mfg. (Hamburg)

Howmet (Whitehall)

Metal Building Manufacturers Assoc. (Traverse City)

Metallamics Inc. (Traverse)

Parker Abex NWL (Kalamazoo)

Thixomat (Ann Arbor)

Valenite, Inc. (Troy)

Minnesota

3M (St. Paul)

FMC Naval Systems Division

(Minneapolis)

Mississippi

Alpha Optical Systems (Ocean Springs) Richard Knof McMullan (Decatur)

Missouri

McDonnell Douglas Corp. (St. Louis)

Montana

Anaconda Foundry Fab. (Anaconda)

Columbia Falls Alumin. (Columbia Falls)

New Hampshire

FLUENT Inc. (Lebanon)

Miniature Precision Bearings (Keene)

New Jersey

AlliedSignal (Morristown)

AT\&T Bell Laboratories (Murrary Hill)

Ceramic Magnetics, Inc. (Fairfield)

Certech, Inc. (WoodRidge)

Engelhard Corp. (Edison)

Exxon Research \& Eng. Co. (Annadell)

INRAD Inc. (Northvale)

Lucent Technologies (Murray Hills)

Materials Technology (Shresburg)

Mobil Technical Co. (Paulsboro)

Nanopowder Enterprises, Inc. (Piscataway)

NEC Research Inst. (Princeton)

Phone-Poulenc, Inc. (Cranbury)

Union Camp Corp. (Princeton)

\section{New Mexico}

Eberline Instruments (Santa Fe)

Environmental Tech. \& Education (Albuquerque)

\section{New York}

Advanced Refractory Tech., Inc. (Buffalo)

AKZO Nobel Chemicals, Inc. (Dobbs Ferry)

Applied Nano Metrics, Inc. (Stormville)

CMP Industries, Inc. (Albany)

Carborundum Co. (Niagara Falls)

Corning Inc. (Corning)

Eastman Kodak Co. (Rochester)

General Electric (Schnectedy)
Monofrax, Inc. (Falcomer)

ReMaxCo Technologies, Inc. (Kenmore)

Sulzer-Metco (Westbury)

T. J. Watson Research Center (Yorktown Heights)

X-Ray Optical Systems (Albany)

\section{North Carolina}

Cree Research, Inc. (Durham)

MicroMet Technology, Inc. (Matthews)

Selee Corp. (Hendersonville)

Teledyne Allvac (Monroe)

\section{Ohio}

Advanced Ceramics Corp. (Lakewood)

Eaton Corp. (Willoughby Hills)

Edison Welding Institute (Columbus)

Doehler-Jarvis Tech. (Toledo)

GE Aircraft Engines (Cincinnati)

Goodyear Tires \& Rubber Co. (Akron)

Lincoln Electric (Cleveland)

LTV Steel Co. (Independence)

Milacron, Inc. (Cincinnati)

Owens Corning Tech. Ctr. (Granville)

Park-Ohio Trans. (Cleveland)

Proctor \& Gamble (Cincinnati)

Sandusky Int'l. (Sandusky)

Rhenium Alloys, Inc. (Elyria)

Tosoh SMD, Inc. (Grove City)

Universal Energy Systems, Inc. (Dayton)

Western Environmental (Franklin)

\section{Pennsylvania}

AHT, Inc. (Chicora)

Advanced Technology Materials, Inc. (University Park)

Alcoa Tech. Center (Alcoa Center)

Aluminum Co. of America (Alcoa Ctr.)

Bethlehem Steel Corp. (Bethlehem)

Calgon Corp. (Pittsburgh)

Carlisle Syntec, Inc. (Carlisle)

Certainteed Corp. (Valley Forge)

Concurrent Technologies Corp. (Johnstown)

IBACOS (Pittsburgh)

J\&L Specialty Steel (Pittsburgh)

Kennametal, Inc. (Latrobe)

Leroy A. Landers (Philadelphia)

PPG Industries, Inc. (Lancaster)

SB\&TD Business Systems (Lancaster)

Thermacore, Inc. (Lancaster)

Westinghouse Science \& Tech Ctr (Pittsburgh)

\section{Rhode Island}

Quadrax Corp. (Portsmouth)

Tennessee

American Magnetics (Oak Ridge)

American Matrix, Inc. (Knoxville)

AMS (Knoxville)

Barrett Firearms Mfg., Inc. (Murfreesboro)

Browne Tech. (Nashville)

Carroll Kenneth Johnson (Oak Ridge)

Cavin Consulting Services (Knoxville)

Church \& Dwight Co., Inc. (Knoxville)
Complete Machine Co. (Clinton)

Computational Mechanics Corp. (Knoxville)

Computational Systems (Knoxville)

Coors Electronic Package (Chattanooga)

CTI, Inc. (Knoxville)

DG Trim Products (Alcoa)

Eastman Kodak/Chemical (Kingsport)

Environmental Engineering Group, Inc. (Knoxville)

Environment Systems Corp., — LMES (Knoxville)

Forged Performance Products, Inc. (Oak Ridge)

ForMat Industries — LMES (Oak Ridge)

Gaylon's Machine Shop (Sweetwater)

Great Lakes Research (Elizabethon)

H. R. DeSelm (Knoxville)

Herbert E. McCoy, Jr. (Clinton)

IMTech Company (Knoxville)

IntraSpec, Inc. (Oak Ridge)

J. A. Martin (Knoxville)

Jeffrey Chain Corp. (Morristown)

Mahle, Inc. (Morristown)

Materials Eng., \& Testing (Oak Ridge)

Microbial Insight, Inc. (Knoxville)

Nano Instruments, Inc. (Knoxville)

Oak Ridge Housing Authority (Oak Ridge)

Oxyrase (Knoxville)

Photogen, Inc. (Knoxville)

ReMaxCo Technologies (Kingston)

SENES Oak Ridge, Inc. (Oak Ridge)

Smelter Service Corp. (Mt. Pleasant)

Smith \& Nephew (Memphis)

Standard Aero (Maryville)

Status Technologies (Knoxville)

Technology for Energy Corp. (Knoxville)

Textron Specialty Materials Div.Avco (Nashville)

Tennessee Center for R\&D (Knoxville)

Third Millenium Tech., Inc. (Knoxville)

TTE Diecasting (Oak Ridge)

Vamistor Corp. (Sevierville)

Texas

Agriboard Industries (Electra)

CarboMedics, Inc. (Austin)

Electrospace Systems, Inc - LMES (Richardson)

Exxon Corp. (Houston)

Ludlum Measurement Inc. (Sweetwater)

Robert Hageman (Austin)

Southwest Research Institute (San Antonio)

Stone \& Webster Eng. (Houston)

Texas Instruments (Dallas)

Tycom Corporation (Austin)

Utah

LoTEC, Inc. (Salt Lake City)

Mantic Corp. (Salt Lake City)

Virginia

B\&W Nuclear Technologies (Lynthburg) Babcock \& Wilcox (Lynchburg)

Institute for Defense Analyses

(Alexandria) 
Virginia (continued)

Energy Recovery, Inc. (Virginia Beach)

E. R. Johnson Associates, Inc. (Fairfax)

Hy-Tech Res. Corp. (Radford)

Materials Modification, Inc. (Fairfax)

Materials Technologies of Virginia (Blacksburg)

Philip Morris (Richmond)

Reynolds Metals Company (Richmond)

Soil and Land Use Tech. (McLean)

\section{Washington}

Chiroscience R\&D Inc./Darwin Molecular (Bothell)

Galvalume Sheet Producers of North America (Kalama)

Kyocera Industrial Ceramics Corp. (Vancouver)
Weyhaeuser Co. (Tacoma)

$$
\text { West Virginia }
$$

INCO Alloys (Huntington)

Weirton Steel Corp. (Weirton)

Wisconsin

Federal Mogul Power Train Systems (Manitowoc)

Tower Automotive (Milwaukee)

Waukesha Electric Systems (Waukesha)

Other Government Facilities - 15

Federal Highway Administration (Virginia)
Idaho National Engineering Laboratory (Idaho Falls)

Los Alamos National Laboratory (Los Alamos)

NASA Langley Research Ctr. (Virginia)

NASA Lewis Research Ctr. (Ohio)

National Highway Traffic Safety (DC)

Naval Post Graduate School (California)

Naval Research Laboratory (DC)

NIST (Maryland)

Sandia National Laboratories (Livermore)

Space and Navel Warfare Systems Center (California)

U.S. Army Research Lab (Virginia)

U.S. Bureau of Mines (New York)

U.S. FDA (Maryland)

U.S. Naval Academy (Maryland) 
UNIVERSITIES - 156

Alabama

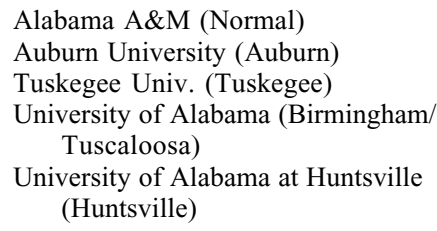

Arizona

Arizona State (Tempe)

Univ. of Arizona (Tucson)

California

California Inst. of Tech. (Pasadena)

California State Univ. (Los Angeles)

Stanford Univ. (Stanford)

Univ. of Calif., Berkeley

Univ. of Calif, Davis

Univ. of Calif., Irvine

Univ. of Calif., Los Angeles

Univ. of Calif., San Diego

Univ. of Calif., Santa Barbara

Univ. of Calif., Santa Cruz

Univ. of S. Calif. (Los Angeles)

\section{Colorado}

Colorado School of Mines (Golden) Univ. of Denver

Connecticut

Univ. of Connecticut (Storrs) Yale Univ. (New Haven)

\section{Delaware}

Univ. of Delaware (Newark)

District of Columbia

The George Washington Univ. Howard University

\section{Florida}

Florida A\&M Univ. (Tallahassee) Florida Atlantic Univ. (Boca Raton) Florida International Univ. (Miami) Florida Solar Energy Center (Cape Canaveral)

Florida State Univ. (Tallahassee)

Univ. of Central Fl. (Orlando)

Univ. of Florida (Gainesville)

Univ. of Salford (West Palm Beach)

\section{Georgia}

Georgia Inst. of Tech. (Atlanta)

$$
\text { Hawaii }
$$

Univ. of Hawaii (Honolulu)

\author{
Illinois
}

Illinois Inst. of Tech. (Chicago)

Northwestern Univ. (Evanston)

S. Ill. Univ.. (Carbondale)

Univ. of Ill. (Urbana)

\section{Indiana}

Indiana University (Indianapolis)

Purdue Univ. Calumet (Hammond)

Purdue Univ. (West Lafayette)

Univ. of Notre Dame (South Bend)

$$
\text { Iowa }
$$

Iowa State Univ. (Ames)

\section{Kansas}

Kansas State Univ. (Manhatten)

Wichita State University (Wichita)

$$
\text { Kentucky }
$$

Berea College (Berea)

Eastern KY State (Richmond)

Univ. of KY (Lexington)

Univ. of Louisville (Louisville)

Western Kentucky Univ. (Bowling Green)

Louisiana

Louisiana State Univ./A\&M College (Baton Rouge)

Southern Univ. (Baton Rouge)

Univ. of New Orleans (New Orleans)

\section{Maine}

Univ. of Maine (Orono)

Maryland

Johns Hopkins Univ. (Baltimore)

Univ. of Maryland (College Park)

\section{Massachusetts}

Boston Univ. (Boston)

Clark Univ. (Worcester)

Harvard Univ. (Cambridge)

Mass. Inst. of Tech. (Cambridge)

Mt. Holyoke College (South Hadley)

Northeastern (Boston)

Tufts Univ. (Medford)

Univ. of Mass. (Amherst)

\section{Michigan}

Michigan State Univ. (East Lansing)

Michigan Tech. Univ. (Houghton)

Univ. of Michigan (Ann Arbor)

Wayne State Univ. (Detroit)

Western Michigan Univ. (Kalamazoo)
Minnesota

Univ. of Minnesota (Minneapolis)

Mississippi

Mississippi College (Clinton)

Mississippi State Univ. (Miss. State)

Missouri

Lincoln Univ. (Jefferson City)

Univ. of Missouri (Columbia)

Univ. of Missouri (Rolla)

Washington Univ. (St. Louis)

Montana

Univ. of Montana (Missoula)

Nebraska

Univ. of Nebraska-Lincoln (Lincoln)

Nevada

Univ. of Nevada, Reno (Reno)

New Hampshire

Dartmouth College (Hanover)

New Jersey

New Jersey Inst. of Tech. (Newark)

Princeton Univ. (Princeton)

Rutgers Univ. (Piscataway)

Stevens Inst. of Tech. (Hoboken)

\section{New Mexico}

New Mexico Tech. (Socorro)

New Mexico State (Las Cruces)

Univ. of NM (Albuquerque)

\section{New York}

Alfred Univ. College of Ceramics (Alfred)

Clarkson Univ. (Potsdam)

Cornell Univ. (Ithaca)

Polytechnic Univ. (Brookland)

Rensselaer Polytechnic Inst. (Troy)

Rochester Inst. of Tech. (Rochester)

State Univ of NY (Stonybrook)

Univ. of Rochester (Rochester)

\section{North Carolina}

Appalachian State Univ. (Boone)

Duke Univ. (Durham)

North Carolina A\&T State Univ.

(Greensboro)

North Carolina State Univ. (Raleigh)

Univ. of North Carolina (Chapel Hill)

Univ. of North Carolina (Charlotte)

UNC School of Dentistry (Chapel Hill) 
North Dakota

Univ. of North Dakota/Energy \&

Environmental Research (Grand Forks)

\section{Ohio}

Case Western Reserve Univ. (Cleveland)

Denison Univ. (Granville)

John Carroll Univ. (University Heights

Kent State Univ. (Kent)

Ohio State Univ. (Columbus)

Ohio Univ. (Athens)

Univ. of Cincinnati (Cincinnati)

Univ. of Akron (Akron)

Univ. of Dayton (Dayton)

Wright State Univ. (Dayton)

Oklahoma

Oklahoma State Univ. (Stillwater)

Univ. of Oklahoma (Oklahoma City)

\section{Oregon}

Oregon Graduate Institute (Portland)

Oregon State Univ. (Corvallis)

Portland State Univ. (Portland)

\section{Pennsylvania}

Carnegie Mellon Univ. (Pittsburgh)

Drexel (Philadelphia)

Lehigh Univ. (Bethlehem)

Pennsylvania State Univ. (University Park)

Univ. of Pennsylvania (Philadelphia)

Univ. of Pittsburgh (Pittsburgh)
Rhode Island

Brown Univ. (Providence)

South Carolina

Clemson Univ. (Clemson)

Univ. of S. Carolina (Columbia)

South Dakota

S. Dakota State Univ. (Brookings)

Tennessee

East Tennessee State Univ. (Johnson City)

Fisk Univ. (Nashville)

Jacksboro State Area Vocation School (Jacksboro)

Maryville College (Maryville)

Tennessee State Univ. (Nashville)

Tennessee Tech. Center (Knoxville)

Tennessee Tech. Univ. (Cookeville)

Univ. of Memphis (Memphis)

Univ. of Tennessee (Knoxville)

Vanderbilt Univ. (Nashville)

Texas

Rice Univ. (Houston)

Texas A\&M Univ. (College Station)

Univ. of Houston (Houston)

Univ. of North Texas (Denton)

Univ. of Texas (Arlington, Austin, El Paso)
Utah

Univ. of Utah (Salt Lake)

Virginia

Norfolk State Univ. (Norfolk)

VPI \& State Univ. (Blacksburg)

Univ. of Virginia (Charlottesville)

Washington \& Lee Univ. (Lexington)

Washington

Gonzaga University (Spokane)

Univ. of Washington (Seattle) Washington

State Univ. (Pullman)

West Virginia

West Virginia Univ. (Morgantown)

Wisconsin

Marquette Univ. (Milwaukee)

Univ. of Wisconsin (Madison)

\section{International Universities - 1}

University of British Columbia 


\section{APPENDIX B}

FY 1998 NONPROPRIETARY RESEARCH PROPOSALS 


\begin{tabular}{|c|c|c|c|c|}
\hline $98-002$ & NP & Allison Engine Co. (07) & Groseclose, Lance & MIRUC \\
\hline $98-003$ & NP & $\begin{array}{l}\text { University Of } \\
\text { Massachusetts (6) }\end{array}$ & Sung, Changmo & MAUC \\
\hline $98-004$ & NP & $\begin{array}{l}\text { Advanced Ceramics } \\
\text { Corporation }(01)\end{array}$ & Lennartz, Jeffrey W. & MCAUC \\
\hline $98-005$ & NP & New Mexico Tech (07) & Alam, Mansoor & RSUC \\
\hline $98-006$ & NP & Univ. Of Kentucky (12) & Davis, Burtron H. & RSUC \\
\hline $98-007$ & NP & Univ. Of Illinois (16) & Economy, James & TPUC \\
\hline $98-008$ & NP & $\begin{array}{l}\text { Bosch Braking Systems } \\
\text { Corp. (01) }\end{array}$ & Wang, Weicherng (Alex) & TPUC \\
\hline $98-009$ & NP & $\begin{array}{l}\text { Univ. Of Mass (7) /Osram } \\
\text { Sylvania (1) }\end{array}$ & Sung, Changmo & MAUC \\
\hline $98-010$ & NP & lowa State Univ. (03) & Akinc, Mufit & TPUC \\
\hline $98-011$ & NP & Alliedsignal, Inc. (25) & Bhattacharya, Arun K. & RSUC \\
\hline $98-012$ & NP & $\begin{array}{l}\text { Univ. Of Tenn. (50) (Ut } \\
\text { Space Inst.) }\end{array}$ & Mccay, MARY HELEN & RSUC \\
\hline
\end{tabular}

\section{Proposal Title}

Thermophysical Characterization of $\mathrm{Ti}_{3} \mathrm{SiC}_{2}$ and H-PHASES (Ex. $\mathrm{Ti}_{2} \mathrm{AIN}, \mathrm{Ti}_{2} \mathrm{AIC}, \mathrm{Ti}_{2} \mathrm{SnC}$ and $\mathrm{Ti}_{2} \mathrm{PbC}$

Evaluation of Machining Techniques for Passage Generation in Silicon Nitride Ceramic Components

Electron Holography and Nanoanalysis of Magnetic Thin Films of Co-Cr-Pt for Hard Disk Technology

Improved Barrier Coatings for Continuous $\mathrm{SiC}$ Fibers in Ceramic Composites

Residual Stress in Deuterium Irradiated Copper Coatings Deposited on 316L

Stainless Steel Substrates by RF Magnetron Sputtering

Residual Stress Measurement of Plasma Sprayed YSZ Coating

Thermal Conductivity Measurement of AIB2 Single Crystal Flake Reinforced Aluminum

Matrix Composites

In-Stop Rotor Surface Temperature

Measurement Using Array of Single Point IR Sensors

High Resolution Transmission Electron

Microscopy and Nanoanalysis of

Polycrystalline Alumina

Thermal Expansion Anisotropy of Boron Doped Molybdenum Silicides

Evaluation of Residual Stresses in a Turbine Disk for aircraft Engine Application

Reduction of Residual Stresses in Laser Induced Surface Improved Layers 


\begin{tabular}{|c|c|c|c|c|c|}
\hline $98-013$ & NP & Univ. Of Tenn. (51) & Liaw, Peter K. & MAUC & $\begin{array}{l}\text { Characterization of Aluminide and Platinum } \\
\text { Aluminide Coatings }\end{array}$ \\
\hline $98-014$ & NP & Univ. Of Tenn. (52) & Liaw, Peter & DUC & $\begin{array}{l}\text { Phase Diagram Study of the Binary Cr-Ta } \\
\text { Systems }\end{array}$ \\
\hline $98-015$ & NP & Penn State Univ (23) & Mayo, Merrilea J. & TPUC & $\begin{array}{l}\text { Effect of Tantala, Niobia and Alumina } \\
\text { Additions on the Thermal Conductivity, } \\
\text { Toughness, Oxygen lon Conductivity and } \\
\text { Thermal Ageing Behaviour of Yttria } \\
\text { Stabilized Zirconia }\end{array}$ \\
\hline $98-016$ & NP & Georgia Tech (29) & Carter, W. B. & MCAUC & $\begin{array}{l}\text { Mechanical Properties of YSZ-Alumina Thin } \\
\text { Films Deposited via Combustion CVD }\end{array}$ \\
\hline $98-017$ & NP & $\begin{array}{l}\text { Cummins Engine Co., Inc. } \\
\text { (14) }\end{array}$ & England, R. D. & RSUC & $\begin{array}{l}\text { Axial Strains in Friction Welded Piston } \\
\text { Variations with Forming Process }\end{array}$ \\
\hline $98-018$ & NP & $\begin{array}{l}\text { General Motors R\&D } \\
\text { Center (03) }\end{array}$ & Morelli, D. & TPUC & $\begin{array}{l}\text { High Temperature Thermal Properties of } \\
\text { Advanced Thermoelectric Materials }\end{array}$ \\
\hline $98-019$ & NP & Lotec, INC. (02) & Nageswaran, R. & TPUC & $\begin{array}{l}\text { Evaluation of NZP-Ceramic Based Thermal } \\
\text { Barrier Coatings for Turbine Applications }\end{array}$ \\
\hline $98-020$ & NP & $\begin{array}{l}\text { University Of Cincinnati } \\
(07)\end{array}$ & Lin, Jerry $Y$. & DUC & $\begin{array}{l}\text { Mechanism of Template Removal in Zeolite } \\
\text { Membrane Synthesis }\end{array}$ \\
\hline $98-021$ & NP & $\begin{array}{l}\text { Universal Energy Systems, } \\
\text { Inc. (03) }\end{array}$ & Bhat, Deepak G. & MIRUC & $\begin{array}{l}\text { Tribological and Microstructural } \\
\text { Characterization of Soft Lubricant Coatings } \\
\text { for Metal-Cutting and Metal-Forming } \\
\text { Applications }\end{array}$ \\
\hline $98-022$ & NP & $\begin{array}{l}\text { Nasa Lewis Research } \\
\text { Center (07) }\end{array}$ & Jacobson, Nathan & DUC & $\begin{array}{l}\text { In-Situ High-Temperature Phase Analysis in } \\
\text { the Ti-Al-O System }\end{array}$ \\
\hline $98-025$ & NP & $\begin{array}{l}\text { Westinghouse Electric } \\
\text { Corp. (9) }\end{array}$ & Choudry, Mahmood S. & MCAUC & $\begin{array}{l}\text { Effect of Steam Side Oxidation/Corrosion on } \\
\text { Thickness Loss, Microstructure, and } \\
\text { Mechanical Properties of Ni-Base Alloys }\end{array}$ \\
\hline $98-026$ & NP & Lehigh University (4) & Williams, David B. & MAUC & $\begin{array}{l}\text { Telepresence Microscopy for Undergraduate } \\
\text { \& Graduate Education }\end{array}$ \\
\hline 98-029 & NP & Ppg Industries, Inc. (05) & Burgman, Jerry & TPUC & $\begin{array}{l}\text { Temperature Increase in Automotive } \\
\text { Coatings Upon Stone Impact }\end{array}$ \\
\hline $98-030$ & NP & Thixomat, Inc. (01) & Walukas, D. Matthew & MIRUC & Wear Properties of Die Cast and Semi-Solid \\
\hline
\end{tabular}




\begin{tabular}{|c|c|c|c|c|c|}
\hline 98-031 & NP & $\begin{array}{l}\text { Univ. Of Tenn. (53) (Ut } \\
\text { Space Inst) }\end{array}$ & Dahotre, Narendra & MCAUC & Ultrahard Ceramic Coatings on Metals \\
\hline 98-032 & NP & Cummins Engine Co. (15) & England, Roger & RSUC & $\begin{array}{l}\text { The Effects of the Limited Area Etch on } \\
\text { Cylinders and Flat Plates on X-ray Diffraction } \\
\text { Stress Depth Profile Measurements }\end{array}$ \\
\hline $98-033$ & NP & $\begin{array}{l}\text { Oak Ridge National } \\
\text { Laboratory(8) }\end{array}$ & Lowndes, Douglas & MAUC & $\begin{array}{l}\text { Epitaxial P-type ZnO Film Growth on } \\
\text { Sapphire Substrate by Pulsed Laser Ablation }\end{array}$ \\
\hline $98-034$ & NP & Coors Tech. Cer. (16) & Johanns, Dave & MCAUC & $\begin{array}{l}\text { Mechanical Characterization of Porous } \\
\text { Alumina Support }\end{array}$ \\
\hline 98-035 & NP & Penn State Univ (24) & Trolier-Mckinstry, Susan & RSUC & $\begin{array}{l}\text { In-Situ Field-Dependent X-ray Diffraction } \\
\text { Analysis of Epitaxial Relaxor-Lead Titanate } \\
\text { Thin Film Actuators }\end{array}$ \\
\hline $98-036$ & NP & $\begin{array}{l}\text { Univ. Of Tenn. (54) (Ut } \\
\text { Space Inst) }\end{array}$ & Dahotre, Narendra & MAUC & Ultrahard Ceramic Coatings on Metal \\
\hline $98-037$ & NP & Univ. Of Virginia (02) & Jesser, William A. & TPUC & $\begin{array}{l}\text { Thermoelectric Materials for Waste Heat } \\
\text { Power Generation }\end{array}$ \\
\hline $98-038$ & NP & $\begin{array}{l}\text { Mobil Technology } \\
\text { Company (01) }\end{array}$ & Kalyanaraman, Mohan & DUC & $\begin{array}{l}\text { Study of Phase Changes in Zeolites at High } \\
\text { Temperatures and Varying Atmospheres }\end{array}$ \\
\hline 98-039 & NP & Valenite, Inc. (05) & Narasimhan, Krishnan & MCAUC & $\begin{array}{l}\text { Study of Mechanical Properties of CVD Hard } \\
\text { Coatings on Cutting Tools }\end{array}$ \\
\hline $98-040$ & NP & Surmet Corporation (01) & Sastri, Suri A. & MCAUC & Reactive Braze Alloy Development \\
\hline $98-041$ & NP & $\begin{array}{l}\text { Energy Conversion } \\
\text { Devices, Inc. (02) }\end{array}$ & Strand, Dave & TPUC & $\begin{array}{l}\text { Thermal Characterization of Phase-Change } \\
\text { Optical Disk Materials }\end{array}$ \\
\hline $98-042$ & NP & Ford Motor Company (10) & Shelef, Mordecai & MAUC & $\begin{array}{l}\text { Distribution of Copper and Lanthanum in } \\
\text { ZSM-5 Zeolite }\end{array}$ \\
\hline $98-043$ & NP & $\begin{array}{l}\text { Rensselaer Polytechnic } \\
\text { Inst. (06) }\end{array}$ & Interrante, Leonard V. & MCAUC & $\begin{array}{l}\text { Oxidatively Stable Interphases for } \mathrm{SiCf} / \mathrm{SiCm} \\
\text { Composites }\end{array}$ \\
\hline $98-044$ & NP & Univ. Of Tenn. (56) & Wunderlich, B. & TPUC & $\begin{array}{l}\text { Analysis of Steady State During } \\
\text { Temperature-modulation in Various } \\
\text { Commercially Available DSC }\end{array}$ \\
\hline
\end{tabular}




\begin{tabular}{|c|c|c|c|c|c|}
\hline $98-045$ & NP & $\begin{array}{l}\text { Federal Mogul Power } \\
\text { Train Sys (01) }\end{array}$ & Winter, John S. & DUC & $\begin{array}{l}\text { Measuring Residual Stresses in Electroplated } \\
\text { Ceramic Chrome Coatings Using X-Ray } \\
\text { Techniques }\end{array}$ \\
\hline $98-046$ & NP & $\begin{array}{l}\text { Georgia Institute Of Tech } \\
(30)\end{array}$ & Melkote, Shreyes & MCAUC & $\begin{array}{l}\text { Surface Generation Mechanisms in Hard } \\
\text { Turning: Characterization of Workpiece } \\
\text { Microstructure }\end{array}$ \\
\hline $98-047$ & NP & Tower Automotive (01) & Noruk, Jeffrey & RSUC & $\begin{array}{l}\text { Comparison of Tailor Welded Blank Sample } \\
\text { Residual Stresses }\end{array}$ \\
\hline $98-048$ & NP & Ford Motor Company (11) & Narula, Chaitanya Kumar & MAUC & $\begin{array}{l}\text { Microstructural Characterization of Diesel } \\
\text { Nox Reduction Catalyst Formulations }\end{array}$ \\
\hline $98-049$ & NP & Plasma Coatings, Inc. (01) & Nava, Yrene L. & TPUC & $\begin{array}{l}\text { Thermal Conductivity of Polymer-Treated } \\
\text { Thermal Spray Coatings }\end{array}$ \\
\hline $98-050$ & NP & University Of Kentucky (13) & Dickey, Elizabeth & RSUC & YAG-A1203 Residual Stress \\
\hline $98-051$ & NP & $\begin{array}{l}\text { Louisiana State University } \\
\text { (7) }\end{array}$ & Ma, En (Evan) & MCAUC & $\begin{array}{l}\text { Mechanical Properties of Bulk } \\
\text { Nanocomposites }\end{array}$ \\
\hline $98-052$ & NP & Univ. Of Tenn. (55) & Devine, Michael D. & MAUC & $\begin{array}{l}\text { Characterization of Novel Nanostructured } \\
\text { Materials }\end{array}$ \\
\hline $98-054$ & NP & Univ. Of Illinois (17) & Devor, Richard E. & RSUC & $\begin{array}{l}\text { Machining-Induced Residual Stresses from } \\
\text { Turning of AISI } 4340\end{array}$ \\
\hline $98-055$ & NP & $\begin{array}{l}\text { Wichita State University } \\
(01)\end{array}$ & Chaudhuri, Jharna & DUC & $\begin{array}{l}\text { Determination of the Coefficient of Thermal } \\
\text { Expansion of Selected Substrate Materials } \\
\text { Used to Grow GaN Epitaxial Layers }\end{array}$ \\
\hline $98-056$ & NP & $\begin{array}{l}\text { Alfred University/Spawar } \\
\text { (1) }\end{array}$ & Misture, Scott & RSUC & $\begin{array}{l}\text { Electric Field and Stress Dependence of } \\
\text { Lattice Parameters in High Strain PMN } \\
\text { Ceramics }\end{array}$ \\
\hline $98-057$ & NP & Alfred University (12) & Misture, Scott & DUC & $\begin{array}{l}\text { Site Occupancy in Copper Ferrite Phase } \\
\text { Using Anomalous Synchrotron Scattering }\end{array}$ \\
\hline $98-058$ & NP & N. C. State University (14) & Kasichainula, Jag & RSUC & Multilayer Diamond Coatings \\
\hline $98-059$ & NP & Hypernex, Inc. (01) & Kozaczek, Kris J. & MCAUC & $\begin{array}{l}\text { Nondestructive Detection of Fatigue Damage } \\
\text { in Metal Alloys }\end{array}$ \\
\hline
\end{tabular}




\begin{tabular}{|c|c|c|c|c|c|}
\hline $98-060$ & NP & Penn State Univ. (25) & Queeney, Richard & RSUC & $\begin{array}{l}\text { Predicting Residual Stresses and } \\
\text { Dimensional Changes in Thermal and } \\
\text { Mechanically Processed Metals }\end{array}$ \\
\hline $98-061$ & NP & Kansas State Univ. (3) & Edgar, James H. & MAUC & $\begin{array}{l}\text { Composition and Crystal Structure of Boron } \\
\text { Gallium Nitride Thin Films on Sapphire and } \\
6 \mathrm{H}-\text { Silicon Carbide Substrates }\end{array}$ \\
\hline $98-062$ & NP & Univ. Of Washington (5) & Bordia, Rajendra K. & TPUC & $\begin{array}{l}\text { Phase Transitions in the Sr and Mg Doped } \\
\text { Lanthanum Gallate } \\
\text { La1-xSrxGa1-yMgy03-d -- LSGM }\end{array}$ \\
\hline $98-063$ & NP & Penn State Univ. (26) & Singh, Jogender & DUC & $\begin{array}{l}\text { Gravity Effects on the Development of Weld } \\
\text { Pool and the Microstructural Behavior on } \\
304 \text { Stainless Steel }\end{array}$ \\
\hline $98-064$ & NP & Machining Research, Inc. & Christopher, John & MIRUC & Cylindrical Grinding Hardened Steels \\
\hline $98-065$ & NP & Drexel University (3) & Barsoum, Michel W. & DUC & $\begin{array}{l}\text { High Temperature } X-\text { Ray and Neutron } \\
\text { Diffraction and Characterization of } \mathrm{Ti}_{3} \mathrm{Al}_{2-}{ }^{-} \mathrm{N}_{2}\end{array}$ \\
\hline $98-066$ & NP & Clemson Univ. (16) & Lee, Burtrand I. & TPUC & $\begin{array}{l}\text { Thermal Behavior of Sol-Gel Derived } \\
\text { Phosphate Ceramics }\end{array}$ \\
\hline $98-067$ & NP & $\begin{array}{l}\text { Univ. Of California - Davis } \\
\text { (1) }\end{array}$ & Gates, Bruce C. & MAUC & $\begin{array}{l}\text { Imaging of }\{\text { Os } 5 \mathrm{C}(\mathrm{CO}) 14\} 2-\text { and Os5 Clusters } \\
\text { on Metal Oxide Supports }\end{array}$ \\
\hline $98-069$ & NP & Saint-Gobain Norton (13) & Pujari, Vimal Kumar & MAUC & Structural Characterization of NBD-300 $\mathrm{SI}_{3} \mathrm{~N}_{4}$ \\
\hline $98-070$ & NP & $\begin{array}{l}\text { Microcoating } \\
\text { Technologies (1) }\end{array}$ & Shanmugham, Subu & MCAUC & $\begin{array}{l}\text { CCVD Oxide Interfaces for Nicalon/SiC } \\
\text { Composites }\end{array}$ \\
\hline $98-071$ & NP & Northwestern Univ. (6) & Faber, Katherine $\mathrm{T}$. & TPUC & $\begin{array}{l}\text { Thermal Conductivity Measurements of } \\
\text { Plasma Sprayed Coatings }\end{array}$ \\
\hline $98-072$ & NP & Columbia University (1) & Hong, Shane Y. & RSUC & $\begin{array}{l}\text { Residual Stresses in Parts Produced by Dry } \\
\text { and Cryogenic Machining }\end{array}$ \\
\hline $98-073$ & NP & $\begin{array}{l}\text { N. C. St. Univ/Cummins } \\
\text { Engine Co. (1) }\end{array}$ & Shih, A. (Nc)/Gust, D. (Cum) & MIRUC & $\begin{array}{l}\text { Investigation of Grinding Debris Assist } \\
\text { Dressing for Cost-Effective Machining of } \\
\text { Zirconia }\end{array}$ \\
\hline $98-074$ & NP & Univ. Of Connecticut (03) & Schulte, Sandy C. & MAUC & Nanoscale Orthorhombic ZIRCONIA \\
\hline $98-075$ & NP & $\begin{array}{l}\text { Carpenter Certech } \\
\text { Engineered (1) }\end{array}$ & Krug, Gene & MCAUC & Casting Core Stability \\
\hline
\end{tabular}




\begin{tabular}{|c|c|c|c|c|c|}
\hline $98-076$ & NP & Tycom Corporation (1) & Gibbs, Max & RSUC & $\begin{array}{l}\text { Residual Stresses Developed in Micro Drills } \\
\text { and Routers from Grinding }\end{array}$ \\
\hline $98-077$ & NP & Hy-Tech Research Corp (2) & Klepper, Chris & MAUC & $\begin{array}{l}\text { Fabrication of Wire Load for Soft X-Ray } \\
\text { Source }\end{array}$ \\
\hline $98-078$ & NP & $\begin{array}{l}\text { Ornl-Chemical \& } \\
\text { Analytical Sci. (7) }\end{array}$ & Moyer, Bruce A. & TPUC & $\begin{array}{l}\text { Thermogravimetric Analysis of the Hydration } \\
\text { of Novel Ion Exchange Resins }\end{array}$ \\
\hline $98-079$ & NP & Southern University (4) & Mirshams, Reza & MCAUC & $\begin{array}{l}\text { The Modeling of Dynamically Recrystallized } \\
\text { Titanium-Aluminide Alloy Using Dislocation } \\
\text { Density in Numerical Simulation }\end{array}$ \\
\hline $98-080$ & NP & Ford Motor Company (12) & Narula, Chaitanya K. & MAUC & $\begin{array}{l}\text { Microstructural Studies on the Aging of } \\
\text { Diesel Lean Burn NOx Catalyst Formulations } \\
\text { of the Type Pt/n\%SiO2-Al203 }\end{array}$ \\
\hline $98-081$ & NP & Univ. Of Alabama (12) & Rigsbee, Michael J. & MAUC & $\begin{array}{l}\text { Metastable Tetragonal Formation and } \\
\text { Transformation in Reactive Sputter } \\
\text { Deposited Zirconia Coatings }\end{array}$ \\
\hline $98-082$ & NP & $\begin{array}{l}\text { Univ. Of California - Davis } \\
\text { (2) }\end{array}$ & Gates, Bruce C. & MAUC & $\begin{array}{l}\text { TEM Imaging of Transition Metal Clusters } \\
\text { Supported on Metal Oxide and Zeolite } \\
\text { Supports }\end{array}$ \\
\hline $98-083$ & NP & $\begin{array}{l}\text { West Virginia University } \\
\text { (02) }\end{array}$ & Stiller, Alfred H. & DUC & $\begin{array}{l}\text { The Effect of Calcination Condition on the } \\
\text { Graphitizability of Novel Synthetic and Coal- } \\
\text { Derived Cokes }\end{array}$ \\
\hline $98-084$ & NP & Caterpillar Inc (08) & Readey, Michael J. & MIRUC & $\begin{array}{l}\text { Effect of Machining Parameters, Grain Size, } \\
\text { and Composition on the Scuffing Resistance } \\
\text { of Zirconia Materials }\end{array}$ \\
\hline $98-085$ & NP & Univ. Of Alabama (13) & Eberhardt, Alan W. & MCAUC & $\begin{array}{l}\text { Nano-Hardness and Nano-Stiffness of } \\
\text { Polyethylene in Regions of Delamination } \\
\text { Wear }\end{array}$ \\
\hline
\end{tabular}


APPENDIX C

FY 1998 RESEARCH PROJECT SUMMARIES, INDUSTRIES AND UNIVERSITIES 
C-2 


\title{
APPENDIX C. FY 1998 RESEARCH PROJECT SUMMARIES
}

\author{
INDUSTRIES
}

\section{Allison Engines, "Evaluation of Machining Techniques for Passage Generation in Silicon Nitride Ceramic Components," L. Groseclose and D. Parsons, HTML No. 98-002}

\section{MIRUC/MAUC/MCAUC}

\begin{abstract}
The machining of holes and passages into silicon nitride materials and components is frequently conducted for use in attachments and/or cooling features in turbine engine components. The ability to accomplish hole generation with accurate geometric positioning and minimal damage to the ceramic is an important characteristic for the successful implementation of ceramic components in advanced engines. The material used in this study was Kyocera SN252 $\mathrm{Si}_{3} \mathrm{~N}_{4}$. Three machining techniques were evaluated: plunge feed grinding, a peck-cycle downfeed grinding program, and a jig grind with a smaller diameter hole core drilled followed by grinding to the final hole diameter. A total of seven material systems were evaluated for hole backing to minimize chipping: machinable wax, epoxy, epoxy filled with alumina, Cerabend, fiberglass resin, Crystal Bond thermosetting epoxy, and polyester resin. Specimens with no backing were also evaluated. Three of these systems (unbacked, epoxy filled alumina, and Cerabend) demonstrated sufficient promise for machining evaluation. The specimens backed with the alumina-filled epoxy exhibited minimal chipping and high strengths in a C-ring test. The peck program provided good quality holes with the highest strengths observed for the machining conditions evaluated.
\end{abstract}

\section{Discussion}

The application of ceramic components to structural components for advanced gas turbine engines offers the potential for significant advantages relative to current metallic-based material systems. The key benefit is the ability to operate at high turbine inlet temperatures without resorting to complex air cooling arrangements. The increased operating temperature results in improved thermodynamic efficiency and enables engines to be produced with increased specific thrust, lower specific fuel consumption, and higher power density. The ceramic materials currently under development have excellent strength characteristics and oxidation/corrosion resistance up to $1500^{\circ} \mathrm{C}$ 


\section{Advanced Ceramics Corp., "Improved Barrier Coatings for SiC Fibers in Ceramic Composites," J. W. Lennartz, HTML No. 98-004}

\section{MCAUC}

This project was a NASA SBIR Phase II project. Silicon and boron nitride barrier layers in oxide and non-oxide matrices were developed and evaluated. The tensile testing part of this work was performed at the HTML.

CVD coatings of silicon and boron nitride (PBSiN) prepared at $1400^{\circ} \mathrm{C}$ were assessed as barrier layers in oxide and non-oxide matrices. Batch coating conditions were optimized for penetration of the fiber bundles and distribution across fabric sheets. It was demonstrated that fibers in woven fabric can be coated as uniformly as fibers in yarn.

BMAS- and SiC-matrix composites made from continuously-coated yarn exhibited greatest strength with PBSiN interfacial layers averaging $0.4 \mu \mathrm{m}$. Superior SiC composites resulted from batch-coated fabric having $0.1 \mu \mathrm{m}$ of coating. For either matrix, the preferred composition of PBSiN was shown to lie between 5 and $15 \mathrm{wt} . \% \mathrm{Si}$.

Suitably tailored PBSiN layers resulted in composite properties superior to those from conventional interfacial layers. SiC-matrix composites containing PBSiN displayed roomtemperature tensile strengths matching those of specimens containing pyrocarbon (PC) coatings. After annealing in air at $1200^{\circ} \mathrm{C}$ for $100 \mathrm{~h}$, the strength of PC specimens fell $80 \%$ while the strength of PBSiN-containing materials endured.

A scalable manufacturing facility has been proposed to produce coated fiber. The system can coat yarn or fabric strip continuously, apply multiple layers in line, and satisfy anticipated nearterm market demand. The proposed facility is shown to coat yarn or fabric with equal cost effectiveness and has potential to dramatically enhance the economics of coating fabric.

\section{Carpenter Certech Engineered, "Casting Core Stability," Gene Krug, HTML No. 98-075}

\section{MCAUC/TPUC/DUC}

Carpenter Certech is utilizing the high temperature compressive creep test to most accurately depict what is happening to our core products during the casting cycle. We are comparing the information from this test with results from the high temperature XRD. From this we hope to get a better understanding of the strengths and weaknesses of the core body. As a result of this testing we want to develop internal test methods as well as be pro-active in responding to changes in our customer's processes.

We have selected six basic core types from two main families of core bodies to compare and contrast compressive creep and cristobalite formation. Our main goal was to determine if our cores behave as expected, based upon chemistry and composition. The compressive creep test was chosen since it most accurately depicts the stresses that our core body is placed under during our customer's casting cycle. We believed that we should see differences between core bodies 
based upon the constituents. We now have a better understanding of the core body properties during the casting cycle.

This research is still on going and we have thus far received insightful information regarding our materials. The current information has been presented to customers who were anticipating our results. They were extremely pleased with the information received to this point. They were very interested in the further study intend to conduct and eagerly await our results. We hope to obtain more work from these customers through the knowledge gained at ORNL. This information will put us quite a few steps ahead of our competitors.

We are currently in the process of purchasing a creep tester for our facility. Through this study we have determined this instrument to be a valuable tool for the qualification of materials. Further testing is still required to establish the appropriate test methods and correlation to other available testing procedures.

\section{Caterpillar, Inc., "Self-Assembling Molecular Templates for Textured Thin Films," Jill E. Rockwood, HTML No. 97-066}

\section{MAUC/MCAUC/DUC}

This project was aimed at devising methods for depositing patterned ceramic thin films. Although a variety of methods have been used for their production, these methods have many drawbacks, including complicated and extremely slow procedures, use of hazardous chemicals and resolution limited to the micrometer scale. This provided an alternative method for the fabrication of nanopatterned ceramic thin films, solving the problems associated with current patterning technology. Patterned thin films are useful in a variety of applications such as creating optical, magnetic and ferroelectric films. In addition, fields such as the catalytic and tribological fields may also benefit from these films.

Relatively recently, self-assembling monolayers (SAMs) have been used to obtain thin films $(<10 \mathrm{~mm}$ thick). The ceramic films initially obtained from this method were dense, continuous films. However, the current trend is to create patterned films. In this work, an organic patterned template is deposited onto the desired substrate by immersion into a SAM solution. The template acts as an organic scaffolding upon which a ceramic thin film is deposited by immersion into a ceramic precursor solution. At relatively low temperatures $\left(300^{\circ} \mathrm{C}\right)$, the organic template is pyrolyzed, leaving behind a patterned ceramic thin film.

Preliminary results obtained with ORNL's Atomic Force Microscope demonstrated the feasibility of this chemical technique. Further research and results obtained at Caterpillar and the Technical University in Dresden, Germany have revealed successful ceramic coatings with nanoscale patterns.

Caterpillar is currently expanding the project to include formation of a variety of patterns on different substrates made from a wide range of thin film materials. 
Ford Research Lab., "Examination of Hot Spot Formation and Movement in Automotive Brake Rotors," Dale Hartsock, HTML No. 97-069

\section{TPUC}

The purpose of this research is to develop methods to detect and measure hot spotting in automotive brake rotors during a brake stop or drag. These hot spots result in pulsations in the brake torque which are usually called judder. Brake judder results in pulsations of the brake pedal, steering wheel, seat and in extreme cases the whole vehicle.

A high speed Galileo infrared camera (Ralph Dinwiddie of ORNL) was used to record images of a brake rotor during many different drags at several different conditions on a brake dynamometer. Over 43 of these images were examined for hot spots, temperature gradients and absolute temperatures. The visual images were also examined for generation and migration of the hot spots. Several issues were identified relative to the sole use of the Galileo camera for analyses purposes. First the absolute temperatures were in question since these depend on the emissivity of the rotor which changes during a brake drag. The Galileo camera must have the emissivity as input. Second only part of the rotor was visible at any given time so determination of how many hot spots existed and their location was in question. Third, the analyses of the temperatures from the infrared scans was tedious and did not lend itself to rapid data reduction.

As a result of this work, the development of a high speed two color infrared fiberoptic system was initiated. Using a two color system would eliminate the need to know the emissivity and thus eliminate this as an error. By using multiple sensors on both sides of the rotor and recording temperatures every few degrees of rotation, a image of the whole rotor could be generated for every revolution. This would give precise data on number and location of the hot spots. Since this would generate data in digital form, it would permit rapid data analyses.

To date, a single fiber optic two wavelength infrared sensor system has been demonstrated to prove the concept. Multiple sensors are being fabricated along with the associated electronics to digitize the data. A full system with multiple sensors on both sides of the rotor will be instituted in 1999 and this data will be coupled with the Galileo camera data to get both a visual and digital image of the brake system. This will be used to validate models used to predict thermoelastic instability. This work is expected to be completed by the end of 1999 or early 2000.

\section{Ford Motor Company, "Microstructural Characterization of Diesel Nox Reductin Catalyst Formulations," Chaitanya K. Narula, HTML No. 98-048}

\section{MAUC}

\section{Part I}

Preparation of $\mathrm{PrOy}\left(\mathrm{Pr}_{6} \mathrm{O}_{11}\right)$ or single-phase fluorite-structured $\mathrm{PrOy}-\mathrm{ZrO}_{2}$ mixed oxide, supported on high-surface-area g-alumina, was achieved for the first time by impregnation of galumina powder with $\operatorname{Pr}\left(\mathrm{OiC}_{3} \mathrm{H}_{7}\right)_{3}$ or a mixture of $\operatorname{Pr}\left(\mathrm{OiC}_{3} \mathrm{H} 7\right)_{3}$ and $\mathrm{Zr}\left(\mathrm{OiC}_{3} \mathrm{H}_{7}\right)_{4} \cdot \mathrm{iC}_{3} \mathrm{H}_{7} \mathrm{OH}$ and 
calcination at $600^{\circ} \mathrm{C}$. Subsequent calcination at $900^{\circ} \mathrm{C}$ caused partial transformation of $\operatorname{Pr}_{6} \mathrm{O}_{11}$ to $\mathrm{PrAlO}_{3}$ but only improved the crystallinity of the mixed oxide.Photographs of the $20 \mathrm{wt} \%$ sample, obtained with HRTEM, show small regions of $\mathrm{PrO}_{\mathrm{y}}-\mathrm{ZrO}_{2}$ material with a $\mathrm{Pr}: \mathrm{Zr}$ ratio of 1:1 on alumina particles (bottom photograph of Fig. C-1) as well as some large $\mathrm{PrO}_{\mathrm{y}}-\mathrm{ZrO}_{2}$ crystallites with particle size $\sim 0.8 \mathrm{~mm}$ (top photograph of Fig. C-1). Such a distribution can be expected because the g-alumina does not contain sufficient hydroxy groups to react with all alkoxy groups of the alkoxide precursors. This will result in the formation of $\mathrm{PrO}_{\mathrm{y}}-\mathrm{ZrO}_{2}$ particles anchored on $\gamma$-alumina as well as some free $\mathrm{PrO}_{\mathrm{y}}-\mathrm{ZrO}_{2}$ particles.
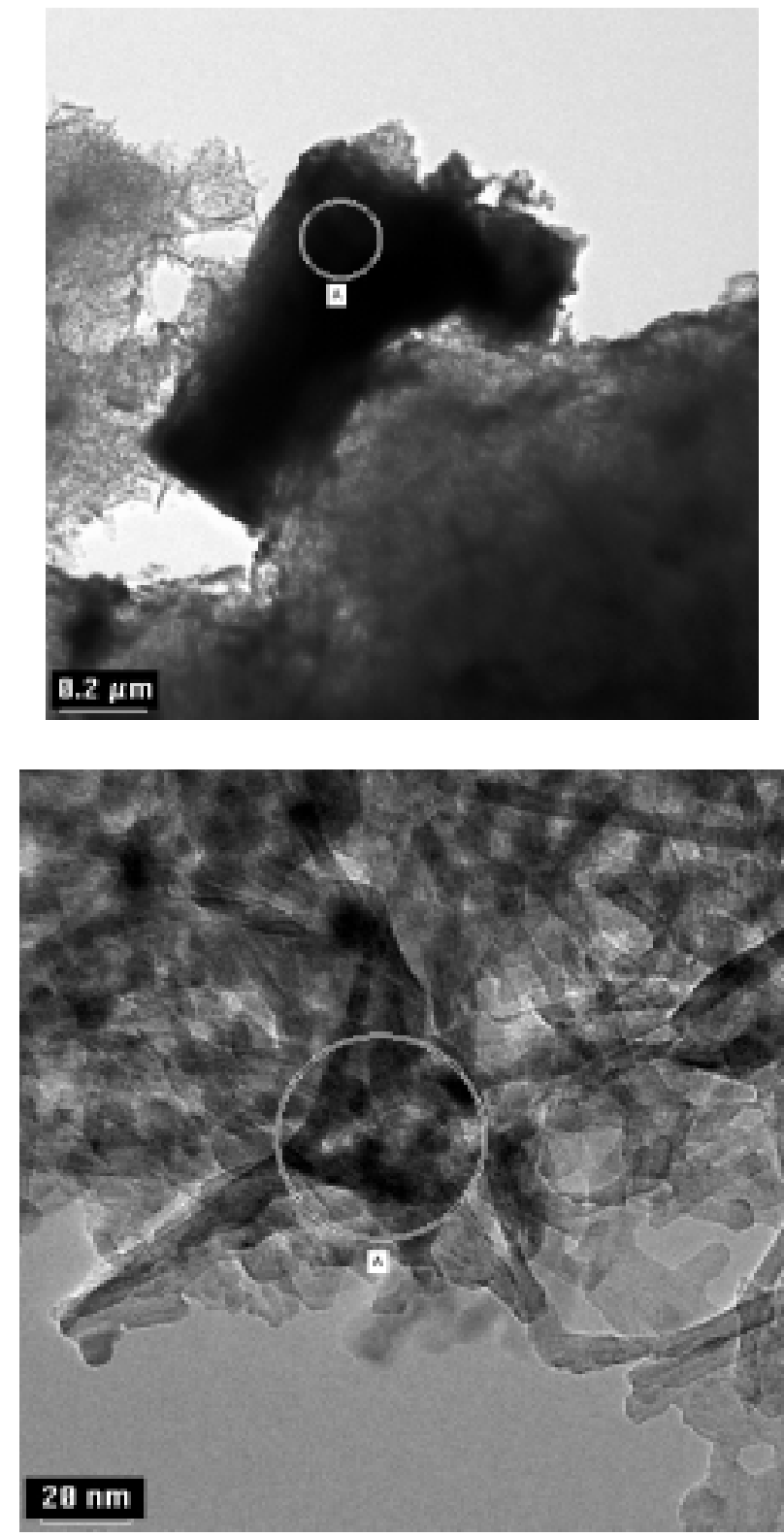

Fig. C-1. HRTEM of PrOy-ZrO $\mathrm{Zr}_{2}$ particles deposited on $\gamma$-alumina from alkoxides after calcining at $900^{\circ} \mathrm{C}$. The EDS of encircled areas show $\mathrm{PrO}_{\mathrm{y}}-\mathrm{ZrO}_{2}$. 
Further calcination at $1200^{\circ} \mathrm{C}$ led to complete transformation of $\operatorname{Pr}_{6} \mathrm{O}_{11}$ but only partial disproportionation of $\mathrm{PrO}_{\mathrm{y}}-\mathrm{ZrO}_{2}$ to $\mathrm{PrAlO}_{3}$ and $\mathrm{ZrO}_{2}$; transformation of $\gamma$ - to $\alpha$-alumina was also inhibited in the case of the mixed oxide. In contrast, there was no evidence of any crystalline phase containing praseodymium upon calcination of $\gamma$-alumina powder impregnated with a mixture of praseodymium nitrate and zirconium chloride in a 1:0 or 1:1 molar ratio. These results show that praseodymium oxide can be supported on alumina and stabilized against reaction with the alumina by the incorporation of zirconium in the form of the mixed oxide, $\mathrm{PrO}_{\mathrm{y}}-\mathrm{ZrO}_{2}$, provided it is deposited using alkoxide precursors. This stabilization should allow praseodymia to undergo redox processes and thus provide oxygen storage capacity when supported on alumina in a catalyst washcoat.

\section{Ford Motor Company, "Microstructural Studies on the Aging of Diesel Lean Burn $\mathrm{NO}_{\mathrm{x}}$ Catalyst Formulations of the Type Pt/n\% $\mathrm{SSiO}_{2}-\mathrm{Al}_{2} \mathrm{0}_{3}$," Chaitanya K. Narula, HTML No. 98-080}

\section{MAUC}

The incorporation of $>30 \%$ silica in alumina matrices prior to platinum impregnation improves the $\mathrm{NO}_{\mathrm{x}}$ conversion efficiency in $200-300^{\circ} \mathrm{C}$ range from 45 to $57 \%$ and reduces lightoff temperature. Further increase in the amount of silica to $50 \%$ is detrimental to $\mathrm{NO}_{\mathrm{x}}$ conversion efficiency. The $1 \mathrm{H}$ and 29Si NMR of the materials suggests that this trend is probably related to the surface acidity. The analyses of these materials by X-ray powder diffraction and electron microscopy do not reveal significant differences (see Fig. C-2).

Additional $\mathrm{NO}_{\mathrm{x}}$ conversion in $350-450^{\circ} \mathrm{C}$ range with a maximum of $30 \%$ at $400^{\circ} \mathrm{C}$ can be achieved if a rhodium impregnated $30 \%$ silica-alumina, $\mathrm{Rh}-30 \% \mathrm{SiO}_{2}-\mathrm{Al}_{2} \mathrm{O}_{3}$, is placed upstream of Pt-30\% $\mathrm{SiO}_{2}-\mathrm{Al}_{2} \mathrm{O}$. It is important to note that mixing Pt- $30 \% \mathrm{SiO}_{2}-\mathrm{Al}_{2} \mathrm{O}$ with Rh- $30 \% \mathrm{SiO}_{2}-$ $\mathrm{Al}_{2} \mathrm{O}$ has no effect on conversion efficiency or effective temperature range. 

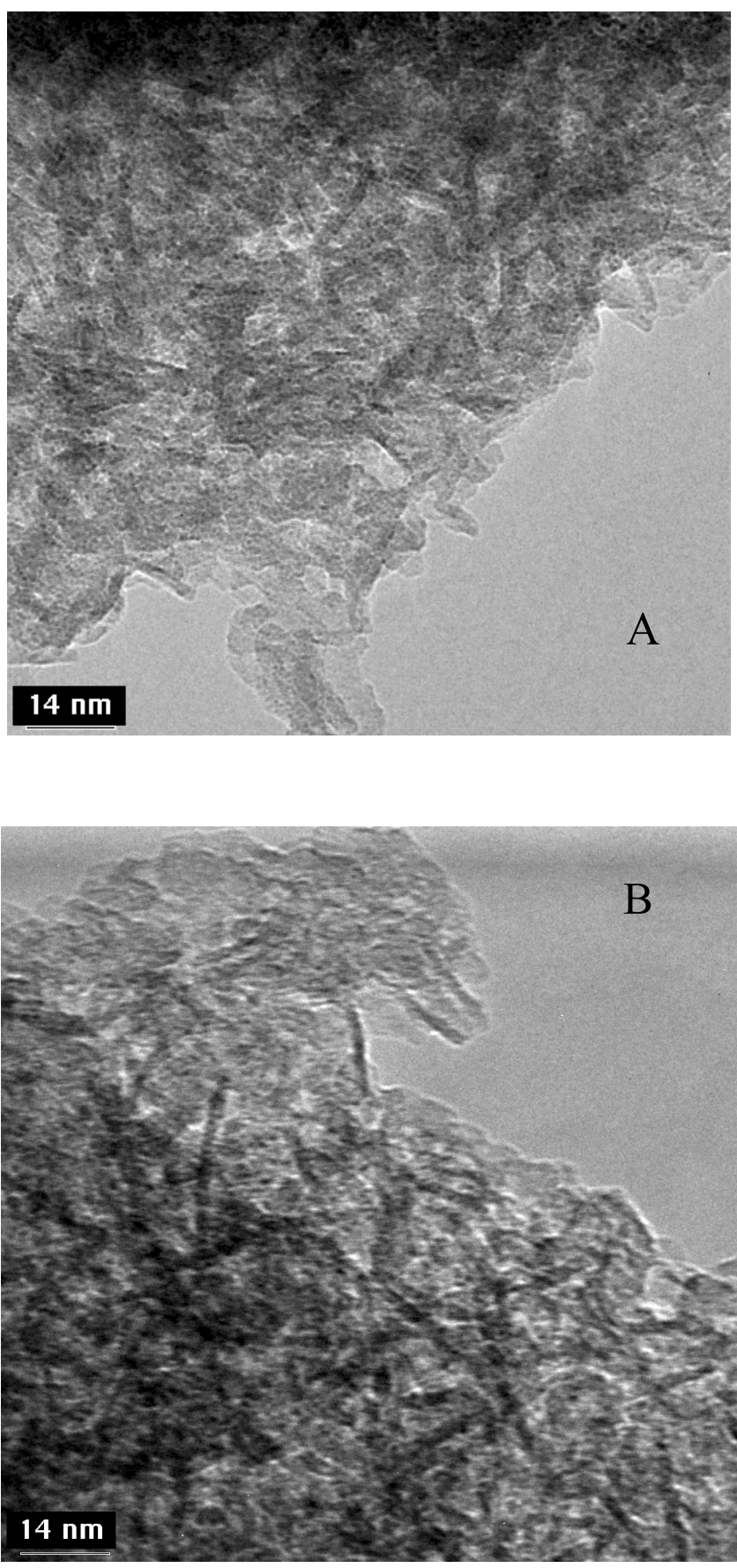

Fig. C-2. Transmission Electron Micrographs of (a) $1 \% \mathrm{Pt} / 30 \% \mathrm{SiO}_{2}-\mathrm{Al}_{2} \mathrm{O}$ and (b) $1 \% \mathrm{Pt} / 50 \% \mathrm{SiO}_{2}-\mathrm{Al}_{2} \mathrm{O}$. 
HY-Tech Research Corporation, "Fabrication of Ribbon Loads for Soft X-ray Sources", R.C. Hazelton, C.C. Klepper, J.J. Moschella, and E.J. Yadlowsky, F. Barakat, J. Niemel, HTML No. 97-057

\section{MAUC}

HY-Tech Research Corporation has a program in the area of plasma radiation sources (PRS). The most common PRS is the z-pinch where wire arrays are imploded (by means of mega-amp scale current pulses) to produce high density $\left(>10^{19} \mathrm{~cm}^{-3}\right)$, hot plasmas. These become intense $\mathrm{x}-$ ray sources for high energy density physics experiments. ${ }^{1}$ The objective of this program was to replace the wires in the loads with thin ribbons $\left(\leq 1 \_\mathrm{m}\right)$, whose composition can be varied over a larger range than can be achieved with alloy wires. The thin ribbons are expected to vaporize more quickly than the (10_m or larger) wires, thereby reducing precursor plasma formation, which can soften the implosion. The mixed composition should increase the x-ray yield by reducing the optical opacity of the source.

The ribbons, which were composed primarily of aluminum, with layers of such elements as $\mathrm{Si}$ and $\mathrm{Mg}$, either mixed in or layer onto the $\mathrm{Al}$, were fabricated at HY-Tech using a combined thermal and electron beam evaporator. In one design, $\mathrm{Mg}$ and $\mathrm{Si}$ were added to the $\mathrm{Al}$ in a layered structure. To analyze this structure, a unique electron probe setup was used at the HTML facility, to simultaneously study the composition and the microstructure of the $1 \times 1 \mathrm{~mm}$ crosssection ribbon. Figure C-3 shows elemental maps of the Al-Mg-Si-Al layered structure. The silicon on the right part of the image is from the Si substrate, which was used for this test sample. To image the individual layers on length scales present required a drastic reduction in the probe's sampling area all while keeping the probe energy sufficiently high to produce the detailed data the HTML facility was able to extract.

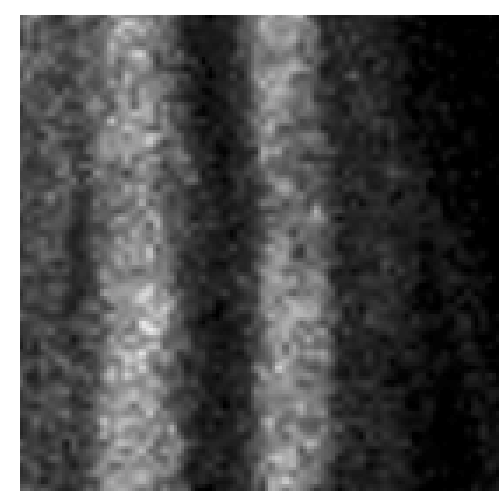

$\mathrm{Al}$

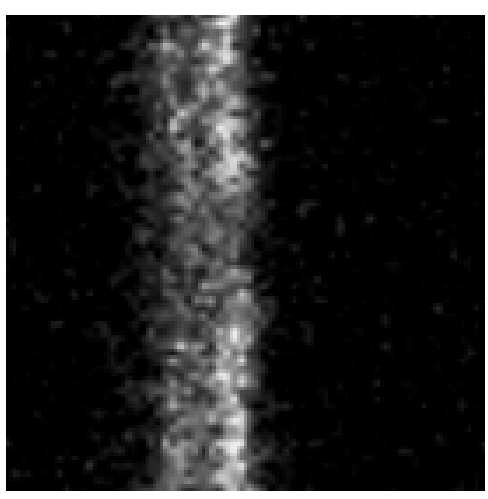

$\mathrm{Mg}$

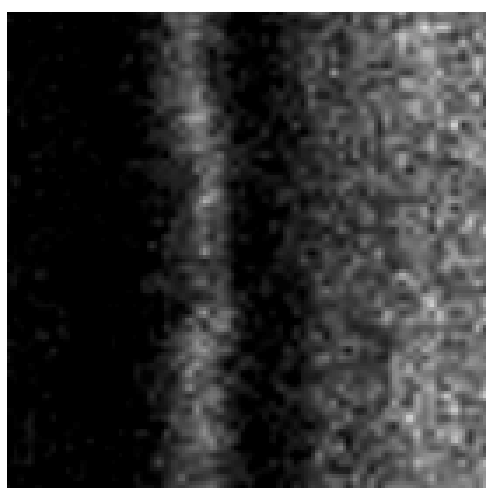

$\mathrm{Si}$

Fig. C-3. Elemental maps showing the discrete layers in the 1 micrometer ribbon.

\footnotetext{
${ }^{1}$ M.Keith Matzen, Phys. Plasmas 4 (5), May 1997
} 
Some of the ribbons made in the same batch as the test sample, which was analyzed at HTML, were loaded on the Double-Eagle pulsed power accelerator in San Leandro, CA. A typical soft x-ray spectrum obtained with a survey spectrometer is shown in Fig. C-4. Spectral features corresponding to all three elements present in the ribbon are seen in this spectrum. Analysis is under way to determine the radiation efficiency of the system and its components.

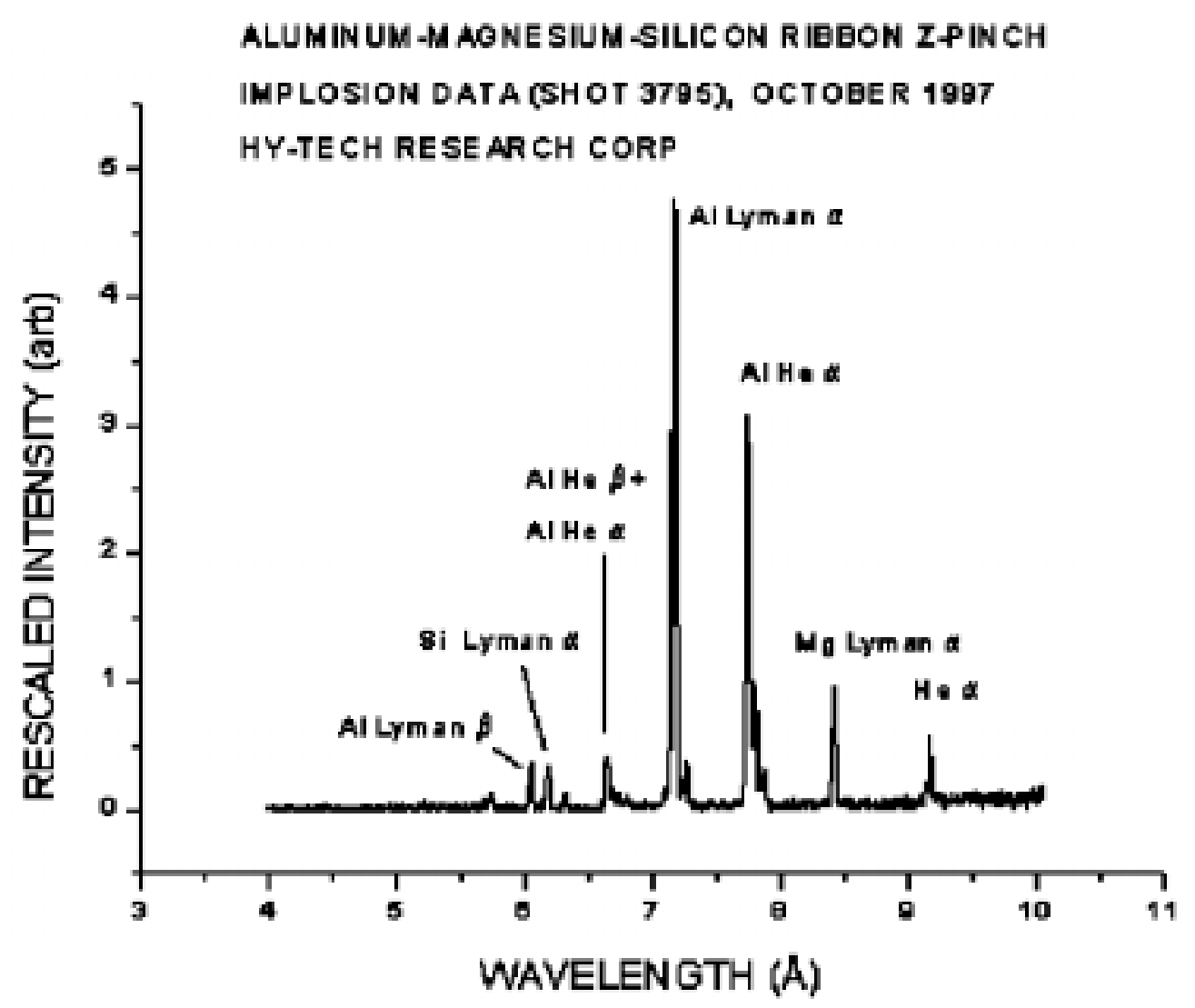

Fig. C-4. X-ray spectrum from the implosion of composite layered ribbons.

HY-Tech Research Corporation, "Fabrication of Wire Loads for Soft X-ray Sources," R. C. Hazelton, C. C. Klepper, J. J. Moschella, E. J. Yadlowsky, F. Barakat, and J. Niemel, HTML No. 98-077

\section{MAUC}

HY-Tech Research Corporation has a program in the area of plasma radiation sources (PRS). The most common PRS is the z-pinch. On today's pulsed power accelerators, multi-megaamperes flow though a z-pinch load, typically wire arrays, which implode producing high density $\left(>10^{19} \mathrm{~cm}^{-3}\right)$, hot plasmas. These become intense $\mathrm{x}$-ray sources for high energy density 
physics experiments. ${ }^{2}$ The purpose of this work was to produce z-pinch loads with thin $(5-25 \mu)$ aluminum wires and to uniformly coat them with a thin layer of an element such as $\mathrm{Si}$, which can be used as a seed for diagnostic purposes. The coating is carried out at HY-Tech using an electron beam evaporator and a specially designed rotisserie to expose all sides of the wires. Because of their fragile nature, special handling of the wires is an important part of the process. The goal of the analysis at HTML was to determine the quality and uniformity of the coating. An SEM was used for this work. Figure C-5 shows a few SEM images of a cross-section of a $25 \mu \mathrm{Al}$ wire, coated with $\sim 1 \mu \mathrm{Si}$. The non-uniformity of the coating is mostly due to the roughness of the commercially obtained wire. Based on the analysis, the process will be modified and new sample will be analyzed. One scheme will be to coat the wires with a layer of Al before depositing the Si. Adding a protective layer of $\mathrm{Al}$ on top of the Si will also be tried. After this series, 15 and $10 \mu$ wires will be produced and analyzed.
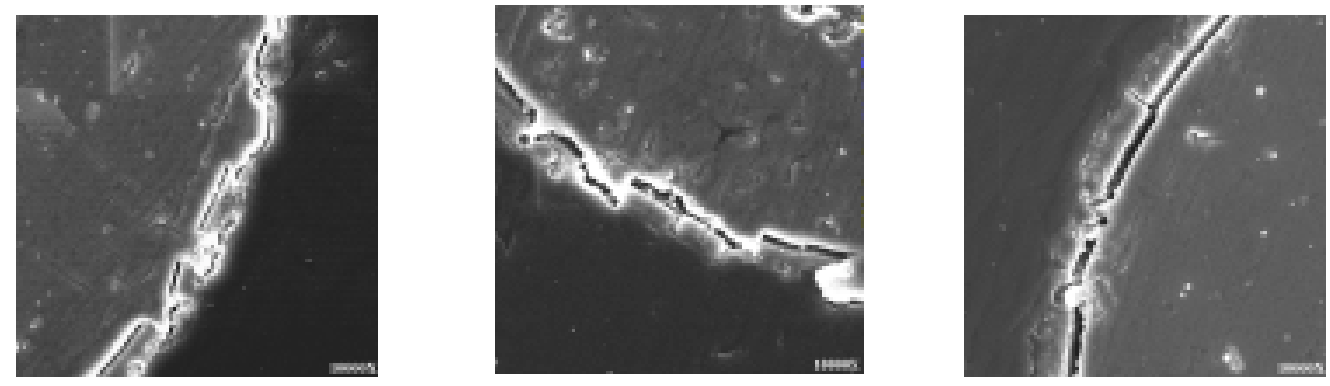

Fig. C-5. SEM images of a cross-section of a $25 \mu$ wire, coated with $\sim 1 \mu$ of Si. The voids are due to the Si layer attaching to the epoxy (used in the sample preparation) and separating from the Al wire substrate.

These wire loads were made, in part, for use in a newly commissioned z-pinch facility here at HY-Tech Research. They were in fact used in some of the first shots of this low current (0.6MA, 300kA) device. Figure C-6 shows a photograph of the imploding wires. This time-lapse photography was done on film. It is possible to see the individual wires from the early part and the collapsing pinch from the later part of the $150 \mathrm{~ns}$ pulse.

${ }^{2}$ M.Keith Matzen, Phys. Plasmas 4(5), May 1997. 

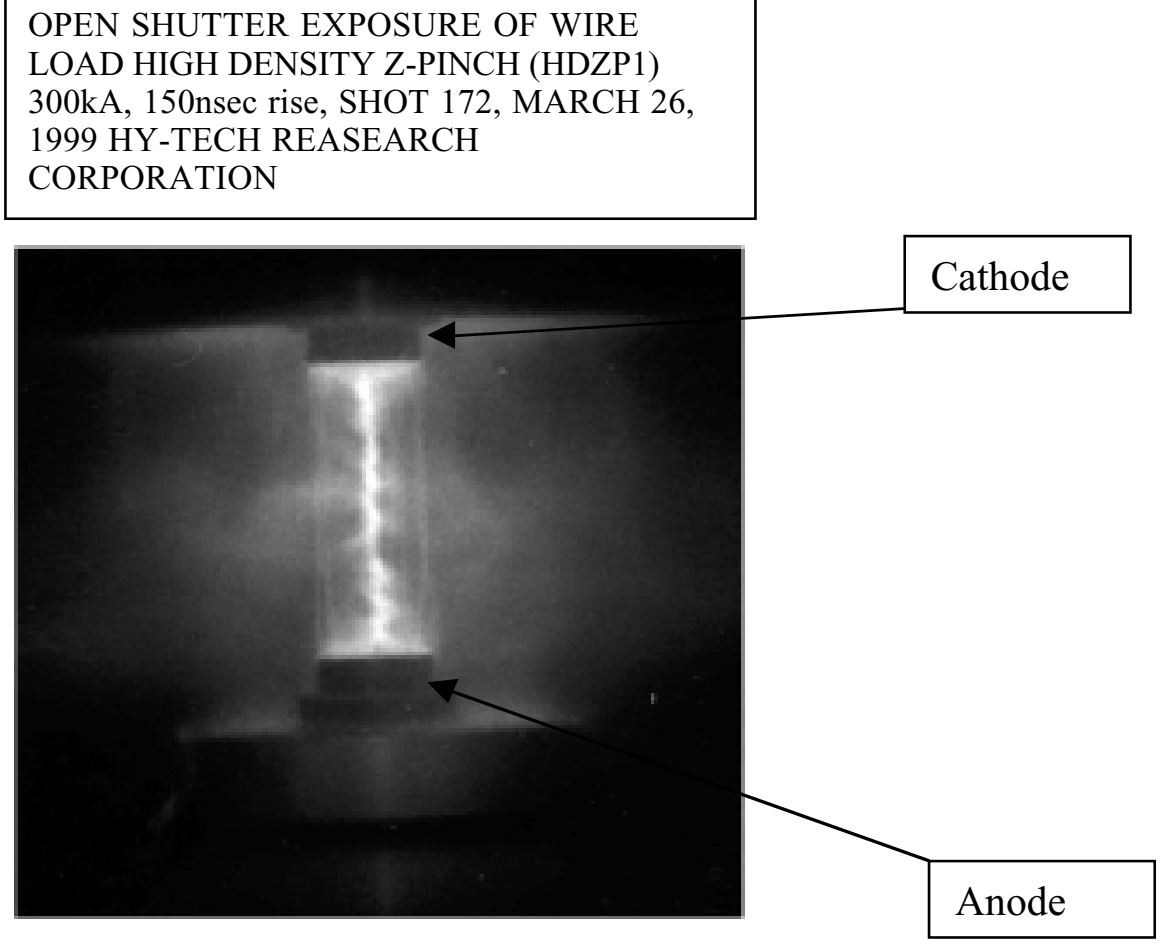

Fig. C-6. Time-lapsed image of z-pinch implosion, as titled. (The original wires are visible. Plasma instability related structures are seen in the imploded plasma.)

Inco Alloys International, Inc., "Stress Relaxation Behavior and Dimensional Stability of INCONEL Alloy 783," M. Fahrmann, HTML No. 97-072

\section{MCAUC}

INCONEL alloy 783 is a recently developed, low coefficient-of-thermal expansion, agehardenable superalloy, intended for use in static parts of steam and gas turbines. To promote usage of this alloy, design data is warranted concerning the behavior of this material under mechanical restraints (e.g., steam turbine bolts).

Material for this study was available from a production heat. The material was tested in the fully heat-treated condition, i.e., after a mill anneal and 3-step aging treatment. Testing encompassed dilatometry (to assess any dimensional changes in the virtually load-free case) and stress relaxation testing under conditions mimicking service conditions in terms of temperature and strain. 
Figure C-7 below depicts the typical stress relaxation curves obtained between 482 and $593^{\circ} \mathrm{C}$, exhibiting a two-stage behavior : (a) an initial transformation-controlled stage during which the stress increases due to shrinkage of the specimen (upon thermal exposure in the rig), (b) the classical creep-controlled stage of a continual stress decrease. Furthermore, by applying a simple phenomenological model, it was possible to deduce the magnitude of the transformation strains under load and compare those with the load-free case.

The generated data is useful from an engineering perspective in that it bounds possible stress changes in the material during service, but also from a scientific perspective in that it helped assessing the effects of stress on transformation strain in this particular material.

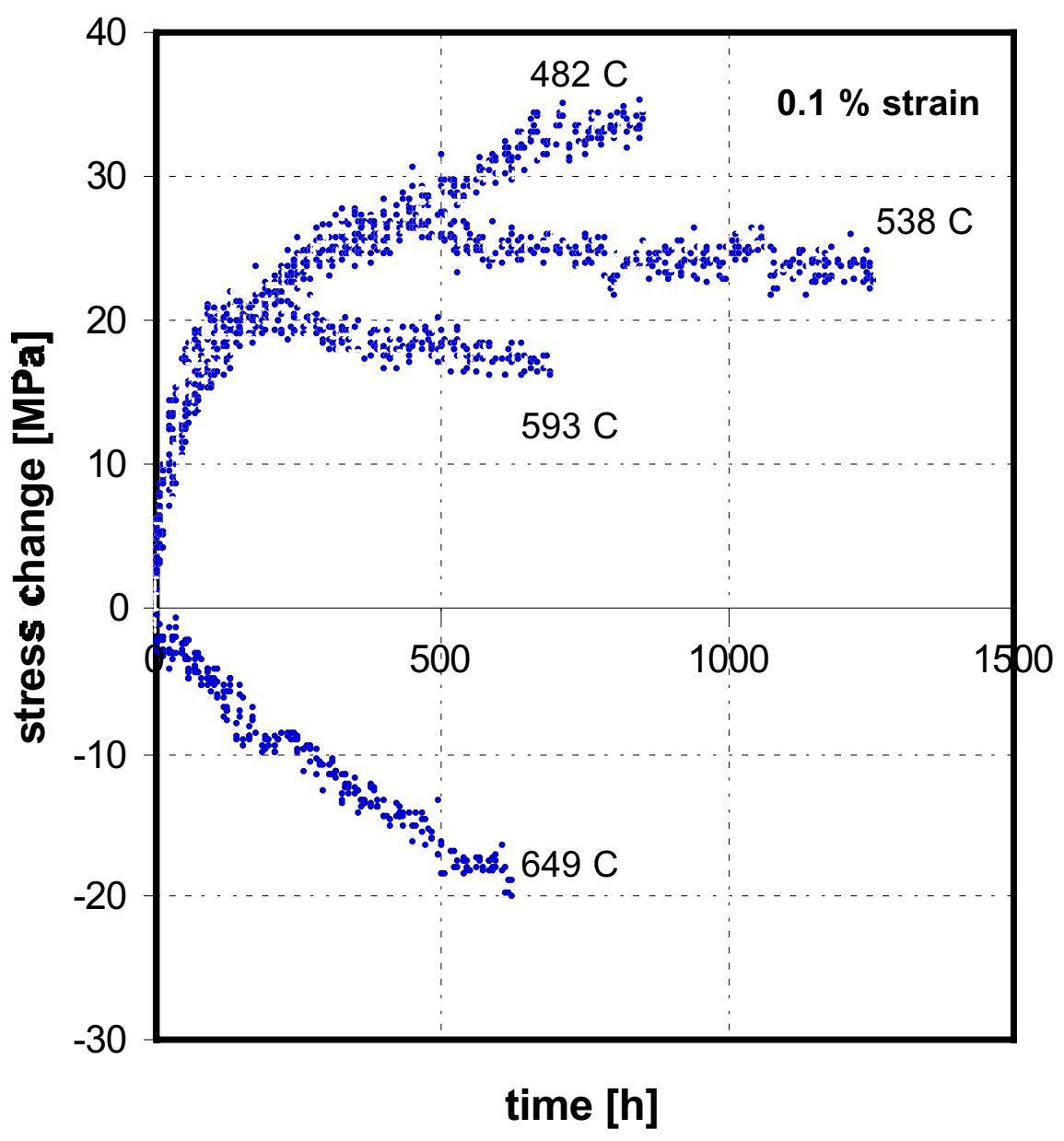

Fig. C-7. Stress-relaxation curves for INCONEL Alloy 783. 


\section{Kyocera Industrial Ceramics Corporation, "Effect of Grinding and Testing Procedures on Measured MOR of SN 282," D. Italiano, HTML No. 97-054}

\section{MCAUC}

The purpose of this work was to perform a preliminary assessment of the sensitivity of room temperature modulus of rupture testing results on the test bar preparation and testing facility. Though our material SN 282 is manufactured in only two locations, ground surfaces may be either prepared and/or evaluated by a third party, such as a customer or outside vendor. When trying to provide a product having a critical material property, it is important to be certain that all evaluations of that property are accurate. For this reason, our analysis included test bars prepared at Kyocera Industrial Ceramics Corporation (KICC), Chand Kare, and Kyocera Corporation (KC), with KICC, KC, and ORNL as evaluation sites.

All of the test bars used in this study were longitudinally ground according to the standard grinding procedure of the grinding facility. In each case, the grinding procedure is better than or equal to the surface quality intended by the ASTM C 1161-94 standard.

The presence of potential machining damage was investigated using two methods. Scanning Acoustic Microscopy was used to image sub-surface cracking due to grinding. It was determined that surface roughness limits imaging ability. Improved sample preparation is expected to improve resolution and future analysis results. Resonant Ultrasound Spectroscopy was also unable to detect presence of machining damage.

Grinding was evaluated by measuring surface profiles perpendicular to the grinding direction. Table C-1 shows that room temperature MOR is essentially independent of grinding within the reported range. This data represents lot 1 of material tested at KICC with the same JIS fixture.

Flexural strength was measured at three locations using two fixture types: the ASTM C 1161-94 design was used at ORNL and KICC, while the JIS design was used at KC and KICC. The data represents material lot 2. The difference in measured flexural strength was $21 \mathrm{MPa}$ for the JIS fixture and $79 \mathrm{MPa}$ for the ASTM test fixture, as shown in Table C-2. However, this level of disagreement is not surprising, as it was found to be typical, as reported in the 1993 ORNL publication, "Study of Flexural and Tensile Strength of US Silicon Nitrides". The Daytronics / microstrain gage method used in that study was employed in this study to show the effect of fixture alignment on true stress distribution. It has been determined that further analysis of this type is needed on all fixtures used in this study.

Table C-1. Surface profilometry

\begin{tabular}{ccccc}
\hline Grinding Location & Profilometry, ra (mic) & \multicolumn{3}{c}{ RT MOR (MPa) } \\
\hline & & Avg. & SD & $\mathrm{n}$ \\
KC & 0.448 & 648 & 81 & 10 \\
KICC & 0.0705 & 634 & 11 & 10 \\
Chand Kare & 0.4175 & 691 & 88 & 10 \\
\hline
\end{tabular}


Table C-2. Test

\begin{tabular}{ccccccc}
\hline Testing Location & \multicolumn{2}{c}{ ASTM RT MOR $(\mathrm{MPa})$} & \multicolumn{3}{c}{ JIS RT MOR (MPa) } \\
\hline Avg. & SD & $\mathrm{n}$ & Avg. & SD & $\mathrm{n}$ \\
KC & & & & 684 & 59 & 10 \\
KICC & 728 & 80 & 10 & 705 & 76 & 10 \\
ORNL / HTML & 649 & 59 & 9 & & & \\
\hline
\end{tabular}

LoTEC, Inc., "Evaluation of NZP-Ceramic Based Thermal Barrier Coatings for Turbine Applications," J. Cassell and R. Nageswaran, HTML No. 98-019

\section{TPUC/MAUC/MCAUC/DUC/RSUC}

Next generation aerospace propulsion and power generation systems have to meet requirements of higher efficiencies and longer lifetimes through increased firing temperatures and the use of better insulation. State-of-the-art thermal barrier coatings (TBCs) based on yttria partially-stabilized zirconia (YPSZ) are inadequate due to: (i) oxidation related problems, (ii) low thermo-chemical stability, and (iii) microstructural changes in-service. Two NZP ceramic compositions viz. BS-25 and CS-50 have attractive properties for such advanced TBC applications because of their high melting temperatures $\left(>1800^{\circ} \mathrm{C}\right.$ low thermal $(\sim 1.0 \mathrm{~W} / \mathrm{mK})$ and oxygen-ion conductivity, and excellent thermal shock resistance. However, the low thermal expansion and chemical incompatibility of NZPs with bond coat materials necessitates the use of NZP as a seal coat on top of YSZ or as discreetly or continuously graded layers along with YSZ.

Two main coating configurations: (i) NZP directly on top of the metallic substrate and (ii) an NZP-YPSZ graded coating on top of an intermediate bond coat were used to evaluate the NZP based TBCs for its basic functionality and potential for further development. Characterization of the NZP-ceramic based thermal barrier coatings was conducted at the High Temperature Materials Laboratory (HTML) of Oak Ridge National Laboratory. Free standing NZP coatings and the NZP coated composites were characterized for the following properties: (a) Phase Content: XRD; (b) Coating Microstructure and Density: SEM; and (c) Thermal Diffusivity and Conductivity: Laser Flash and DSC.

From the phase analyses and lattice parameter measurement studies, it was found that the BS-25 and CS-50 (NZP) compositions were intact after plasma spray forming, although a small amount of monoclinic zirconia was noticeable in the X-ray pattern. Table C-3 summarizes the lattice parameters of the BS-25 and CS-50 plasma-spray coatings. Comparison of this data with that of the standards clearly indicates that there is no change in the stoichiometry of the NZP compositions after plasma spraying. 
Table C-3. Lattice parameters of the NZP-TBC samples as compared to standards

\begin{tabular}{cccccc}
\hline Sample I.D. & $\mathrm{a}$ & $\mathrm{b}$ & Sample I.D. & $\mathrm{a}$ & $\mathrm{b}$ \\
\hline BS-25 (Standard) & 8.68 & 24.01 & CS-50 (Standard) & 8.72 & 23.15 \\
BS-TBC (Type 1) & 8.69 & 24.03 & CS-TBC (Type 1) & 8.71 & 23.13 \\
BS-TBC (Type 2) & 8.68 & 23.99 & CS-TBC (Type 2) & 8.71 & 23.15 \\
BS-TBC (Type 3) & 8.68 & 24.02 & CS-TBC (Type 3) & 8.71 & 23.14 \\
BS-TBC (Type 4) & 8.68 & 24.03 & CS-TBC (Type 4) & 8.71 & 23.11 \\
\hline
\end{tabular}

SEM observations revealed the characteristic melt-formed splats with a porous structure. The density of the coatings was determined to be $76 \%$ for BS-25 and $67 \%$ for CS-50 using estimates of porosity under SEM based image analysis. The NZP-YSZ graded coatings revealed good adherence with the underlying bond coat and a distinct two-phase microstructure in the regions of grading.

Thermal conductivity was computed from measurements of the thermal diffusivity and specific heat capacity of the freestanding NZP coatings (as a function of temperature), and the density of the coatings. The plot in Fig. C-8 shows a comparison of the thermal conductivities of the APS BS-25 and CS-50 free-standing coatings with that of a standard YSZ coating. The data for YSZ correspond to a low density APS coating, $4.7 \mathrm{gm} / \mathrm{cc}(\sim 77.5 \%)$, which is comparable to the density of BS-25 coating. The NZP coatings exhibit better thermal barrier characteristics compared to YSZ coatings.

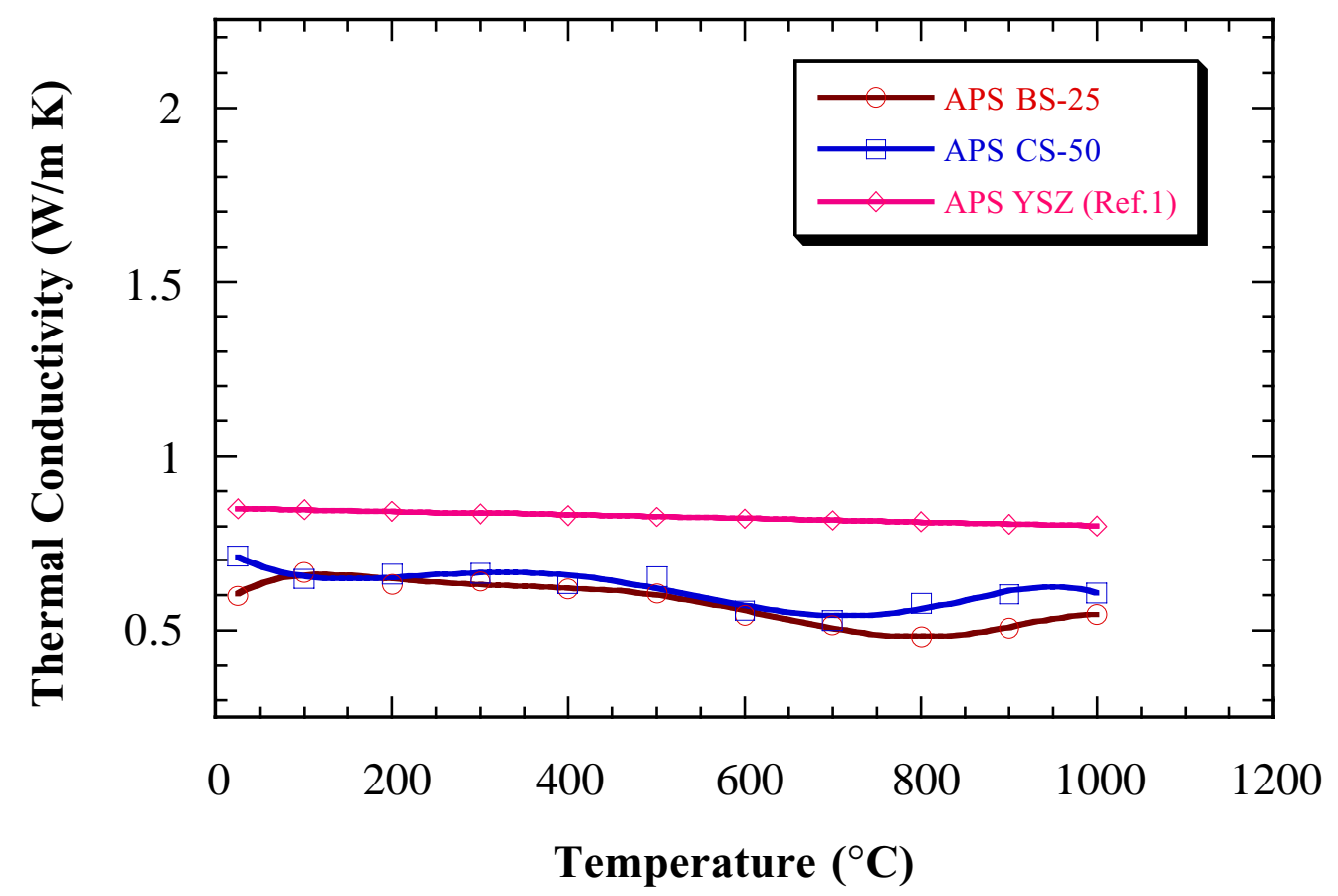

Fig. C-8. Temperature-dependent thermal conductivities of BS-25, CS-50, and YSZ TBCs. 
Norton Company, "Evaluation of Residual Stress in Silicon Nitride Ground with a New 'Innovative Grinding Wheel," R. H. Licht and D. Murphy, HTML No. 97-061

\section{RSUC/DUC}

Norton Company successfully completed a second phase of a Heavy Vehicle Propulsion System Materials Program to develop a novel grinding wheel for cost-effective cylindrical grinding of advanced ceramics [1]. The goal was to develop a cost-effective grinding wheel product that improved productivity but did not have an adverse effect on surface quality compared to standard commercial grinding wheel products.

During the development of cost-effective machining processes or development of new grinding wheels, it is critically important to maintain and characterize the surface integrity of the ground ceramic. In addition to damage and surface finish, surface integrity includes grindinginduced residual stress. Residual stress in ground surfaces can affect component strength and wear resistance. While grinding conditions and grit size are expected to affect surface residual stress, it was not certain whether different wheel-bond compositions alone would produce significantly different residual stress.

Four NT551 silicon nitride samples underwent residual stress testing at Oak Ridge National Lab's X-14A Synchrotron beamline at the National Synchrotron Light Source at Brookhaven National Lab. The experiment evaluated residual-stress characteristics of silicon nitride cylinders after grinding with the experimental metal-bonded and the standard resin-bonded wheels, in both the traverse and plunge modes. All residual stress testing and the final test report was completed by the research team of Dawn Murphy (Norton), Jianming Bai (BNL), and Thomas Watkins (ORNL) [2], and the results were included in the Innovative Grinding Wheel Phase II Final Report [1]. Grazing incidence X-ray diffraction (GIXD) measurements were conducted at ORNL's X-14A beamline at the National Synchrotron Light Source, BNL. A 6-axis goniometer was employed for the stress measurements using the " $\Omega$-goniometer geometry." Synchrotron radiation was used to provide the necessary intensity with the parallel beam optics required for these highly curved samples (6-mm-diameter).

A large residual stress gradient as a function of depth was observed in the axial direction of the samples. The resulting $\tau$ - and Z-profiles indicated that the residual stresses in the samples that were traverse-ground were effectively the same, independent of wheel type. In contrast, substantial differences in residual stresses were found in the samples that were plunge ground (Fig. C-9). The residual stresses at the surface were the severest in the sample that was plunge ground with a resin-bonded wheel. The residual stresses at the surface were the mildest in sample that was plunge ground with a metal-bonded wheel.

While high compressive surface stresses are considered beneficial in advanced ceramics, the specimen plunge-ground with the experimental metal-bonded wheel would be considered superior to the resin-bond wheel because of the relatively deeper tensile zone and lower stress gradient. The overall conclusion is that the experimental metal-bonded wheel does not appear to adversely affect the grinding residual stress profile and may have some benefit in plunge grinding. 


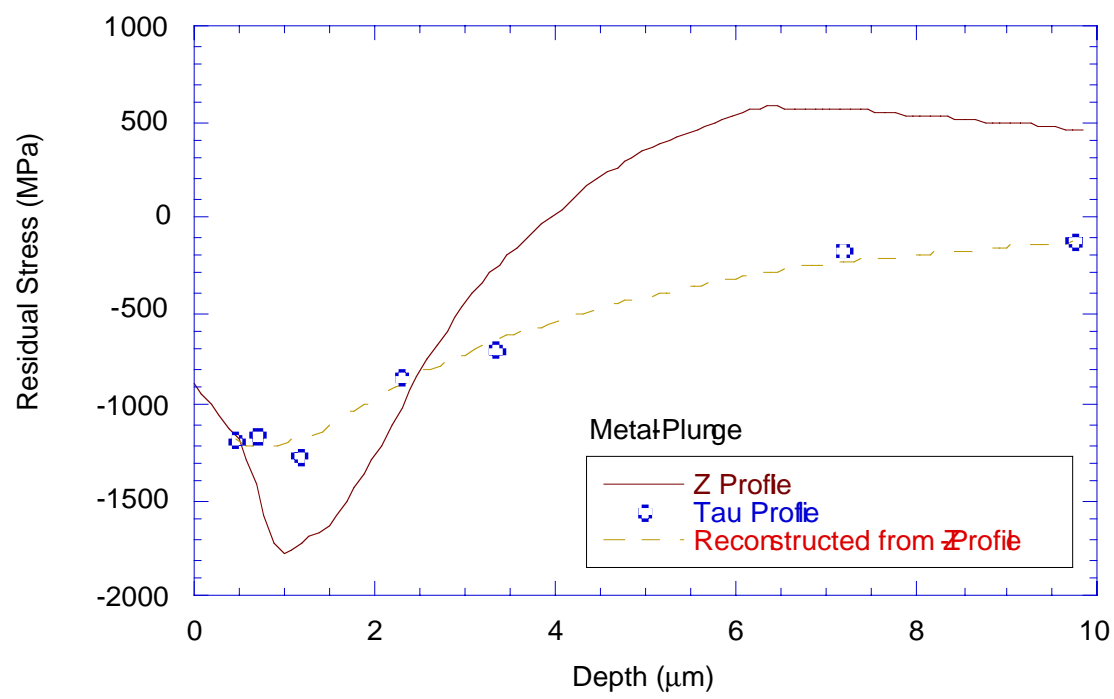

(A) Experimental metal-bond, plunge grinding.

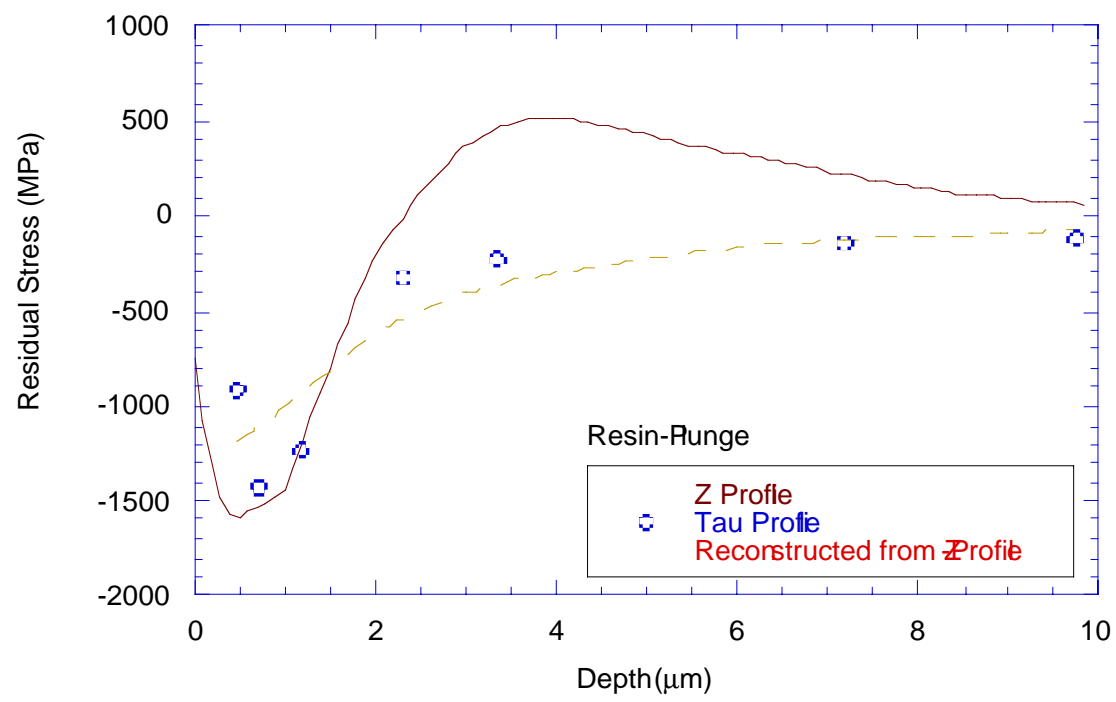

(B) Resin-bonded wheel, plunge grinding.

Fig. C-9. Residual stress tau and Z-profiles vs depth for plunge-ground NT551 silicon nitride. (A) Experimental metal-bond. (B) Standard resin-bond. 


\section{ORNL Chemical Technology Division, "XRD Study of the Stability and Thermal Properties of Perovskite-Type Materials at High Temperatures," Michael Z.-C Hu, HTML No. 97-068,}

\section{TPUC/DUC}

For the period from October 1, 1997 through September 30, 1998, we have been working on the study of the several perovskite-type ceramics using HTXRD instrument: (1) zirconia-doped $\mathrm{SrCo}_{0.4} \mathrm{Fe}_{0.6} \mathrm{O}_{3-\delta}$ membrane for ionic oxygen conduction (2) barium titanate electroceramics. Currently working on the characterization of newly synthesized zirconium titanate amorphous materials, in the form of submicron microspheres.

\section{SALUT, “Thermal Expansion of Ettringite," Naga Shashidhar, HTML No. 97-001}

\section{DUC}

Ettringite, which forms in concrete structures over a period of time is suspected of causing cracks. The other mechanism which would potentially cause cracks is alkali-silica reactivity. In order to conclusively show which mechanism is responsible for crack formation, the thermal coefficient of expansion, and any expansion anisotropy in the material have to be measured.

The a- and c-axis lattice parameters were measured using $\mathrm{x}$-ray diffraction as a function of temperatures between $25^{\circ} \mathrm{C}$ (room temperature) and $70^{\circ} \mathrm{C}$. It was found that both the axis parameters decreased as the temperature was raised from $25^{\circ}$ to $70^{\circ} \mathrm{C}$. Also, it was found that the diffraction pattern vanished at $70^{\circ} \mathrm{C}$ showing evidence of decomposition of the material. The a-axis parameter dereased from $11.2143 \AA$ to $11.2062 \AA$ when heated from $30^{\circ} \mathrm{C}$ to $60^{\circ} \mathrm{C}$ showing an expansion coefficient of $-12.7 \times 10^{-6} /{ }^{\circ} \mathrm{C}$. The c-axis decreased from 21.4298 to 21.4192 in the same temperature range indicating an expansion coefficient of $-16.4 \times 10^{-6} /{ }^{\circ} \mathrm{C}$.

It is unlikely that these results should indicate that ettringite has a negative thermal expansion coefficients due to the two reasons:

(1) Even crystals that show a net negative expansion coefficient have one axis contracting while another expands. Our results show that both the axis contract with temperature.

(2) Measurements in the literature do not support these results.

The more likely mechanism is that the loss in water from the crystal lattice is shrinking the unit cell as the temperature is raised. In order to verify this hypothesis, the experiments should be repeated in controlled humidity conditions or at temperatures where the loss in water is not significant, perhaps between $-50^{\circ} \mathrm{C}$ and $25^{\circ} \mathrm{C}$.

At this stage, the research is not publishable. 


\section{Siemens Westinghouse Power Corporation, "Life Determination of Thermal Barrier Coatings in Fatigue," Maria Arana Antelo, HTML No. 96-047}

\section{MCAUC}

Thermal Barrier Coatings (TBCs) are an integral technological component of advanced energy efficient low emission combustion turbine technology. As design strategies progress from using TBCs primarily for the life extension to taking full advantage of the TBC in thermal design, requirements for TBC reliability will increase markedly. To address the development of advanced, high reliability TBC systems, Siemens Westinghouse has been contracted by DOE to develop improved compositions, application processes and life prediction models. The subject of this program is to generate fatigue life data on TBC specimens to assist in development and validation of the TBC life prediction model.

The approach taken here will use a compression/compression fatigue on a tubular substrate/bond coat/Thermally Grown Oxide(TGO)/TBC in a strain controlled mode to a series of pre-selected strains at two temperatures. Failure is defined as coating spallation. Failure detection and prior damage to failure is being recorded by an infrared camera system. The principle data required will be cycles to failures versus strain range.

Successful acquisition of these data points implies a step forward to the final decoupling between fatigue and diffusion induced failure modes. This a key step in the future development of a life prediction model. Simultaneously, determination of the cycles to TBC spallation under fatigue conditions will form the baseline of a database to determine refurbishing and inspection periods.

During the first year, the project's activities have been focused in overtaking challenging experimental barriers to mechanically test TBCs. Currently, the experimental set-up is capable of mechanically cycling $\mathrm{TBC}$ coated specimens at a maximum temperature of $1100^{\circ} \mathrm{C}$ under strain controlled conditions and simultaneously monitor surface with an IR camera in order to detect and in some cases anticipate failure of TBC's. Further improvements as internal cooling and implementation of a rudimentary thermal cycle are currently under discussion.

Results can be summarized as follows:

- Surface temperature changes prior to an spallation event have been detected.

- Prior to the spallation the coating buckles. These two events: spallation and buckling are very dynamic and happened, in most of the cases, in consecutive cycles. No growth by buckling has been captured by the IR camera (see Fig. C-10). 


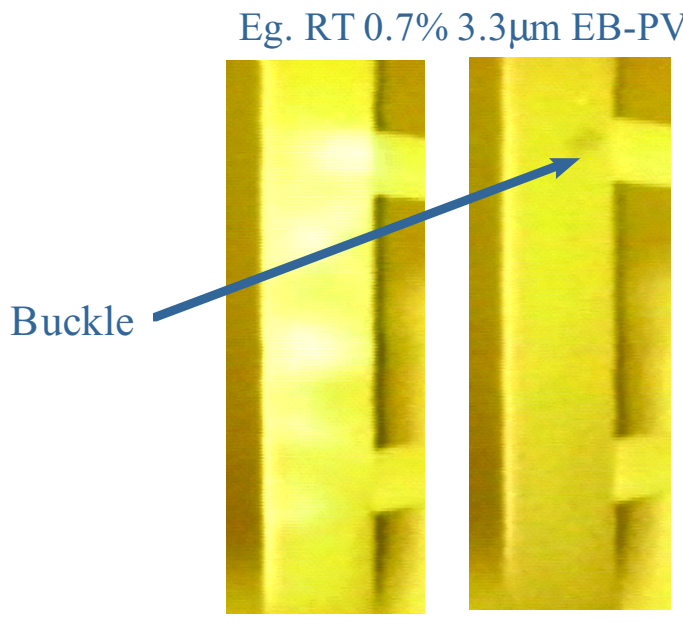

cycle 1
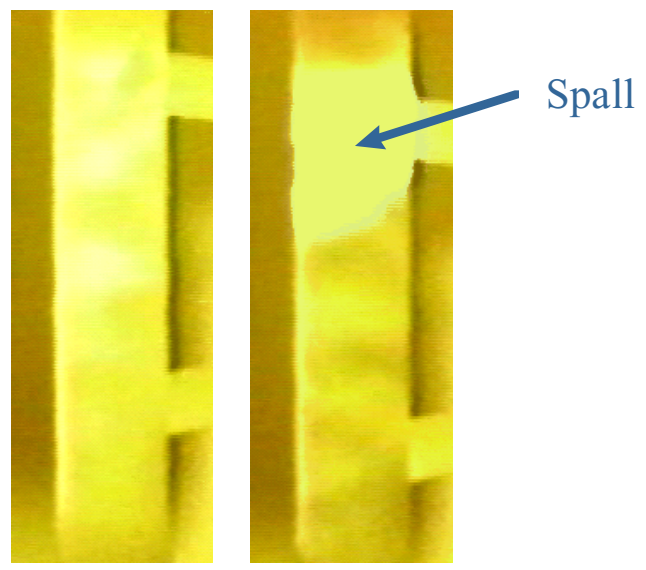

cycle 2

Fig. C-10. Spallation and buckling in TGO TBC.

A systematic and consistent trend on the monotonic strain to fracture as a function of the TGO thickness has been measured (see Fig. C-11).

I $B C$ monotonic compresive sura in to spailad on

-room te mperature-

300 microns ceramic thickness

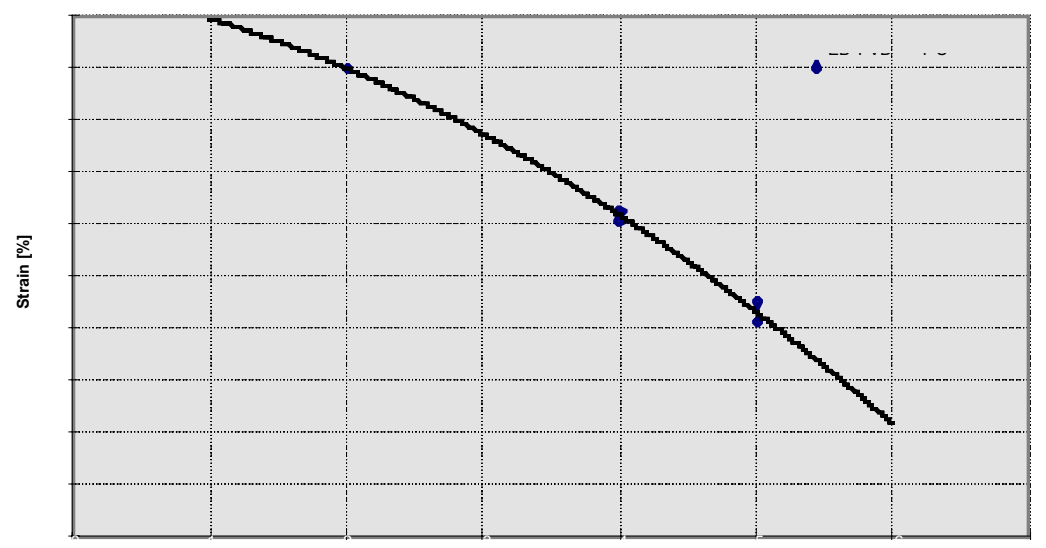

Fig. C-11. Trend in strain to fracture of TGO TBC. 


\section{Siemens Westinghouse Power Corporation, "YAG-An Alternate Standard for Thermal Expansion Measurement," R. J. Ruka, HTML No. 98-024}

\section{TPUC/DUC}

Sapphire is typically used as a secondary reference standard for high temperature thermal expansion measurements by dilatometers using alumina push rods. It has one disadvantage in that its crystal structure is not cubic so that thermal expansion varies with crystallographic direction. A more ideal material for the same thermal expansion range would be yttrium aluminum garnet (YAG). YAG has equivalent chemical stability in contact with alumina push rods in both oxidizing and reducing atmospheres but has the advantage of cubic crystal structure so that its thermal expansion is independent of crystallographic orientation. It could, therefore, could act as a primary standard in either single crystal or polycrystalline form. The available thermal expansion data for YAG, however, is not of high accuracy. The purpose of this work is to obtain more accurate thermal expansion data in the high temperature range up to $1500^{\circ} \mathrm{C}$. The first phase of this work has been to provide, at Siemens Westinghouse (SWPC), a calibration of the thermal expansion of both single crystal and polycrystalline $\mathrm{YAG}$ in the range $25-1000^{\circ} \mathrm{C}$ using platinum as the calibration standard. The second phase will be to provide confirming data by $\mathrm{x}-$ ray diffraction to be done at ORNL/HTML. A third phase will extend the data to higher temperatures and serve as a basis for a joint HTML/SWPC proposal to NIST for a material certification project.

\section{Torrington Company, "Role of Residual Stresses in the Manufacture of 52100 Steel Bearing Rings," S. Shrivastava and H. Walton, HTML No. 97-059}

\section{RSUC}

Distortion occurring during the heat treatment of bearing rings millions of dollars each year in terms of additional material and grinding costs. There are a number of causes of distortion, which include residual stress in the material, non-uniform phase transformation, and non-uniform heating and cooling. It is important to understand the relative contributions of each of these factors. In the present study, the efforts were focused on understanding the role of residual stresses in heat treatment distortion. The intent of this project was to utilize the ORNL's neutron diffraction facility to understand and quantify the role of residual stresses in distortion occurring during the heat treatment of bearing rings.

AISI52100 steel rings of 6" OD were used in the present study. Residual stress measurements were carried out on these rings after different processing steps. The data indicated that the magnitude of residual stress varied around a ring and that these stresses were related to the dimensional changes occurring during heat treatment of these rings. Pre-stressing technique was found to create residual stresses in the pre-stressed location as well as at other locations around the ring. The data are being analyzed to relate the magnitude of residual stress with the 
amount of distortion occurring after heat treat. Neutron diffraction is a very useful tool, which will help understand this behavior of materials and develop manufacturing processes to improve the quality of our products.

\section{Valenite, Inc., "Study of Mechanical Properties of CVD Hard Coatings on Cutting Tools," K .Narasimhan, HTML No. 98-039}

\section{MCAUC/MAUC/MIRUC}

Main focus during 1998 was to establish the methodology of fracture toughness measurements for CVD hard coatings using the Nanoindenter. The purpose of this work was to evaluate the relative differences in fracture toughness between various CVD coating configurations deposited on cemented carbide substrates. Specifically, fracture toughness evaluation of the various coatings $\mathrm{TiCN}, \mathrm{TiN}, \mathrm{ZrCN}, \mathrm{Al}_{2} \mathrm{O}_{3}$ (Monolayers, Bilayers, Multilayers) can assist in developing coated cemented carbide tools for specific machining applications, based on their mechanical properties.

Cube corner and Vickers indenters were initially used to place indents on thinner coating designs $(3-5 \mu \mathrm{m})$. Some indents showed signs of cracking while other indents did not $(<100 \mathrm{mN})$. Examination of cracks from the Vickers indents $(75-150 \mathrm{mN})$ revealed that they did not emanate from the corner of the indents and could be related to the existence of the free surface (Thin coatings). It also suggested that with Vickers indenter we were below the optimum cracking threshold for these coatings. Cube corner indents revealed massive "caving" in of the indents due to high stresses in the load range $75-200 \mathrm{mN}$ for the thin coatings.

Further investigation was carried out with thicker multilayer TiCN-TiN coatings $(>6 \mu \mathrm{m})$ and cube corner indenter $(62 \mathrm{mN}, 125 \mathrm{mN}, 250 \mathrm{mN}, 400 \mathrm{mN}$, and $650 \mathrm{mN})$. Multiple cracks with uneven lengths (not usable for $\mathrm{K}_{\mathrm{IC}}$ measurements) were observed at the higher loads and no cracking was observed at the lower load $(62 \mathrm{mN})$. Indents from the $125 \mathrm{mN}$ load showed stable, even crack lengths. These cracks are at the limit for what is considered as ideal for this method. The standard deviation for $\mathrm{K}_{\mathrm{IC}}$ was $30 \%$ of the mean value, indicating important limitations to the measurement.

Future plans include the study of indents (cube corner method) on other coating designs (thicker coatings $>6 \mu \mathrm{m}$ ) under similar loading conditions $(125 \mathrm{mN})$ and fine tuning the repeatability of fracture toughness measurements for these coatings. It is our intention to evaluate the relative differences in toughness between the coating designs with the realization that there are important limitations in this method (standard deviation of $\mathrm{K}_{\mathrm{IC}}$ values). 


\section{UNIVERSITIES}

\section{Alfred University, "Field-Induced Strain Mapping of Piezoelectric and Electrostrictive Materials Using Neutron Diffraction," Scott Misture, HTML 97-022}

\section{RSUC/DUC}

Recent efforts on electrostrictive materials have led to the use of $\mathrm{Pb}\left(\mathrm{Mg}_{1 / 3} \mathrm{Nb}_{2 / 3}\right) \mathrm{O}_{3}-\mathrm{PbTiO}_{3^{-}}$ $(\mathrm{Ba}, \mathrm{Sr}) \mathrm{TiO}_{3}(\mathrm{PMN}-\mathrm{PT}-\mathrm{BT})$ in major transducer systems. Despite this success, and the previously outstanding transducers made with PMN-PT-BT, there are a number of unanswered questions regarding the performance and power generation capabilities of the PMN materials. In order to fully exploit the unique characteristics of PMN and not use it merely as a drop-in replacement for traditional piezoelectrics, there is a need to better understand the microscopic strains, dopant behavior, and power response.

Before completing the work with HTML, there were no models to correlate the macroscopic behavior of a random polycrystalline material to the lattice strains induced by an applied electric field. Such a model was determined during the course of the work at HTML, and has allowed us to determine:

- the maximum expected macroscopic strain for the specific composition of the material (single crystals of PMN-BT are not reliably available),

- the possible benefits of processing the materials to yield highly-oriented grains to take advantage of the anisotropic properties, and

- the effects of field and strain inhomogeneities on power output and device reliability.

Neutron powder diffraction measurements were carried out on HB2 at HFIR and a constitutive model was used to determine the bulk longitudinal and transverse electrostrictive coefficients (Qijkl) for polycrystalline samples of the subject material. Effective single crystal Qijkl were calculated from the powder neutron diffraction data. The resulting values of the three independent Qijkl, as determined from the cubic symmetry of the underlying lattice, are Q3333 = $2.1 \times 10^{-2} \mathrm{~m} 4 / \mathrm{C} 2, \mathrm{Q} 3322=-0.87 \times 10^{-2} \mathrm{~m} 4 / \mathrm{C} 2$, and Q3232 $=1.2 \times 10^{-2} \mathrm{~m} 4 / \mathrm{C} 2$. Using these effective single crystal values, a random ensemble average was used to predict the electromechanical performance of the polycrystalline material. Predicted values of bulk Q3333 = $1.86 \times 10^{-2} \mathrm{~m} 4 / \mathrm{C} 2$ and $\mathrm{Q} 3322=-0.78 \times 10^{-2} \mathrm{~m} 4 / \mathrm{C} 2$ are $89 \%$ and $87 \%$ respectively of the effective single crystal values for Q3333 and Q3322, while measured values of polycrystalline specimens are only $\sim 70 \%$ of the single crystal values. 


\section{Alfred University, "Site Occupancy in Copper Ferrite Phase Using Anomalous Synchrotron Scattering," Scott Misture, HTML No. 98-057}

\section{DUC}

Pushing communication devices into the tetrahertz operational frequencies will have an enormous impact on wireless communication bandwidth. Ferromagnetic resonance devices are the primary enabling technology to reach the tetrahertz range, and copper ferrites are, in principle, useful for this technology.

The composition $\mathrm{Cu}_{0.5} \mathrm{Fe}_{2.5} \mathrm{O}_{4}$ where the copper is monovalent and occupies the tetrahedral site ideally will exhibit a very high net magnetic moment of $7.5 \mathrm{mB}$ (about 11,000 Gauss, or double the magnetization of the current materials) at $0 \mathrm{~K}$. In fact, this value has never been observed due to the redox of $\mathrm{Cu}^{1+}$ and $\mathrm{Fe}^{3+}$ forming $\mathrm{Cu}^{2+}$ and $\mathrm{Fe}^{2+}$ and/or disorder of $\mathrm{Cu}^{1+}$ onto the $\mathrm{A}$ and $\mathrm{B}$ sites of the spinel. It is possible to calculate the cation distribution from measurements of saturation magnetization by making use of the Neel theory of ferrimagnetism. This solution, however, is not always unique. Hence, it is critical to have an independent experimental method to ascertain the site occupancy of cations in the spinel structure.

In principle, X-ray diffraction is the best way to study the site occupancy of cations, but one must make use of the anomalous dispersion phenomenon and synchrotron radiation to improve the scattering contrast between $\mathrm{Cu}$ and Fe ions.

To this end, copper ferrite samples were run at the HTML beamline at NSLS to collect full diffraction patterns at appropriate wavelengths. Samples were quenched from high temperatures in controlled atmospheres to attempt to keep the cation distribution in the high-magnetization state. Whole pattern fitting using Rietveld analysis to determine the cation distribution in the ferrite system of interest is currently underway, and the complete diffraction patterns and the structure factors have been successfully calculated for each anomalous scattering wavelength. Small ambiguities in the observed intensities have caused us to re-evaluate one of the samples using magnetization measurments, so a manuscript describing the work has not yet been submitted. The target date for submission of a manuscript to a refereed journal is currently late June 1999.

\section{Alfred University/Spawar, "Electric Field and Stress Dependence of Lattice Parameters in High Strain PMN Ceramics,” J. C. Hicks, HTML No. 98-056}

\section{RSUC}

Current work follows on our previous success in HTML proposal 97-022, where neutron strain measurements allowed a complete description of the electrostrictive materials of interest under ambient conditions. Transducers, however, do not operate under ambient conditions, but rather are prestressed both by hydrostatic and mechanical loads. Electromechanical coupling, which defines the efficiency of the transducers, decreases rather severely under prestress loads. 
Our previous results showed that polycrystalline ceramics perform at only slightly greater than $70 \%$ of the single crystal value. This suggests that there are still significant losses in the grain boundaries and/or grain structure and that the loss in performance when compared to that of a single crystal is the result of both random orientation and losses in the individual grain boundaries and/or microstructure. This would further imply that the prestress degradation in current PMN materials may also be due in large part to losses in the grain boundaries and/or grain structure. Craig Hom's constitutive model implies that the prestress degradation may be derived from a thermodynamic approach and as such is simply a fundamental property of the lattice and that further refinements in the grain sizes and/or microstructure would not significantly improve this prestress degradation. Clearly, from our results, the prestress degradation may in fact be in large part due to losses in the grain boundaries. It is this hypothesis that we have begun to address in this work.

Preliminary measurement showed degradation in strain response on the order of $50 \%$ for prestress loads of 3ksi. Further measurements are planned for summer of 1999 to fully elucidate the relations between electric field, prestress, and strain, and hence to clarify the structureperformance map for these materials.

\section{Clemson University, "Thermal Behavior of Sol-Gel Derived Phosphate Ceramics," Paul Z. Cao, HTML No. 98-066}

\section{TPUC/DUC}

In this project we studied the thermal conductivity as a function of compostition and temperature using Hot Disk measurement. It was found that the thermal conductivity increased with the increasing of phosphorus in phosphosilicates. This study provided the fundamental information about the sol-gel derived phosphate ceramics in terms of thermal property. When the temperature goes up, the thermal conductivity of sol-gel derived phosphosilicates increases accordingly.

The structure evolution upon firing of sol-gel derived phosphate ceramics is of interest and is one of the goals of this project. The DSC results about phosphotitanate shows that there is only one phase transition, which occurred at $850^{\circ} \mathrm{C}$. This was proven by the results of high temperature $\mathrm{x}$-ray diffraction. From the DSC results about phosphosilicate derived through solgel process, we found that the sample was crystallized at $220^{\circ} \mathrm{C}$. The phase transition and crystal structure of phosphosilicate upon firing was carefully investigated through HTXRD. 
Drexel University, "Thermophysical Characterization of $\mathrm{Ti}_{3} \mathrm{SiC}_{2}$ and $\mathrm{H}-\mathrm{Phases}$ (e.g. $\mathrm{Ti}_{2} \mathrm{AIN}, \mathrm{Ti}_{2} \mathrm{AlC}$, Ti $\mathrm{i}_{2} \mathrm{SnC}$ and $\left.\mathrm{Ti}_{2} \mathrm{PbC}\right)$," M. W. Barsoum, HTML 98-001

\section{DUC}

The thermal properties of polycrystalline $\mathrm{Ti}_{3} \mathrm{SiC}_{2}$ in the $25-1000{ }^{\circ} \mathrm{C}$ temperature range determined by Rietveld refinement of high temperature neutron diffraction data, show that at all temperatures, the amplitudes of vibration of the Si atoms are higher than those of the $\mathrm{Ti}$ and $\mathrm{C}$ atoms. Up to $700{ }^{\circ} \mathrm{C}$, the vibrations of the $\mathrm{Si}$ atoms are quite isotropic but the vibrations of the other atoms are greater along the c- than along the a-axis. The amplitudes of vibration of the Ti atoms adjacent to the $\mathrm{Si}$ atoms are higher and more anisotropic than for the other Ti atom sandwiched between the C-layers. Good agreement is obtained between the bulk thermal expansion coefficients measured by dilatometry, $9.1( \pm 0.2) \times 10^{-6}{ }^{\circ} \mathrm{C}^{-1}$, and the values from the neutron diffraction results, $8.9( \pm 0.1) \times 10^{-6}{ }^{\circ} \mathrm{C}^{-1}$. The thermal expansion coefficients along the aand c-axes are, respectively, $8.6( \pm 0.1) \times 10^{-6}{ }^{\circ} \mathrm{C}^{-1}$ and $9.7( \pm 0.1) \times 10^{-6}{ }^{\circ} \mathrm{C}^{-1}$. The room temperature thermal conductivity is $37 \mathrm{~W} / \mathrm{m} . \mathrm{K}$ and decreases linearly to $32 \mathrm{~W} / \mathrm{m} . \mathrm{K}$ at $1200{ }^{\circ} \mathrm{C}$ [see Fig. C-12 (a)]. The thermal conductivity is dominated by delocalized electrons. The heat capacity is $110 \mathrm{~J} / \mathrm{mol} \mathrm{K}$ at ambient temperatures and extrapolates to at $\approx 155 \mathrm{~J} / \mathrm{mol} \mathrm{K}$ at $1200{ }^{\circ} \mathrm{C}$ [Fig. C-12 (b)]. The heat capacity of $\mathrm{Ti}_{3} \mathrm{SiC}_{2}$ is almost equal to three times that of $\mathrm{TiC}$.

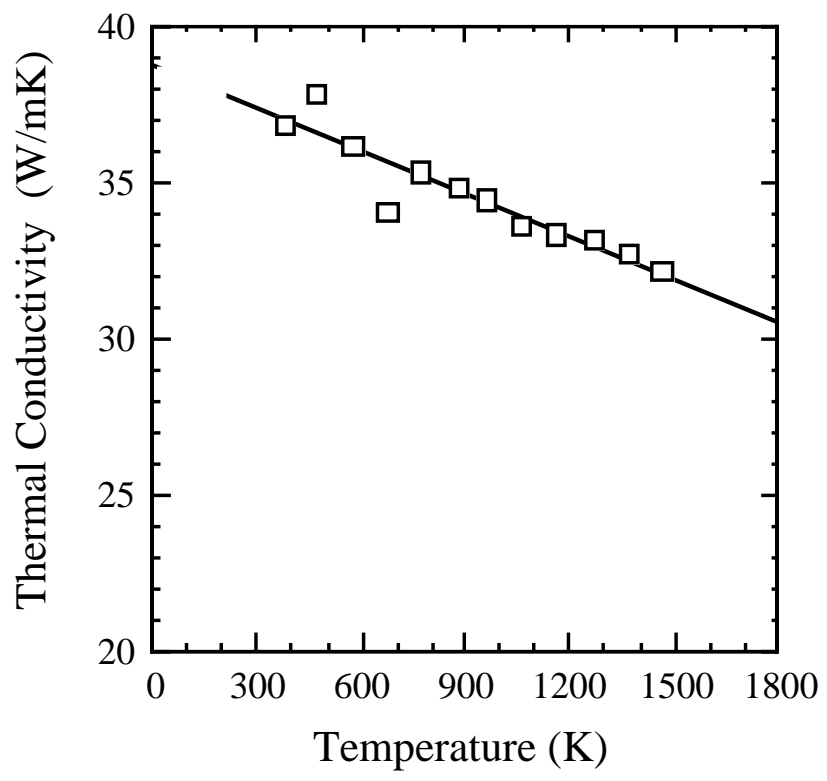

(a)

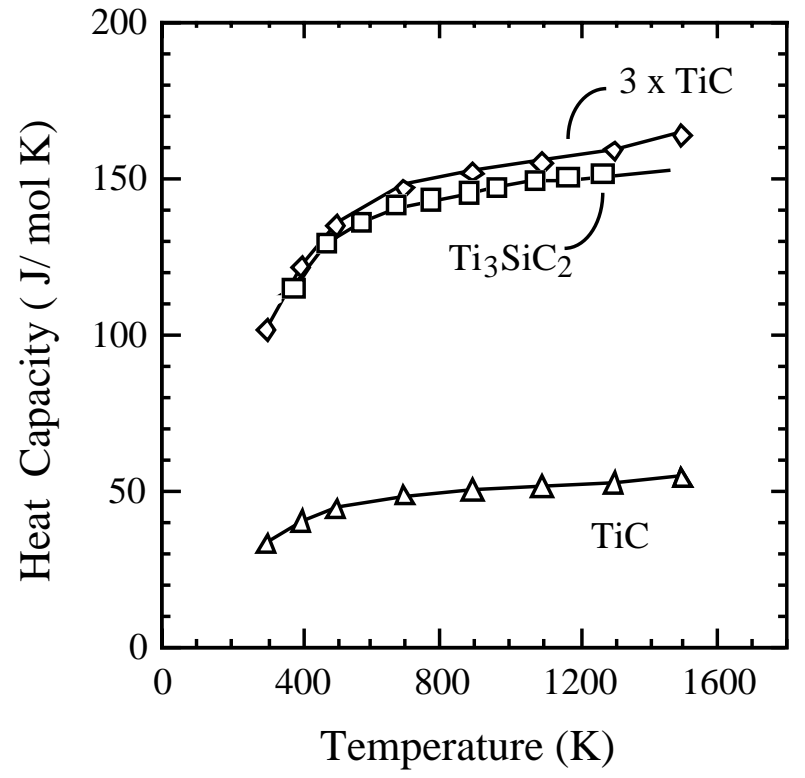

(b)

Fig. C-12. Temperature dependence of (a) thermal conductivity and (b) heat capacity of $\mathrm{Ti}_{3} \mathrm{SiC}_{2}$. 


\section{Georgia Institute of Technology, "The Effective Thermal Properties of Damaged Composites," D. L. McDowell and S. Graham, HTML No. 97-041}

\section{TPCU/MCAUC}

The development of matrix microcracking, fiber-matrix debonding, and interfacial oxidation often occur in $\mathrm{SiC}$ reinforced ceramic composites under high stress in high temperature environments. It is well known that these mechanisms affect the performance of SiC reinforced materials by degrading both thermal and mechanical properties. Since these materials are designed for use in high temperature environments, it is desirable to understand how microscale damage affects the thermal characteristics of the composites. This aspect of the material behavior is not well understood yet both from an experimental and analytical point of view.

In this research, the changes in thermal diffusivity of a glass-ceramic composite subjected to mechanical loading and oxidation exposure were measured. The material, chosen as a model system, was unidirectional reinforced Nicalon-LAS II composites. This material was subjected to monotonic tensile loading between 300-450 MPa which induced parallel matrix cracking and fiber-matrix debonding. The crack density of the specimens was determined through surface replication methods. Changes in room temperature thermal diffusivity were evaluated by the flash diffusivity method in the directions parallel and transverse to the fibers direction.

Experimental results showed that the damage induced by mechanical-loading caused no changes in the thermal diffusivity transverse to the fiber axis. However, relatively small changes in thermal diffusivity along the fiber direction (transverse to parallel matrix cracking) were evident as shown in Fig. C-13. Oxidation of these mechanically-loaded samples induced greater changes in thermal diffusivity by as much as $10 \%$. This was due to the removal of the carbon interfacial coating which acts as a thermal coupling between the fiber and the matrix. These data show that the interfacial resistance is a primary factor in controlling the thermal diffusivity of Nicalon reinforced glass-ceramic composites both parallel and transverse to the fiber direction.

Oxidation of Nicalon-LAS II was also performed at $500^{\circ} \mathrm{C}$ and $900^{\circ} \mathrm{C}$ for periods up to 40 hours in laboratory air. Changes in room-temperature thermal diffusivity transverse to the fiber direction were also determined by the flash method. These measurements were made periodically during the isothermal oxidation by removing the specimens from the laboratory oven. The effects of oxidation were also characterized through thermogravimetric analysis. The results of these tests both conclude that oxidation exposure at $500^{\circ} \mathrm{C}$ is more detrimental to the integrity of the composite (Figs. C-14 and C-15). This is due to the inability of the matrix seal itself to prevent further oxidation at intermediate temperature exposures. The loss of the carbon interface resulted in a weight change on the order of $0.5 \%$ and large decrease in transverse thermal diffusivity of up to $25 \%$. Such changes were not manifested at $900^{\circ} \mathrm{C}$. By characterizing the changes in thermal diffusivity with the microstructural evolution, it is intended to use these data to analyze to validity of analytical damage-thermal conductivity relationships. 


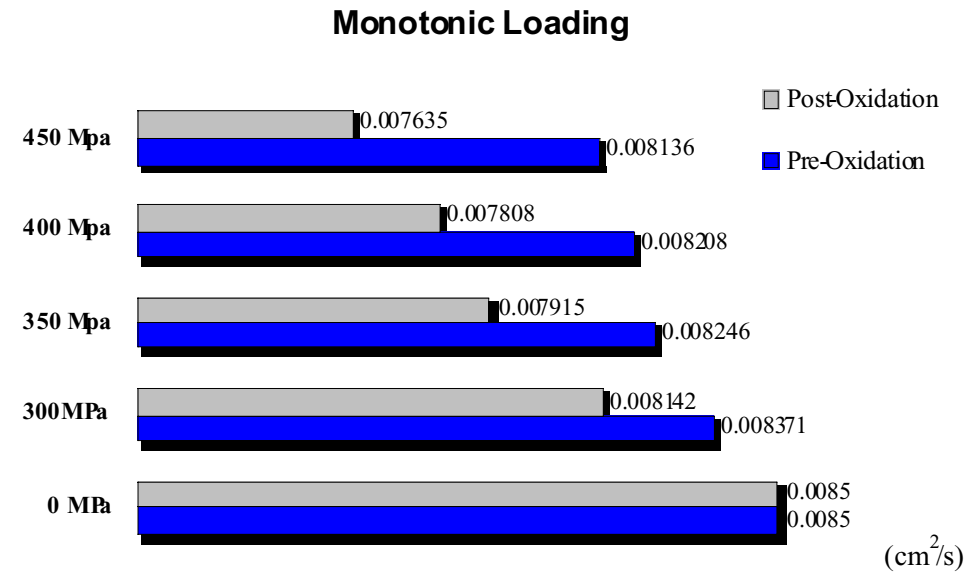

Fig. C-13. The effect of monotonic loading on the longitudinal thermal diffusivity of Nicalon-LAS II.

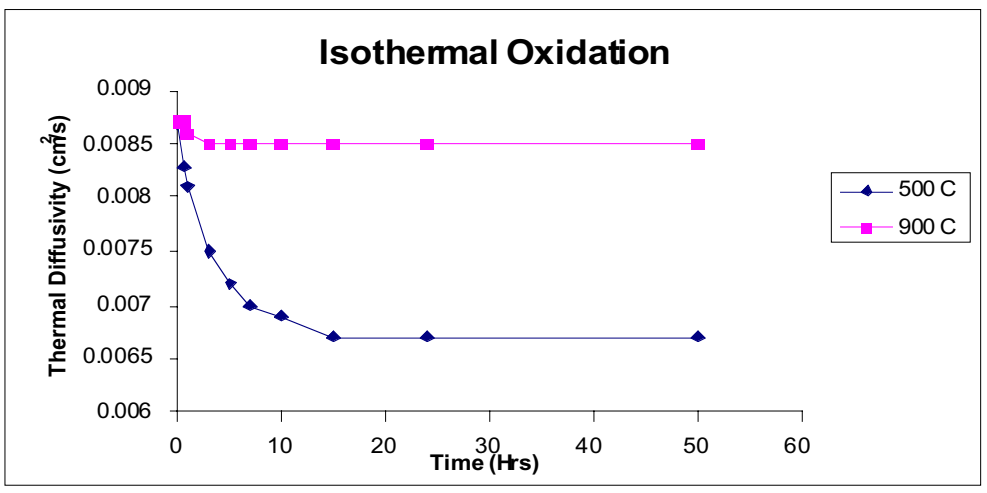

Fig. C-14. The effect of isothermal oxidation on the transverse thermal diffusivity of Nicalon-LAS II.

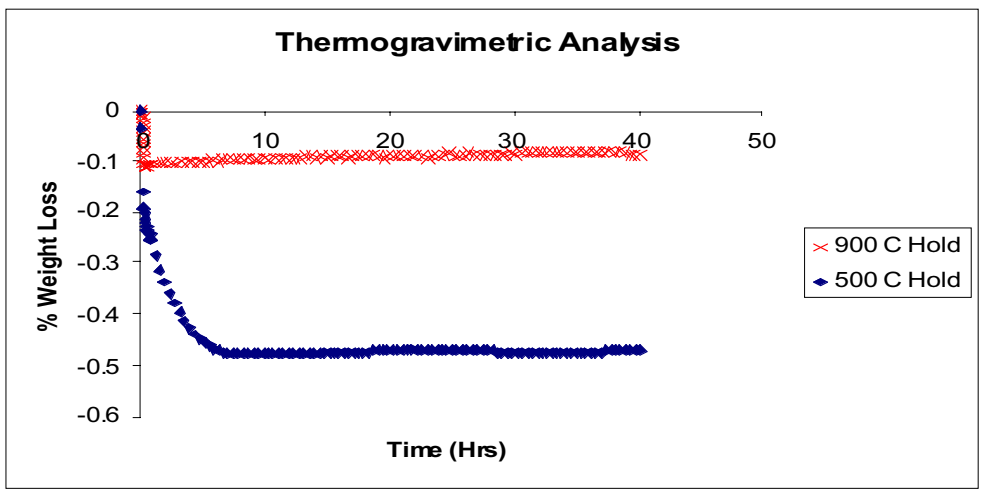

Fig. C-15. Weight loss of Nicalon-LAS II exposed to isothermal oxidation at $500^{\circ} \mathrm{C}$. 
Georgia Institute of Technology, School of Materials Science and Engineering, "Mechanical Properties of YSZ-Alumina Thin Films Deposited via Combustion CVD", D.W. Stollberg, W.B. Carter, and J.M. Hampikian, HTML No. 98-016

\section{MCAUC}

Combustion chemical vapor deposition (combustion CVD) is a technique being developed at Georgia Tech to deposit yttria-stabilized zirconia, $\mathrm{Y}_{2} \mathrm{O}_{3}$ stabilized $\mathrm{ZrO}_{2}$ (YSZ) and yttriastabilized zirconia with alumina $\left(\mathrm{YSZ}-\mathrm{Al}_{2} \mathrm{O}_{3}\right)$ on alumina substrates. Combustion CVD uses a flame to provide the heat for the chemical reactions and the medium for the deposition of ceramic films. Combustion CVD is performed in the open atmosphere and is relatively quick and inexpensive compared to conventional CVD processes. YSZ- $\mathrm{Al}_{2} \mathrm{O}_{3}$ is being considered as a material with which to toughen the interface between air plasma sprayed YSZ and the nickelchromium-aluminum-yttrium bond coat of thermal barrier coatings (TBC's) used on hot section components of gas turbines. The failure of TBC's during thermal cycling has shown the formation of a thermally grown oxide and cracking in the YSZ near the bond coat. Toughening the TBC-bond coat interface with a material such as $\mathrm{YSZ}-\mathrm{Al}_{2} \mathrm{O}_{3}$ may be beneficial. Quantifying the toughness of the combustion CVD YSZ- $\mathrm{Al}_{2} \mathrm{O}_{3}$ thin films to be added to the TBC's is a necessary step to fully understand the failure mechanisms involved in the thermal cycling of the TBC's. Mechanical properties measurements (hardness, elastic modulus as well as the fracture toughness) were accomplished with the HTML's Nanoindenter ${ }^{\circledR}$. These mechanical properties varied depending on the quality of the film and on amounts of YSZ and alumina in the film. Fracture toughness values were found to increase with increasing proportions of alumina in the YSZ-alumina coatings up to $45 \mathrm{~mol} \%$ alumina.

Figure C-16 shows the hardness versus the indentation depth for each of the YSZ-alumina films. The elastic moduli of the films versus indentation depth are shown in Fig. C-17. In addition to the data for the five films, data from indentation on the a-plane alumina substrate without any coating is included. Both the hardness and elastic modulus show lower values for coatings with more alumina with one exception: for the $62.8 \mathrm{~mol} \%$ alumina sample the hardness and elastic modulus both increase as indentation depth increases. Crack lengths were easily measured from SEM micrographs of the cube-corner indentations made in the five different films. Figure C-18 was prepared from these crack length measurements. This figure shows the fracture toughness versus the amount of alumina present in the film. The trend is readily apparent that fracture toughness increases as the amount of alumina increases up to the $45 \mathrm{~mol} \%$ alumina sample above which the toughness decreases slightly. 


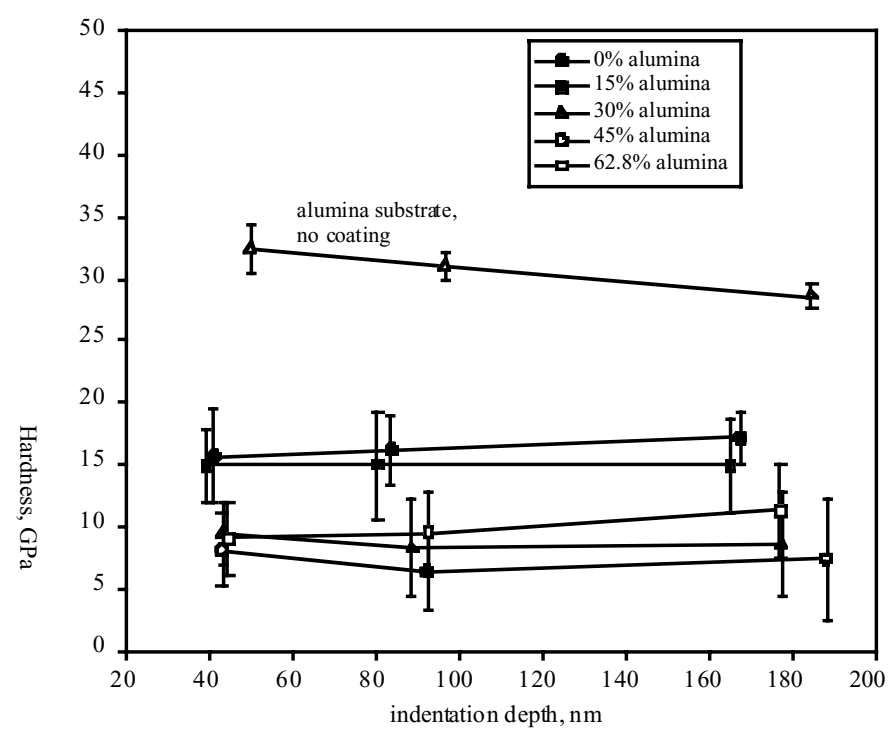

Fig. C-16. Nanoindenter ${ }^{\circledR}$ hardness versus indentation depth for the YSZalumina films.

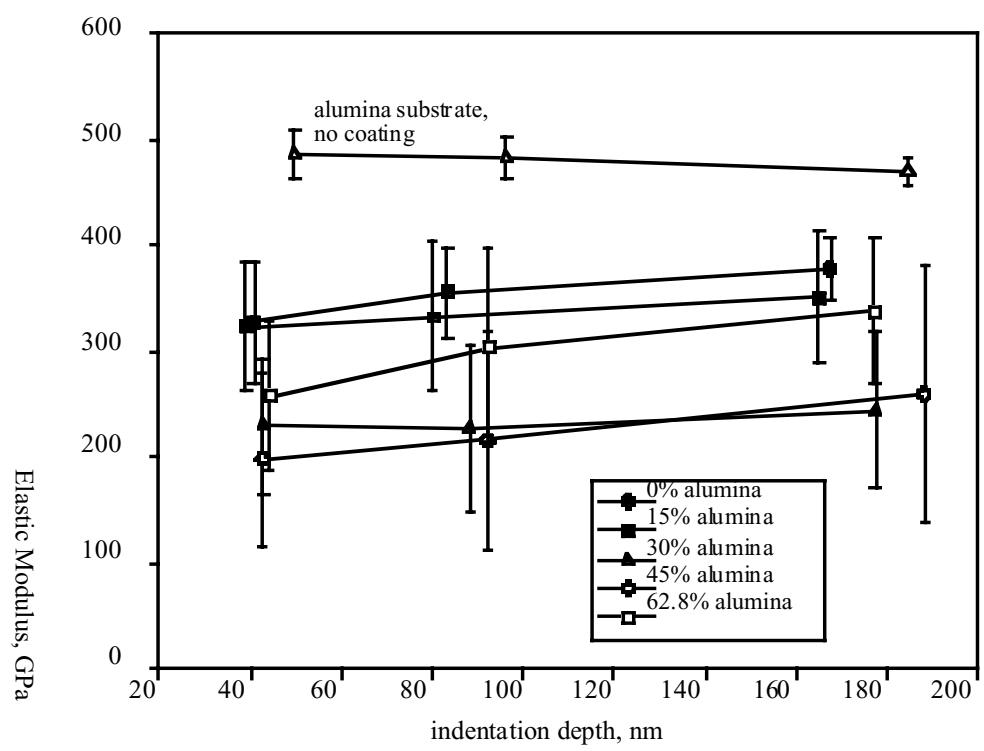

Fig. C-17. Nanoindenter ${ }^{\circledR}$ elastic modulus versus indentation depth for the YSZalumina films.

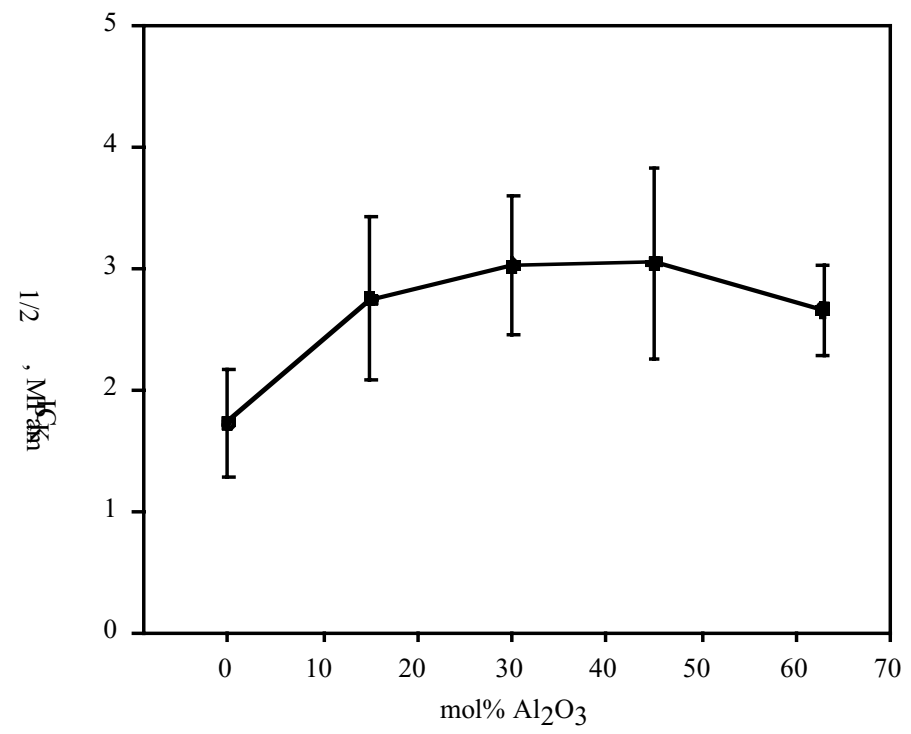

Fig. C-18. Nanoindenter ${ }^{\circledR}$ fracture toughness versus mole percent alumina in the deposition precursor. 
Kansas State University, "Composition and Crystal Structure of Boron Gallium Nitride Thin Films on Sapphire and 6H-Silicon Carbide Substrates," James H. Edgar, HTML No. 98-061

\section{MAUC}

Gallium nitride is a wide energy band gap semiconductor under development for short wavelength optoelectronics (blue light emitting diodes, ultraviolet laser diodes, and UV detectors), high temperature electronics, and high power-high frequency electronics. However, the poor lattice constant mismatch with the most common substrates for gallium nitride epitaxy introduces many crystal defects into the layer, thereby degrading its properties.

In this study, the possibility of adding boron to gallium nitride to eliminate its lattice constant mismatch with silicon carbide substrates was considered. Thin films containing boron, gallium, and nitrogen were deposited on $6 \mathrm{H}-\mathrm{SiC}(0001)$ from diborane, trimethygallium, and ammonia in a reduced pressure (76 torr) metalorganic chemical vapor deposition system. Analysis of the samples included: the surface morphology by scanning electron microscopy; crystal structure by $\mathrm{x}$-ray diffraction; optical transitions by photoluminescence; and the composition by scanning Auger microscopy.

The addition of even a small amount of diborane reduced the deposition rate of the film by $75 \%$ at a substrate temperature of $1000^{\circ} \mathrm{C}$, the usual growth temperature for GaN. Higher growth rates and greater boron incorporation was only possible at a reduced temperature, which resulted in poor crystal quality films. Single phase BGaN alloys were prepared with up to 2 at \% boron. For these low boron content films, there was a small increase in the lattice constants and a small increase in the energy band gap. Attempts to produce films with higher boron contents resulted in the formation of two polycrystalline phases, essentially pure GaN and BN. While the GaN phase could be detected by X-ray diffraction, the BN phase could only be detected by SAM, suggesting that it was amorphous or poorly-ordered nanocrystalline. Thermodynamic analysis indicates that $\mathrm{BN}$ solubility in $\mathrm{GaN}$ is very low due to the large differences in lattice constant size and structural differences.

\section{Lehigh University, “ANALYSIS OF SUBSURFACE PLASTIC DEFORMATION DURING SOLID PARTICLE EROSION OF DUCTILE ALLOYS,” B. F. Levin and A.R. Marder, HTML NO. 97-032}

\section{MCAUC}

The subsurface deformation behavior of ductile Ni, Co and Fe-base superalloys and commercially pure $\mathrm{Ni}, \mathrm{Cu}$ and $\mathrm{Ta}$ exposed to solid particle erosion was analyzed. The HTML nanoindentation hardness tester was used to determine load-displacement and stress-strain responses of materials below the eroded surface. A nanoindentation method was utilized to estimate the restitution coefficient within plastically deformed regions of eroded samples that provided a measure of the rebounding ability of a material during particle impact. An increase in 
hardness $(\mathrm{H})$ near the eroded surface led to an increase in restitution coefficient (e) according to the logarithmic relationship:

$$
\mathrm{e}=-0.38+0.39 \log (\mathrm{H})
$$

Consequently, the increase in hardness produced a decrease in the amount of plastic deformation dissipated into the material.

As a result of this research an experimental technique was developed to determine changes in stress-strain behavior of material below the eroded surface. Strength and strain-hardening coefficients decreased with distance from the eroded surface. Stress-strain behavior of materials near the eroded surface was similar to that observed during high strain-rate compression tests. Thus, strain rates imposed below the eroded surface were comparable to those measured during high strain-rate compression tests $(103-104 \mathrm{~s}-1)$. High strain rate compression tests can be used to estimate stress-strain behavior of materials during erosion.

\section{Lehigh University, "Undergraduate Teaching of Electron Microscopy Using TelePresence Microscopy," D. B. Williams, HTML No. 98-026}

\section{MAUC}

The research was attempting to improve the quality of remote electron microscopy for undergraduate and graduate education by determining the factors that limit the transmission of good TEM images and diffraction patterns. We attempted to run two remote demonstrations over the time period (10/1/97-9/30/98) between students at Lehigh and the HF 2000 high resolution transmission electron microscope (TEM) at HTML, in collaboration with Dr. E. Voelkl. The results were as follows:

a) The first demonstration was in November 1997 when an undergraduate class (Mat 334 Electron Microscopy and Microanalysis) interacted with Dr. Voelkl and observed high resolution phase-contrast images of metal catalyst particles on an amorphous carbon film. The students were able to control the instrument and obtain images and diffraction patterns

b) The second demonstration was in June 1998 when a group of graduate students participated in a remote microscopy demonstration from HTML via Capitol Hill where the technique was being demonstrated to members of the House and Senate. Transmission was again of very variable quality with frequent losses of contact.

There was little impact on our institution except that the students were able to experience using a high resolution TEM to which they do not have access here at Lehigh.

No publications arose out of this interaction.

Remote microscopy demonstrations were not scheduled for this academic year since I was on sabbatical leave. The demonstrations still remain constrained by the bandwidth of the internet. Lehigh has recently received funding to get onto Intenert2 and this should improve communication between ORNL and Lehigh. When higher bandwidth lines are in place we will 
attempt further demonstrations. When these prove feasible it is planned to develop a series of formal laboratories that can be carried out over the internet and will be accessible to any university that wishes to interact with HTML and run remote laboratories.

\section{New Mexico Institute of Mining and Technology, "Residual Stress in Deuterium Irradiated Copper Coatings Deposited on Al-6061 Substrates by RF Magnetron Sputtering," M. Alam, HTML No. 98-005}

\section{RSUC}

Accelerator production of tritium concept is based on the exothermic reaction between spallation neutrons and ${ }^{3} \mathrm{He}$ gas $\left[{ }^{3} \mathrm{He}(\mathrm{n}, \mathrm{p})^{3} \mathrm{H}\right]$ inside Al-6061 tubes. Since the tritons are produced with a high energy $(\sim 192 \mathrm{keV})$, about $10-15 \%$ of the tritons is likely to be implanted in the tube walls. New Mexico Tech is evaluating the use of metallic coatings like copper on Al6061 to minimize the retention and permeation of implanted tritium in and through the Al-6061 tube walls. One important issue in this regard is the integrity of the coatings from the point of view of the coating-substrate bond strength, which is likely to be affected by the presence of residual stresses in the coatings and their evolution upon tritium implantation. The objective of this research was to understand the effects of deuterium ion implantation on the evolution of residual stress in $\mathrm{Cu}$-coatings prepared on flat Al-6061 coupons by RF Magnetron Sputtering. Deuterium was used to simulate the effects of tritium because of its non-radioactive nature.

$\mathrm{Cu}$-coatings having weights of $0.03,0.06$ and $0.088 \mathrm{~kg} / \mathrm{m}^{2}$ were prepared on polished substrates under the following conditions: $\mathrm{RF}$ power $=250 \mathrm{~W}$, Pressure $=0.25 \mathrm{~Pa}$, Temperature $=473 \mathrm{~K}$, Ar flow rate $=10 \mathrm{sccm}$, Substrate bias $=-100 \mathrm{~V}$, Target-Substrate distance $=60 \mathrm{~mm}$. The coatings were implanted with deuterium in an accelerator at energies of 40 and $120 \mathrm{keV}$, and fluences of $1 \times 10^{21}, 2 \times 10^{21}$ and $3 \times 10^{21} \mathrm{D}^{+} / \mathrm{m}^{2}$. The as-deposited coatings and the implanted coatings were analyzed for residual stress in the RSUC of HTML at the ORNL. The instrument used at RSUC was the Spellman DF3 series $4 \mathrm{~kW}$ generator equipped with Scintag PTS goniometer.

Initially, $\Theta-2 \Theta$ scans taken using $\mathrm{CuK} \alpha$ radiation indicated the presence of intermetallic phases $\mathrm{CuAl}_{2}$ and $\mathrm{Cu}_{9} \mathrm{Al}_{4}$ beside the metallic phases $\mathrm{Cu}$ and $\mathrm{Al}$. Intermetallic formation is probably due to the high deposition temperature of $473 \mathrm{~K} . \mathrm{Cu}(220)$ and $\mathrm{CuAl}_{2}(422)$ reflections were used for residual stress measurements in the respective phases using $\mathrm{CrK} \alpha$ radiation. The $\sin ^{2} \Psi$ technique was employed. For each $\phi$ angle $\left(0^{\circ}, 45^{\circ}\right.$ and $\left.90^{\circ}\right)$ seven $\Psi$ tilts were examined $\left(0^{\circ}, \pm 18.33^{\circ}, \pm 33.67^{\circ}\right.$ and $\left.\pm 55^{\circ}\right)$. Triaxial stress analysis revealed the surface normal stress component to be negligible in both phases, and the inplane stress components to be roughly equal in both directions in both the phases (although different in the two phases), suggesting the existence of isotropic plane stresses in both phases. The effects of coating weight, ion energy and ion fluence on the isotropic plane stresses in the coatings are shown in Fig. C-19. Under all conditions, residual stresses in the two phases remain compressive. The stresses are large in $\mathrm{CuAl}_{2}$ and relatively small in $\mathrm{Cu}$. Compressive residual stresses are due to the higher thermal expansion coefficient of $\mathrm{Al}$ as compared to $\mathrm{Cu}$, and the atomic peening effect during growth. The 
decrease in the compressive residual stresses of the two phases upon implantation suggest annihilation of lattice parameter inflating defects due to thermal effects similar to local annealing. The bell shaped character of residual stress curves probably indicates competition between defect annihilation and defect generation processes.

The measured residual stresses after substantial deuterium implantation, under conditions simulating the reactor environment, are all compressive and relatively minor. Therefore, coating integrity in the reactor will not be compromised at least due to implantation related affects.
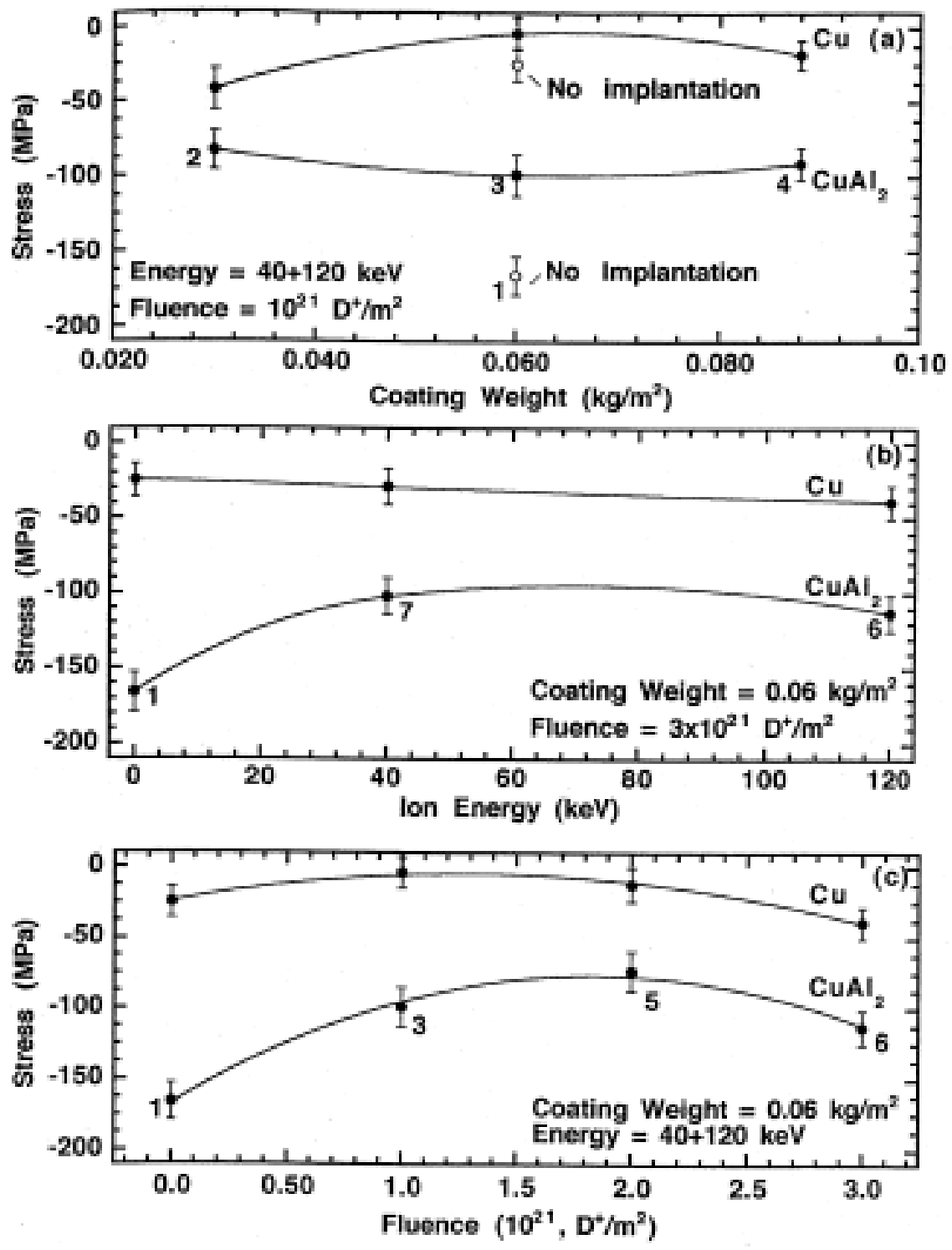

Fig. C-19. Variation of the isotropic plane stress as a function of coating weight, ion energy, and ion fluence. Numbers next to the data points refer to the different samples. 


\section{North Carolina State University, "Multilayer Diamond Coatings," J. Kasichainula, HTML No. 97-035}

\section{TPUC/RSUC}

High frequency, high power electronic devices generate large amount of thermal energy during operation of the device, leading to a sharp raise in temperature and susceptibility to both electronic and mechanical failure.These devices include: microwave power devices, high power switches, and modern laser diodes that are built on semiconductor substrates such as silicon, gallium arsenide, silicon carbide and other wide band gap semiconductors. Progress in size reduction of the active devices to submicron level with a corresponding increase in device density and frequency of operation is expected to lead to large increase in the heat dissipation requirements as much as $1.5 \mathrm{Kwatts}$ per an eight inch diameter wafer. Therefore, it is imperative that appropriate heat spreaders are built into the design of the electronic devices. Low cost, high reliability and high heat spreader characteristic substrates are explored currently for use in electronic industry (e.g., diamond, sintered aluminum nitride, copper alloys, and a variety of composite materials). For high frequency power devices, high thermal conductivity heat spreaders made of diamond are the most desirable. However, adhesion of diamond to most high heat capacity substrates is low and therefore, failure of the heat spreader by delamination of the diamond film from the substrate under thermal cycling is common and must be avoided if diamond films are to become useful heat spreaders. We have designed a multilayer diamond thin film heat spreader consisting of diamond/aluminum nitride/diamond that exhibited improved adhesion. The present research aims to establish that the effective thermal conductivity of the multilayer layer diamond films, deposited by plasma chemical vapor deposition, and aluminum nitride, deposited via magnetron sputtering, is sufficiently high so that heat spreader characteristics and adhesion are both improved. We have measured the thermal conductivity of the multilayer diamond films of different thicknesses and with different volume fractions of aluminum nitride. The three-omega technique is used to measure the thermal conductivity perpendicular to the film and infrared imaging technique is used to determine the heat spreader characteristics. The interfacial thermal barrier resistance between diamond and aluminum nitride is determined from these investigations.

Results: The results from these two techniques illustrate that the thermal conductivity of commercially available low cost aluminum nitride can be improved by factor of two upon formation of composites with diamond. Similarly, thermal conductivity of multilayer diamond films is not reduced very much but the adhesion is improved by the presence of aluminum nitride intermediate layer. Furthermore, whereas the effective thermal conductivity of the multilayer diamond films is slightly lower than that of single layer diamond films of equal thickness, the heat spreader characteristics are improved for two reasons. First the microscopic voids present in diamond films deposited by low pressure CVD are reduced by the presence of aluminum nitride so that the effective thermal conductivity is improved. Second, the heat capacity of the multilayer diamond film is higher than that of single layer diamond.

Residual stress analysis using X-ray diffraction methods was carried out to determine the factors responsible for improvement of adhesion of the multilayer diamond films. A three- 
dimensional stress analysis to determine the different stress components was performed using the high angle peaks associated with diamond. The residual stresses in the multilayer diamond film are not reduced. Therefore, it is concluded that the observed absence of delamination is due to the improvement of interfacial adhesion by the presence of aluminum nitride intermediate layer. These results illustrate that multilayer diamond heat spreaders are reliable because of improved adhesion and also exhibit better heat spreader characteristics.

\section{North Carolina State University/Cummins Engine Co., "Investigation of Grinding Debris Assist Dressing for Cost-Effective Machining of Zirconia," Albert J. Shih, HTML No. 98-073}

\section{MIRUC/MAUC/DUC}

The project has just started in late December. To date, most of the time was used to understand the limitation of the machines and to set up grinding tests for data-gathering. More grinding tests will be conducted later in the year.

(1) The goal of this project is to find the use of grinding debris assist dressing method for cost-effective grinding of zirconia ceramics. This new grinding method will be able to reduce the manufacturing cost of zirconia plungers.

(2) Grinding tests were conducted on the Harig and Nicco surface grinding machines. During grinding, the forces and wheel wear were measured. Grinding debris will be collected and studied.

(3) Standard Coors ceramics samples $(20 \times 20 \times 6 \mathrm{~mm})$ were used. Two special fixture was made using the wire EDM. Some zirconia samples were ground and showed good results. The same process was tested on alumina parts and could not repeat the same success.

(4) The impact of this project is to possibly reduce the cost of grinding zirconia and also extend the study of cost-effective centerless grinding of zirconia.

\section{Pennsylvania State University, "Effect of Tantala and Niobia Additions on the Thermal Conductivity of Yttria Stabilized Zirconia," Srinivasan Raghavan and Merrilea J. Mayo, HTML No. 98-015.}

\section{TPUC}

The purpose of the current study was to determine the thermal conductivity of zirconia codoped with various amounts of yttria and either tantala or niobia. The objective was to evaluate the above systems for potential thermal barrier applications. Thermal diffusivities, $\alpha$, were measured at HTML by the laser flash thermal diffusivity apparatus on disc shaped pellets coated with platinum and graphite from $100-1000^{\circ} \mathrm{C}$ in air. Specific heat capacities, $\mathrm{C}_{\mathrm{p}}$, were measured, also at HTML, over the same temperature range by differential scanning calorimetry. $\alpha$ and $\mathrm{C}_{\mathrm{p}}$ were then used to calculate thermal conductivity. 
Thermal conductivities of chemistries that contain extrinsic oxygen vacancies, obtained by doping with an excess of yttria over the pentavalent oxide, and proportional to the amount of excess yttria are plotted as a function of temperature in Fig. C-20. Compositions in mole $\%$ are indicated. Z, Y, N, T stand for zirconia, yttria, niobia and tantala respectively. It is seen that inspite of a higher dopant concentration these chemistries do not have a significantly lower thermal conductivity than the 6-8 wt. \% YSZ. Thermal conductivities of chemistries that contain no extrinsic oxygen vacancies, obtained by doping with equal amounts of yttria and the pentavalent oxide, are compared with those of dense YSZ in Fig. C-21. The ternary chemistries are also expected to have densities in excess of $95 \%$ of theoretical density. It is seen that the conductivities are comparable to that of the 6-8 wt. \% YSZ in spite of the absence of oxygen vacancies which are mostly responsible for the low thermal conductivity of YSZ.

These results show that from the thermal conductivity point of view these compositions are comparable to the $6-8 \mathrm{wt}$. \% YSZ that is currently being used for thermal barrier applications.

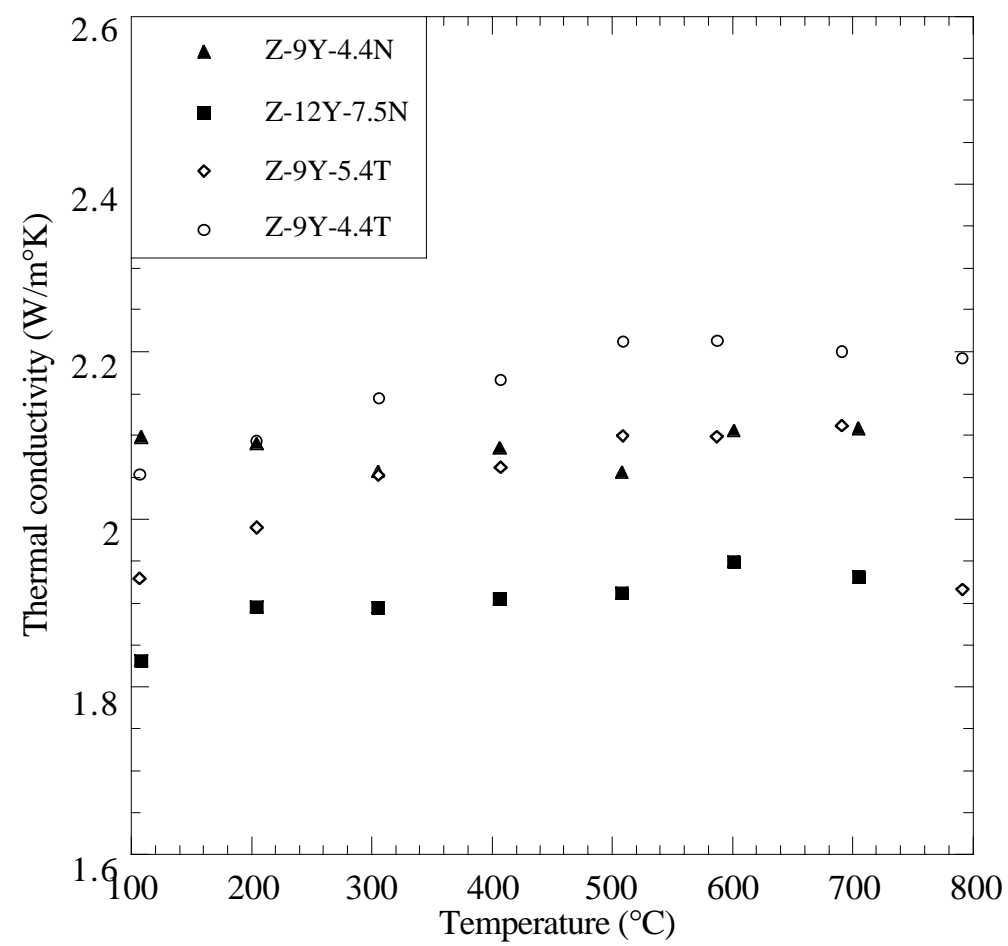

Fig. C-20. Thermal conductivities of compositions containing excess ytrria. 


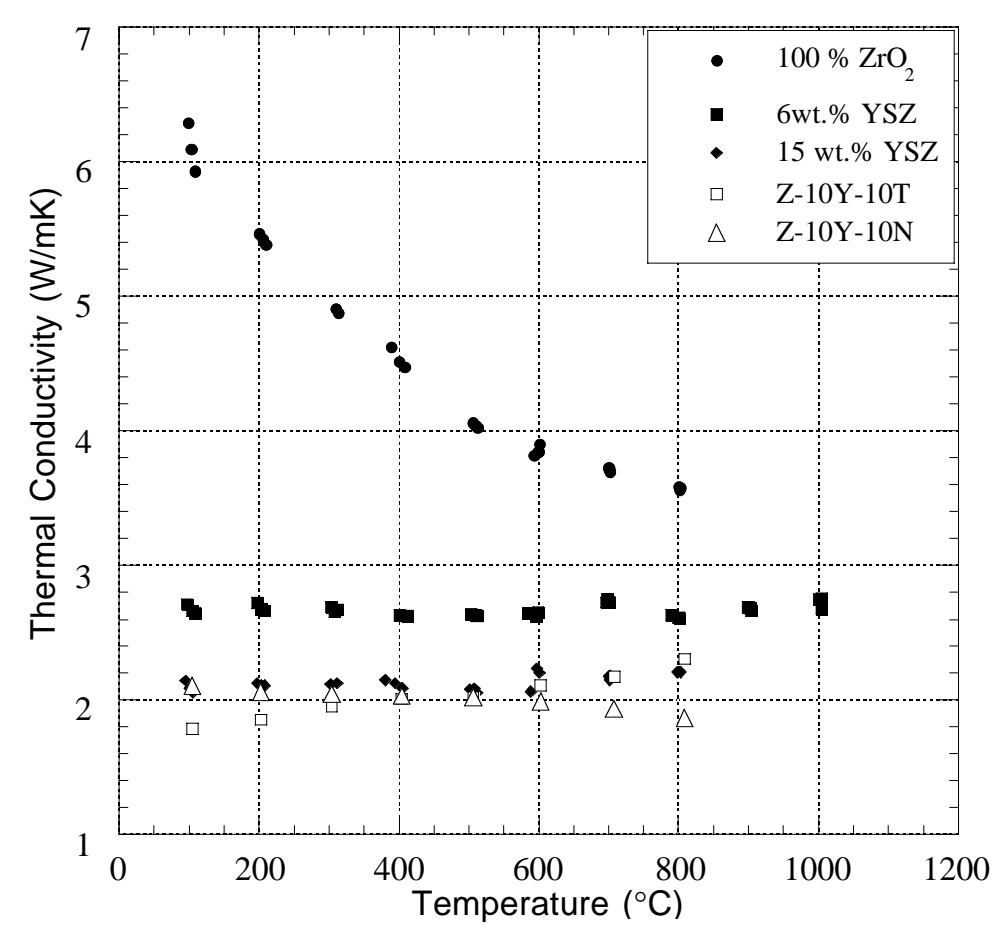

Fig. C-21. Comparison of thermal conductivities of YSZ with those of compositions containing no extrinsic oxygen vacancies (monoclinic zirconia and the $\mathrm{Ta}$ and $\mathrm{Nb}$ doped chemistries).

\section{Southern University, "High Temperature Tensile Property of the Super Alloy IN738LC," Reza A. Mirshams, HTML No. 97-058}

\section{MCAUC}

Three properties of the superalloy IN738LC were investigated in this research: i) precipitate microstructure evolution, ii)tensile properties, and iii) thermal expansion characteristics.

IN738LC is a Ni-base, gamma-prime $\mathrm{Ni}_{3} \mathrm{AI}(\mathrm{Ti})$ precipitate-strengthened alloy. This alloy includes about 20-43 volume \% gamma-prime and also some (Ta, Ti)C at the grain boundaries and in the matrix. Different heat treatments were carried out to study the precipitate evolution mechanisms and kinetics in this superalloy. It was found that the proper solution treatment producing a near single phase supersaturated solid solution condition was $1235^{\circ} \mathrm{C} / 4 \mathrm{~h} /$ water quench (WQ). Solution treatment at $1200^{\circ} \mathrm{C} / 4 \mathrm{~h} / \mathrm{WQ}$, however, produced a refined precipitate microstructure. Aging treatments after both of these solution treatments gave similar microstructures. The precipitates grew in cuboidal form after aging at 1120 to $1130^{\circ} \mathrm{C} / 24 \mathrm{~h}$. However, longer aging times $(>48 \mathrm{~h})$ yield a duplex size precipitate morphology in this temperature range. Likewise, the duplex size morphology developed at $1140^{\circ} \mathrm{C}$, but in a much shorter time (5 min.), and it was stable in the range $1140-1500^{\circ} \mathrm{C}$. 
X-ray diffraction studies showed that different precipitate microstructures possess different preferred orientations. Precipitates tended to have the (220) or (200) orientation. Whereas most of the precipitate microstructures had single texture, the duplex-size precipitate microstructure had the (111) and (200) preferred orientations for the matrix and the precipitates, respectively.

Tensile and thermal expansion tests proved that the size and morphology of the precipitate phase were very effective in the magnitude of these properties. Tensile test were carried out in a range of 650 to $850^{\circ} \mathrm{C}$. Only one set of experiments was carried out on the fine microstructure at $1200^{\circ} \mathrm{C}$ to examine stability of microstructure at very high temperature under tensile loading. Generally, microstructures having fine size precipitates showed higher yield strength, and elasticity modulus; in contrast, microstructures with coarser precipitates exhibited higher elongation, higher strain hardening, and better tensile strength. Fracture characteristics were in the cleavage type with fine precipitates microstructures and in the ductile type with the coarse ones. Thermal expansion of the microstructures with fine precipitates were in general less than that of the microstructures with coarse precipitates. A doctoral dissertation was developed on this research and no further investigation is in progress now.

\section{Southern University, "The Modeling of Dynamically Recrystallized Titanium-Aluminde Alloy Using Dislocation Density in Numerical Simulation," Reza Mirshams, HTML No. 98-079}

\section{MCAUC}

Gamma titanium-aluminide is being developed for use for high temperature engine components in the aerospace, aeronautical, and automobile industries. Hot forging processes are used in developing turbine blades and other products for these industries. Intergration of microstructure characteristics in the forging process has been investigated by different researchers. The main purpose of this investigation is to develop a mathematical relationship for the flow strength under hot deformation based on microstructural evolution during the hot forming. For engineering applications, gamma titanium-aluminide, which is composed of 46-50 at. $\% \mathrm{Al}$, is desired in the duplex microstructure. This alloy is difficult to process because it requires a temperature of 0.60-0.75 melting point to properly control the microstructure and grain growth. At ORNL, compression tests were conducted in the temperature range between $950-1100{ }^{\circ} \mathrm{C}$ at strain rates of $0.001 / \mathrm{s}$ and $0.1 / \mathrm{s}$ to develop a duplex gamma with $5-20 \%$ alpha-two microstructure. By using the experimental data, mathematical relationships were verified for different stages of hardening, recovery, recrystallization, and grain growth. The simulation was based on the theory used in the Sandström and Lagneborg model and the numerical analysis approach by Pietrzyk. The simulation proved that the model and numerical simulation were valid for compression testing of titanium-aluminide alloys at constant strain rates. The results of this part of project are going to be integrated in a finite element program for prediction of microstructure in the forged parts. A master of science thesis developed on this research work and a paper will be presented soon. 


\section{University of Alabama at Birmingham, "Thermal Diffusivity of Refractory Sands and Coatings for the Lost Foam Casting Process," T. Molibog, HTML No. 97-033}

\section{TPUC}

The thermal conductivity of unbonded casting sands has been measured. The sands studied were Silica 40/60, Olivine 40/140, and Mullite 30/50 (see Fig. C-22). The Hot Disk method developed by the Swedish company Hot Disk was used for measurements. The Hot Disk method is based on the Transient Plane Source technique and uses a sensor that consists of an electrically conductive pattern (Ni foil) in the form of a double spiral sandwiched between two sheets of Mica insulation. The sensor works both as a heater and as a temperature sensor. The method allows for measurements of thermal conductivity, thermal diffusivity and specific heat of solid and granular materials.

The conductivity of sands was measured in the temperature range of RT- $950^{\circ} \mathrm{C}$ and at two different sand densities: loose (low density) and compacted (high density). The results of the measurements can be summarized as follows. Thermal conductivity of sand is a function of (a) temperature and (b) packing density. For Silica and Olivine sands, a $\sim 9 \%$ increase in density resulted in an $\sim 18 \%$ increase in conductivity. For Mullite sand, a $\sim 7 \%$ increase in density resulted in a $\sim 10 \%$ increase in conductivity. The smaller increase in density and conductivity can be explained by the spherical shape of the Mullite sand particles. Among the three sands, the Silica sand had the highest conductivity at a low density at temperatures below $600^{\circ} \mathrm{C}$. The thermal conductivities of compacted sands did not differ more than $10 \%$. The conductivity data on sands is currently being compared to the literature values. The thermal conductivity measurements of casting sands have completed the 2-year research project on thermal properties of casting sands and Lost Foam coatings. During the course of the research, the thermal properties of casting sands and Lost Foam coatings such as thermal conductivity, thermal diffusivity and specific heat capacity have been measured. The data obtained will be used in computer modeling of the Lost Foam casting process. 
Thermal Conductivity of Sands at High Density.

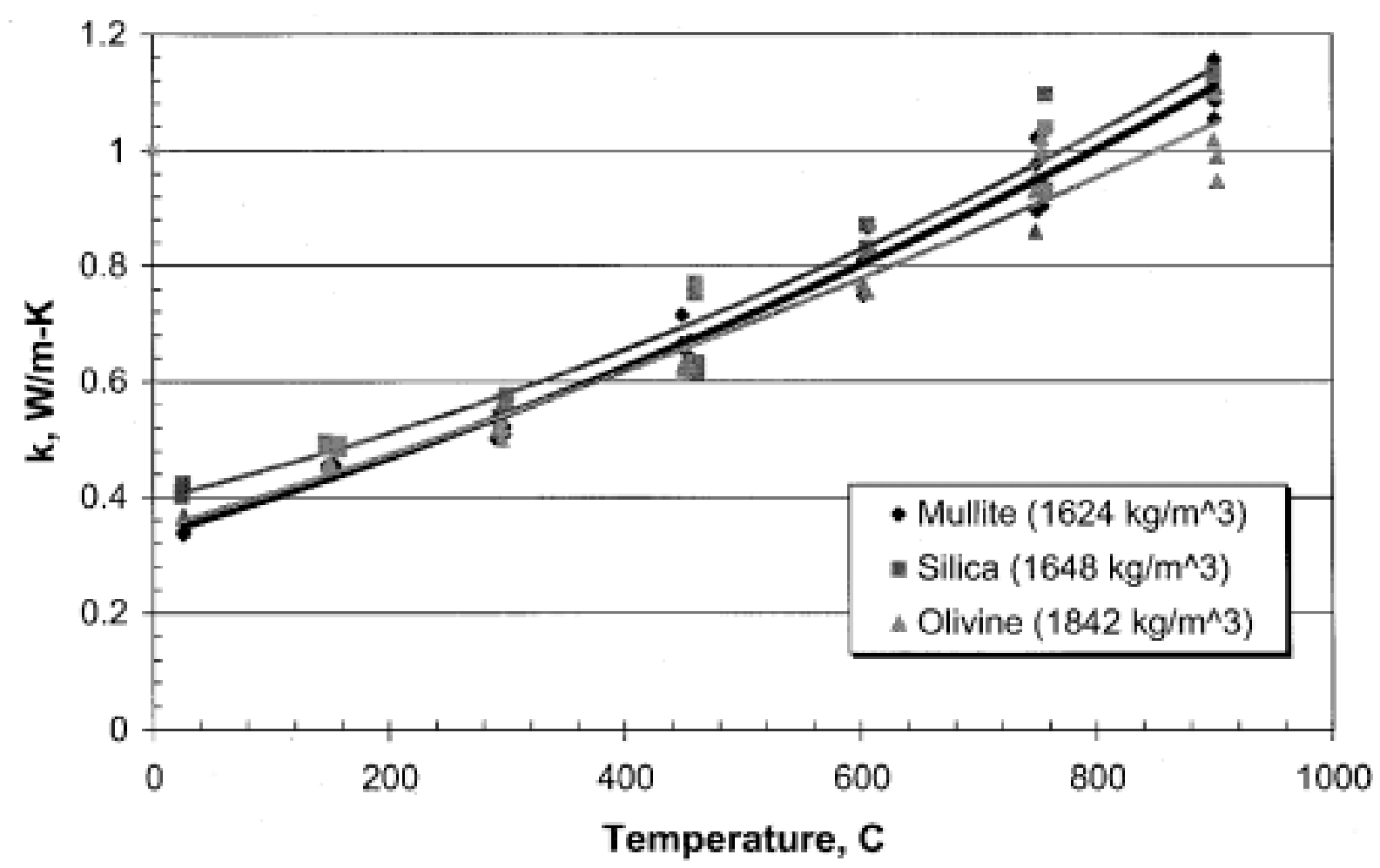

Fig. C-22. Thermal conductivity of sands at high density.

\section{University of Cincinnati, "Mechanism of Template Removal in Zeolite Membrane Synthesis," Junhang Dong and YU. S. Lin, HTML No. 98-020}

\section{DUC/RSUC}

$\mathrm{TPA}^{+1}$ is commonly used as a structure directing template in synthesis of silicate/ZSM-5 zeolites. To activate the zeolite, the TPA template must be removed, usually by calcination at $\sim 450^{\circ} \mathrm{C}$. Recently, thin polycrystalline silicate/ZSM-5 membranes were successfully synthesized on porous ceramic supports, such zeolite/ceramic composite membranes offer great potential of applications in gas and liquid separations. Since the thermal behavior of the silicate/ZSM-5 film and the substrate (alpha alumina or alumina supported YSZ membrane) are much different, heattreatment (membrane activation) may cause crack formation in the zeolite layer which can seriously reduce the separation factor.

The goal of this research project was to study the thermal behavior of the zeolite layer and the support and determine the residual stress in the zeolite film under the condition of calcination. Thermal expansion/contraction coefficients of the substrate and the zeolite layer was measured by HTXRD. It was demonstrated by the HTXRD experiments that the unit cell of 
silicate/ZSM-5 crystal shrinks while those of the substrates expand (as shown in Fig. C-23). Thus a mechanical stress may be developed in the zeolite layer and results in crack formation. This information provides understanding of the mechanism of crack formation in the supported zeolite film during membrane activation.

The measurement of residual stress in the supported zeolite film has not been conducted due to some technical problems and will be done as soon as we find a way to solve the problems.

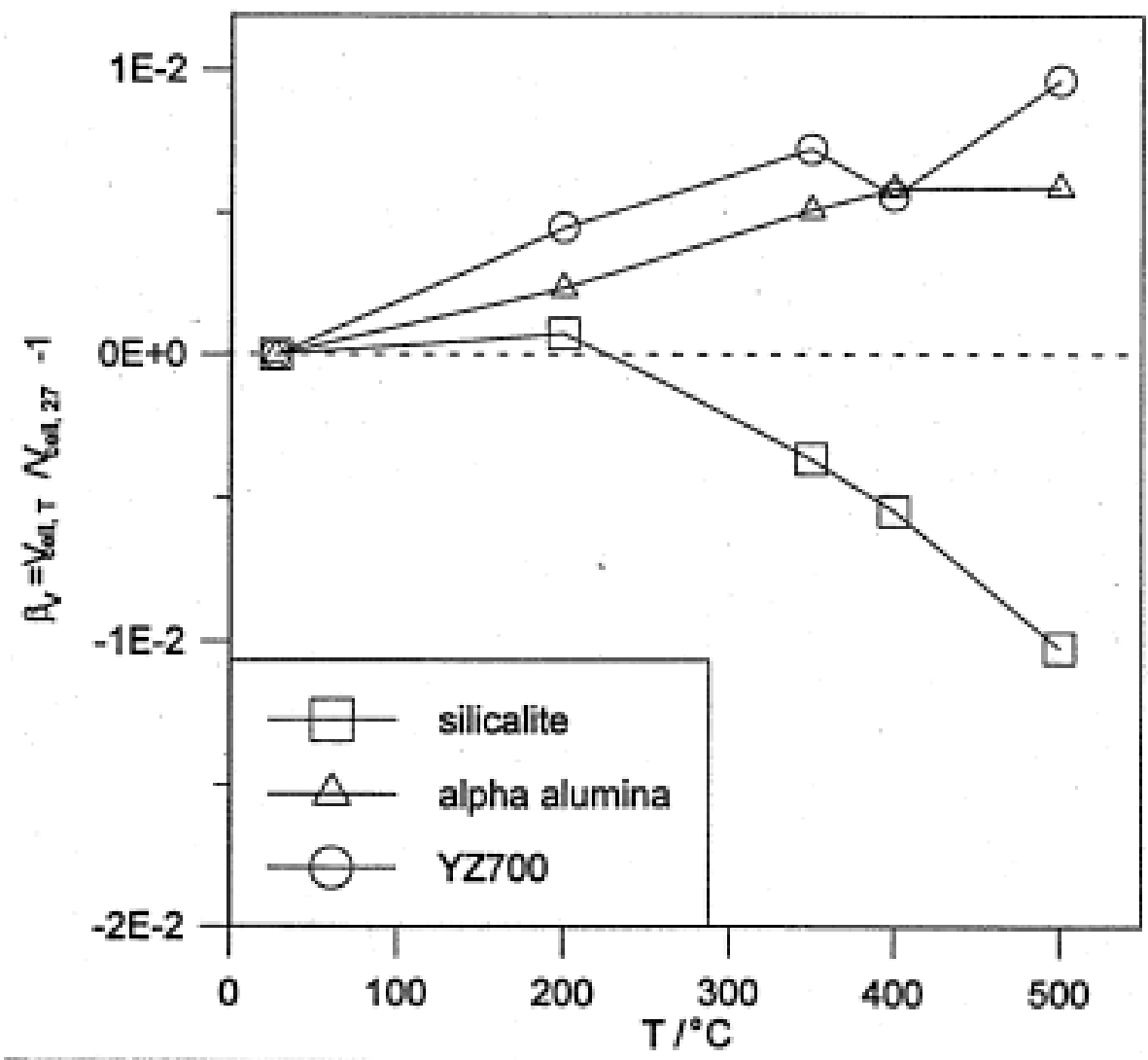

Fig. C-23. Thermal behavior of the silicate film and the substrates during calcination.

\section{University of Connecticut, "Nanoscale Orthorhombic Zirconia," Sandy C. Schulte, HTML No. 98-074}

\section{MAUC/TPUC/DUC}

Research conducted at the HTML at Oak Ridge National Laboratory was centered around the use of the HF-2000 High Resolution Transmission Electron Microscope (HRTEM). Sample preparation methods to view the material were also developed at the lab. The work was conducted from the 5 th to the 9 th of October 1998. This work was carried out with the assistance of Dr. Karren More and the staff of the HTML laboratory. 
The objective of the work was to determine the effect of synthesis conditions on the crystallite size and phase of zirconium oxide produced by sol-gel methods in our laboratory. Previous work in our laboratory using dynamic light scattering indicated that as the amount of acid reactant in the process was reduced, the initial particle size became larger. Corresponding to this change in crystallite size was a transformation in structure, from an apparent meta-stable high pressure orthorhombic phase (found at $21 \mathrm{GPa}$ and $1000^{\circ} \mathrm{C}$ ) to a meta-stable tetragonal zirconium oxide phase as detected by electron diffraction images of single crystals. To assure that the change in the structure with crystallite size was reproducible, fresh reagent, $1 \mathrm{~N}$ nitric acid and anhydrous 1-butanol were used to prepare samples.

Using the HRTEM it was possible to image the crystallites and crystal lattices in each of the samples. From the micrographs of the imaged lattices, Fast Fourier Transforms(FFT) were used to obtain d-spacings for each of the samples. The results of the HRTEM imaging produced sizing data that conflicted with that obtained by dynamic light scattering. HRTEM images indicated that the primary synthesized at lower acid concentrations were unchanged as a function of acid concentration. This revealed that at lower acid concentrations, dynamic light scattering was detecting larger agglomerates rather than larger particles (crystallites). Further, the FFT analysis of imaged lattice micrographs showed that:

- crystallite size did not change with acid concentration. Only agglomerate size changed;

- the zirconium oxide synthesized at ambient pressure and temperature was the highest pressure form of orthorhombic phase, confirming conclusions previously derived from single particle electron diffraction; and

- the synthesis produced the orthorhombic structure in each sample, regardless of the $1 \mathrm{~N}$ nitric acid concentration indicating this was not the factor affecting the change in structure.

These results suggest some factor other than crystallite size, such as possible interaction with excess water, influenced the phase distribution.

In summary, these results have been drawn from our research at HTML:

- confirmed that the first major objective of the project had been completed, that the highest pressure phase of orthorhombic zirconium oxide had been synthesized.

- gave a clearer understanding of the synthesis process developed to produce this form of zirconium oxide.

- were instrumental in providing data which suggest that factors other than crystallite size (e.g. surface energy) contribute to the formation of specific metastable phases in nanoscale zirconia. 


\section{University of Illinois, "Nanoindentation Studies of Phase Transformations in Semiconductors and Ceramics," Yury Gogotsi, HTML No. 97-071}

\section{MCAUC}

It has been shown that some hard materials such as silicon undergo a phase transformation under contact loading. In case of indentation, such phase transformation is achieved even at a very low load since the contact area is small and the pressure is sufficiently high. Here we conducted analysis of indentation diagrams based on information on indentation-induced phase transformations obtained from previous Raman analysis of indentation on semi-conductors. Nanoindentation experiments have been conducted at ORNL on $\mathrm{Si}<001>, \mathrm{Si}<110>, \mathrm{Ge}<100>$, $\mathrm{GaAs}<100>$, InSb $<111>$, various Zirconia, $\mathrm{SiC}$ and diamonds. The focus of the experiments was to observe the material's response under a sharp indenter at various loading conditions with a particular attention to the effect of loading/unloading rate. In our experiments, Si was consistent in displaying the "pop-out" effects, which can be explained by the reverse phase transformation from a metallic phase. Volume change upon reverse phase transformation of metallic phases results either in a "pop-out" (or a kink) or in a slope change of the unloading part of the indentation diagram. Indentation-induced phase transformation at room temperature have been observed in $\mathrm{Si}$, Ge, InSb, but not in GaAs.

The phase transformation of Si during nanoindentations was confirmed subsequently using Raman microspectroscopy. Presence of transformed phases, namely, Si-XII, Si-III, and SiI'(amorphous), was confirmed by Raman microspectroscopy. From the studies with Raman microspectroscopy, we deduce that the "pop-out" on the unloading curve should be assigned to $\mathrm{Si}-\mathrm{II} \rightarrow \mathrm{Si}$-XII, rather than to $\mathrm{Si}-\mathrm{II} \rightarrow \mathrm{Si}$-III transformation. The contact pressure needed to cause the reverse phase transformation decreased with increasing unloading rate. A similar trend was also observed in InSb and Ge.

The slope of the unloading curve for Ge, GaAs, and InSb was found to decrease as the maximum load increases. More importantly, the slope of the unloading curve for some of the $\mathrm{InSb}$ and GaAs samples showed a strong dependency on the unloading rate. SiC, Zirconia and diamonds did not display any significant responses in these studies.

\section{University of Kentucky, "Residual Stresses in YAG- $\mathrm{Al}_{2} \mathrm{O}_{3}$ Directionally Solidified Eutectics," E. C. Dickey and C. S. Frazer, HTML No. 98-050}

\section{RSUC/DUC}

Two major problems associated with structural ceramics are lack of damage tolerance and insufficient strength and creep resistance at the very high temperatures of interest for aerospace applications. A large body of work has demonstrated that acceptable levels of toughness may be achieved in inherently brittle materials by incorporating fibrous reinforcements and carefully controlling the interface between matrix and fibers.[1] However, the constituents of man-made composites are rarely thermodynamically compatible. During extended high temperature 
operation, the poor oxidation resistance of $\mathrm{C}$ and $\mathrm{BN}$, common interface coatings, is a major impediment to the use of these materials in applications requiring cyclic fatigue resistance under thermomechanical loads.[1] Oxide-based composites are therefore particularly desirable for oxidative environments. However, polycrystalline oxide fibers based on alumina or mullite are currently limited to about $1000{ }^{\circ} \mathrm{C}$ by low creep resistance and by microstructural instabilities associated with grain growth.[2] Directionally solidified eutectics (DSEs) offer advantages in both improved ease of fabrication and superior high-temperature properties. The high-temperature microstructural stability, large aspect ratio and strong interphase bonding found in many DSE composites contributes to their superior creep resistance, compared to that of conventional ceramics. The phases comprising a eutectic are thermodynamically compatible at higher homologous temperatures than man-made composites and, as such, offer the potential for superior high-temperature properties.[3-6] The mechanical properties of two-phase eutectics can be superior to that of either constituent alone due to strong constraining effects provided by the interlocking microstructure.

Oxide eutectic temperatures are usually higher than $1700^{\circ} \mathrm{C}$, so during the solidification processing, enormous residual stresses can accumulate in the material if there are appreciable differences in the thermal expansions between the two phases. Since residual stresses will ultimately affect the mechanical behavior of the DSE, it is important to understand residual stresses in this class of materials. For a given DSE system, it is difficult to regulate the residual stress state, since neither the volume fractions nor the crystallographic orientation relationships can be controlled appreciably. Because there are few degrees of freedom, if low residual stresses are important, it is necessary to choose eutectics in which the two phases have similar thermal expansion behaviors. Such is the case for $\mathrm{YAG}-\mathrm{Al}_{2} \mathrm{O}_{3}$ in which the thermal expansion properties are within approximately $5 \%$ of each other. Residual stress measured by x-ray diffraction at HTML, shown in Fig. C-24, indicate that no significant stresses are present at room temperature within the experimental measurement error.[7] This is shown in contrast to a DSE system, $\mathrm{NiO}-\mathrm{ZrO}_{2}$ (cubic), in which significant differences in thermal expansion behavior exist between the two phases and lead to residual stresses approaching one GPa (Fig. C-25).[8]

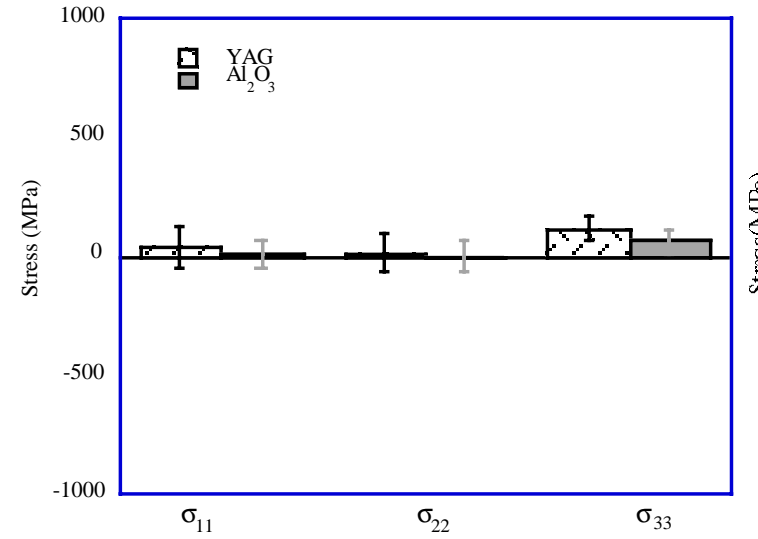

Fig. C-24. Residual stresses in a $\mathrm{YAG}-\mathrm{Al}_{2} \mathrm{O}_{3}$ DSE as measured by $\mathrm{X}-\mathrm{ray}$ diffraction.

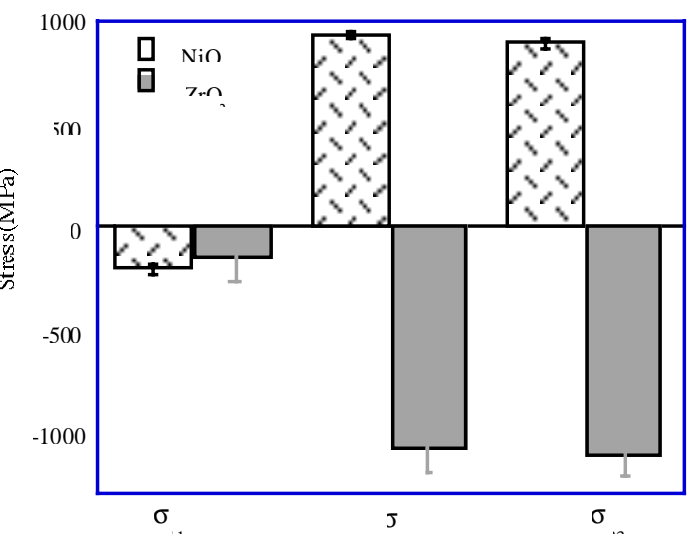

Fig. C-25. Residual stresses in a $\mathrm{NiO}-\mathrm{ZrO}_{2}$ (cubic) DSE 
Upper estimates of predicted residual stresses for $\mathrm{YAG}-\mathrm{Al}_{2} \mathrm{O}_{3}$ assuming complete interfacial constraint and a simplified lamellar geometry are on the order of $50 \mathrm{MPa}$ (tensile in $\mathrm{Al}_{2} \mathrm{O}_{3}$ and compressive in YAG), well below the measurement error. To assess internal stresses currently below our experimental measurement accuracy, finite element modeling was employed. Fig. C-26 shows the finite element results from a YAG- $\mathrm{Al}_{2} \mathrm{O}_{3}$ tricrystal subject to cooling from the eutectic temperature to room temperature. It was assumed that the interface was completely constrained (i.e. no stress limiting processes such as slip occurred). As can be seen in Fig. C-26, compressive stresses develop in the YAG near the interface but decay towards the center of the crystal, while tensile stresses develop in $\mathrm{Al}_{2} \mathrm{O}_{3}$ near the interface. Although the average stresses in both phases are very small, the stresses at the interfaces (on the order of $100 \mathrm{MPa}$ ) may have consequences for the mechanical behavior of the interfaces. Future finite element studies will explore more complicated geometries that more closely reflect the actual YAG- $\mathrm{Al}_{2} \mathrm{O}_{3}$ DSE microstructure.

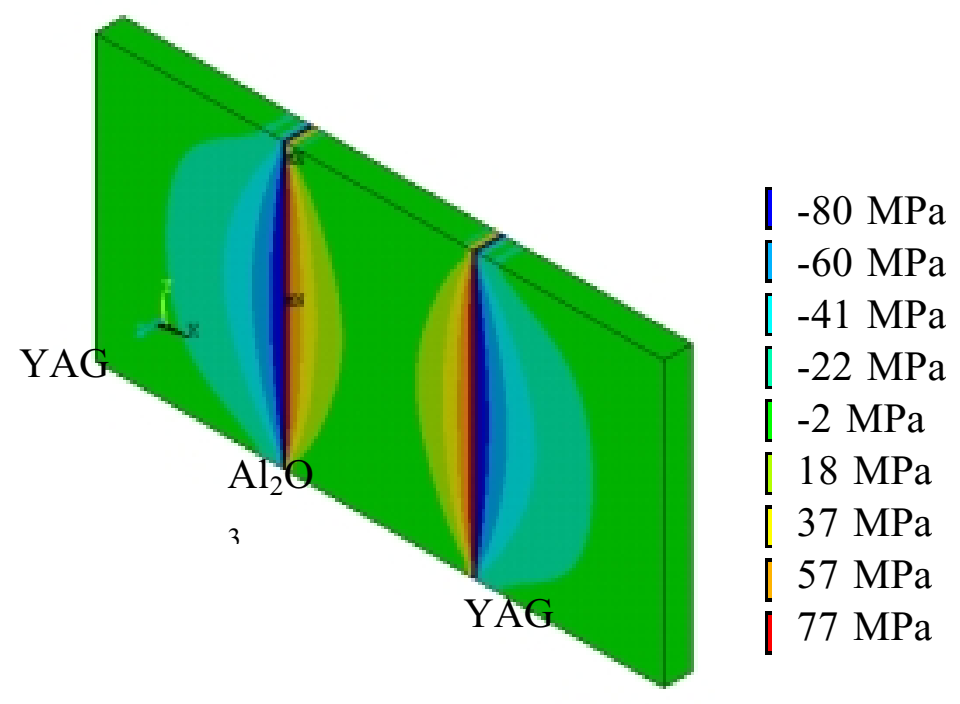

Fig. C-26. Finite element model of a $\mathrm{YAG}-\mathrm{Al}_{2} \mathrm{O}_{3}$ trycrystal subject to cooling from $1700^{\circ} \mathrm{C}$ to room temperature assuming complete interfacial constraint.

\section{References}

1. A. G. Evans, in "Processing and Design Issues in High Temperature Materials," eds. N.S. Stoloff and R. H. Jones, TMS Publications, (1996) 3-34.

2. R. E. Tressler and J. A. DiCarlo, Proc. for HTCMC-2, Ceramic Trans., 57 (1995) 141-153.

3. V. S. Stubican and R. C. Bradt, Ann. Rev. Mater. Sci., 11 (1981) 267-297.

4. A. Sayir and L. E. Matson, in HITEMP Review Vol. 1 NASA CP-10082, (1992) pp. 83.1 83.13.

5. A. Sayir, R. M. Dickerson, H. M. Yun, S. Heidger and L. E. Matson, in HITEMP Review Vol. 1, NASA CP-10146, (1994) pp. 74.1 - 74.12. 
6. A. Sayir and S. C. Farmer, in "Ceramic Matrix Composites-Advanced High-Temperature Structural Materials," eds., R. A Lowden, M. K. Ferber, J. R. Hellmann, K. K. Chawla, and S. G. DiPietro, Mat. Res. Soc. Proc., 365 (1995) 11-21.

7. E.C. Dickey, C.S. Frazer, T.R.Watkins and C.R. Hubbard, "Residual Stresses in HighTemperature Ceramic Eutectics," J. Europ. Cerm. Soc. (1999) in press.

8. E.C. Dickey, C.R. Hubbard, V.P. Dravid"Interlamellar Residual Stresses in Single Grains of $\mathrm{NiO}-\mathrm{ZrO}_{2}$ (cubic) Directionally Solidified Eutectics," Journal of the American Ceramic Society, 80 [12] (1997) 2773-80.

\section{University of Massachusetts /Osram Sylvania, "High Resolution Transmission Electron Microscopy and Nanoanalysis of Polycrystalline Alumina," Changmo Sung, HTML No. 98-009}

\section{MAUC}

The goal was to understand microsegregation of $\mathrm{Zr}$ and $\mathrm{Y}$ at grain boundaries since FEG provides us with very high electron current as well as a fine probe size. Also, the question about amorphous phase formed on grain boundaries in the Na-attacked samples can be understood in terms of $\mathrm{Na}$ segregation and the presence of elements such as $\mathrm{Zr}, \mathrm{Y}, \mathrm{Mg}$, and $\mathrm{Tb}$. We have tried ultra-high resolution images of grain boundaries along with high spatial resolution analysis of EDXS. The followings are summaries of findings.

1) DZW-10 (control) posttest, $1500 \mathrm{hrs:} 500 \mathrm{MgO}, 350$ ppm $\mathrm{Y}_{2} \mathrm{O}_{3}$ large amount of amorphous region.

High Na peak found.

YAG phases on grain boundaries

No segregation of $\mathrm{Y}_{2} \mathrm{O}_{3}$ and $\mathrm{MgO}$.

No Na segregation in regular G.B.

2) DZU-7 (DS-8) posttest, 1500 hrs: $200 \mathrm{MgO}, 400$ ppm $\mathrm{ZrO}_{2}, 20$ ppm $\mathrm{Y}_{2} \mathrm{O}_{3}$ medium size amorphous region.

$\mathrm{No} \mathrm{Na}$ found in this region.

$\mathrm{Y}_{2} \mathrm{O}_{3}$ containing $\mathrm{ZrO}_{2}$ phases g.b. segregation of $\mathrm{Zr}$.

In general, clean boundaries observed.

3) DS-37-15A, as-sintered: $200 \mathrm{MgO}, 400$ ppm $\mathrm{Tb}_{2} \mathrm{O}_{3}, 20$ ppm $\mathrm{Y}_{2} \mathrm{O}_{3}$

Tb-Al-(Mg)-Y-O phase

Tb segregation in g.b. found.

$\mathrm{No} \mathrm{Tb}$ in matrix

4) DS-37-3, 2500 hrs. Surface section: $200 \mathrm{MgO}, 400$ ppm $\mathrm{Tb}_{2} \mathrm{O}_{3}, 20$ ppm $\mathrm{Y}_{2} \mathrm{O}_{3}$ amorphous region observed without $\mathrm{Na}$.

Tb-Al-(Mg)-Y-O phase

No segregation in regular g.b. 
$\mathrm{Tb}$ and $\mathrm{Y}$ segregation near $\mathrm{Tb}-\mathrm{Y}-(\mathrm{Mg})-\mathrm{Al}-\mathrm{O}$ phase

This is a middle section sample. Inner surface is being prepared again.

5) DS-33R-14 as-sintered: $200 \mathrm{MgO}, 180$ ppm $\mathrm{ZrO}_{2}, 350$ ppm $\mathrm{Y}_{2} \mathrm{O}_{3}$

YAG phase + Ca peak

g.b. segregation of $\mathrm{Y}$ and $\mathrm{Zr}$.

No $\mathrm{Y}$ and $\mathrm{Zr}$ found in matrix

6) DS-33-1 (2500hrs) posttest: $200 \mathrm{MgO}, 180$ ppm $\mathrm{ZrO}_{2}, 350$ ppm $\mathrm{Y}_{2} \mathrm{O}_{3}$

small amount of amorphous region.

$\mathrm{Na}$ has not been found.

Zr-containing YAG phase

g.b. segregation of $\mathrm{Y}$ and $\mathrm{Zr}$.

7) $\mathrm{C}-4,1500 \mathrm{hrs}$, ID surface: $500 \mathrm{MgO}, 350 \mathrm{ppm} \mathrm{Y}_{2} \mathrm{O}_{3}$

large amount of $\mathrm{Na}$ attacked region with significant $\mathrm{Na}$ peak.

Beta-alumina containing $\mathrm{Mg}$ and $\mathrm{Na}$.

g.b. segregation of $\mathrm{Y}_{2} \mathrm{O}_{3}$.

In summary, reactions of PCA arc tubes with $\mathrm{Na}$ at high temperatures depended on the diffusion of the products through the PCA wall. This manifested by Al depositing on and darkening the inner surface of the lamp's outer glass bulb. The rates of the reactions and grain boundary diffusion were related to the structure and composition of the grain boundaries of PCA.

Grain boundary degradation was observed, characterized by the formation of an amorphous or nanocrystalline Al-O or Na-Al-O phase, and the formation of cativities at grain boundaries. A high resistance to sodium attach required the absence of spinel second phase and a low grain boundary $\mathrm{MgO}$ level in PCA. Tailoring of the $\mathrm{MgO}$ content by (1) reducing the $\mathrm{MgO}$ level in the dopant formulation, (2) doping with tetravalent cations to charge-compensate for the $\mathrm{Mg}$ at $\mathrm{Al}$ lattice sites, and/or (3) forming a second phase to absorb supersaturated $\mathrm{MgO}$ in-situ, such as Tb-Al-O, significantly improved the resistance of PCA tubes to sodium attack.

\section{University of Tennessee (UT Space Institute), "Ultrahard Ceramic Coatings on Metals," Narendra B. Dahotre, HTML No. 98-031}

\section{MCAUC}

Superhard $\mathrm{TiB}_{2}$ (titanium diboride) based "composite" coatings on 1010 steel are being developed using laser surface engineering (LSE) at University of Tennessee Space Institute. $\mathrm{TiB}_{2}$ has excellent wear resistance and other high temperature properties such as resistance to oxidation and hot corrosion by molten metal viz. Al and Zn. LSE produces composite coating where superhard $\mathrm{TiB}_{2}$ particles are embedded in Fe matrix on surface. It is difficult to measure mechanical properties such as hardness $(\mathrm{H})$ and Young's Modulus $(\mathrm{E})$ using a microhardness tester as it provides a value which is a combination of all phases due to the load ranges used with the microhardness tester. The nanoindenter, on the other hand, provides high resolution in both 
positioning the indents and measuring the mechanical properties at various locations such as $\mathrm{TiB}_{2}$ particles of various size, $\mathrm{TiB}_{2}$ particle/Fe dendrite interface, heat affected zone (HAZ) and unaffected substrate. In the present work, mechanical properties such as $\mathrm{H}$ and $\mathrm{E}$ were measured for various LSE samples as a function of processing parameters such as laser traverse speed and power.

The results were very consistent and duplicated over a range of several indentations. Hardness was measured up to $34 \mathrm{GPa}$ for pure $\mathrm{TiB}_{2}$ particle which is very consistent with the hardness of monolithic cearmic such as $\mathrm{TiB}_{2}$. An intermediate level of hardness (10-15 GPa) was observed for the "mixed" zone which had a high concentration of very fine $\mathrm{TiB}_{2}$ particles and $\mathrm{Fe}$ dendrites. Hardness in the HAZ and substrate were significantly lower in the range of 2-4 GPa. Corresponding Young's Modulus values were also calculated from the data which will assist in computation of effective Young's Modulus of composite coating. There was no crack at the $\mathrm{TiB}_{2} / \mathrm{Fe}$ interface which suggests high interfacial strength between ceramic and metal.

Figure C-27 shows the load-displacement curve for an indentation on ${\mathrm{a} i B_{2}}_{2}$ particle. The hardness is $32.7 \mathrm{GPa}$ and the Young's modulus is $547 \mathrm{GPa}$.

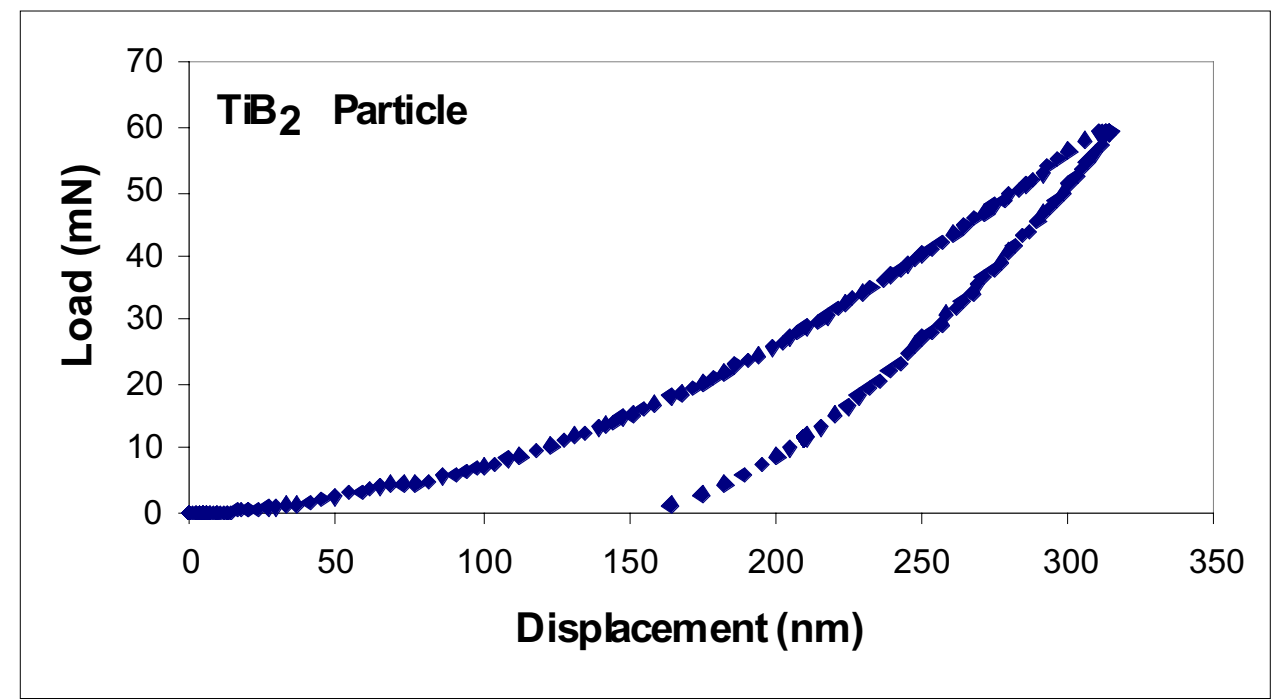

Fig. C-27. Load-displacement curve for an indentation on a $\mathrm{TiB}_{2}$ particle.

\section{University of Tennessee (UT Space Institute), "Ultrahard Ceramic Coatings on Metal," Narendra B. Dahotre, HTML No. 98-036}

\section{MAUC}

$\mathrm{TiB}_{2}$ based superhard "composite" coatings on steel surface are being developed using laser surface engineering (LSE) at University of Tennessee Space Institute (UTSI). Laser surface engineering incorporate high cooling rates and hence leads to formation of novel microstructure and phase(s). TEM is the only technique to characterize such novel phase(s). Moreover, TEM 
investigations provide detailed information about $\mathrm{TiB}_{2} / \mathrm{Fe}$ interface. Ceramic/metal interface is also characterized at atomic level using high resolution transmission electron microscopy (HRTEM). It provided a detailed information about "composite" coating morphology, reactions occuring at ceramic/metal interface and level of atomic misfit at interface. This would assist in predicting the mechanical properties of these coatings.

Please see some of these TEM images at the following address:

http://work5.utsi.edu:8000/ aagarwal/tem1.jpg http://work5.utsi.edu:8000/ aagarwal/tem2.jpg http://work5.utsi.edu:8000/ aagarwal/tem3.jpg http://work5.utsi.edu:8000/ aagarwal/tem4.jpg http://work5.utsi.edu:8000/ aagarwal/tem5.jpg http://work5.utsi.edu:8000/ aagarwal/tem6.jpg

\section{Wichita State University, "Determination of the Lattice Constants and Coefficient of Thermal Expansion of Selected Substrate Materials Used to Grow GaN Epitaxial Layers," J. Chaudhuri, HTML No. 98-055.}

\section{DUC/TPUC}

Recent successes of GaN compound semiconductor light emitting diodes point to the future use of these materials in displays, optical data storage, reprographics, underwater communications, etc. Their direct optical band gaps span the UV-orange spectral region. They are mechanically robust, with high melting temperature and good resistance to chemical attack. These materials offer several advantages over their main competitors, such as II-VI compounds and silicon carbide, in that they offer longer device lifetimes, higher efficiencies and higher powers.

The problems which stand in the way of realization of a laser diode made of GaN are: (1) very high densities of structural imperfections, that may be described either as dislocations or grain boundaries, (2) relative difficulty of p-doping, ascribed to acceptor passivation and (3) the presence of an uncontrolled deep center, that contributes to a strong yellow luminescence band in competition with the band-edge emission. All of these problems relate, to a greater or lesser extent, to the lattice mismatch that exist in all cases between the GaN epilayer and the underlying substrate. Use of the novel oxide substrates for the epitaxial growth of GaN and its III-N alloys might be the course to overcome some of these problems. These oxide substrates, namely, $\mathrm{LiAlO}_{2}, \mathrm{LiGaO}_{2}$, and $\mathrm{NdGaO}_{3}$, offer much better lattice matching than any of the conventional substrates (i.e. $\mathrm{Al}_{2} \mathrm{O}_{3}$ and $6 \mathrm{H}-\mathrm{SiC}$ ) to grow these materials.

Since, the film deposition is generally carried out at high temperatures, lattice parameters at elevated temperature and coefficient of thermal expansion (CTE) should be known to estimate lattice parameter mismatch. No lattice parameters at elevated temperature and CTE values for $\mathrm{LiAlO}_{2}$ and $\mathrm{LiGaO}_{2}$ are available. These values have been previously published for $\mathrm{NdGaO}_{3}$, but the data is scatter from author to author. The purpose of the present study was to determine the 
lattice parameters and CTE of these semiconductors at high temperature. This study used the high temperature x-ray diffraction and dilatometry facilities at HTML. In addition, the values of CTE and high temperature lattice parameters of $\mathrm{GaN}$ were determined. Thermal analysis was also performed on $\mathrm{NdGaO}_{3}$ only to identify any structural transitions.

High temperature x-ray diffraction (HTXRD) measurements were conducted using a Scintag PAD X vertical $\theta / \theta$ goniometer equipped with a modified Buehler HDK-2 diffraction furnace. The diffractometer utilized $\mathrm{CuK} \alpha$ radiation $(45 \mathrm{kV}$ and $40 \mathrm{~mA})$ and a $\mathrm{Si}(\mathrm{Li})$ Peltier-cooled solid state detector. The data were collected as step scans, with a step size of $0.02^{\circ} 2 \theta$ and a count time of $1 \mathrm{sec} / \mathrm{step}$ between 30 and $85^{\circ} 2 \theta$. All data were collected in $1 \mathrm{~atm}$ of flowing He gas. The sample temperature was monitored with a $\mathrm{Pt} / \mathrm{Pt}-10 \% \mathrm{Rh}$ thermocouple spot-welded to a $\mathrm{Pt}-30 \% \mathrm{Rh}$ heater strip on which a thin layer of the powder was dispersed. The calibration of the thermocouple was verified with an optical pyrometer. Data were collected on heating at room temperature, $200,400,600,800,1000$, and $1200{ }^{\circ} \mathrm{C}$ and on cooling at room temperature.

Table C-4 shows the mean CTE values calculated from the data obtained in this study and compared with the values obtained by other researchers.

Table C-4. Mean CTE values calculated for the data collected under user project 98-055 and by Leszczynski et al. ${ }^{1}$ the mean CTE values reported by Maruska and Tietjen ${ }^{2}$

\begin{tabular}{|c|c|c|c|c|c|c|}
\hline $\begin{array}{l}\text { Temperature } \\
\text { (C) }\end{array}$ & $\begin{array}{c}\mathrm{CTE}_{\mathrm{a}} \\
\text { Ref. 1 } \\
\left(\mathrm{x} 10^{-6}\right)\end{array}$ & $\begin{array}{c}\mathrm{CTE}_{\mathrm{a}} \\
\text { This study } \\
\left(\mathrm{x} 10^{-6}\right)\end{array}$ & $\begin{array}{l}\mathrm{CTE}_{\mathrm{a}} \\
\text { Ref. 2 } \\
\left(\mathrm{x} 10^{-6}\right)\end{array}$ & $\begin{array}{l}\mathrm{CTE}_{\mathrm{c}} \\
\text { Ref. 1 } \\
\left(\mathrm{x} 10^{-6}\right)\end{array}$ & $\begin{array}{c}\mathrm{CTE}_{\mathrm{c}} \\
\text { This study } \\
\left(\mathrm{x} 10^{-6}\right)\end{array}$ & $\begin{array}{l}\mathrm{CTE}_{\mathrm{c}} \\
\text { Ref. 2 } \\
\left(\mathrm{x} 10^{-6}\right)\end{array}$ \\
\hline 45.5 & 3.2 & & & 2.8 & & \\
\hline 100 & 3.1 & & & 2.1 & & \\
\hline 111 & & 5.1 & & & 5.2 & \\
\hline 155 & 3.8 & & & 2.8 & & \\
\hline 205 & 3.8 & & & 2.7 & & \\
\hline 227 & & & & & & 3.2 \\
\hline 255 & 4.4 & & & 2.7 & & \\
\hline 300 & & 5.8 & & & 4.0 & \\
\hline 305 & 4.4 & & & 3.8 & & \\
\hline 327 & & & 5.6 & & & \\
\hline 355 & 5.0 & & & $8.6^{*}$ & & \\
\hline 405 & 6.3 & & & 4.9 & & \\
\hline 455 & 6.3 & & & 6.2 & & \\
\hline 500 & & 5.0 & & & 3.2 & \\
\hline 527 & & & & & & 7.8 \\
\hline 700 & & 6.7 & & & 7.5 & \\
\hline 900 & & 8.2 & & & 6.2 & \\
\hline
\end{tabular}

${ }^{*} 86 \%$ larger than the reported value of $4.6 \times 10^{-6}$

${ }^{1}$ M. Leszczynski et al., J. Appl. Phys. 76, 4909 (1994).

${ }^{2}$ H.P. Maruska and J.J. Tietjen, Appl. Phys. Lett. 15, 327 (1969). 
APPENDIX D

\section{PUBLICATIONS AND PRESENTATIONS}





\section{APPENDIX D. PUBLICATIONS \& PRESENTATIONS}

Note: Asterisks indicate HTML staff members.

\section{D.1 PUBLICATIONS}

Allard,* L. F., E. Voelkl,* T. A. Nolan,* C. K. Narula, C. Montreuil, W. C. Bigelow, and J. F. Mansfield, "A Telepresence Microscopy Research Session in the DOE2000 Materials Microcharacterization Collaboratory," in Proceedings of Microscopy and Microanalysis 1998, 4 (Supplement 2), 20 (1998).

Allard,* L. F., E. Voelkl,* A. K. Datye, and A. H. Carim, "Electron Holography And Digital Imaging For Analysis Of Nanostructured Materials," in Proceedings of Microscopy and Microanalysis, 4 (Supplement 2), 750 (1998).

Andrews, * M. J., A. A. Wereszczak," K. Breder,* T. P. Kirkland,* and M. K. Ferber,* "Investigation of the Weibull Modulus as a Function of Stressing Rate," Cer. Eng. Sci. Proc. 19(4), 79-87 (1998).

Bae, Y. W., W. Y. Lee, T. M. Besmann, O. B. Cavin,* and T. R. Watkins, "Effects of Processing Parameters on Alumina Coatings Deposited on Nickel Substrates by Reacting Aluminum Chloride and Hydrogen/Carbon Dioxide Gas Mixtures," J. Am. Ceram. Soc. 81(7), 1945-48 (1998).

Ballard, B. L., P. K. Predecki, T. R. Watkins, * K. J. Kozaczek, D. N. Braski,* and C. R. Hubbard,* "Depth Profiling Biaxial Stresses in Sputter Deposited Molybdenum Films; Use of the $\operatorname{Cos}^{2} \phi$ Method," pp. 363-70 in Proceedings in Advances in X-Ray Analysis, 39, ed. J. V. Gilfrich, Plenum Press, New York, 1997.

Blanton, T. N., T. R. Watkins, * and M. A. Howey, "The Effect of Gelatin on Silver Halide Strain in Photographic Films," pp. 559-70 in Proceedings in Advances in X-ray Analysis 40, CD ROM, ed. J. V. Gilfrich, ICDD, Newtown Square, Pennsylvania, 1998.

Breder," K., M. K. Ferber," and R. D. Ott, "Grinding of Silicon Nitride by Creep-Feed Grinding and Conventional Surface Grinding," pp. 388-93 in Proceedings of the 6th International Symposium on Ceramic Materials and Components for Engines, ed. K. Niihara, S. Kanzaki, K. Komeya, S. Hirano, and K. Morinaga, Japan (1998). 
Breder," K. and A. A. Wereszczak,* "Fatigue and Slow Crack Growth," in Mechanical Testing Methodology for Ceramic Design and Reliability, ed. D. Cranmer and D. Richerson, Marcel Dekker, Inc., 1998.

Breder," Kristin, Andrew A. Wereszczak,* and Mark J. Andrews," "Exploration of The Weibull Modulus as a Function of Surface Preparation and Flexure Testing Conditions," Cer. Eng. Sci. Proc. 19(4), 89-97 (1998).

Choi, Ju-Hwan, Changmo Sung, Lawrence F. Allard," and Kyung Ho Shin, "The Effects of P and Pt on the Microstructure of Co-Cr-P-Pt Thin Film Magnetic Recording Media," in Proceedings Microscopy \& Microanalysis, San Francisco Press, Inc., 1997.

Crumpacker, Jill E., Master's Thesis, Bradley University, Chemistry Department, 1998.

Curtis, J. A., R. Nageswaran, S. Y. Limaye, C. R. Hubbard, * W. D. Porter," and S. T. Misture., "Characterization of Innovatively Synthesized Low Cost NZP Powders," in Proceedings $21^{\text {st }}$ Annual Cocoa Beach Conference/Exposition on Composites, Advanced Ceramics, Materials, And Structures, American Ceramic Society, 1997.

Dickey, E. C., C. R. Hubbard,* and V. P. Dravid, "Interlamellar Residual Stresses in Single Grains of NiO-ZrO (cubic) Directionally Solidified Eutectics," J. Am. Ceram. Soc. 80, 2773-80 (1997).

Dickey, E. C., B. A. Pint, K. B. Alexander, and I. G. Wright "The Effect of Platinum on the Growth and Adhesion of $\mathrm{A}_{-} \mathrm{Al}_{2} \mathrm{O}_{3}$ Scales," in Proceedings of High Temperature Surface Engineering Conference, ed. J. Nicholls, Edinburgh, Scotland, September 1997.

Dinwiddie,* Ralph B. and Kwangjin Lee, "IR-Camera Methods for Automotive Brake System Studies," in Thermosense XX, Proceedings of SPIE 3361, 66-74 (1998).

Dragoi, D., T. R. Watkins," and K. J. Kozaczek, "Peak Broadening in Asymmetric X-Ray Diffraction Resulting from Chi Tilts," pp. 499-503 in Proceedings in Advances in X-Ray Analysis, 39, ed. J. V. Gilfrich et al., Plenum Press, New York, 1997.

Erauw, J. P., W. Hendrix, E. VanHoof, K. Breder," and M. K. Ferber,* "Machining of Silicon Nitride: Process Parameters- Mechanical Properties Relationships," pp. 394-399 in Proceedings of the 6th International Symposium on Ceramic Materials and Components for Engines, ed. K. Niihara, S. Kanzaki, K. Komeya, S. Hirano, and K. Morinaga, Japan, 1998. 
Ferber,* M. K., M. G. Jenkins, and A. A. Wereszczak, * Fracture Strength, Mechanical Testing Methodology for Ceramic Design and Reliability, ed. D. Cranmer and D. Richerson, Marcel Dekker, Inc., 1998.

Frost,* B. and E. Voelkl,* "On the Reliability of Phase Measurements By Low Magnification Off-Axis Image Plane Electron Holography,” Ultramicroscopy 72, 101-107 (1998).

Gibbs, M. A., K. T. Hartwig, L. R. Cornwell, R. E. Goforth, and E. A. Payzant,* "Texture Formation in Bulk Iron Processed By Simple Shear," Scripta Materialia 39(12), 1699-1704 (1998).

Gruss, K. A., T. Zheleva, R. F. Davis, and T. R. Watkins, * "Characterization of Zirconium Nitride Coatings Deposited by Cathodic Arc Sputtering," Surf. Coat., Technol. 107, 115-24 (1998).

Haynes, J. A., M. K. Ferber,* and W. D. Porter,* "Damage Accumulation in ThermallyCycled $\mathrm{Al}_{2} \mathrm{O}_{3}$ Scales on Plasma-Sprayed NiCrAlY," pp. 146-157 in Electrochemical Society Proceedings , 98-9, The Electrochemical Society, Inc., Pennington, New Jersey, ed. P. Y. Hou, M. J. McNallan, R. Oltra, E. J. Opila, and D. A. Shores, 1998.

Jagannadham, K., T. R. Watkins, * and J. Narayan, "Residual Stresses in Single and Multilayer Composite Diamond Coatings," pp. 459-64 in Proceedings in Interfacial Engineering for Optimized Properties, 458, of the Materials Research Society Symposium, MRS, 1997.

Jang, D. Y., T. R. Watkins, * K. J. Kozaczek, C. R. Hubbard, * and O. B. Cavin,* "Surface Residual Stresses in Machined Austenitic Stainless Steel," Wear 194, 168-73 (1996).

Ji, John, E. Voelkl,“* A. Haynes, and J. M. Rigsbee, "Reactively Magnetron Sputter Deposited Yttria Stabilized Zirconia Coatings: Phase Formation, Crystallographic Texture and Growth Morphology," in Proceedings of the Annual International Conference on Metallurgical Coating and Thin Films (ICMCTF), San Diego, April 12-16, 1998.

Jiang, H., T. J. Klemmer, J. A. Barnard, W. D. Doyle, and E. A. Payzant," "Epitaxial Growth of $\mathrm{Cu}(111)$ Films on $\mathrm{Si}(110)$ by Magnetron Sputtering: Orientation and Twin Growth," Thin Solid Films 315, 13-16 (1998).

Joy,* D. C. and E. Voelkl,* "Quantifying SEM Resolution and Performance," in Proceedings of Microscopy and Microanalysis, 4(Supplement 2), 276 (1998). 
Keiser, J. R., B. Taljat, X.-L. Wang,* R. W. Swindeman, P. J. Masiasz, L. E. Meyers, R. L. Thomas, S. T. Elliot, D. L. Singbeil, and R. Prescott, "Causes and Solutions for Cracking of Coextruded and Weld Overlay Floor Tubes in Black Liquor Recovery Boilers," pp. 213-220 in Proceedings of the $9^{\text {th }}$ International Symposium on Corrosion in the Pulp and Paper Industry, Pulp and Paper Research Institute, Vancouver, Canada (1998).

King, H. W., E. A. Payzant," and T. A. Caughlin, "Temperature Discrepancies in High Temperature Diffractometry," Adv. X-Ray Analysis 40, 681-87 (1998).

Knepfler, C. A., K. T. Faber, J. Wertman, G. B. Olson, C. R. Hubbard,* O. B. Cavin,* and N. Packen, "High Temperature Stability and Thermal Expansion Behavior of Molybdenum-Chromium $\mathrm{M}_{2}$ C Carbides," J. Alloy Compd. 248, 139-42 (1997).

Lance, M. J., J. A. Haynes, W. R. Cannon and M. K. Ferber, "Piezospectroscopic Characterization of Thermal Barrier Coatings," Ceramic Transactions: Nondestructive Evaluation of Ceramics, ed. C. H. Schilling and J. N. Gray, Am. Ceram. Soc. Inc., Westerville, Ohio, 89, 229-37 (1998).

Lara-Curzio,* E., “Oxidation-Induced Stress-Rupture of Fiber Bundles,” Journal of Eng. Mater. Tech. 120, 75-80 (April 1998).

Lara-Curzio,* E., "Composite Systems," Chapter 17, Section 1, in Handbook of Ceramic Engineering, Marcel Dekker, New York, (1998).

Lee, Kwangjin and Ralph B. Dinwiddie, * "Conditions of Frictional Contact in Disk Brakes and Their Effects on Brake Judder," SAE980598, International Congress and Exposition, Detroit, Michigan, 98PC-392, 1998.

Lee, W. Y., E. Lara-Curzio,* and K. L. More,* "Multilayered Oxide Interphase Concept for Ceramic Matrix Composites,” J. Am. Ceram. Soc. 81(4), 600-604 (1998).

Li, Jackie, Erik T. Thostenson, Tsu-Wei Chou, and Laura Riester,* "An Investigation of Thin-Film Coating/Substrate Systems by Nanoindentation," Transactions of the ASME, J. Eng. Mat. Tech. 120(2), 154-62 (April 1998).

Long, Marc, Laura Riester," and Gordon Hunter, "Nano-Hardness Measurements of Oxidized Zr-2.5Nb and Various Orthopaedic Materials," in Transactions XXI, 528, Society for Biomaterials, Minneapolis, Minnesota, at the 24th Annual Meeting of the Society for Biomaterials, San Diego, California, April 22-26, 1998. 
Makinson, J. D., W. N. Weins, R. Schalek, S. C. Axtell, H. Wang,* and R. B. Dinwiddie,* "Isochronal Annealing Behavior of Mechanically Milled Nanocrystalline Copper Based Iron Alloys," in Nanocrystalline Materials 9(1-8), 519-22 (1997).

Maya, L, L. Riester, * T. Thundat, and C. S. Yust, "Characterization of Sputtered Amorphous Platinum Dioxide Films," J. of Appl. Phys. 85(11) (1998).

Maziasz, P. J., E. A. Payzant,* M. E. Schlienger, and K. M. McHugh, "Residual Stresses and Microstructure of H13 Steel Formed by Combining Two Different Direct Fabrication Methods," Scripta Materialia 39, 1471-76 (1998).

Merkulpv, V. I., D. H. Lowndes, L. R. Baylor, A. A. Puretzky, G. E. Jellison, D. B. Geohegan, M. J. Paulus, C. E. Thomas, M. L. Simpson, J. A. Moore, and E. Voelkl,* "An Addressable Field Emission Array For E-beam Lithography Using Planar, Pulsed-Laser Deposited Amorphous Diamond Cathodes," p. 178 (extended abstract) in Proceedings of the 11th International Vacuum Microelectronics Conference, Asheville, North Carolina, July 19-24, 1998.

Misture, S. T., S. M. Pilgrim, J. C. Hicks, C. T. Blue, E. A. Payzant,* and C. R. Hubbard,* "Measurements of the Electrostrictive Coefficients of Modified Lead Magnesium Niobate Using Neutron Powder Diffraction,” Appl. Phys. Lett. 72(9), 1042-44 (1998).

More, Karren L.,* Edward A. Kenik, Dorothy W. Coffey,* Thomas S. Geer,* William J. LaBarge, Richard Beckmeyer, and Joseph Theis, "Thermally-Induced Microstructural Changes in a Three-Way Automotive Catalyst," SAE Technical Paper Series - 972905, in Topics in General and Advanced Emissions (SP-1296), International Fall Fuels \& Lubricants Meeting \& Exposition, Tulsa, Oklahoma, October 13-16, 1997.

More,*. K. L., R Subramanina, S. Viswanathan, L. Walker, ${ }^{*}$ L. Riester, ${ }^{*}$ D. W. Coffey,* and T. S. Greer, *Microstructural Evaluation of ORNL-Produced Steel/Al Bonds," ORNL/Cummins Engine Quarterly CRADA Review Meeting, Oak Ridge National Laboratory, 1998.

Modine, F. A., H. Wang, * R. B. Dinwiddie, * M. Bartkowiak, L. Boatner and G. D. Mahan, "Influence of Ceramic Microstructure on Varistor Electrical Properties," Proc. of the International Symposium Dielectric Ceramics, ed. K. M. Nair and A. G. Bhalla, 469-491 (1998).

Narula C. K.,and L.F. Allard, * "Novel Zirconium Nitride Precursor: Synthesis, Decomposition Pathway, and Pyrolysis of $\left[\left(\mathrm{Ch}_{3}\right)_{3} \mathrm{Si}\right]_{2} \mathrm{NH}-\mathrm{ZrCl}_{4}$, " J. Mater. Chem. 8(8), 1881-84 (1998). 
Osborne, M. C., C. R., Hubbard,* L. L Snead, and D. Steiner, "Neutron Irradiation Effects on the Density, Tensile Properties and Microstructural Changes in Hi-Nicalon (TM) and Sylramic (TM) SiC Fibers," J. Nucl. Mater. 253, 67-77 (1998).

Page, T. F., G. M. Pharr, J. L. Hay, W. C. Oliver, B. N. Lucas, E. Herbert, and L. Riester, * "Nanoindentation Characterization of Coated Systems: P:S2. A New Approach Using the Continuous Stiffness Technique," in Proceedings of the MRS Spring Meeting, San Francisco, California,. Symposium T. Fundamentals of Nanoindentation and Nanotribology, 522, 53-64, April 12-19, 1998.

Page, Trevor, Laura Riester,* and Sarah Hainsworth, "The Plasticity Response of SiC and Related Isostructural Materials to Nanoindentation: Slip vs. Densification," in Proceedings of the MRS Spring Meeting, San Francisco, California, Symposium T. Fundamentals of Nanoindentation and Nanotribology, 522, 113-18, April 12-19, 1998.

Pasto,* A. E., "The Role of National User Facilities," in proceedings Advance Ceramics for the New Millennium Conf., Atlanta, Georgia, March 10-12, 1998.

Pasto,* A. E., and B. J. Russell,* "High Temperature Materials Laboratory - Tenth Annual Report: October 1996 through September 1997," ORNL/TM-13565 (1998).

Payzant,* E. A., W. D. Porter,* and C. R. Hubbard,* "High Temperature Phase Transformation in Rhombohedral Bismuth Strontium Oxide," Thermochimica Acta 318, 45-50 (1998).

Rabin, Barry H., Richard L. Williamson, Hugh A. Bruck, Xun-Li Wang,* Thomas R. Watkins, * Yue-Zhong Feng, and David R. Clarke, "Residual Strains in an $\mathrm{Al}_{2} \mathrm{O}_{3}-\mathrm{Ni}$ Joint Bonded with a Composite Interlayer: Experimental Measurements and FEM Analyses," J. Am. Ceram, Soc. 81(6), 1541-49 (1998).

Raghavan, S., H. Wang, * R. B. Dinwiddie, * W. D. Porter,* and M. Mayo, "The Effect of Grain Size, Porosity and Yttria Content on the Thermal Conductivity of Nanocrystalline Zirconia," Scripta Materialia 39(8), 1119-25 (1998).

Raine,* D., P. M. Whaley, M. Wright, and C. R. Hubbard,* "Designs for Neutron Radiography and Computed Tomography at ORNL," Adv. X-ray Analysis 41, 361-66 (1998).

Riester,* L., R. J. Bridge, and K. Breder,* "Characterization of Vickers, Berkovich, Spherical and Cube Cornered Diamond Indenters by Nanoindentation and SFM," in Proceedings of the MRS Spring Meeting, San Francisco, California, Symposium T. Fundamentals of Nanoindentation and Nanotribology, 522, p. 45-50, April 14,1998. 
Riester,* L., M. K. Ferber, * K. Breder,* and R. J. Bridge,* "Elastic Modulus Calculations from Load/Displacement Curves Using Spherical and Pointed Indenters," Ceramic Transactions: Nondestructive Evaluation of Ceramics 89, ed. C. H. Schilling and J. N. Gray, American Ceramic Society, 1997.

Shih, A. J., M. B. Grant, T. M. Yonushonis, T. O. Morris, * and S. B. McSpadden,* "Vitreous Bond CBN High Speed and High Material Removal Rate Grinding of Ceramics," in 1998 Proceedings, American Society for Precision Engineering, 18, 622-625 (1998).

Shih, A. J., T. M. Yonushonis, M. B. Grant, T. O. Morris, * and S. B. McSpadden,* "Vitreous Bond CBN Wheel for High Speed Grinding of Ceramic and M2 Steel," in Proceedings $26^{\text {th }}$ North American Manufacturing Research Conference (NAMRC), 195200, Georgia Tech, Atlanta, Georgia, May 18-22, 1998.

Sinclair, J. W., K. T. Hartwig, R. E. Goforth, D. A. Hardwick and E. Voelkl, * "Superplastic Behaviour of Commercial Al-5083 Processed by equal channel angular extrusion," TMS, 1998.

Srinivasan, R., T. R. Watkins, * C. R. Hubbard,* and B. H. Davis, "Sulfated Zirconia Catalysts. The Crystal Phases and Their Transformations," Chem. Mater. 7(4), 725-30 (1995).

Sriram, M. A., P. H. McMichael, A. Waghray, P. N. Kumta, S. T. Misture, and X.-L. Wang, "Chemical Synthesis of the High Pressure Cubic-Spinel Phase of $\mathrm{ZnIn}_{2} \mathrm{~S}_{4}$," J. Mat. Sci. 33, 4333-39 (1998).

Taljat, B., T. Zacharia, X.-L. Wang,* J. R. Keiser, Z. Feng, and M. J. Jirinec, "Numerical Analysis of Residual Stress Distribution in Tubes with Spiral Weld Overlay," Welding J. 77, S328-335 (1998).

Taljat, B., T. Zacharia, X.-L. Wang, * J. R. Keiser, R. W. Swindeman, and C. R. Hubbard, "Mechanical Design of Steel Tubing for Use in Black Liquor Recovery Boiler," pp. 193197 in Proceedings of the $9^{\text {th }}$ International Symposium on Corrosion in the Pulp and Paper Industry, Pulp and Paper Research Institute, Vancouver, Canada (1998).

Varga, L., H. Jiang, T. J. Klemmer, W. D. Doyle, E. A. Payzant, * "Magnetic and Structural Properties of Epitaxially Grown FeTaN Thin Films," J. Appl. Phys. 83(11), 5955-66 (1998).

Varga, L., A. Stephenson, S. Timkovich, T., Klemmer, W. D. Doyle, and K. J. Kozaczek, "The Effect of Annealing on (001) FeTaN Heteroepitaxial Films," IEEE Transactions on Magnetics 33, 3616-18 (1997). 
Viano, A. M., E. H. Mazjoub, R. M. Stroud, M. J. Kramer, S. T. Misture, P. C. Gibbons, and K. F. Kelton, "Hydrogen Absorption and Storage in Quasicrystalline and Related Ti-Zr-Ni Alloys," Philosophical Magazine A - Physics of Condensed Matter, Structure Defects, and Mechanical Properties 78, 131-41 (1998).

Viswanathan, S., C. R. Brinkman, W. D. Porter, and R. M. Purgert, "Production of A357 Motor Mount Bracket by the Metal Compression Forming Process," in Proceedings North American Die Casting Association Congress, Minneapolis, Minnesota, November 3-6, 1997.

Viswanathan, S., W. D. Porter,* W. Ren, and R. M. Purgert, "Application of the Metal Compression Forming Process for the Production of an Aluminum Alloy Component," in Proceedings Annual Meeting Min. Met. Mater. Soc., Orlando, Florida, February 9-13, 1997, TMS, Warrendale, Pennsylvania, 1997.

Voelkl,* E., L. F. Allard,* J. Bruley, V. J. Keast, and D. B. Williams, "The Teaching of TEM by Telepresence Microscopy Over the Internet," Inst. Phys. Conf. Ser. 153(2), 4548 (1997).

Voelkl,* E., K. B. Alexander, J. C. Mabon, M. A. O'Keefe, M. T. Postek, M. C. Wright, and N. J. Zaluzec, "The DOE2000 Materials MicroCharacterization Collaboratory," pp. 289-290 in the Proceedings of the ICEM '98, Cancun, Mexico, 1998.

Wang,* H. and R. B. Dinwiddie, " Microscopic Thermal Diffusivity Mapping Using an IR Camera," Thermal Conductivity 24, ed. P. G. Gaal, Technomic Pub. Co., 303-12 (1998).

Wang,* Hsin, Miroslaw Bartkowiak, Frank A. Modine, Ralph B. Dinwiddie,* Lynn A. Boatner, and Gerald D. Mahan, "Nonuniform Heating in Zinc Oxide Varistors Studied by Infrared Imaging and Computer Simulation," J. Am. Ceram. Soc. 81(8) 2013-22 (1998).

Wang, * X.-L., C. R. Hubbard,* S. Spooner, B. Taljat, and J. R. Keiser, "Residual Stresses due to Processing of Composite Tubes," pp. 70-75 in Proceedings of the Fifth International Conference on Residual Stress, Institute of Technology, Linkoping University, Linkoping, Sweden (1998).

Wang,* X.-L., S. Spooner, and C. R. Hubbard,* "Theory of the Peak Shift Anomaly due to Partial Burial of the Sampling Volume in Neutron Diffraction Residual Stress Measurements," J. Appl. Cryst. 31, 52-59 (1998).

Wang, * X.-L., S. Spooner, C. R. Hubbard,* Z. Feng, and B. Taljat, "Characterization of Welding Residual Stresses with Neutron Diffraction," pp. 491-494, in Proceedings of the 1998 SEM Spring Conference on Experimental and Applied Mechanics, SEM, Bethel, Connecticut (1998). 
Wang, Z.-M., C. Wei, Q. Feng, S. H. Whang, and L. F. Allard,* "Dissociated Core Configurations of [-101] Superdislocations and Their Relative Stability in Single Crystal Ti-56Al Deformed at 573K, “Intermetallics 6, 131-39 (1998).

Watkins,"* T. R., S. P. Beckman, and C. R. Hubbard,* "Residual Strain Measurement in Thermal Barrier Coatings," pp. 524-33 in Proceedings in Advances in X-ray Analysis 40, CD ROM, ed. J. V. Gilfrich et al., ICDD, Newtown Square, Pennsylvania, 1998.

Wereszczak,* A. A., "Creep of Melter Crown and Regenerator Refractories," in The GlassResearcher 7(2), 19-20 (Winter 1998), Bulletin of Glass Science and Engineering, New York State College of Ceramics at Alfred University (1998).

Wereszczak," A. A., "Which Superstructure Refractories Do Glassmakers Desire Creep Data For?" Glass Industry, 17-18 (1998).

Wereszczak," A. A., K. Breder," M. J. Andrews," T. P. Kirkland,* and M. K. Ferber,* "Strength Distribution Changes in a Silicon Nitride as a Function of Stressing Rate and Temperature," in Proceedings from the ASME Turbo Expo 98, Stockholm, Sweden, 1998, paper 98-GT-527, ASME, Danvers, Massachusetts, 1998.

Wereszczak,* A. A., J. Heide, T. P. Kirkland,* G. V. Srinivasan, and S. M. Winder, "High Temperature Deformation of an AZS Refractory," Advances in Fusion and Processing of Glass II, Ceramic Transactions 82, 379-84 (1998).

Wereszczak,* A. A., J. G. Hemrick,* T. P. Kirkland,* J. A. Haynes, T. J. Fitzgerald, and J. E. Junkin, "Stress Relaxation of MCrAlY Bond Coat Alloys as a Function of Temperature and Strain," ASME Paper No.98-GT-403, in Proceedings of the International Gas Turbine and Aeroengine Congress and Exhibition, Stockholm, Sweden, June 2-5, 1998.

Wereszczak,"* A. A., T. P. Kirkland,"* and W. F. Curtis, "Compressive Creep Resistance of Magnesia Refractories at Temperatures $\geq 1400^{\circ} \mathrm{C}\left(2550^{\circ} \mathrm{F}\right)$," Advances in Fusion and Processing of Glass II, Ceramic Transactions 82, 407-12 (1998).

Wereszczak, A. A., * T. P. Kirkland,* M. K. Ferber,* T. R. Watkins,* and R. L. Yeckley, "The Effects of Residual $\alpha$ Phase on the Creep Performance at $1370^{\circ} \mathrm{C}$ of Yttria-Doped HIPed Silicon Nitride," J. Mat. Sci. 33, 2053-60 (1998).

Wereszczak,* A. A., T. P. Kirkland,* G. A. Pecoraro, and R. A. New, "Compressive Creep Behavior of Fusion-Cast Alumina Refractories," Advances in Fusion and Processing of Glass II, Ceramic Transactions 82, 401-6 (1998). 
Wereszczak,* A. A., L. Riester,* and K. Breder,* "Young's Modulus, Hardness, Fracture Toughness and Geometric Comparisons of Equivalent Multilayer Capacitors," Executive Summary, May 26, 1998.

Wereszczak, * A. A., J. D. Smith, and R. E. Moore, "Probabilistic Life Design of Refractories for Steel Casting," in Proceedings of the 34th Annual Symposium on Refractories, Univ. of Missouri-Rolla, 1998.

Widjaja, J., K. Jakus, J. E. Ritter, E. Lara-Curzio, * E. Y. Sun, T. R. Watkins, * and J. J. Brennan, "Creep-Induced Residual Stress Strengthening in Nicalon ${ }^{\mathrm{TM}}$ Fiber-Reinforced BMAS Glass-Ceramic Matrix Composites,” J. Am. Ceram. Soc. 82(3), 657-64 (1999).

Wright, M. C. and C. R. Hubbard, * "The Materials Microcharacterization Collaboratory: Scientific Collaboration over the Internet," published by Argonne National Laboratory at: http://www.aps.anl.gov/xfd/bcda/nobugs/proceed/MMC.html (1998).

Yang, Fan, Ashok Saxena, and Laura Riester,* "Use of Nanoindentation Technique for Studying Microstructure/Crack Interaction in Fatigue of 4340 Steel," Metallurgical Transactions A 29A, 3029-36 (1998).

Zanoria, E. S., T. R. Watkins, * K. Breder,* L. Riester, * M. Bashkansky, J. Reintjes, J. G. Sun, W. A. Ellingson, and P. J. Blau,* "Assessment of Techniques for Characterizing the Surface Quality of Ground Silicon Nitride," J. Mat. Eng. Perf. 7(4), 533-47 (1998).

Zhu,* X. and C. R. Hubbard, *A Calibration Procedure for Position Sensitive Detectors Used in Neutron Residual Strain Mapping," Adv. X-ray Analysis 40 (1998). 


\section{PRESENTATIONS --}

Akdogan, E. K., W. Mayo, A. Safari, C. J. Rawn," and E. A. Payzant," "Structure-Property Relations in Mesoscopic $\mathrm{BaTiO}_{3}$ and $\mathrm{PbTiO}_{3}$," presented at the $4^{\text {th }}$ European Conference on Applications of Polar Dielectrics, Montreaux, Switzerland, August 26, 1998.

Allard,* L. F. and E. Voelkl,* "Electron Microscopy via the Internet," Principal Organizer and presented Invited Tutorial, 14th International Congress on Electron Microscopy, Cancun, Mexico, September 1998.

Allard,* L. F. and E. Voelkl,* "The Remote Use of a Transmission Electron Microscope," presented at the Symposium on the Future of Remote Microscopy in Materials Science Education, Dept. of Materials Science and Engineering, Carnegie Mellon University, September 1998 .

Andrews, * M. J., A. A. Wereszczak," K. Breder,* T. P. Kirkland,* and M. K. Ferber,* "Investigation of the Weibull Modulus as a Function of Stressing Rate," presented at the $22^{\text {nd }}$ Annual Cocoa Beach Conference and Exposition, Cocoa Beach, Florida, January 2024, 1998 .

Barsoum, M. W., T. El-Raghy, C. J. Rawn,* E.A. Payzant," and C. R. Hubbard,* "Lattice Expansion and HT Structure of $\mathrm{Ti}_{3} \mathrm{SiC}_{2}$," presented at the Sixth European Powder Diffraction Conferrence, Budapest, Hungary, August 22-25, 1998.

Barsoum, M. W., T. El-Raghy, C. J. Rawn,* W. D. Porter,* H. Wang,* E. A. Payzant,* and C. R. Hubbard," "High temperature X-ray Diffraction Characterization of $\mathrm{Ti}_{3} \mathrm{SiC}_{2}$," presented at the 100th Annual American Ceramic Society Conference, Cincinnati, Ohio, May 4-6, 1998.

Barsoum, M. W., T. El-Raghy, C. J. Rawn,* W. D. Porter," H. Wang,* E. A. Payzant,* and C. R. Hubbard," "The Structure of $\mathrm{Ti}_{3} \mathrm{SiC}_{2}$," presented at the 6th European Powder Diffraction Conference, Budapest, Hungary, August 22, 1998.

Breder," K., M. K. Ferber," and R. D. Ott, "Grinding of Silicon Nitride by Creep-Feed Grinding and Conventional Surface Grinding," presented at the 6th International Symposium on Ceramic Materials and Components for Engines, Arita, Japan, October 19-23, 1997.

Curtis, J. A., R. Nageswaran, S. Y. Limaye, C. R. Hubbard, * W. D. Porter,* and S. T. Misture., "Characterization of Innovatively Synthesized Low Cost NZP Powders," presented at the $21^{\text {st }}$ Annual Cocoa Beach Conference/Exposition on Composites, Advanced Ceramics, Materials. And Structures, American Ceramic Society, 1997. 
Dickey, E. C., "Residual Stresses in High-Temperature Ceramic Composites," New Developments in High-Temperature Ceramics, Istanbul, Turkey, 1998.

Dickey, E. C., "Residual Stresses in High Temperature Ceramics," Advanced Materials for Extreme Environments: New Experimental Opportunities in Neutron Scattering, Argonne National Laboratory, Argonne, Illinois, September 11-12, 1998.

Dickey, E. C., B. A. Pint, K. B. Alexander, and I. G. Wright "The Effect of Platinum on the Growth and Adhesion of $\mathrm{A}-\mathrm{Al}_{2} \mathrm{O}_{3}$ Scales," presented at the High Temperature Surface Engineering Conference, Edinburgh Scotland, September 1997.

Dinwiddie,* R. B. and H. Wang,* "Temperature Measurement, Thermal Transport Properties, and NDE Characterization Using a High Sensitivity, High Speed IR Camera," Annual Automotive Technology Development Customers' Coordination Meeting, Dearborn, Michigan, October 27-30, 1997.

Erauw, J. P., W. Hendrix, E. VanHoof, K. Breder,* and M. K. Ferber, * "Machining of Silicon Nitride: Process Parameters- Mechanical Properties Relationships," presented at the 6th International Symposium on Ceramic Materials and Components for Engines, Arita, Japan, October 19-23, 1997.

Greenwood, O. D., R. J. Lad, and P. J. Blau, * "Microstructure-Tribology Relationships in $\mathrm{WO}_{3}$ Thin Films," presented at the 1997 Fall Meeting of the Materials Research Society, Boston, Massachusetts, November 1997.

Haynes, J. A., M. K. Ferber,* and W. D. Porter,* "Damage Accumulation in ThermallyCycled $\mathrm{Al}_{2} \mathrm{O}_{3}$ Scales on Plasma-Sprayed NiCrAlY," presented at the Symposium on High Temperature Corrosion and Materials Chemistry at the $25^{\text {th }}$ Intl. Conf. on Metallurgical Coatings on Thin Films, San Diego, California, April 27-May 1, 1998.

Hecht, R. L., R. B. Dinwiddie, * W. D. Porter, * and H. Wang,* "Thermal Transport Properties of Aluminum Metal Matrix Composites for Brake Applications," Annual Automotive Technology Development Customers' Coordination Meeting, Dearborn, Michigan, October 27-30, 1997.

Hilmas, G. E. and S. B. Nowell, "Zirconium and Hafnium Based Ceramic Matrix Composites for High Temperature Aerospace Applications," presented at the 22nd Annual Cocoa Beach Conference \& Exposition, Cocoa Beach, Florida, January 20-24, 1998.

Hu, M. Z.-C., G. Miller, E. A. Payzant,* and C.J. Rawn,* "Chemical Synthesis of Monodispersed Ultrafine Composite Ceramic Particles," 5th International Conference on Composites Engineering, Las Vegas, Nevada, July 6, 1998. 
Hu, Michael A.-C., E. A. Payzant," and C. R. Hubbard,* "Comparative Studies of Monodispersed Ultrafine Ceramic Precursor Particles by Various Homogeneous Precipitation Methods," poster presented at the 22nd Annual Cocoa Beach Conference \& Exposition, Cocoa Beach, Florida, January 20-24, 1998.

Hubbard,* C. R., S. T. Misture, and E. A. Payzant,* "High Temperature X-ray Diffraction," presented at the 47th Annual Denver X-ray Conference (workshop), Colorado Springs, Colorado, August 3, 1998.

Hubbard,* C. R., E. A. Payzant,"* X.-L. Wang,* S. Spooner, and M. Wright, "Through Thickness Residual Stress Mapping Facility Development and Example User Projects," Annual Automotive Technology Development Customers' Coordination Meeting, Dearborn, Michigan, October 27-30, 1997.

Hubbard,* C. R., W. Wong-Ng, and J. Rodgers, "Assessment of the Completeness of Engineering Ceramic Materials in the ICDD's PDF," poster presentation, at the Denver X-Ray Conference, Colorado Springs, Colorado, August 2-6, 1998.

Ji, John, E. Voelkl,"* A. Haynes, and J. M. Rigsbee, "Reactively Magnetron Sputter Deposited Yttria Stabilized Zirconia Coatings: Phase Formation, Crystallographic Texture and Growth Morphology," presented at the Annual International Conference on Metallurgical Coating and Thin Films (ICMCTF), San Diego, April 12-16, 1998.

Jiang, H., T. J. Klemmer, J. A. Barnard, W. D. Doyle, and E. A. Payzant,* "Cu Epitaxial Growth on H-Terminated Si by Magnetron Sputtering," presented at the Materials Research Society Meeting, Boston, Massachusetts, December 1-5, 1997.

Lara-Curzio,* E., "A Model of the Oxidation-Induced Stress-Rupture of Ceramic Matrix Composites with Carbonaceous Fiber Coatings," presented at International Symposium on Ceramic Matrix Composites, 5th Japan International SAMPE Symposium \& Exhibition, Tokyo, Japan, October 28-31, 1997.

Lara-Curzio,* E., "Development of Test Standards for Continuous Fiber Ceramic Composites in the United States," presented at International Symposium on Ceramic Matrix Composites, 5th Japan International SAMPE Symposium \& Exhibition, Tokyo, Japan, October 28-31, 1997.

Lara-Curzio," E., "Effect of Overstress on the Reliability of Continuous Fiber Ceramic Composites under Stress-Rupture Conditions," presented at 22nd Annual Cocoa Beach Conference and Exposition, ITAR Restricted Sessions, Cocoa Beach, Florida, January 2530, 1998. 
Lara-Curzio,* E., "Life Prediction of CFCCs under Stress-Rupture Conditions," presented at 22nd Annual Cocoa Beach Conference and Exposition, Cocoa Beach, Florida, January 2024, 1998.

Lee, W. Y., E. Lara-Curzio, * and K. L. More, * "Multilayered Oxide Interface Concept for Ceramic Matrix Composites," presented at 22nd Annual Cocoa Beach Conference and Exposition, Cocoa Beach, Florida, January 20-24, 1998.

Lee, W. Y., E. Lara-Curzio," K. L. More,* D. W. Coffey,* J. C. McLaughlin, K. M. Cooley, and E. A. Payzant,* "Multilayer Oxide Interface Design for Oxidation-Resistant Ceramic Matrix Composites," presented at the American Ceramic Society's 99th Annual Meeting \& Exposition, Cincinnati, Ohio, April 1997

Liao, T. W. and S. B. McSpadden," Jr., "Tracing the Morphological Changes of Diamond Abrasives with Lead-Tape Imprints and SEM," presented at NAMRC XXVI, Georgia Institute of Technology, May 19-22, 1998.

Long, Marc, Laura Riester," and Gordon Hunter, "Nano-Hardness Measurements of Oxidized $\mathrm{Zr}-2.5 \mathrm{Nb}$ and Various Orthopaedic Materials," poster presentation at the 24th Annual Meeting of the Society for Biomaterials, San Diego, California, April 22-26, 1998.

McGinnis, A. J., K. Jagannadham, H. Wang,* and R. B. Dinwiddie,* "Heat Spreader Characteristics of Multilayer Diamond Films for High Frequency Power Devices," MRS Fall Meeting, Boston, Massachusetts, December 1-5, 1997.

McGinnis, A. J., K. Jagannadham, H. Wang,* and R. B. Dinwiddie,* "Thermal Conductivity Measurements of Diamond Films," MRS Fall Meeting, Boston, Massachusetts, December 1-5, 1997.

Merkulpv, V. I., D. H. Lowndes, L. R. Baylor, A. A. Puretzky, G. E. Jellison, D. B. Geohegan, M. J. Paulus, C. E. Thomas, M. L. Simpson, J. A. Moore, and E. Voelkl,* "An Addressable Field Emission Array For E-beam Lithography Using Planar, Pulsed-Laser Deposited Amorphous Diamond Cathodes," presented at the 11th International Vacuum Microelectronics Conference, Asheville, North Carolina, July 1924, 1998.

Misture, S. T., S. M. Pilgrim, J. C. Hicks, C. T. Blue, E. A. Payzant,"* and C. R. Hubbard,* "In-Situ Neutron Diffraction Measurements of Electric Field-Induced Strain in Modified Lead Magnesium Niobate Relaxor Ferroelectrics,” MRS Fall Meeting, Boston, Massachusetts, December 1-5, 1997. 
Misture, S. T., S. M. Pilgrim, J. C. Hicks, C. T. Blue, E. A. Payzant," and C. R. Hubbard,* "Neutron Diffraction Strain Measurements of Electroactive Ceramics Under DC Fields," Denver X-Ray Conference, Denver, Colorado, August 1998.

More," K. L., D. W. Coffey,* P. F. Tortorelli, and B. A. Pint, "TEM Specimen Preparation of Oxidized Surface Structures Using the Focused Ion Beam (FIB) Technique," presented at the 4th International Conference on the Microscopy of Oxidation, Cambridge, England.

More,*. K. L., R Subramanina, S. Viswanathan, L. Walker,* L. Reister,* D. W. Coffey,* and T. S. Greer, * "Microstructural Evaluation of ORNL-Produced Steel/Al Bonds," presented at the ORNL/Cummins Engine Quarterly CRADA Review Meeting, Oak Ridge National Laboratory, 1998.

More, * Karren L., Edward A. Kenik, Dorothy W. Coffey, ${ }^{*}$ Thomas S. Greer, * William J. LaBarge, Richard Beckmeyer, and Joseph Theis, "Thermally-Induced Microstructural Changes in a Three-way Automotive Catalyst," presented at the International Fall Fuels \& Lubricants Meeting \& Exposition, Tulsa, Oklahoma. October 13-16, 1997.

Moulzolf, Scott C., Robert J. Lad, and Peter J. Blau,* "Microstructural Effects on the Friction and Wear of $\mathrm{ZRO}_{2}$ Films," presented at the 1997 Fall Meeting of the Materials Research Society, Boston, Massachusetts, November 1997.

Page, Trevor, Laura Riester,* and Sarah Hainsworth, "The Plasticity Response of SiC and Related Isostructural Materials to Nanoindentation: Slip vs. Densification," poster presentation at the MRS Spring Meeting, San Francisco, California, Symposium T. Fundamentals of Nanoindentation and Nanotribology, April 12-19, 1998.

Pasto,* A. E., "Advanced Materials Characterization at the HTML," presented at the Fifth International Conference on Composites Engineering (ICCE/5), Las Vegas, Nevada, July 5-11, 1998.

Pasto,* A. E., "The Role of National User Facilities," presented at the Advance Ceramics for the New Millennium Conf., Atlanta, Georgia, March 10-12, 1998.

Payzant,* E. A.,"Applications of Neutron Diffraction Using the High Flux Isotope Reactor", presented a Penn State Chapter of ASM International, State College, Pennsylvania, November 17, 1997.

Payzant,* E. A., "Time Resolved Characterization of Crystallization and PhaseTtransformations by HTXRD” presented at the 47th Annual Denver X-ray Conference, Colorado Springs, Colorado, August 7, 1998. 
Payzant,* E. A., M. A. Gibbs, and K. T. Hartwig, "Texture Formation in Iron Processsed by Equal Channel Angular Extrusion,” Materials Week/ TMS Fall Meeting, Indianapolis, Indiana, September 14, 1997.

Payzant,* E. A., and H. Wang,* "Thermal Characterization of a High Temperature XRD Furnace," presented at the 47th Annual Denver X-ray Conference, Colorado Springs, Colorado, August 4, 1998.

Rawn,* C. J., "Single and Polycrystalline X-ray and Neutron Characterization of $\mathrm{Ba}_{6-}$ ${ }_{3 \mathrm{x}} \mathrm{Ln}_{8+2 \mathrm{x}} \mathrm{Ti}_{18} \mathrm{O}_{54}$ Microwave Dielectrics," The Graduate Student Seminar Series of the Department of Ceramic and Materials at Clemson University, September 15, 1998.

Rawn,* C. J., E. A. Payzant,* C. R. Hubbard,* M. W. Barsoum, and T. El-Raghy, "Structure and Lattice Expansion of $\mathrm{Ti}_{3} \mathrm{SiC}_{2}$," presented at the $100^{\text {th }}$ Annual Meeting of the American Ceramic Society, Cincinnati, Ohio, May 3-7, 1998.

Riester,* L., R. J. Bridge,* and K. Breder,* "Characterization of Vickers, Berkovich, Spherical and Cube Cornered Diamond Indenters by Nanoindentation and SFM," poster presentation MRS Spring Meeting, San Francisco, California, Symposium T. Fundamentals of Nanoindentation and Nanotribology, April 14, 1998.

Shih, A. J., M. B. Grant, T. M. Yonushonis, T. O. Morris, * and S. B. McSpadden,* "Vitreous Bond CBN Wheel for High Speed Grinding of Ceramic and M2 Steel," presented at $26^{\text {th }}$ North American Manufacturing Research Conference (NAMRC), Georgia Institute of Technology, Atlanta, Georgia, May 18-22, 1998.

Shih, A. J., M. B. Grant, T. M. Yonushonis, T. O. Morris, * and S. B. McSpadden,* "Vitreous Bond CBN High Speed and High Material Removal Rate Grinding of Ceramics," presented at American Society for Precision Engineering, 1998.

Tomforde, Chad G., John P. Hurley, Frank R. Karner, and Karren More,* "Influence of Bright and Dull Coal Lithotypes on Char Formation in a Pressurized Fluidized-Bed Reactor," presented at the Geological Society of America Annual Convention in Salt Lake City, Utah, October 20-23, 1997.

Viswanathan, S., C. R. Brinkman, W. D. Porter, and R. M. Purgert, "Production of A357 Motor Mount Bracket by the Metal Compression Forming Process," presented at the North American Die Casting Association Congress, Minneapolis, Minnesota, November 3-6, 1997.

Viswanathan, S., W. D. Porter,* W. Ren, and R. M. Purgert, "Application of the Metal Compression Forming Process for the Production of an Aluminum Alloy Component," presented at the Annual Meeting Min. Met. Mater. Soc., Orlando, Florida, February 9-13, 1997. 
Voelkl,* E., K. B. Alexander, J. C. Mabon, M. A. O'Keefe, M. T. Postek, M. C. Wright, and N. J. Zaluzec, "The DOE2000 Materials MicroCharacterization Collaboratory," poster presented at the ICEM '98, Cancun, Mexico, 1998.

Wang, * X.-L., S. Spooner, C. R. Hubbard, * Z. Feng, and B. Taljat, "Characterization of Welding Residual Stresses with Neutron Diffraction,” 1998 SEM Spring Conference, Houston, Texas, June 1-3, 1998.

Watkins,* T. R., C. R. Hubbard,* and E. A. Payzant,* "In Situ Residual Stress Characterization of Curved Surfaces and at Elevated Temperatures," Annual Automotive Technology Development Customers' Coordination Meeting, Dearborn, Michigan, October 27-30, 1997.

Watkins,* T. R., E. A. Payzant,* J.-P. Maria, and S. Trolier-McKinstry, "In-situ Field Dependent X-ray Diffraction Analysis of Epitaxial Relaxor-Lead Titanate Thin Film Actuators," 47 $7^{\text {th }}$ Annual Denver Conference, Colorado Springs, Colorado, August 6, 1998.

Watkins, T. R., L. Reister,* D. N. Braski," and J. Zhang, "Properties of Thin Coatings for Heavy Equipment Applications," Annual Automotive Technology Development Customers Coordination Meeting, Dearborn, Michigan, October 27-30, 1997.

Watkins, * T. R., L. Riester,* R. D. England, and C. A. Klepser, "Determination of X-ray Elastic Constants for Nitrided Steels," poster presentation Annual Meeting, American Ceramic Society Meeting, Cincinnati, Ohio, May 3-7, 1998.

Wereszczak, * A. A., K. Breder,* M. J. Andrews, * T. P. Kirkland,* and M. K. Ferber,* "Strength Distribution Changes in a Silicon Nitride as a Function of Stressing Rate and Temperature," presented at the ASME Turbo Expo 98, Stockholm, Sweden, June 2-5, 1998.

Wereszczak, * A. A., K. Breder, * M. K. Ferber,* R. J. Bridge, L. Riester, ${ }^{*}$ and T. P. Kirkland,* "Failure Probability Prediction of Dielectric Ceramic in Multilayer Capacitors," presented at The American Ceramic Society Meeting, Cincinnati, Ohio, May 3-7, 1998.

Wereszczak, * A. A., J. G. Hemrick, * T. P. Kirkland,* J. A. Haynes, T. J. Fitzgerald, and J. E. Junkin, "Stress Relaxation of MCrAlY Bond Coat Alloys as a Function of Temperature and Strain," ASME Paper No.98-GT-403, presented at International Gas Turbine and Aeroengine Congress and Exhibition, Stockholm, Sweden, June 2-5, 1998. 
Wright, M. C. and C. R. Hubbard,* "Scientific Collaboration Over the Internet at Neutron and X-ray Beamlines," $47^{\text {th }}$ Annual Denver X-ray Conference, Colorado Springs, Colorado, August 3-7, 1998.

Zhang, Jian, "Properties of Thin Coating for Heavy Equipment Application," poster presented Annual Automotive Technology Development Customers' Coordination Meeting, Dearborn, Michigan, October 27-30, 1997. 
ORNL/TM-2000/2

\section{INTERNAL DISTRIBUTION}

Central Research Library Laboratory Records-OSTI Laboratory Records-RC

L. F. Allard

P. Angelini

T. M. Besmann

P. J. Blau

D. Blom

E. E. Bloom

R. A. Bradley

D. N. Braski

E. W. Coffey

E. G. Cumesty

R. B. Dinwiddie

L. B. Dunlap

T. Ely

M. K. Ferber

R. G. Gilliland

D. Haynes

L. L. Horton

M.-C. Hu

C. R. Hubbard

T. Jenkins

D. R. Johnson

D. Joy

M. Karnitz

T. Kirkland

M. Lance

R. Lowden
E. Lara-Curzio

Gail Ludtka

S. B. McSpadden

W. H. Miller, Jr.

D. Mitchell

K. L. More

T. A. Nolan

L. O'Rourke

R. Ott

R. Parten

A. E. Pasto

E. A. Payzant

W. D. Porter

M. Rawlins

C. Rawn

L. Riester

J. Roberto

B. J. Russell

A. C. Schaffhauser

E. Sheldon

S. Spooner

P. Tortorelli

E. Voelkl

L. Walker

H. Wang

X.-L. Wang

T. R. Watkins

A. A. Wereszczak

R. E. Ziegler

\section{EXTERNAL DISTRIBUTION}

Advanced Ceramics Corporation, 11907 Madison Ave., Lakewood, OH 44107

Lennartz, Jeffrey

Advanced Materials Technologies, Inc., 6010 Wright Street, Arvada, CO 80004

Stephan, James

AlliedSignal Engines, 111 S. 34th ST - M/S 93-74/553-10, Phoenix, AZ 85048

Bhattacharya, Arun

AlliedSignal Ceramic Comp., 2525 W. 190th St., Box 2960, Torrance, CA 90504

Savitz, M. L. 
AlliedSignal Ceramic Comp., 2525 W. 190th St., M/S TOR-1/5-1-27000, Torrance, CA 90504

Twait, James

Allison Engine Company, P. O. Box 420, Mail Stop W-5, Indianapolis, IN 46206

Groseclose, Lance Parsons, Duane

ARCO Aluminum Inc., 2900 National City Tower, P. O. Box 32860, Louisville, KY 40232

Das, Subodh K. Mohr, James C.

Bosch Braking Systems Corp., 24755 Halsted Road, Famington HIlls, MI 48335-1672

Wang, Alex

BTR Automotive, 2200 Stock Creek Boulevard, Rockford, TN 37853

Ryan, David

Carpenter Certech, 1 Park Place West, Wood-Ridge, NJ 07075

Krug, Eugene LaRocco, Corie Pietras, Raymond

Carrasquillo, Gilbert

Caterpillar, Inc., Technical Center E-854, P. O. Box 1875, Peoria, IL 61656-1875

Zhang, Jian

Caterpillar, Inc., P. O. Box 1875,Technical Center, Building K, Peoria, IL 61656-1875

Thiele, Jeffrey

Caterpillar Technical Center, P. O. Box 1875, Building E, Peoria, IL 61656-1875

Readey, Michael J. $\quad$ Bougher, Jeff Rajan

Chand Associates, 2 Coppage Dr., Worcester, MA 01603-1252

Chand, Ronald

Clemson University, 201C Olin Hall, Clemson, SC 29634

Lee, Burtrand Cao, Paul

Clemson University, Olin Hall, Room 201B, Clemson, SC 29634-0907

Ballato, John

Clemson University, 110 Olin Hall, Clemson, SC 29634-0907

Rack, Henry Roussel, Aexandrei 
Columbia University, 500 W120 St. Rm 220, Dept. of Mech. Eng., New York, NY 10027
Hong, Shane
$\mathrm{Li}$, Wayne (Wenchuan)

Coors Ceramics, 1100 Commerce Park Drive, Oak Ridge, TN 37830

Johanns, Dave

Coors Ceramics Co.-Chattanooga Operations, 511 Manufacturers Rd., Chattanooga, TN 37405
Minehan, Bill
Emerick, Daniel
Winters, Earl

Corning, Inc., SP-FR-18, Corning, NY 14831

Holland, H. J. Kohli, J. T.

CTI, Inc., 810 Innovation Drive, Knoxville, TN 37932

Carey, Alexander A. Eriksson, Lars Siegel, Stefan

Eriksson, Marita

Cummins Engine Co., 1900 McKinley Ave., Box 3005, Columbus, IN 47202

England, Roger

Cummins Engine Co., Box 3005/MC 50183, Columbus, IN 47202-3005

Gust, Darryl J. Raebel, Suzanne Bai, Dong

Patten, Jim

DOE, Albuquerque Operations, 5305 Noreen Dr., NE, Albuquerque, NM 87111

Andrews, Mark

DOE, Office of Assistant Secretary for Defense Programs, Forrestal Building, 1000 Indepedence Ave., Washington, DC 20585-0121

Byrd, D.

DOE, Office of Assistant Secretary for Energy Efficiency and Renewable Energy, Office of Transportation Technologies, EE-30, Forrestal Building, 1000 Indepedence Ave., Washington, DC 20585-0121
Gross, T. J.
Hegnauer, A.

DOE, Office of Assistant Secretary for Energy Efficiency and Renewable Energy, Office of Transportation Technologies, Office of Advanced Automotive Technologies, EE-32, Forrestal Building, 1000 Indepedence Ave., Washington, DC 20585-0121

Haught, D. Marechaux, T. Patil, P. 
DOE, Office of Assistant Secretary for Energy Efficiency and Renewable Energy, Office of Transportation Technologies, Office of Heavy Vehicle Technologies, EE-33, Forrestal Building, 1000 Indepedence Ave., Washington, DC 20585-0121

Diamond, S. $\quad$ Eberhardt, J. J.

DOE, Office of Assistant Secretary for Energy Research, Forrestal Building, 1000 Indepedence Ave., Washington, DC 20585-0121

Vojnovich, T.

Dow Corning Corporation, P. O. Box 994, Mail\#C041A1, Midland, MI 48686-0994

Liou, Huey-Chiang

Dow Corning Corporation, P. O. Box 994, Mail\#CO41D1, Midland, MI 48686-0994

Chen, Wei Dinah, Paul Tzou, Misha

Drexel University, Department of Materials Engineering, Philadelphia, PA 19104

Barsoum, Michael El-Raghy, Tamer Tzenov, Nikolay

Edison Welding Institute, 1250 Arthur E. Adams Drive, Columbus, OH 43221

Lienert, Thomas

Energy Conversion Devices, Inc., 1675 W. Maple Road, Troy, MI 48084

Strand, Dave Wicker, Guy

Federal Mogul Power Train Sys., PO Box 910, 2318 Waldo Blvd., Manitowoc, WI 54221-0910

Winter, John Eskew, David Jain, Amit

Ford Motor Company, P. O. Box 2053 MD 3179/SRL, Dearborn, MI 48121

Shelef, Mordecai

Ford Motor Co., 20000 Rotunda Dr., , MD-3182 Rm. 2160 SRL, Dearborn, MI 48121-2053

Narula, Chaitanya

Ford Motor Company, Ford Research Laboratory, P.O. Box 2053 - MD 3135, Dearborn, MI

Sherman, Andy

General Motors R\& D Center, 30500 Mound Road, Box 9055, Warren, MI 48090-9055

Morelli, D. Eesley, G.

Georgia Institute of Technology, 778 Atlantic Drive, Atlanta, GA 30332

Carter, W. Stollberg, D. Hampikian, J. 
Georgia Institute of Technology, 813 Ferst Drive, N.W. Rm 437 Manuf. Res. Center, Atlanta, GA 30332-0405

Melkote, Shreyes Thiele, Jeffrey

Georgia Institute of Technology, 778 Atlantic Dr., Rm195, Bunger-Henry Bldg., Atlanta, GA 30332-0245

Johnson, Steven Clark, David

Georgia Institute of Technology, 337373 Georgia Tech Station, Atlanta, GA 30332-0400

Wilkinson, Angus Lind, Cora

Georgia Institute of Tech., 770 State St., School of Chem \& Biochem, Atlanta, GA 30332-0400

Zhang, Z. John Rondinone, Adam

HY-Tech Research Corporation, 104 Centre Court, Radford, VA 24141

Klepper, Chris Yadlowsky, Ed

Hypernex, Inc., 3006 Research Drive, State College, PA 16801-2768

Kozaczek, KrisJ. Moran, Paul Crelling, James

Idaho National Eng. and Environmental Lab., P. O. Box 1625, Idaho Falls, ID 83415-2210

Moore, Glenn Peterson, Eric

lowa State University, 3053 Gilman Hall, Ames, IA 50010

Akinc, Mufit Huebsch, Jesse

Kansas State University, 2 Fairchild Hall, Manhattan, KS 66506-1103

Edgar, James Alkhatib, Weesam Greenway, Scott

Lehigh University, Whitaker Lab, 5 East Packer Avenue, Bethlehem, PA 18015-3195

Williams, David DuPont, John Newbury, Brian

Marder, Arnold Banovic, Stephen

Los Alamos National Lab., MS-H805, Bldg. 622, TA-53, LANSCE, Los Alamos, NM 87545

Bourke, Mark A.M. Brown, Donald Holden, Thomas

LoTEC, Inc., 181 West 1700 South, Salt Lake City, UT 84115

Cassell, J. 
Louisiana State University, 2513 CEBA, Dept. of Mech. Eng., Baton Rouge, LA 70803

Ma, Evan $\mathrm{He}, \mathrm{Li}$

Machining Research, Inc., 7785 Foundation Drive, Suite 1, PO Box 6119, Florence, KY 41042

Christopher, John Hughes, Guy R.

MascoTech Forming Technologies, 9312 Arrow Road, NW, Minerva, OH 44657

Crews, Michael Wilusz, Daryl

Materials Modification, Incorporated, 2929 Eskridge Road, P-1, Fairfax, VA 22031

Stiglich, Jacob J.

Materials Sci. \& Eng. - Penn State, 222 Steidle Bldg., University Park, PA 16802

Mayo, Merrilea Raghavan, Srinivasan

Metalspray North America, LLC, 11637 Busy St., Richmond, VA 23236

Hill, Hayden A.

Michigan Technological University, 1400 Townsend Drive, Houghton, MI 49931

Zhou, Xin Nassaralla, Claudia

MicroCoating Technologies, 3901 Green Industrial Way, Chamblee, GA 30341

Shanmugham, Subu

MicroMet Technology, Inc., P. O. Box 810, Matthews, NC 28105

Job, Robert Clinton Craig, Jim

Milacron Marketing Company, P. O. Box 9013, Cincinnati, OH 45209-9013

Kelly, Ralph Krueger, Mark Yoon, Charles

Gary, Roger Harvey, Tommy

Mobil Technology Company, P. O. Box 480, Paulsboro, NJ 08066-0480

Kalyanaraman, Mohan Borghard, W. S.

Motorola, 1750 Bell Meade Court, Lawrenceville, GA 30043

Maleki, Hossein Byer, Bruno

Nasa Lewis Research Center, Mail Stop 106-1, Cleveland, OH 44135

Jacobson, Nathan 
New Mexico Inst. of Mining and Technology, 114 Jones Hall, Socorro, NM 87801

Alam, Mansoor Inal, Mehmet

New York State College of Ceramics, 2 Pine Hill Street, Alfred, NY 14802

Misture, Scott Jones, Linda Howe, Jane

North Carolina State University, P.O. Box 7916, Burlington Lab., Raleigh, NC 27695-7916

Kasichainula, Jag Babic, Darijo

North Carolina State University, Box 7910, Dept. of Mech. Eng., Raleigh, NC 27695-7910

Shih, Albert Gust, Darryl Rhoney, Brian

Curry, Adam Clark, William Qu, Jun

Northwestern Univ., 2225 N. Campus Drive, Dept of Mat Sci \& Eng., Evanston, IL 60208

Dravid, Vinayak P. Campbell, Charles Johnson, Kevin

Faber, Katherine Su, Jennifer

Norton Company, 1 New Bond Street, Box Number 15008, Worcester, MA 01615-0008

Block, Robert Picone, Joseph Dennison, S. Keoni

Breder, Kristin

NYSCC/SPAWAR, 2 Pine Hill Street, Alfred, NY 14802

Durbin, Mary Hicks, Charles Jacobs, Everett

Oak Ridge National Laboratory, Mail Stop 6056, Oak Ridge, TN 37831-6056

Lowndes, Douglas Park, Jae-Won

Oak Ridge National Laboratory, P. O. Box 2008, MS-6115, Oak Ridge, TN 37831-6115

Schneibel, Joachim $\mathrm{H}$.

Oak Ridge National Laboratory, P.O. Box 2008, Bldg. MS-6119, Oak Ridge, TN 37831-6119

Moyer, Bruce Klingshiran, Marc Alexandratos, Spiro

OSRAM Sylvania Inc., 71 Cherry Hill Dr., Beverly, MA 01915-1068

Wei, George

Parker Abex NWL Aerospace, 2220 Palmer Avenue, Kalamazoo, MI 49024

Dirkin, William

Penn State Univ., 227 Hammond Bldg., Eng. Sci. \& Mech. Dept., University Park, PA 16802

Queeney, Richard Delbrugge, Vince 
Penn State University, 148 Materials Res. Lab., University Park, University Park, PA 16802 Maria, Jon-Paul Trolier-McKinstry, Susan

Penn State Univ., P.O. Box 30, Applied Research Laboratory, State College, PA 16804 Singh, Jogender Kang, Nam Hyun

Pittsburg State University, Kansas Technology Center, Plastics Eng Tech, Pittsburg, KS 66762 Ibeh, Christopher Rosmait, Russell

Plasma Coatings, Inc., 758 East Main Street, Waterburg, CT 06702 Nava Yrene L.

PPG Industries, Inc., 440 College Park Drive, Monroeville, PA 15146 Burgman, Jerry Agrawal, Gaurav Schoff, Clifford

Rensselaer Polytechnic Institute, 110 8th Street, Cogswell Laboratory, Troy, NY 12180 Interrante, Leonard Moraes, Kevin

Saint-Gobain Norton, Goddard Road, Northboro R\&D Center, Northboro, MA 01532-1545

Pujari, Vimal Bateman, Charles

Siemens Westinghouse Power Corp., 1310 Beulah Rd., Pittsburgh, PA 15235-5068

Thompson, Daniel Burke, Michael Clarelli, Eric Lane, Jay Merrill, Gary

Southern University and A\&M College, Dept. of Mech. Eng., Baton Rouge, LA 70813

Mirshams, Reza Abernathy, Michael

Stevens Institute of Technology, Dept. of Materials Sciences and Eng., Hoboken, NJ 07030

Lee, Woo Torzillie, Michele Lee, J.

Su, Yi-Feng

Surmet Corporation, 33 B Street, Burlington, MA 01803

Gunda, Nilesh Sastri, Suri Karandiker, Prashant Jayaraman, Mohan

Tennessee Technology University, Box 5013, Cookeville, TN 38505

Ayers, Jerry B. Biernacki, Joseph Williams, Paul 
The Institute of Paper Science and Technology, 500 10th St. N.W., Atlanta, GA 30318-5794 Habeger, Charles Vorakunpinij, A. Watehouse, John

The Ohio State University, 2041 College Rd., 177 Watts Hall, Columbus, OH 43210 Snyder, Robert Detrie, Terry

Sandia National Laboratories, P.O. Box 969 MS 9054, Livermore, CA 94551-0969 McLean, William

113 Newell Lane, Oak Ridge, TN 37830

Tennery, V. J.

Thixomat, Inc., 717 East Huron Street, Ann Arbor, MI 48104

Walukas, Matthew

Tower Automotive, 3533 North 27th Street, Milwaukee, WI 53216

Noruk, Jeffrey Peters, Rob

TPL, Incorporated, 3921 Academy Parkway North, Albuquerque, NM 87109-4416

Taylor, Douglas

TYCOM Corporation, 10435 Burnet Road, Suite 122, Austin, TX 78758

Gibbs, Max Watson, Kimberly Wetherly, Mike

UKSS, Inc., 30 Hemlock Drive, Grand Island, NY 14072

Winder, Steve M. Cockcroft, Steve Au, Dominic

Universal Energy Systems, Inc., 4401 Dayton-Xenia Road, Dayton, OH 45432-0894

Bhat, Deepak

University of Akron, Department of Mechanical Engineering, Akron, $\mathrm{OH} 44325-3903$

Srivatsan, Tirumalai S.

University of Alabama, University Station, BEC Room 254, Birmingham, AL 35294

Chawla, Krishan Coffin, Charles

University of Alabama at Birmingham, 254 BEC, 1150 10th Ave. S., Birmingham, AL 35294

Rigsbee, J. M. Ji, ZhiQiang (John) 
University of Alabama at Birmingham, 1075 13th St. S., Birmingham, AL 35294-4440

Lucas, Linda Haman, Jeannie

University of Alabama-Birmingham, 1150 10th Ave. S., BEC 356E, Birmingham, AL 35222

Eberhardt, Alan Bland, Tracie

University of Calif. - Davis, 3110 Bainer, Dept. of Chem. Eng. \& Mat. Sci., Davis, CA 95616

Gates, Bruce C. $\quad$ Goellner, Jesse F. $\quad$ Argo, Andrew M.

Salvi, Samir Panjabi, Ghansham

University of Cincinnati, Dept. of Chemical Engineering, CIncinnati, OH 45221-0171

Lin, Jerry $\quad \mathrm{Hu}$, Michael

University of Connecticut, Box U-222, Storrs, CT 06269-3222

Helble, Joseph J. $\quad$ Schulte, Sandy C. Leffler, M. P.

University of Florida, Department of Chemical Engineering, Gainesville, FL 32611

Anderson, Timothy Chang, Chih-Hung

University of Illinois, Dept. of Matls. Sci. \& Eng. - 1304 W. Green St., Urbana, IL 61801

Economy, James Hall, Aaron

University of Illinois/Dept. of Mech. \& Ind. Engr., 1304 W. Main St., 341 Com. \& Systems Res. Lab, Urbana, IL 61801

DeVor, Richard Jacobus, Kurt Kapoor, Shiv

University of Illinois, Loomis Lab. of Physics, 1110 W. Green St., Urbana, IL 61801-3080

Williams, Wendell

University of Kentucky, 177 Anderson Hall, Lexington, KY 40506-0046

Dickey, Elizabeth Frazer, Colleen Baglyono, Bagiyono

Grulke, Eric Medley, John

Univ. of Kentucky, Center Applied Eng. Res., 3572 Iron Works Pk, Lexington, KY 40511-8433

Davis, Burtron Srinivasan, Ram

University of Massachusetts, 1 University Ave., Lowell, MA 01854

Sung, Changmo Choi, J.

University of Missouri-Rolla,, 1870 Miner Circle, Metallurgical Eng., Rolla, MO 65409-0340

Schlesinger, Mark 
Univ. of North Carolina - Chapel Hill, CB \#3255, Chapel Hill, NC 27599-3255

Parikh, Nalin

University of South Carolina, 300 Main Street, Dept. of Mech. Eng., Columbia, SC 29208

Sutton, Michael A. Abdelmajld, Issam $\quad$ Zhao, Wei

Woolley, William Jr.

University of Tennessee, Dept. of Material Sciences \& Eng., Knoxville, TN 37996-2200

$\begin{array}{lll}\text { Liaw, Peter } & \text { Zhang, Ying } & \text { Zhu, Jiahong } \\ \text { Jiang, Liang } & \text { Pedraza, Anthony } & \text { Kim, Won-Seok } \\ \text { Fowlkes, Jason } & \text { Jesse, Stephen } & \text { Kim, Jeong }\end{array}$

Yang, Bing

University Of Tennessee, 404 Andy Holt Tower, Office of Res., Knoxville, TN 37996-0140

Devine, Michael Compton, Robert

University of Tennessee, 100 Eastbrook Hall, Knoxville, TN 37996-2350

McHargue, C. J. Ackleh, Samer $\quad$ Ononye, Lawretta

University of Tennessee, Dept. of Physics and Astronomy, Knoxville, TN 37996

Weitering, Hanno $\mathrm{H}$. Park, Jae-Won

University of Tennessee, Dept. of Chemistry, Knoxville, TN 37996-1600

Wunderlich, B. Pyda, M. Androsch, R.

University of Tennessee Space Inst., MS 24, Ctr. for Laser Applications, Tullahoma, TN 37388

McCay, Mary Helen Xiao, Chenghe Dahotre, Narendra

Dahotre, Narendra Agarwal, Arvind

Univ. of Virginia, Dept. of Matls. Sci. \& Eng., Thornton Hall, Charlottesville, VA 22903-2442

Jesser, William Wang, Hsiang-Jen Elzey, Dana

Hammond, Vince

University of Washington, 3935 University Way, NE, Box 352120, Seattle, WA 98195

Flinn, Brian D. Meyer, Christopher Bordia, Rajendra

Zheng, Feng

Valenite, Inc., 1711 Thunderbird, Troy, MI 48084

Narasimhan, Krishnan 
West Virginia University, PO Box 6102, 413 Eng. Sci. Bldg., Morgantown, WV 26506-6102 Stiller, Alfred Bennett, Barbara E.

Westinghouse Electric Company, 1310 Beulah Road, Pittsburgh, PA 15235

Ruka, R. J. Liu, S. W.

Westinghouse Electric Corporation, 4400 Alafaya Trail, Mail Code-303, Orlando, FL 32826 Arana, M. Choudry, Mahmood

Wichita State University, 1845 Fairmount, Mech. Eng. Dept., Wichita, KS 67260-0133 Chaudhuri, Jharna 